\title{
The predictive value of molecular markers for recurrent endometrial carcinoma
}

Citation for published version (APA):

Pijnenborg, J. M. A. (2005). The predictive value of molecular markers for recurrent endometrial carcinoma. [Doctoral Thesis, Maastricht University]. Maastricht University. https://doi.org/10.26481/dis.20051202jp

Document status and date:

Published: 01/01/2005

DOI:

10.26481/dis.20051202jp

Document Version:

Publisher's PDF, also known as Version of record

\section{Please check the document version of this publication:}

- A submitted manuscript is the version of the article upon submission and before peer-review. There can be important differences between the submitted version and the official published version of record.

People interested in the research are advised to contact the author for the final version of the publication, or visit the DOI to the publisher's website.

- The final author version and the galley proof are versions of the publication after peer review.

- The final published version features the final layout of the paper including the volume, issue and page numbers.

Link to publication

\footnotetext{
General rights rights.

- You may freely distribute the URL identifying the publication in the public portal. please follow below link for the End User Agreement:

www.umlib.nl/taverne-license

Take down policy

If you believe that this document breaches copyright please contact us at:

repository@maastrichtuniversity.nl

providing details and we will investigate your claim.
}

Copyright and moral rights for the publications made accessible in the public portal are retained by the authors and/or other copyright owners and it is a condition of accessing publications that users recognise and abide by the legal requirements associated with these

- Users may download and print one copy of any publication from the public portal for the purpose of private study or research.

- You may not further distribute the material or use it for any profit-making activity or commercial gain

If the publication is distributed under the terms of Article $25 \mathrm{fa}$ of the Dutch Copyright Act, indicated by the "Taverne" license above, 
The predictive value of molecular markers for recurrent endometrial carcinoma 
Copyright @ 2005 J.M.A.Pijnenborg, Loon op Zand, 2005 ISBN 90-9020074-6

Niets uit deze uitgave mag worden verveelvoudigd, opgeslagen in een geautomatiseerd gegevensbestand of openbaar gemaakt worden in enige vorm of op enige wijze, hetzij elektronisch, mechanisch of door fotokopieën, opname, of op enige andere manier, zonder voorafgaande schriftelijke toestemming van de auteur.

Cover illustration designed by Willian Pijnenborg

The studies presented in this thesis were financially supported by the profileringsfonds (PF160)

Financial support for publication of this thesis has kindly been provided by:

Tweesteden Ziekenhuis Tilburg

Organon Nederland N.V.

Schering B.V.

Johnson \& Johnson

Pie Medical

Drukkerij Gianotten BV Tilburg 


\title{
The predictive value of molecular markers for recurrent endometrial carcinoma
}

\author{
Proefschrift \\ Ter verkrijging van de graad van doctor aan de Universiteit Maastricht, \\ op gezag van de Rector Magnificus, Prof. mr. G.P.M.F. Mols, \\ volgens het besluit van het College van Decanen, in het openbaar te verdedigen \\ op vrijdag 2 december 2005 om 12:00 uur \\ door \\ Johanna Maria Antoinetta Pijnenborg \\ Geboren 30 oktober 1969 te Haaren
}


Promotor

Co-promotor

Beoordelingscommissie
Prof. Dr. J. de Haan

Dr.P.G. Groothuis

Prof. Dr. M.J.A. P. Daemen

Prof. Dr. J.L.H. Evers

Prof. Dr. Ph Lambin

Prof. Dr. C.D.A. Stehouwer

Prof. Dr. A.G.J. van der Zee 
The predictive value of molecular markers for recurrent endometrial carcinoma

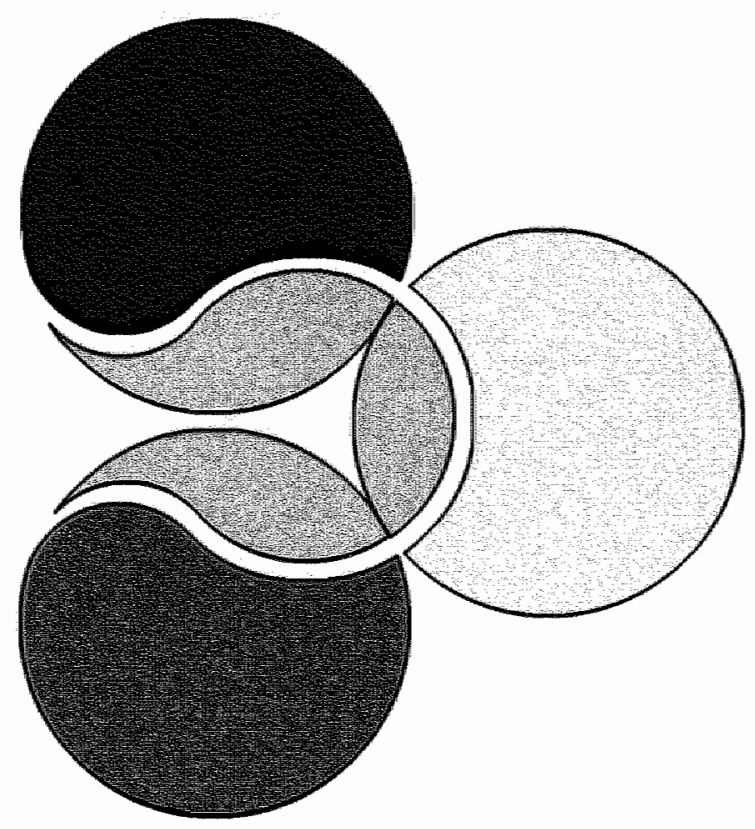




\section{Contents}

$\begin{array}{ll}\text { Abbreviations } & 9\end{array}$

Chapter 1 General introduction and outline of the thesis 11

Chapter 2 Material and methods $\quad 37$

Chapter 3 APC, $\beta$-catenin and E-cadherin and the development of recurrent endometrial carcinoma 45

Chapter 4 Defective mismatch repair and the development of recurrent endometrial carcinoma $\quad 69$

Chapter 5 Aberrations in the progesterone receptor gene and The risk of recurrent endometrial carcinoma

Chapter 6 RASSF1A methylation and K-ras and B-raf mutations and recurrent endometrial cancer

Chapter 7 Classification of genetic alterations in the p53 pathway in recurrent endometrial carcinoma

Chapter 8 Microvessel density and carbonic anhydrase IX expression in recurrent endometrial carcinoma $\quad 165$

$\begin{array}{lll}\text { Chapter } 9 & \text { General discussion } & 179\end{array}$

$\begin{array}{ll}\text { Summary } & 191\end{array}$

Samenvatting $\quad 195$

$\begin{array}{lr}\text { Curriculum vitae } & 199\end{array}$

Dankwoord 200

$\begin{array}{ll}\text { Color figures } & 205\end{array}$ 


\section{List of Abbreviations}

APC

adenomatous polyposis coli

ATM

atxia telangiectasia mutated

BSA

bovine serum albumin

CA-IX

carbonic anhydrase IX

$\mathrm{Cl}$

confidence interval

$E_{1}$

estrone

$\mathrm{E}_{2}$

estradiol

ER

estrogen receptor

GSK-3 $\beta$

glycogen synthase kinase- $3 \beta$

HE

haematoxylin and eosin

HNPCC

hereditary nonpolyposis coli

HSD

$17 \beta$-hydroxysteroid dehydrogenase

IGF-I

insulin-like growth factor I

IGFBP-I

insulin-like growth factor binding protein I

LEF

lymphoid enhancer factor

$\mathrm{LOH}$

loss of heterozygosity

MMR

mismatch repair

MSI

microsatellite instability

MSP

methylation specific PCR

MVD

microvessel density

OR

odds ratio

PCR

polymerase chain reaction

PBS

phosphate buffer saline

PR

progesterone receptor

PR-A

progesterone receptor isoform $A$

PR-B

progesterone receptor isoform $B$

RFLP

restriction fragment length polymorphism

WWF

von Willebrand factor 
Chapter 1

General introduction and outline of the thesis

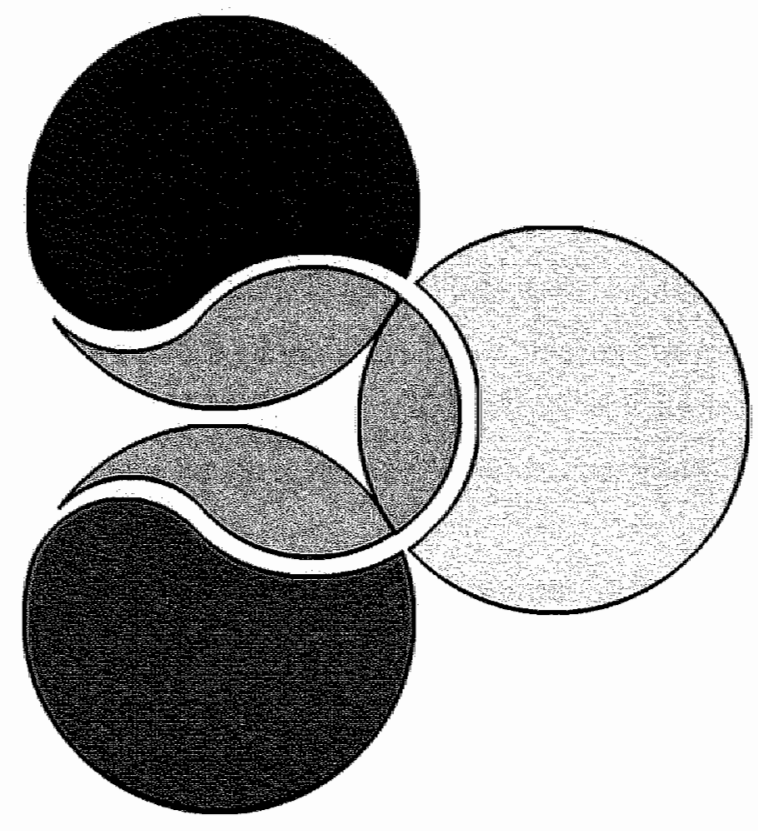




\section{Introduction}

Endometrial carcinoma is the most common malignancy of the female tract, with an incidence of 15-130 per 100000 women each year, increasing in Western countries [1,2]. Most patients are diagnosed at an early stage, and the 5-year survival rate is good $(>80 \%)$ [3]. Current treatment consists of total abdominal hysterectomy with bilateral salpingo-oophorectomy. Pelvic lymphadenectomy is not routinely performed in the Netherlands. The risk of pelvic node metastasis was found to be $<10 \%$ in grade I and II surgical stage I endometrial carcinoma, and $18 \%$ in the subgroup of grade III tumors [4,5]. Although, extensive surgical staging provides additional prognostic information, the therapeutic role and its ability to modify adjuvant therapy is not clear yet. Currently, when myometrial invasion is $>50 \%$ and/or tumor differentiation is moderate or poor, pelvic radiotherapy is considered in order to reduce the risk of recurrent disease. Results of a large randomized trial, including patients with stage I disease, demonstrated that the application of postoperative radiotherapy indeed could significantly reduce local recurrence [6]. However, in this study still $4 \%$ presented with local recurrence even if postoperative radiotherapy was applied, this percentage is in line with other reports [6-8].

The molecular approach in understanding initiation and progression of tumors has gained increasing attention and studies on all kinds of tumors and pathways have been reported. Considering endometrial carcinoma, a dualistic model describes two distinctive pathways in the development of endometrial carcinoma: the estrogen dependent type I, and the estrogenindependent type II endometrial carcinoma (Table 1) [9-12]. Type I endometrial carcinoma is characterized by diploid tumors, the presence of estrogen -, and progesterone receptors (ER, PR), mutations in K-ras, PTEN and CTNNB1 ( $\beta$-catenin), and the presence of microsatellite instability (MSI), used as a marker for defective mismatch repair (MMR). These molecular markers will be explained later in detail. 
On the contrary, type II endometrial carcinomas are frequently aneuploid, harbor p53 mutations and present with Her-2 neu overexpression [13-17]. Also in the presence of epigenetic alterations, there are differences between type I and type II endometrial carcinoma. Risinger et al. demonstrated that epigenetic inactivation of genes by gene promoter methylation was rarely observed in type |l endometrial carcinomas [18]. Histopathology of type I endometrial carcinoma is represented mainly by the endometrioid differentiation. Type II is represented by the serous, and clear cell tumor differentiation. The serous type is the most aggressive variant and accounts for less than $10 \%$ of endometrial tumors, whereas the endometrioid type occurs most frequently and accounts for $57-80 \%$ of all cases $[19,20]$. Although these two types of endometrial carcinoma have their specific molecular characteristics, recent molecular based evidence suggests that carcinogenesis of the endometrium evolves through several pathways overlapping both types of endometrial carcinoma [14].

Table 1 Molecular profiles of type I and II endometrial carcinoma

\begin{tabular}{lcc}
\hline & Type I & Type II \\
\hline Ploidy & Diploid & Aneuploid \\
Steroid receptors (ER/PR) & + & - \\
K-ras mutations & + & - \\
P53 mutations & - & + \\
PTEN mutation & + & - \\
CTNNB1 mutation & + & - \\
Microsatellite instability & + & - \\
Her-2 neu overexpression & - & + \\
Gene promoter methylation & + & - \\
\hline
\end{tabular}

Currently, clinicopathological characteristics like tumor grade and myometrial invasion are used in the selection for appropriate therapy. Nevertheless, these tumor characteristics are not sufficient in the prediction of recurrence, 
and therefore new markers are needed. The advantage of the molecular approach compared to the clinicopathological approach is that tumor behavior instead of tumor appearance is studied. When more insight into the molecular carcinogenesis is obtained, these markers could be used to make a proper selection for each individual patient, independent of tumor stage and or grade.

After a short introduction into the molecular carcinogenesis, several molecular pathways will be described in relation to recurrent endometrial carcinoma.

\section{Molecular carcinogenesis}

The cell cycle can be divided in four different phases i.e. G1-S-G2-M (Figure 1.) Although cells usually divide when they have doubled in volume, genes in two ways control the cell cycle. Genes control the production of proteins necessary for the replication of DNA, or they control the initiation of the different cell phases. Points where new phases are initiated are called checkpoints, and only if all items are present the next phase can be entered. This mechanism of cell cycle control is very precise. Cancer is characterized by abnormal cell proliferation, and the ability to invade the surrounding tissue. The development of a carcinoma is a consequence of inappropriate activity of certain genes. Cancer related genes could be divided into tumorsuppressor genes, oncogenes, and mismatch repair genes. Tumorsuppressor genes act by suppressing mallignant growth, through delay of cell cycle progression to allow DNA repair, or by the induction of programmed cell death (apoptosis). When bi-allelic loss occurs due to both mutations and deletions or to loss of heterozygosity $(\mathrm{LOH})$, the "brake" of the cell cycle is disabled. The most important tumor suppressor is p53, which is called the "guardian of the genome". DNA damage or cellular stress induces p53 expression and subsequently the progression of the cell cycle is inhibited to allow repair of DNA. 


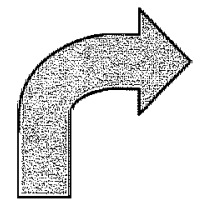

$\mathbf{G}$

M - phase:

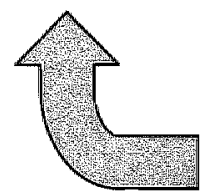

G

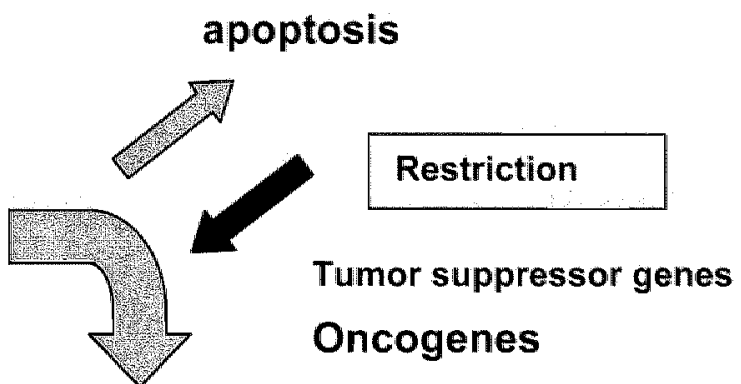

S - phase: synthesis of

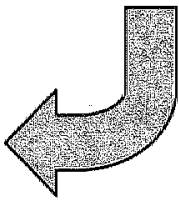

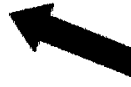

Mismatch repair

$G_{1}$ - checkpoint: cell environment, cell size

$\mathrm{G}_{2}$ - checkpoint: complete DNA replication

However, if the damage is too extensive and repair is not possible, apoptosis is induced, thereby preventing further accumulation of cells harboring damaged DNA. In contrast to the tumor-suppressor genes, oncogenes act as 'accelerators' of the cell cycle, and only one allele is necessary to activate the oncogene. In the non-activated form cellular oncogenes are called protooncogenes. Activation can be the result of a mutation, translocation to an active strong promoter region, or gene amplification. Proto-oncogenes can be classified in at least four categories: tyrosine kinases, growth factors, GTP-binding proteins, and DNA binding proteins. As proto-oncogenes they seem to function normally at low levels, however, as oncogenes they can induce excessive cell growth. 
Ras is an example of an oncogene that is frequently mutated in endometrial carcinoma, and hence can lead to accelerated proliferation. Both mutations in proto-oncogenes as well as in tumor suppressor genes can lead to uncontrolled cell growth [21-23].

Mismatch repair genes are important for the control of DNA mutations in the cell. In every cell DNA damage occurs, and it is clear that insufficient DNA repair results in an accumulation of mutations, which is part of tumor development.

\section{Wnt pathway}

The Wnt signaling transduction pathway was first identified some 20 years ago in the Drosophila, in which it plays a key role in several developmental processes [24]. Molecular studies have pointed out that activating mutations of the Wnt signaling pathway are present in approximately $90 \%$ of colorectal cancers (CRC), and somewhat less frequently in other cancers, including endometrial carcinoma [25-27].

In normal epithelial cells, free $\beta$-catenin is rapidly phosphorylated by

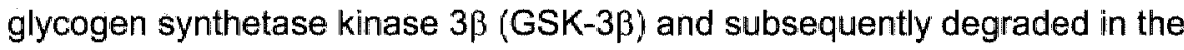
ubiquitin-proteasome pathway [26-29]. As a result of activating mutations in the Wnt pathway, high levels of $\beta$-catenin accumulate in the cytoplasm, and subsequently translocate to the nucleus to form a complex with the T-cell factor (TCF) and the lymphoid enhancer factor (LEF) which leads to activation of proliferation [30,31]. The $\beta$-catenin degradation complex consists of among other, the adenomatous polyposis coll (APC) tumor suppressor protein, axin, and glycogen synthase kinase, GSK-3 $\beta$. When the tumor suppressor adenomatous polyposis coli (APC) is non-functional, GSK$3 \beta$ activity is blocked and $\beta$-catenin is not phosphorylated and degraded. Mutations in APC or $\beta$-catenin can deregulate the critical tumor suppressor function of APC resulting in activation of the Wnt pathway [32]. In 
endometrial carcinoma, the presence of $\beta$-catenin (CTNNB1) mutations ranges from $13-50 \%$, and mutations in APC have not been reported [33-35]. Besides the important role in the Wnt pathway, $\beta$-catenin is involved in cell adhesion through interaction with E-cadherin by specific binding sites [36]. Loss of E-cadherin expression is associated with dedifferentiation of the tumor, increased invasive behavior, and metastatic potential in endometrial as well as other carcinomas $[29,36-41]$.

\section{Mismatch repair}

DNA mismatch repair (MMR) was originally described in E.coli. Inactivation of MMR results in an deficient repair of replication errors and thus an increase of spontaneous mutations [42]. In the early 1990s the importance of inactivation of this DNA repair system as a primary cause of hereditary nonpolyposis colorectal cancers (HNPCC) was demonstrated [43]. Several mismatch repair proteins have been characterized, and so far hMLH4, $\mathrm{hMSH} 2$, and $\mathrm{hMSH} 6$ have been implicated in endometrial carcinoma. In sporadic endometrial carcinoma, $h M L H 1$ gene promoter methylation and subsequently loss of hMLH1 expression is a major cause for defective MMR, and to a lesser extent, mutations in $h M S H 2$, and $h M S H 6$ are associated with defective MMR [44-47]. The presence of $h M L H 1$ gene promoter methylation was also observed in normal endometrium adjacent to the tumor, and in hyperplastic endometrium, indicating that this may be an early step in tumorgenesis [48-50].

Defective mismatch repair will lead to accumulation of mutations in both exons and introns. DNA microsatellites, which are simple sequence repeats of one to six nucleotides distributed throughout the genome, are sensitive for defective MMR. Microsatellite instability signifies changes in the length of these microsatellites as a result of defective MMR [51,52]. The presence of microsatellite instability (MSI) can therefore be used as a marker for defective mismatch repair. In endometrial carcinoma the presence of MSI was found to be an important prognostic marker for a shorter disease free 
not reported. Another complex of nucleic acid sequence aberrations of the PR, known as PROGINS has been identified. It consists of a haplotype carrying a $306 \mathrm{bp}$ PV/HS-1 Alu insertion in intron-G, a silent point mutation in exon $5(\mathrm{H} 770 \mathrm{H})$ and a single amino acid change in exon 4 (V660L) [77-79]. PROGINS has been identified as a risk modifier for benign and malignant gynecological diseases, due to affected PR function [80-83]. The presence of PROGINS has not been reported in endometrial carcinoma.

\section{Ras signaling}

Ras proteins are involved in the regulation of cell proliferation and differentiation [84]. The ras gene is an oncogene that is mutated in up to $35 \%$ of human tumors. Most of these mutations are activating mutations that lead to uncontrolled cell growth [85]. The Ras family consists of three closely related genes, $H$-ras, $K$-ras, and $N$-ras, which are expressed differently in tissues [86]. Mutations in codon 12 and 13 of $K$-ras are found in $10-30 \%$ of the endometrial carcinomas [87-90]. A more aggressive behavior of $K$-ras mutated endometrial tumors was reported by Ito et al. [88] and Semczuk et al. [87], but could not be confirmed by others [91,92]. Ras is known to activate in various other signaling pathways, one of which is the Raf/MAPK pathway. Raf proteins were identified as key effectors of Ras proteins [93]. However, mutated B-raf proteins can bypass Ras activating mutations, and induce tumor growth in cancer cell lines without the necessary ras mutations [94]. Most of the B-raf mutations occur within the kinase domain, resulting in elevated kinase activity and transforming capacity in NIH3T3 cells [94]. A single base substitution (T-A change at nucleotide 1796) resulting in an amino acid substitution (V599E) accounts for $80-90 \%$ of these mutations [94]. The presence of $B$-raf mutations was associated with a better outcome in both colorectal cancer and melanoma $[95,96]$. Recently, a new Ras effector, RASSF1A was characterized by Dammann et al. [97]. RASSF1A might be responsible for the Ras-dependent growth inhibition through its proapoptotic function [98]. Loss of RASSF1 expression by methylation may shift 
the balance towards a growth promoting effect without the necessity of activating ras mutations. Mutual exclusivity of $K$-ras mutations and RASSF1A methylation was observed in colon cancer [99]. Mutual exclusivity of $B$-raf mutations and RASSF1A methylation was described in thyroid cancer [100]. So far, the presence of B-raf mutations and RASSF1A methylation has not been reported in endometrial carcinoma.

\section{p53 pathway}

The $p 53$ gene encodes for a $53 \mathrm{kD}$ nuclear phosphoprotein, which is involved in the suppression of cell growth, and is the most frequently mutated gene in human neoplasms $[101,102]$. P53 is a tumor-suppressor and in response to DNA damage and cellular stress, accumulation of p53 induces cell cycle arrest to allow DNA repair, or if this is not possible, induces apoptosis (Figure 1) [103]. Point mutations in p53 often lead to overexpression of the non-functional protein, since degradation of mutant p53 is delayed and half-life time prolonged. In the serous type endometrial carcinoma overexpression of $p 53$ is well correlated with the presence of $p 53$ gene mutations. However, in the endometrioid type this correlation is not present, suggesting an alternative mechanism for p53 inactivation $[89,104,105]$. The level of p53 is normally controlled by its negative regulator: $\mathrm{mdm} 2$. High expression of $\mathrm{p} 53$ induces the transcription of $\mathrm{mdm} 2$, which stimulates $\mathrm{p} 53$ degradation or blocks the transactivation domain of p53 [106]. P14 ARF, one of the products of the INK4a/ARF locus, is the counterpart of $\mathrm{mdm} 2$, it is an important positive regulator of the p53 protein, and prohibits mdm2 mediated degradation of p53 [107]. Several studies have pointed out the prognostic capacity of $\mathrm{p} 53$ (over)expression in endometrial carcinoma, however, the underlying mechanism is still unclear, since mutations appear to be present in the minority of the endometrioid carcinomas [105]. 


\section{Aims of the thesis}

1. To determine whether proteins involved in the different molecular pathways can be used to predict recurrence in stage / endometrioid endometrial carcinoma.

2. To evaluate whether analysis of recurrent tumors can be of additional value in the understanding of tumor progression.

3. To correlate proteins of different molecular pathways in order to find the best set of predictors for recurrence.

4. To analyze prognostic makers in relation to the prediction of success rate for postoperative radiotherapy. 


\section{Outline of the thesis}

In chapter 2, an overview is given of the specialized molecular diagnostic techniques used in this thesis: Mutation analysis by direct sequencing, and Restriction Fragment Length Polymorphism (RFLP), and Methylation Specific Polymerase Chain Reaction (MSP).

In chapter 3, the prognostic value of three components associated with the Wnt pathway i.e. APC (adenomatous polyposis coli), $\beta$-catenin, and $\mathrm{E}$ cadherin in the development of recurrent disease was evaluated in a pilot case-control study of 28 patients with stage I endometrial carcinomas. .

In chapter 4, it was determined whether a defective MMR system was related to the development of recurrent disease. This was studied in an extended case-control group of 44 patients with and 44 patients without recurrent stage I endometrial carcinoma. For this purpose, immunohistochemical analysis of hMSH2 and hMLH1, hMLH1 gene promoter methylation, and MSI analysis was performed.

In chapter 5, we investigated, whether screening for genetic aberrations in the progesterone receptor (PR) i.e. PROGINS and the $+331 \mathrm{G} / \mathrm{A}$ polymorphism, additional to immunohistochemical analysis of PR can improve the prediction of the risk for recurrence. The same set of patients $(n=44)$ with and without recurrent $(n=44)$ stage I disease was used.

In chapter 6, epigenetic and genetic alterations in three members of the Ras-signaling pathway i.e. RASSF1A, K-ras and B-raf, were studied in relation to the development of recurrent endometrial carcinoma.

In chapter 7, p53 and proteins closely related to its action and turnover were studied for their role in the development of recurrent endometrial carcinoma. 
Protein expression of $\mathrm{p} 53, \mathrm{mdm} 2$, and $\mathrm{p} 21$ was evaluated by immunohistochemistry. Mutation analysis was performed of $p 53$ exons 5-8 and 11.

In Chapter 8, the correlation of microvessel density and carbonic anhydrase X expression with the development of recurrent disease was studied in a subgroup of 25 patients with and without recurrence

In Chapter 9, all findings are discussed in the light of the current understanding of the development of recurrent disease, and the impact for the clinical practice as well as future research.

\section{References}

1. Visser, O., Coebergh, J.W.W., Schouten, L.J, and Van Dijk, J.A.A.M. (1998) Incidence of cancer in the Netherlands 1995. Netherlands Cancer Registry, Utrecht, pp. 43.

2. Lalloo, F. and Evans, G. (2001) Molecular genetics and endometrial cancer. Best practice \& research. Cinical obstetrics \& gynaecology, 15, 355-63.

3. Creasman, W., Odicino, F., Maisonneuve, P. and Benedet, J. (1998) FIGO annual report on the results of treatment in gynaecological cancer. Carcinoma of the corpus uteri. Journal of Epidemiology and Biostatistics, 3, 35-61.

4. Creasman, W.T., Morrow, C.P., Bundy, B.N., Homesley, H.D., Graham, J.E. and Heller, P.B. (1998) Surgical pathologic spread patterns of endometrial cancer. A Gynecologic Oncology Group Study. Cancer, 60, 2035-41.

5. Yenen, M.C., Dilek, S., Dede, M., Goktolga, U., Deveci, M.S. and Aydogu, T. (2003) Pelvic paraaortic lymphadenectomy in clinical Stage I endometrial adenocarcinoma: a multicenter study. European Journal of Gynaecololgic Oncology, 24, 327-9.

6. Creutzberg, C.L., van Putten, W.L.J., Koper, P.C.M., Lybeert, M.L.M., Jobsen, ل.J., Wárlám-Rodenhuis, C.C. De Winter, K.A.J., Lutgens, L.C.H.W. van den Bergh, A.C.M., van de Steen-Banasik, W., Beerman ${ }_{1}$ H. and van Lent, M. (2000) Surgery and postoperative radiotherapy versus surgery alone for patients with stage-1 endometrial carcinona: multicenter randomised trial. 355, 1404-1411.

7. Brady, L.W. Perez, C.A. and Bedwinek, J.M. (1986) Failure patterns in gynecologic cancer. International Joumal af Radiation Oncology, Biology "Physics, 12, 549-57.

8. Grigsby, P.W., Perez, C.A., Kuten, A., Simpson, J.R., Garcia, D.M., Camel, H.M., Kao, M.S. and Galakatos, A.E. (1992) Clinical slage I endometrial cancer, prognostic 
factors for local control and distant metastasis and implications of the new FIGO surgical staging system. Intemational Joumal of Radiation Oncology and biological physiology, 22, 905-11.

9. Sherman, M.E. (2000) Theories of endometrial carcinogenesis. A muitidisciplinary approach. Modem Pathology, 13, 295-308.

10. Baker, V.V. (1996) The molecular biology of endometrial adenocarcinoma. Clinical Obstetrics and Gynecology, 39، 707-715.

11. Burton, J.L. and Wells, M. (1998) Recent advances in the histopathology and molecular pathology of carcinoma of the endometrium. Histopathology, 33, 297-303.

12. Kounelis, $S_{., i}$ Kapranos, N., Kouri, E., Coppola, D., Papadaki, $H$. and Jones; M.W. (2000) Immunohistochemical profile of endometrial adenocarcinoma: a study of 61 cases and review of the literature. Modern Pathology, 13 (4), 379-388.

13. Oehler, M.K., Brand, A. and Wain, G.V. (2003) Molecular genetics and endometrial cancer. Joumal of the British Menopause Society, 9, 27-31.

14. Inoue, M. (2001) Current molecular aspects of the carcinogenesis of the uterine endometrium. international Journal of Gynecological Cancer, 11, 339-48.

15. Salvesen, H.B. and Akslen, L.A. (2002) Molecular pathogenesis and prognostic factors in endometrial carcinoma. Acta Pathologica, Microbiologica, et Immunologica Scandinavica, 110, 673-689.

16. Bussaglia, E. Del Rio, E. Matias-Guiu, X. and Prat, J. (2000) PTEN mutations in endometrial carcinomas: a molecular and clinicopathologic analysis of 38 cases. Human Pathology, 31, 312-316.

17. Sasano, H. Watanabe, K., Ito, K., Sato, S. and Yajima, A. (1994) New concepts in the diagnosis and prognosis of endometrial carcinoma. Pathol Annu., 29, 31-49.

18. Risinger, J.I., Maxwell, G.L., Berchuck, A. and Barrett, J.C. (2003) Promoter hypermethylation as an epigenetic component in Type I and Type II endometrial cancers. Annals of the New York Academy of Siciences, 983, 208-12.

19. Longacre, T.A., Kempson, R.L. and Hendrickson, M.R. (1995) Obstetrical and Gynaecological Pathology. Churchill Livingstone, Edinburgh.

20. Hoffman, K., Nekhlyudar, L. and Deligdisch, L. (1995) Endometrial carcinoma in elderly women. Gymecologic Oncology, 58, 198-201.

21. Vogelstein, B., Lane, D.P. and Levine, A.J. (2000) Surfing the p53 network. Nature, 408, 307-310.

22. Prolla, T.A. (1998) DNA mismatch repair and cancer. Current Opinion in Cell Biology, 10, 311-316.

23. Jacob, S. and Praz, F. (2002) DNA mismatch repair defects: rolle in colorectal carcinogenesis. Biochimie, 84, 27-47.

24. Giles, R.H., van Es, J.H. and Clevers, H. (2003) Caught up in a Wnt storm: Wnt signaling in cancer. Biochimica et Biophysica Acta, 1653, 1-24. 
25. Sparks, A.B., Morin, J.P., Vogelstein, B. and Kinzler, K.W. (1998) Mutational analysis of teh APC/beta-catenin/T cf pathway in colorectal cancer. Cancer Research, 58 , 1130-1134.

26. Akiyama, T. (2000) Wnt/b-catenin signaling Cytokine \& Growth Factor Reviews, 11 , $273-282$,

27. Barker, N. and Clevers, H: (2000) Catenins, Wht signaling and cancer. BioEssays, 22 961-965.

28. Guilford, P. (1999) E-Cadherin downregulation in cancer: fuel on the fire ? Molecular Medicine Today, 5, 172-177.

29. He TC, S.A., Rago C, Hermeking H, Zawel L, da Costa LT, Morin PJ, Vogelstein B, Kinzler KW (1998) Identification of C-MYC as a target of the APC pathway. Science, 281, 1509-1512.

30. Morin, J.P. (1999) B-catenin signaling and cancer. BioEssays, 21, 1021-1030.

31. Christofori, G. and Semb, H. (1999) The role of the cell-adhesion molecule ECadherin as a tumour-suppressor gene. Trends in Biochemical Science, 24, 73-76.

32. Morin, P.J., Sparks, A.B., Korinek, V., Barker, N., Clewers, H., Vogelstein, B. and Kinzler, K.W. (1997) Activation of beta-catenin-Tcf signaling in colon cancer by mutations in beta-catenin or APC. Science, 275, 1787-90.

33. Mirabelli-Primdahll, L., Gryfe, R., Kim, H., Millar, A., Luceri, C., Dale, D., Holowaty, E., Bapat, B., Gallinger, S. and Redston, M. (1999) Beta-catenin mutations are specific for colorectal carcinomas with microsatellite instability but occur in endometrial carcinomas irrespective of mutator pathway. Cancer Research, 59, 3346-3351.

34. Fukuchi, T., Sakamoto, M., Tsuda, H., Maruyama, K., Nozawa, S. and Hirohashi, S. (1998) Beta-catenin mutation of the uterine endometrium. Cancer Research, 58, 3526-3528.

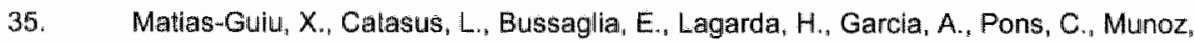
J., Arguelles, R., Machin, P. and Pralt, J. (2001) Molecular pathology of endometrial hyperplasia and carcinoma. Human Pathology, 32, 569-77.

36. Fujimoto, J., Ichigo, S., Hori, M. and Tamaya, T. (1998) Expressions of E-Cadherin and alpha- and beta-catenin mRNAs in uterine endometrial cancers. European Journal of Gynaecologic Oncology, 19, 78-81.

37. Tamura, S., Shiozaki "H., Miyata, M., Kadowaki "T. Inoue, M. Matsui, S., Iwazawa, T., Takayama, T., Takeichi, M. and Monden, M. (1996) Decreased E-cadherin expression is associated with haematogenous recurrence and poor prognosis in patients with squamous cell carcinoma of the oesophagus. British Joumal of Surgery, 83, 1608-1614.

38. Sakuragi, N., Nishiya, M., Ikeda, K., Ohkouch, T., Furth, E.E., Hareyama, H., Satoh, C. and Fujimoto S. (1994) Decreased E-cadherin expression in endometrial 
carcinoma is associated with tumor dedifferentiation and deep myometrial invasion. Gynecologic Oncology, 53, 183-189.

39. Kallakury, B.V., Sheehan, CE. Winn-Deen, E., Olver, J. Fisher, H.A., Kaufman, R.P. and Ross, J.S. (2001) Decreased expression of catenins (alpha and beta), p120 CTN. and $\mathrm{E}$-cadherin cell adhesion proteins and E-cadherin gene promoter methylation in prostatic adenocarcinomas. Cancer, 92, 2786-2795.

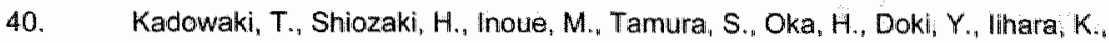
Matsui, S. I wazawa, T. Nagafuchi, A., Tsukita, S. and Mori, T. (1994) E-cadherin and a-catenin expression in human esophageal cancer. Cancer Research, 54, 291-296.

41. Jiang, W.G. (1996) E-Cadherin and its associated protein catenins, cancer invasion and metastasis. British Journal of Surgery, $83,437-446$.

42. Radman, M., Wagner, R. and Glickman, B.W. (1986) Mismatch repair in Escherichia colli. Annual Rewiew of Genetics, 20, 523-538.

43. Peltomakii, P. (2001) Deficient DNA mismatch repair: a common etiologic factor for colon cancer. Human Malecular Genetics, 10, 735-740.

44. Stefansson, I., Akslen, L.A., MacDonald, N., Ryan, A, Das, S., Jacobs, I.J. and Salvesen, H.B. (2002) Loss of hMSH2 and hMSH6 expression is frequent in sporadic endometrial carcinomas with microsatellite instability: a population-based study. Clinical Cancer Research, 8, 138-143.

45. Goodfellow, P.J., Buttin, B.M., Herzog, T.J., Rader, J.S., Gibb, R.K., Swisher, E., Look, K., Walls, K.C., Fan, M.-Y. and Mutch, D.G. (2003) Prevalence of defective DNA mismatch repair and MSH6 mutation in an unselected series of endometrial cancers. Procedings of the National Academy of Science, 100, 5908-5913.

46. Salvesen, H.B., MacDonald, N., Ryan, A., Iversen, O.E., Jacobs, l.J., Akslen; L.A. and Das, S. (2000) Methylation of hMLH1 in a population-based series of endometrial carcinomas. Clinical Cancer Research, 6, 3607-3613.

47. Ellenson, L.H. (1999) hMLH1 promoter hypermethylation in microsatellite instabilitypasitive endometrial carcinoma. Amenican Journal of Pathology, 155, 1399-1402.

48. Esteller, M., Catasus, L., Matias-Guiu, X., Mutter, G.L., Prat, J., Baylin, S.B. and Herman, J.G. (1999) hMLH1 Promoter hypermethylation is an early event in thuman endometrial tumorigenesis. American Journal of Pathology, 155, 1767-1772.

49. Kanaya, T., Kyo, S., Maida, Y., Yatabe, N., Tanaka, M., Nakamura, M. and Inoue, M. (2003) Frequent hypermethyllation of $\mathrm{MLH} 1$ promoter in normal endometrium of patients with endometrial cancers. Oncogene, 22, 2352-2360.

50. Horowitz, N., Pinto, K., Mutch, D.G., Herzog, T.J., Rader, J.S., Gibb, R., BockerEdmonston, T, and Goodfellow, P.J. (2002) Microsatellite instability, MLH1 promoter methylation, and loss of mismatch repair in endometrial cancer and concomitant atypical hyperplasia. Gynecologic Oncology, 86, 62-68. 
51. Parsons, R., Li, G.M. Longley, M.J., Fang, WH., Papadopoulos, N., Jen, J, de la Chapelle, A. Kinzler, K.W. Vogelstein, B. and Modrich, P. (1993) Hypermutability and mismatch repair deficiency in RER+ tumor cells. Cell, 75, 1227-1236.

52. Jiricny, $\mathrm{J}$. and Nystrom-Laht, M. (2000) Mismatch repair defects in cancer. Current Ophinon in Genetics \& Development, 10, 157-161.

53. Flumicino, S., Ercoli, A.,Ferrandina, G., Hess, P. Raspaglio, G., Genuardi, M.; Rovella, V., Bellacosa, A., Cicchillitti, L. Mancuso, S., Bignami, M. and Scambia, G. (2001) Microsatellite instability is an Independent indicator of recurrence in sporadic stage l-1l endometrial adenocarcinoma. Joumal of Chinical Oncology, 19, 1008-14.

54. Peiro, G., Diebold, J., Mayr, D., Baretton, G.B., Kimmig, R., Schmidt; M. and Lohrs, U. (2001) Prognostic relevance of hMLH1, hMSH2, and BAX protein expression in endometrial carcinoma. Modern Pathology, 14, 777-783.

55. Caduff, R.F., Johnston, C.M., Svoboda-Newman, S.M., Poy. EL. ,Merajver, S.D. and Frank, T.S. (1996) Clinical and pathological significance of microsatellite instability in sporadic endometrial carcinoma. American Joumal of Pathology, 148, 1671-1678.

56. Maxwell, G.L., Risinger, J.J., Alvarez, A.A.,Barrett, J.C, and Berchuck, A. (2001) Favorable survival associated with microsatellite instability in endometrioid endometrial cancer. Obstetrics and Gymecology, 97, 417-22.

57. Kaaks, R., Lukanova, A. and Kurzer, M.S. (2002) Obesity, endogenous hormones, and endometial cancer risk: a synthetic review. Cancer, Epidemiology, Biomarkers \& Prevention, 11, 1531-1543.

58. Kleinman, D. Karas, M., Roberts, C.T.J., LeRoith, D., Phillip, M., Segev, Y., Levy, J. and Sharoni, Y. (1995) Modulation of insulin-like growth factor I (IGF-I) receptors and membrane-associatted IGF-binding proteins in endometrial cancer cells by estradiol. Endocrinology, 136, 2531-7.

59. Yang, S., Fang, Z., Gurates, B., Tamura, M., Miller, J., Ferrer, K. and Bullun, S.E. (2001) Stromal PRs medlate induction of 17 beta-hydroxysteroid dehydrogenase type 2 expression in human endometrital epithelum: a paracrine mechanism for inactivation of E2. Molecular Endocitrology, 15, 2093-105.

60. Falany, J.L. and Falany, C.N. (1996) Regulation of estrogen sulfotransferase in human endometrial adenocarcinoma cells by progesterone. Endocrinology, 1137 , $1395-401$

61. Liu, H.C., He, Z.Y., Mele, C, Damaria, M., Davis, O. and Rosenwaks, Z, (1997) Hormonal regulation of expression of messenger RNA encoding insulim-like growth factor binding proteins in human endometrial stromal cells cultured in vitro. Molecular Human Reproduction, 3, 21-6.

62. Ayabe, T., Tsutsumi, O. Sakai, H., Yoshikawa, H., Yano, T., Kurimoto, F. and Taketani, Y. (1997) Increased circulating lewels of insulin-like growth factor-l and 
decreased circulating levels of insulin-like growth factor binding protein- 1 in postmenopausal women with endometrial cancer. Endocrine Jouma, 44, 419-24.

63. Bray. G.A. (2002) The underlying basis for obesity: relationship to cancer. Joumal of Nutrition, 132, 3451S-3455S.

64. Gehrig, P.A., Van Le, L., Olatidoye, B. and Geradts, J. (1999) Estrogen receptor status, determined by immunohistochemistry, as a predictor of the recurrence of stage I endametrial carcinoma. Cancer, 86, 2083-2089.

65. Steiner, E., Eicher, O., Sagemuller, J., Schmidt, M., Pilch, $H_{.,}$Tanner, B., Hengstler, J.G., Hofmann, M. and Knapstein, P.G. (2003) Multivariate independent prognostic factors in endometrial carcinoma: a clinicopathologic study in 181 patients: 10 years experience at the Department of Obstetrics and Gynecology of the Mainz University. International Journal of Gynecologic Cancer, 13, 197-203.

66. Creasman, W.T. (1993) Prognostic significance of hormone receptors in endometrial cancer. Cancer, 71, 1467-70.

67. Gehrig. P.A. and Van Le. L. (2000) The prognastic value and clinical utility of estrogen and progesterone receptors in endometrial carcinoma. Prim Care Update Ob/Gyn, 7 , 55-59.

68. Hirai, M., Hirono, M., Oosaki, T., Hayashi, Y., Yoshihara, T. and Matsuzaki, O. (1999) Prognostic faclors relating to survival in uterine endometrioid carcinoma. Internationa! Joumal of Gynaecology and Obstetrics, 66, 155-62.

69. Sasaki, M., Tanaka, Y., Perinchery, G., Dharia, A., Kotcherguina, I., Fujimoto, S. and Dahiya, R. (2002) Methylation and inactivation of estrogen, progesterone, and androgen receptors in prostate cancer. Joumal of the National Cancer Institute, 94, 384-90.

70. Sasaki, M., Kotcherguina, L., Dharia, A., Fujimoto, S. and Dahiya, R. (2001) Cytosinephosphoguanine methylation of estrogen receptors in endometrial cancer. Cancer Research, 61, 3262-3266.

71. Navari, J.R., Roland, P.Y., Keh, P., Salvesen, H.B., Akslen, L.A., Iversen, O.E., Das, S. Kothari, R., Howey, S. and Phillips, B. (2000) Loss of estrogen receptor (ER) expression in endometrial tumors is not associated with de novo methylation of the $5^{\text {" }}$ end of the ER gene. Clinical Cancer Research, 6, 4026-4032.

72. Sasaki, M., Kaneuchi, M. ,Fujimoto, S., Tanaka, Y. and Dahiya, R. (2003) Hypermethylation can selectively silence multiple promoters of steroid receptors in cancers. Molecular Cell Endocrinology. 202, 201-7.

73. Kraus, W.L., Weis, K.E. and Katzenellenbogen, B.S. (1995) Inhibitory cross-talk between steroid hormone receptors: differential targeting of estrogen receptor in the repression of its transcriptional activity by agonist- and antagonist-occupied progestin receptors. Molecular Cell Biology, 15, 1847-57. 
74. Vegeto, E, Shahbaz, M.M., Wen, D.X.; Goldman, M.E, O'Malley, B.W. and McDonnell, D.P. (1993) Human progesterone receptor A form is a cell- and promoterspecific repressor of human progesterone receptor B function. Molecular Endocrinology, 7, $1244-55$.

75. Smid-Koopman, E, Blok, L.J., Kuhne, L.C., Burger, C.W., Hellmerhorst, T.J., Brinkmann, A.O and Huikeshoven $F . J$. (2003) Distinct functional differences of human progesterone receptors $A$ and $B$ on gene expression and growth regulation in two endometrial carcinoma cell lines. Joumal of the Society for Gynecologic Investigation, 10, 49-57.

76. De Vivo, I., Huggins, G.S., Hankinson, S.E., Lescault, P.J., Boezen, M., Colditz, G.A. and Hunter, D.J. (2002) A functional polymorphism in the promoter of the progesterone receptor gene associated with endornetrial cancer risk. Proceedings National Academy Science, 99, 12263-12268.

77. Kieback, D.G., Tong, X.-W., Weigel, N.L. and Agoulnik, I.U. (1998) A genetic mutation in the progesterone receptor (PROGINS) leads to an increased risk of non-familial breast and ovarian cancer causing inadequate control of estrogen receptor driven proliferation. Joumal of the Society for Gynecologic Investigation, 5, 40a.

78. McKenna, N.J., Kieback, D.G., Carney, D.N., Fanning, M., McLinden, J. and Headon, D.R. (1995) A germline Taql restriction fragment length polymorphism in the progesterone receptor gene in ovarian carcinoma. British Joumal of Cancer, 71, 4515 .

79. Rowe, S.M., Goughlan, S.J., McKenna, N.J., Garrett, E., Kleback, D.G., Carney, D.N. and Headon, D.R. (1995) Ovarian carcinoma-associated Taql restriction fragment length polymorphism in intron $G$ of the progesterone receptor gene is due to an Alu sequence insertion. Cancer Research, 55, 2743-5.

80. Wang-Gohrke, S., Chang-Claude, J., Becher, H., Kieback "D.G. and Runnebaum, I.B. (2000) Progesterone receptor gene polymorphism is associated with decreased risk for breast cancer by age 50. Cancer Research, 60, 2348-50.

81. Wieser, F., Schneeberger "C., Tong, D., Tempfer, C., Huber, J.C. and Wenzl, R. (2002) PROGINS receptor gene polymorphism is associated with endometriosis. Fertility and Sleritity, 77, 309-12.

82. Donaldson, C.J., Crapanzano, J.P. Watson, J.C., Levine, E.A. and Batzer, M.A. (2002) PROGINS Alu insertion and human genomic diversity. Mutation Research, 501. 137-141.

83. Romano, A, Fischer, D.C." Delvoux, B., Paulussen, A., R., J. and Kieback, D.G. (2003) The PROGINS and +331 G/A polymorphisms in the human progesterone receptor gene are associated with an increased risk for ovarian cancer in women below the age of 50. SGI 2004, March 24-27, Houston TX, USA, pp. abstract no. 989. 
84. Kalz, M.E. and McCormick, F. (1997) Signal transduction from multiple ras effectors. Cument Opinion in Genetics \& Development, 7, 75-79.

85. Bos, J.L. (1989) Ras oncogenes in human cancer: a review. Cancer Research, 49, 4682-4689.

86. Crespo, P. and Leon, J. (2000) Ras proteins in the control of the cell cycle and cell differentiation. Cellular and Molecular Life Sciences, 57, 1613-1636.

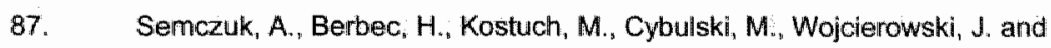
Baranowski, W. (1998) K-ras gene point mutations in human endometrial carcinomas: correlation with clinicopathological features and patients' outcome. Journal of Gancer Research and Clinical Oncology, 124 (12), 695-700.

88. Ito, K., Watanabe, K., Nasim, S., Sasano, H., Sato, S., Yajima, A., Silverberg, S.G. and Garrett, C.T. (1996) K-ras point mutation in endometrial carcinoman effect on outcome is dependent on age of patient. Gynecologic Oncology, 63, 238-246.

89. Lax, S.F., Kendall, B., Tashiro, H., Slebos, R.J.C. and Ellenson, L.H. (2000) The frequency of $\mathrm{p} 53, \mathrm{~K}$-ras mutations, and microsatellite instability differs in uterine endometroid and serous carcinoma. Cancer, 88, 814-824.

90. Mizuuchi, H., Nasrim, S., Kudo, R., Silverberg, S.G., Greenhouse, S. and Garret, C.T. (1992) Clinical implications of K-ras mutations in malignant epithelial tumors of the endometrium. Cancer Research, 52, 23777-2781.

91. Jones, M.W., Kounelis, S., Hsu, C., Papadlaki, H. bakker, A., Swalsky, P.A. and Finkellstein, S.D. (1997) Prognostic wallue of p53 and K-ras-2 topographic genotyping in endometrial carcinoma. International Journal of Gynecological Pathology, 16, 354 360 .

92. Esteller, M., Garcia, A., Martinex-Palones, J.M., Xercavins, J. and Reventos, J. (1997) The clinicopathological significance of K-ras point mutation and gene amplification in endometrial cancer. European Jounal of Cancer, 33 (10), 1572-1577.

93. Avruch, J., Zhang, X.F. and Kyriakis, J.M. (1994) Raf meets Ras: completing the framework of a signal transduction pathway. Trends in Biochemical Sciences, 19 , 279.83 .

94. Davies, H., Bignell, G.R., Cox C., Stephens, P., Edkins, S., Clegg, S., Teague, J.. Woffendin, H., Garnett, M.J., Bottomley, W., Davis, N., Dicks, E., Ewing, R., Floyd, Y., Gray, K., Hall, S., Hawes, R., Hughes, J., Kosmidou, V., Menzies, A., Mould, C., Parker, A., Stevens, C., Watt, S., Hooper, S., Wilson, R., Jayatilake, H., Gusterson, B.A., Cooper, C., Shipley, J., Hargrave, D., Pritchard-Jones, K., Maitland, N. Chenevix-Trench, G., Riggins, G.J., Bigner, D.D., Palmierl, G., Cossu, A., Flanagan, A., Nicholson, A., Ho, J.W., Leung, S.Y., Yuen, S.T., Weber, B.L., Seigler, H.F.。 Darrow, T.L., Paterson, H., Marais, R., Marshall, C.J., Wooster, R. Stratton, M.R. and Futreal, P.A. (2002) Mutations of the BRAF gene in human cancer. Nature, 417, 94954. 
95. Kumar, $\mathbb{R}_{\text {, }}$ Angelini, S. Czene, $K$, Sauroja, $l_{2}$, Hahka-Kemppinen, $M$, Pyrhonen, $S$. and Hemminki, K. (2003) BRAF mutations in metastatic melanoma: a possible associalion with clinical oulcome. Chincal Cancer Research, 9, 3362-8.

96. Yuen, S.T. Davies, H, Chan, T. L. Ho, J.W., Bignell, G.R., Cox "C. Stephens, P." Edkins, S., Tsui, WW, Chan, A S, Futreal, P.A., Stratton, MR. Wooster, R. and Leung, S, Y. (2002) Similarity of the phenotypic patterns associated with BRAF and KRAS mutations in colorectal neoplasia. Cancer Research, 62, 6451-5.

97. Dammann, F, L. C, Yoon, J.-H., Chin, P.L., Bates, S. and Pfeiffer, G.P. (2000) Epigenetic inactivation of a RAS association family protein from the lung tumor suppressor locus 3p21.3. Nature Genetics, 25, 315-319.

98. Vos, MD., Ellis, C.A., Bell, A., Birrer M.J. and Clark, G.J. (2000) Ras uses the novel tumor suppressor RASSF1 as an affector to mediate apoptosis. Joumal of Biological Chemistry, 275, 35669-35672.

99. Engelland van, M. Roemen, G.M.J.M., Brink, M., Pachen, M.M.M., Weijenberg, M.P., Bruine de. A.P., Arends, J.-W., Brandt van den, P.A., Goeij, A.F.P.M. and Herman, J.G. (2002) K-ras mutations and RASSF1A promoter methylation in colorectall cancer: Oncogene, 21, 3792-3795.

100. Xing, M., Cohen, Y., Mambo, E., Tallini, G., Udelsman, R., Ladenson, P.W. and Sidransky, D. (2004) Early occurrence of RASSF1A hypermethylation and its mulual exclusion with BRAF mutation in thyroid tumorigenesis. Cancer Research, 64, 1664-8.

101. Hollstein, M., Sidransky, D., Vogelstein, B. and Harris, C.C. (1991) p53 mutations in human cancers. Science, 253, 49-53.

102. Vogelstein, B. and Kinzler K.W. (1992) p53 function and dysfunction. Cell, 70, 523-6.

103. Lane, D.P. (1992) Cancer. p53, guardian of the genome. Nature, 358, 15-16.

104. Tastiro, H., Isacson, C., Levine, R., Kurman, R.J., Cho, K.R. and Hedrick, L. (1997) p53 gene mutations are common in uterine serous carcinoma and occur early in their pathogenesis. American Joumal of Surgical Pathology "150, 177-185.

105. Stewart, R.L., Royds, J.A., Burton, d.L., Heatley, M.K. and Wells, M. (1998) Direct sequencing of the p53 gene shows absence of mutations in endometroid endometrial adenocarcinomas expressing p53 protein. Histopathology, 33, 440-445.

106. Juven-Gershon, T. and Oren, M. (1999) Mdm2: The ups and downs. Molecular Medicine, 5, 71-83.

107. Sherr, C.J. and Weber, J.D. (2000) The ARF/p53 pathway. Current Opinion in Genetics \& Development, 10, 94-99.

108. Prescott, S.M. and Fitzpatrick. F.A. (2000) Cyclooxygenase-2 and carcinogenesis. Biochinica et Biophysica Acta, 1470, M69-78.

109. Tsujii "M. Kawano, S. Tsuji, S., Sawaoka, H. Hori, M. and DuBoils, R. (1998) Cyclooxygenase regulates angiogenesis induced by colon cancer cells. Cell, 93, $705-$ 16. 
110. Daniel, T.O., Liu, H., Morrow, J.D., Crews, B.C. and Marnett, L.U. (1999) Thromboxane A2 is a mediator of cyclooxygenase-2-dependent endothelial migration and angiogenesis. Cancer Research, 59, 4574-7.

111. Grosch, S., Tegeder, I., Niederberger, E., Brautigam, L. and Geisslinger, G. (2001) COX-2 independent induction of cell cycle arrest and apoptosis in colon cancer cells by the selective COX-2 inhibitor celecoxib. FASEB Jaumal, $15,2742-4$.

112. Wagenaar-Miller, R.A., Hantey, G., Shattuck-Brandt, R., DuBois, R.N., Bell, R.L. Matrisian, L.M. and Morgan, D.W. (2003) Cooperative effects of matrix metalloproteinase and cyclooxygenase-2 inhibition on intestinal adenoma reduction: British Joumal of Cancer, $88,1445-52$.

113. Costa, C. Soares, R., Relis-Filho, J.S., Leitao, D. Amendoeira, 1. and Schmitt, F.C. (2002) Cyclo-oxygenase 2 expression is associated with angiogenesis and lymph node metastasis in human breast cancer. Joumal of Clinical Pathology, 55, 429-34.

114. Thun, M.J., Namboodiri, M.M. and Heath, C.W.J. (1991) Aspirin use and reduced risk of fatal colon cancer. New England Joumal of Medicine, 325, 1593-6.

115. Giovanmucci, E., Rimm, E.B., Stampfer, M.J., Colditz, G.A., Ascherio, A. and Willett, W.C. (1994) Aspirin use and the risk for colorectal cancer and adenoma in male health professionals. Annals of internal Medicine, 121, 241-6.

116. Tomozawa, S., Tsuno, N.H., Sunami, E., Hatano, K., Kitayama, J., Osada, T. Saito, S., Tsuruo, T., Shibata, Y. and Nagawa, H. (2000) Cyclooxygenase-2 overexpression correlates with tumour recurrence, especially haematogenous metastasis, of colorectal cancer. British Joumal of Cancer, 83, 324-8.

117. van Rees, B.P., Saukkonen, K., Ristimaki, A., Polkowski, W., Tytgat, G.N., Drillenburg, P. and Offerhaus ${ }_{*}$ G.J. (2002) Cyclooxygenase-2 expression durng carcinogenesis in the human stomach. Journal of Pathology, 196 $171-9$.

118. Buskens, C.J., Van Rees, B.P., Sivula, A. Reitsma, J.B., Haglund, C., Bosma, P.J., Offerhaus, G.J., Van Lanschot, J.J. and Ristimaki, A. (2002) Prognostic significanice of elevated cyclooxygenase 2 expression in patients with adenocarcinoma of the esophagus. Gastroenterology, 122, 1800-7.

119. Yoshimura, R., Sano, H., Mitsuhashi, M. Kohno, M., Charguli, J. and Wada, S. (2001) Expression of cyclooxygenase-2 in patients with bladder carcinoma. Journal of Urology, 165, 1468-72.

120. Yoshimura, R.., Sano, H. Masuda, C., Kawamura, M. "Tsubouchi, Y. Chargul " J., Yoshimura, N., Hla, T. and Wada, S. (2000) Expression of cyclooxygenase-2 in prostate carcinoma. Cancer, 89, 589-96.

121. Ferrandina, G. Ranelletti ,F. O., Lauriola, L., Zannoni, G.F. Legge, F., Gessï "M. , Salutari, $V$. and Scambia, G. (2003) Cyclooxygenase 2 expression in lymph node metastasis of cervical and vulvar cancer. Oncology Reports, 10, 1799-804. 
122. Fulwaki, R, lida, K., Kanasaki, H. Ozaki, T, Hata, K and Myazaki, K. (2002) Cyclooxygenase-2 expression in endometrial cancer: correlation with microvessel count and expression of wascular endothellal growth factor and hymidine phosphorylase. Human Pathology, 33, 213-9.

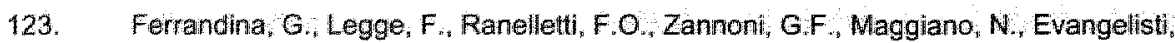
A. Mancuso, S., Scambia, G. and Lauriola L. (2002) Cyclooxygenase-2 expression in endometrial carcinoma: correlation with clinicopathologic parameters and clinical outcome. Cancer; $95,801-7$.

124. Richards, J.A. Petrel, T.A. and Brueggemeier, R.W. (2002) Signaling pathways regulating aromatase and cyclooxygenases in normal and malignant breast cells. Journal of Steroid Biochemistry \& Molecular Biolology, $80,203-212$.

125. Brueggemeier, R.W., Richards, J.A. and Petrel, T.A. (2003) Aromatase and cyclooxygenases: enzymes in breast cancer. Joumal of Steroid Biochemistry \& Molecular Biolology, 86, 501-507. 


\section{Chapter 2}

\section{Material and Methods}

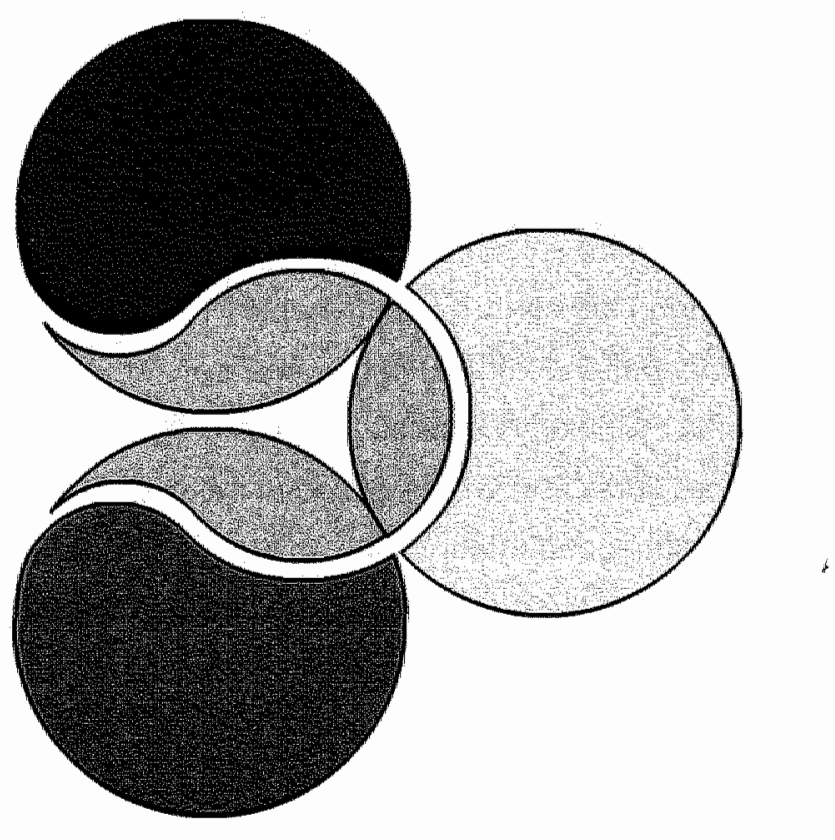




\section{Introduction}

In this chapter the selection of the patients and collection of the material is described. Moreover, the specialized techniques, i.e. mutation analysis, methylation specific PCR (MSP) and restriction fragment length polymorphism (RFLP) are described in more detail as compared to the description in the published papers. Generally used assays such as immunohistochemical analysis are assumed to be known, and microsatellite instability analysis is described in detail in chapter 4 .

\section{Patients and tissue specimens}

For the pilot study group (Chapter 3), 14 patients with recurrent stage I (FIGO [1]) were collected at the University hospital Maastricht, controls were selected out of the same patient population. To extend the study group (Chapter 4-8) patients with recurrent endometrioid endometrial carcinoma were selected from the Dutch National Pathology Database (PALGA) from January 1990 till December 2000. PALGA mediated in the acquirement of both the paraffin embedded tumor tissue as well as the clinical patient information from the gynecologist, who treated the patient. Equally, only patients with stage I endometrial carcinoma with recurrence within three years of diagnosis and treatment were included. Patients with clear cell and serous type endometrial carcinoma were excluded.

Control patients were selected out of the University hospital and one of the neighboring hospitals. All control patients were matched for tumor stage, tumor differentiation, age at diagnosis, and radiotherapy. Both clinical information and the tissue material were coded. The study was approved by the Medical Ethical Committee of the University Hospital of Maastricht (MEC 02-009.5). In both groups first-line therapy consisted of a hysterectomy and bilateral 
salpingo-oophorectomy. External pelvic radiotherapy was applied, when myometrial invasion was more than $50 \%$, and/or when the tumor was poorly differentiated. Patients presented with local recurrence at the vaginal vault $(n=35)$, pelvic wall $(n=1)$, distant metastases ( $n=5$ ) or a combination of a local recurrence and distant metastases ( $n=3)$. The histopathology of all primary $(n=88)$ and, available recurrent tumors $(n=32)$ was revised by an independent pathologist, and the diagnosis of endometrioid adenocarcinomas was confirmed in all cases.

\section{Direct sequencing for mutation analysis}

Mutation analysis of $K$-ras and $P 53$ was performed by using the Autoload Solid phase sequencing system (Amersham Biosciences): The advantage of this technique is that a purification step is introduced within the procedure. Especially DNA, extracted out of paraffin embedded tissue, is highly fragmentized and therefore PCR products can be contaminated with incomplete strands. The sequencing procedure is described in detail by Storgärds [2]. Briefly, the DNA fragment of interest is amplified PCR is performed using one standard and one biotinylated primer. The PCR product is captured on a sequencing comb containing immobilized streptavidin. Subsequently, the non-biotinylated strand is removed by alkaline denaturation. The immobilized strand remains bound to the sequencing comb, and is used as a template in dideoxy sequencing using a Cy5-, fluorescent primer. The products of the sequencing reaction remain bound to the immobilized template strand until the comb is loaded on the sequencing gel. After releasing the fluorescently labeled PCR-product in the sequencing gel fluorescently labeled fragments from the template. Dideoxy sequencing is based on the principle that, in addition to the four dNTP's (adenine (A) - cytosine (C) - guanine (G) - thymine (T)) the 
incubation mixture contains a $2^{\prime}, 3^{\prime}$-dideoxy analog of one of each dNTP. The incorporation of this analog blocks further amplification of the new chain because it lacks the 3'-hydroxyl terminus needed to form the next phophodiester bond. Hence, four sets of chainterminated fragments of various lengths are produced in which the dideoxy analog is at the 3-end. DNA sequence is then determined using the ALF express II DNA analysis system (Amersham Biosciences).

\section{Gene promoter methylation}

Gene expression of tumor suppressor and DNA repair genes can be influenced by epigenetic alterations, amongst which gene promoter methylation, in which a methyl group is added to the cytosine ring resulting in methyl cytosine. This occurs in humans only in the cytosine that precedes the guanine ( $C p G)$. $C p G$ sequences are clustered in the so-called CpG islands, and they are merely located in the promoter region of the gene where transcription of DNA starts. Gene methylation in the promoter region generally correlates with gene silencing. This epigenetic inactivation is frequently observed in tumor suppressor genes in several types of cancer [3].

\section{Methylation Specific PCR (MSP)}

Detection of the methylcytosine can be performed using several techniques [4,5] (Laird 2002, Nature Reviews Cancer), amongst which methylation specific PCR (MSP) The bisulphate-conversion based methods have the advantage that rapid identification is possible with less amount of DNA. MSP makes use of sodium bisulfite conversion of is unmethylated cytosine into uracil, whereas the methylated cytosine remains unchanged $[6,7]$. The obtained sequence alterations can be detected he methylation specific PCR (MSP) by using primers specific for methylated as well as 
unmethylated DNA. Since DNA was obtained from paraffin embedded tissue, a nested PCR approach was performed to increase sensitivity. Both PCR products are loaded on a nondenaturing $6 \%$ polyacrylamide gel, stained with ethidium bromide and visualized under UV illumination. The presence of a PCR product in respectively the $U$ and $M$ lane indicates the presence of unmethylated or methylated alleles. All PCR reactions were performed with a control for unmethylated alleles (DNA from normal lymphocytes), a control for methylated alleles (in vitro methylated DNA of normal lymphocytes treated with Sssl methyltransferase (New England Biolabs)), and a negative control $\left(\mathrm{H}_{2} \mathrm{O}\right)$ (Figure 1).

\section{Figure 1}

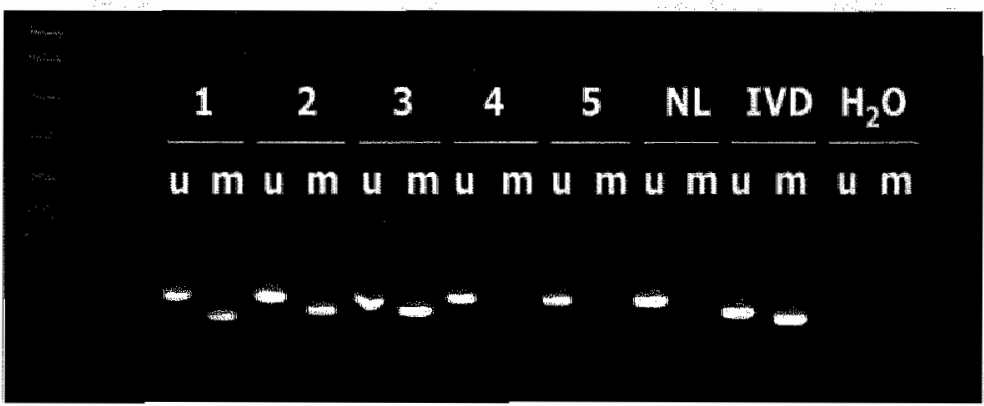

Representative examples of MSP reactions of five samples of endometrial carcinoma patients. A visible PCR product in the lanes marked $U$ indicates the presence of unmethylated alleles. A PCR product in the M marked lanes indicates the presence of methylated alleles. Normal lyimphocytes (NL) and in vitro methylated DNA (IVD) were used as negative and positive controls, respectively. The $\mathrm{H}_{2} \mathrm{O}$ control was included in the flanking PCR and in the MSP.

This technique was developed in 1996, and the relative sensitivity was originally estimated to be one in 1000 (detection of methylated DNA in 1000-foid excess of unmethylated DNA) [5]. 


\section{Restriction Fragment Length Polymorphism (RFLP)}

For detection of progesterone receptor polymorphism (PROGINS, $+331 \mathrm{G} / \mathrm{A}$ ) and for the detection of BRAF (V599) mutations RFLP was used. This technique is based on the principle that restriction enzymes are able to digest the DNA on specified places [8]. The presence of a mutation can change a restriction site and hence creates polymorphisms of length that can discriminate between mutated and wild-type allele (Fig.2, page 205). A large amount of restriction enzymes exist, and the restriction enzyme is properly selected for the area of interest. In the current thesis (semi) nested PCRs were performed and after digestion with the proper enzyme, the product was loaded on a $2 \%$ agarose gel (PROGINS, $+331 \mathrm{G} / \mathrm{A}$ ) or a $6 \%$ polyacrylamide gel (BRAF), and the digested PCR products were visualized by ethidium bromide staining under UV illumination. The advantage of RFLP is that it is cheap compared to direct sequencing, relatively easy and rapid. However, RFLP can only be used for known mutations, therefore positive and negative controls should always be included to be sure that there is complete digestion.

\section{References}

1. Creasman, W.T. (1990), New gynecologic cancer staging. Obstetrics and Gynecology $75,287-288$.

2. Storgards, M. (1999) Sequence-based HLA typing. Life Science News, 2 , $1-4$.

3. Herman, A.G. and Baylin , S.B. (2003) Gene silencing in cancer in association with promoter hypermethylation. New England Journal of Medicine, 349, 2042-54.

4. Frommer, M., McDomald, L.E. Millar, D.S., Collis, C.M., Watt, F., Grigg, G.W. Molloy, P.L. and Paul C.L. (1992) A genomic sequencing protocol 
that yields a positive display of 5-methylcytosine residues in individual DNA strands. Procedings of the National Academy of Science, 89, 1827-34.

5. Herman, J.G., Graff, J.R., Myohanen, S., Nelkin, B.D, and Baylin, S.B. (1996) Methylation-specific PCR: a novel PCR assay for methylation status of $\mathrm{CpG}$ islands. Procedings of the National Academy of Science, 93, 98216.

6. Sasaki, M., Anast, J., Bassett, W., Kawakami, T. Sakuragi, N and Dahiya, R. (2003) Bisulfite conversion-specific and methylation-specific PCR: a sensitive technique for accurate evaluation of $\mathrm{CPG}$ methylation.

Biochemical and Biophysical Research Communications, 309, 305-309.

7. Clark , S.J. , Harrison, J., Paul ${ }_{2}$ C.L. and Frommer, M. (1994) High sensitivity mapping of methylated cytosines. Nucleic Acids Research, 22, 2990-7.

8. R.H., T. (1996) DNA Cloning and sequencing. In Sievers, E.M. (ed.), Principles of Genetics. Wm. C. Brown Publisher, Boston, pp. 327-330. 


\section{Chapter 3}

\section{APC, $\beta$-catenin and E-cadherin and the development of recurrent endometrial carcinoma}

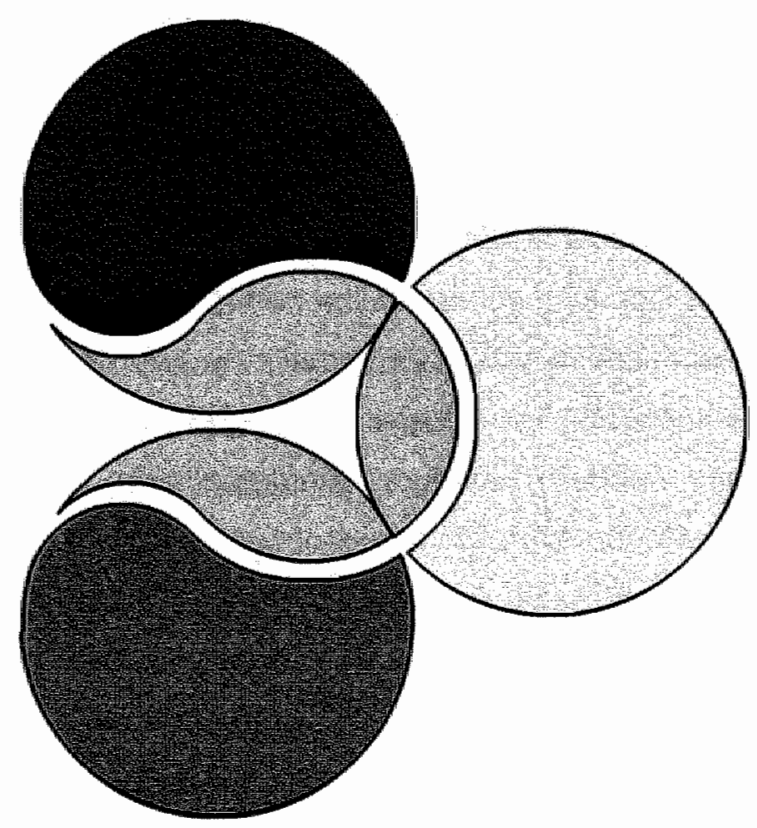

Johanna M.A. Pijnenborg, Natasja Kisters, Manon van Engeland, Gerard A.J. Dunselman, Jelte de Haan, Anton F.P.M. de Goeij, Patrick G. Groothuis Int J Gynecol Cancer 2004 Sep-Oct; 14(5):947-56 


\section{Abstract}

Endometrial carcinoma generally has a good prognosis. However, in some patients the tumor appears to behave very aggressively, a course that cannot be explained with histopathological characteristics. More insight in the molecular background can be valuable to clarify these differences in tumor behavior. Three components associated with the Wint pathway i.e. APC (adenomatous polyposis coli), $\beta$-catenin, and E-cadherin were evaluated in a case-control study of 28 patients with stage I endometrial carcinomas, to determine their involvement in the development of recurrent disease. Mutation analysis of the Mutation Cluster Region of the APC gene, determination of gene promoter methylation status of the APC-1A and Ecadherin genes, and immunohistochemical analysis of APC, E-cadherin and $\beta$-catenin were performed using paraffin-embedded tumor tissue. Twentyone APC gene mutations were detected in $12 / 28$ (43\%) patients. Only three mutations would result in a stopcodon in the APC gene. APC gene promoter methylation was assessed in 12/28 (43\%) patients. APC immunostaining was absent in 2/24 patients. The occurrence of APC mutations, APC gene promoter methylation, and APC immunostaining were not predictive for recurrence. No E-cadherin expression was observed in 4/24 patients $(17 \%)$. $E$-cadherin gene promoter methylation could not be detected in any of the patients. The absence of E-cadherin expression was predictive for distant metastases, but not for local recurrence. Nuclear localization of $\beta$-catenin was present in 9/24 (38\%) patients and was not predictive for recurrent disease. Involvement of epigenetic and genetic aberrations in APC and $\beta$ catenin genes seems to be of minor importance for the development of lacal recurrences and distant metastases. Although the number of cases is limited, E-cadherin expression appears to be predictive for the development of distant metastases in endometrial carcinoma. 


\section{Introduction}

Endometrial carcinoma is the most frequently diagnosed malignancy of the female genital tract. Although the overall prognosis is good, some patients present with recurrent disease shortly after primary treatment [1]. Differences in tumor behavior that are not related to histopathological characteristics could possibly be explained by differential activation of specific molecular pathways. Identification of the various pathways involved is a first step towards a better understanding of the tumorigenic process. The impact of aberrations in the Wnt pathway on the initiation and eventually progression of several types of cancer has recently gained much attention, in particular in colon cancer, but to date only occasionally in endometrial cancer [2-4]. Under normal conditions, free $\beta$-catenin is rapidly phosphorylated by glycogen synthetase kinase $3 \beta$ (GSK-3 $\beta$ ) and subsequently degraded in the ubiquitin-proteasome pathway [3-6]. When the tumor suppressor APC is non-functional, e.g. as a result of truncating mutations in both alleles of the gene, GSK-3 $\beta$ activity is blocked. As a result, high levels of $\beta$-catenin accumulate in the cytoplasm, and subsequently translocate to the nucleus to form a complex with the T-cell factor (TCF) and the lymphoid enhancer factor (LEF) which leads to activation of proliferation $[7,8]$. Aberrations in the APC (adenomatous polyposis coli) gene or in the $\beta$-catenin gene may disturb the signaling through the Wnt pathway and are associated with tumor development as has been reported for colon, ovarian and endometrial cancer [9-16]. Recent studies have shown that in $85 \%$ of colorectal cancers mutations are detected in the APC gene and mutations in the $\beta$-catenin gene are observed in half of the remaining 15\% [9]. The majority of reported APC mutations is found in the Mutation Cluster Region (MCR) of this large gene and often leads to the expression of a truncated protein, which is unable to bind $\beta$-catenin. Recently, gene promoter methylation has been observed as another way of inactivation of the APC protein and this mechanism is described for colorectal cancer and endometrial carcinoma [17-20]. To date, studies on inactivating mutations of the APC gene in endometrial cancer are 
limited, although mutations in the $\beta$-catenin gene are reported to occur in approximately $17 \%$ of the endometrial carcinomas studied $[2,14-16,21]$. In ovarian cancer the presence of nuclear $\beta$-catenin is an indicator of a good prognosis, in endometrial carcinoma this has not been studined yet [13]. $\beta$ Catenin is also involved in cell adhesion, together with $E$-cadherin, $\alpha$-catenin and $y$-catenin $[4,5,22]$. Without normal catenin binding sites the E-cadherin function is impaired [22]. Loss of E-cadherin expression is associated with dedifferentiation of the tumor, invasive behavior, and metastatic potential in endometrial as well as other carcinomas, which demonstrates the importance of normal E-cadherin function [6,22-27]. The absence of $E$ cadherin has also been attributed to methylation of $\mathrm{CpG}$ islands in the promoter region and is correlated with an increased tumor aggressiveness and a poor prognosis [25,28-30]. To date, the occurrence of E-cadherin promoter methylation in endometrial carcinoma has been reported by Saito et al.[31] and Moreno-Bueno et al.[32] in different frequencies.

Taken together, the involvement of aberrations in components of the Wnt pathway in recurrent endometrial carcinoma is not clear. Therefore, the predictive value of APC mutations, APC-1A and E-cadherin gene promoter methylation, and expression of APC, $\beta$-catenin and E-cadherin proteins, for the development of early recurrences was determined in a case-control study. 


\section{Patients and methods}

Patients and tissue specimens

In this study 28 patients treated for stage I disease, classified according the FIGO criteria [33], were included. Patients were treated by hysterectomy and bilateral salpingo-oophorectomy, without lymphadenectomy. Postoperative external pelvic radiotherapy was applied when tumor invasiveness was more than $50 \%$ of the myometrial wall and/or when the tumor was poorly differentiated. Fourteen patients with recurrence within three years of diagnosis were matched with fourteen control patients without recurrence for tumor stage, tumor differentiation, age at diagnosis, and therapy. Patients with recurrent endometrial carcinoma presented local recurrence at the vagina vault $(n=11)$, distant metastasis $(n=1)$ or both local recurrence and distant metastases $(n=2)$. A pathologist revised the histopathology of the tumor and the endometrioid type adenocarcinomas were confirmed in all cases. The study was approved by the Medical Ethical Committee of the University Hospital Maastricht.

\section{DNA isolation}

After identification by a pathologist, areas that predominantly contained tumor cells were macroscopically dissected from five consecutive $20 \mu \mathrm{m}$ sections of the paraffin-embedded tissue specimens. Genomic DNA was extracted using a proteinase $\mathrm{K}$ (Qiagen) digestion followed by DNA isolation using the Puregene DNA Isolation Kit (Gentra Systems).

\section{APC mutation analysis}

Mutation analysis of the APC mutational cluster region was performed as described previously [34]. In brief, in a first step two overlapping fragments (356 and $511 \mathrm{bp}$, respectively) were amplified, which comprised the mutation cluster region. Subsequently each fragment was subjected to two nested PCRs, which generated two overlapping fragments, using one biotinylated 
primer in each primer sel. The four resulting biotinylated fragments with sizes of $219,204,205$, and $267 \mathrm{bp}$, respectively, were subsequently sequenced using the autoload solid phases sequencing kit (Amersham Pharmacia Biotech). The biotinylated fragments were captured on a comb coated with strepavidin, and the non-biotinylated fragments are removed by alkaline denaturation. The remaining strand serves as a template for dideoxy sequencing with extended Cy5-labeled primers and $T 7$ polymerase. The products are separated and recorded on the ALF Express DNA Analysis System, and analyzed using ALFwin software (Amersham Pharmacia Biotech).

\section{Methylation analysis of APC and E-cadherin promoter region}

DNA methylation in the CpG islands of the APC-1A and E-cadherin promoter region was determined by chemical modification of genomic DNA with bisulphite and subsequent methylation-specific PCR (MSP) as described elsewhere [35]. To enable MSP analysis on DNA retrieved from formalinfixed, paraffin-embedded tissue, a nested MSP was performed with primers flanking the $\mathrm{CPG}$ islands in the promoter regions. Primer sequences and PCR conditions for APC-1A and E-cadherin promoters are presented in Table 1 and are described by Esteller et al. and Corn et al. [36,37]. All MSP reactions were performed with a control for unmethylated $\mathrm{APC}$ and $\mathrm{E}-$ cadherin alleles (DNA from normal lymphocytes), a control for methylated $A P C$ and E-cadherin alleles (in vitro methylated DNA of normal lymphocytes by treatment with SssI methyltransferase from New England Biolabs) and a negative control $\left(\mathrm{H}_{2} \mathrm{O}\right)$. A total of $6 \mu$ of each MSP reaction was loaded on a nondenaturing $6 \%$ polyacrylamide gel, stained with ethidium bromide and visualized under UV illumination. The presence of a PCR product in the $U$ and $\mathrm{M}$ lane indicates the presence of unmethylated or methylated alleles, respectively. Samples were analyzed in duplicate (reproducibility $85 \%$ for APC and $100 \%$ for E-cadherin). Cases methylated in one of two duplicate reactions were considered as methylated. 


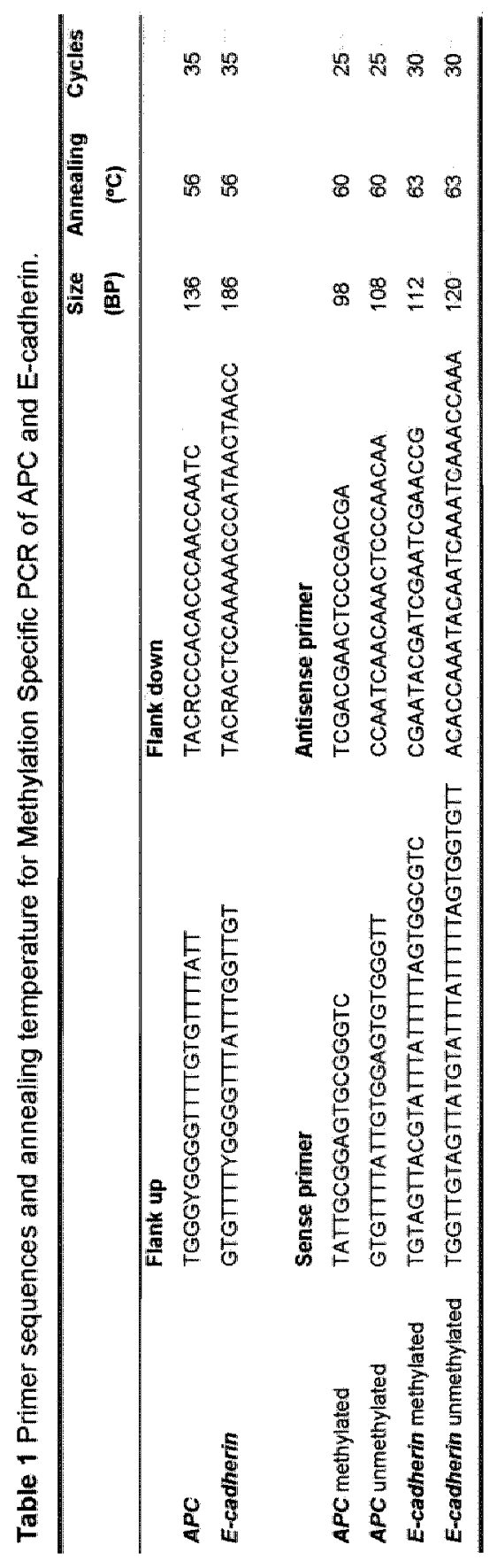


For two cases the E-cadherin methylation-specific PCR could repeatedly not be performed, probably due to poor DNA quality, and these cases were omitted from analysis.

\section{Immunohistochemical analysis}

Immunohistochemical staining was performed on formalin-fixed, paraffinembedded specimens ( 14 cases and 14 controls). Parallel haematoxylin and eosin stained sections were used to select the tumor area of the specimens. Sections of $5 \mu \mathrm{m}$ were cut and mounted on starfrost adhesive slides (Klinipath, The Netherlands). Sections were deparaffinized in xylol and rehydrated prior to the blocking of endogenous peroxidase activity by incubation in $0.3 \%$ hydrogen peroxide/methanol solution for 20 minutes. Antigen retrieval was performed by heat treatment for 20 minutes in $10 \mathrm{mM}$ citrate buffer $(\mathrm{pH} 6.0)$. Sections were allowed to cooll down to room temperature. Non-specific binding was blocked with $5 \%$ bovine serum albumin for 30 minutes at room temperature. Incubation was performed overnight at $4^{\circ} \mathrm{C}$ with monoclonal antibodies directed to the $\mathrm{N}$-terminus of APC protein (OP80, Calbiochem), $\beta$-catenin (C19220, Transduction Laboratories). After incubation, the Envision kit (Dako) was applied for 30 minutes to enhance staining. Antibody binding was visualized by incubating for 3 minutes with 3,3'-diaminobenzidine [38]. Sections were counterstained with diluted haematoxylin. For E-cadherin staining, the Polymica detection kit (The Binding Site) was used $[38,39]$. In this protocol there was no blocking step, and the primary antibody against E-cadherin (G-10, sc-8426, Santa Cruz Biotechnology, INC) was applied for 15 minutes at room temperature after which four intensification steps were applied. Staining was acquired by the application of 3,3'-diaminobenzidine and sections were counterstained lightly with haematoxylin.

The immunostaining of each case was scored for the percentage and intensity of staining independently by three observers (JP, NK, PG). 
The percentage of staining was classified into categories $0=0 \%, 1=0-10 \%$, $2=10-50 \%, 3=>50 \%$ of positive tumor cells. The intensity was defined as 0 $=$ absent, $1=$ weak, $2=$ moderate, or $3=$ strong. The staining index was calculated as the product of the percentage and the intensity [40].

\section{Statistics}

The SPSS software program (9.01) was used for statistical analysis. Median values were calculated of the patient's age and follow-up time. To test whether the differences in both patient groups were significant, a T-test for paired analysis was performed for continuous variables (age, follow-up and staining index). Mc Nemar's test for paired analysis was performed for the dichotomous variables (tumor differentiation, tumor invasion, APC mutations, APC and $E$-cadherin methylation, absent or nuclear staining). $A \chi^{2}$ was calculated for the presence of promoter methylation, and the absence of protein by immunohistochemistry. For all statistical tests, a p-value of 0.05 was considered significant. 


\section{Results}

\section{Patients}

All patients ( $h=28$ ) were postmenopausal, and no significant differences in clinico-pathological characteristics were found between patients with and without recurrence. However, the follow-up time differed, i.e. 27.5 months for patients with recurrence and 60 months for patients without recurrent disease $(p<0.01)$ (Table 2).

Table 2 Patient and tumor characteristics

\begin{tabular}{|c|c|c|c|}
\hline & $\begin{array}{l}\text { Patients with } \\
\text { recurrence } \\
(n=14)\end{array}$ & $\begin{array}{l}\text { Patients without } \\
\text { recurrence } \\
(n=14)\end{array}$ & P-value \\
\hline Age at diagnosis & $68.5(51-80)$ years & $70(56-82)$ years & 0.847 \\
\hline (Median and range) & & & 1.000 \\
\hline Figo stage & 0 & 1 & \\
\hline la & 9 & 7 & \\
\hline $\mathrm{lb}$ & 5 & 6 & \\
\hline \multicolumn{4}{|l|}{ 10 } \\
\hline Tumor grade & & & 1.000 \\
\hline Grade 1 & 3 & 5 & \\
\hline Grade II & 7 & 5 & \\
\hline Grade III & 4 & 4 & \\
\hline Post-operative radiotherapy & 7 & 7 & - \\
\hline $\begin{array}{l}\text { Recurrence after } \\
\text { (median and range) }\end{array}$ & $12.5(4-28)$ months & & - \\
\hline Follow-up (median and range) & $27.5(12-72)$ manths & $72(36-120)$ months & 0.007 \\
\hline
\end{tabular}

\section{APC mutations}

Overall, 14 mutations were demonstrated in the APC gene of 11 out of 28 patients ( $39 \%$ ) with endometrial carcinoma (Table 3 ). Only three mutations would lead to a stopcodon and hence to a truncation of the APC protein, indicated by a highlighted $X$ in Table 3 . Six other mutations would putatively lead to the substitution of an amino acid. The occurrence of 4 silent 
mutations and of 15 polymorphisms in the mutation cluster region would not result in a change in the APC protein. One mutation was located in the gene directly downstream of an inserted stopcodon and therefore would also not lead to an extra change of the protein. Six patients with recurrence harbored mutations in the APC gene, and in five of these patients this leads to a change in the APC protein. Five control patients showed APC mutations, and in 3 of them the protein would be altered. The difference in mutation frequency between patients with and without recurrence was not statistically significant.

\section{APC methylation and immunostaining}

Overall, $43 \%(12 / 28)$ of patients with endometrial carcinoma demonstrated APC promoter methylation (Table 3). Although there was a small difference in frequency of APC promoter methylation in patients with recurrence compared to patients without recurrence, this was not statistically significant $(p=0.13)$ (Table 3). Representative samples are shown in Figure 1.

Immunohistochemical analysis of the APC protein using an antibody to the $\mathrm{N}$-terminus demonstrated cytoplasmic staining (Fig.3a, page 206) without nuclear staining or granulation in the majority of specimens. In two patients with recurrence however, APC staining was absent (Fig.3b, page 206. Table 3). One of these two patients demonstrated an APC gene mutation with a stopcodon as well as APC gene promoter methylation, whereas in the other patient only APC gene promoter methylation was observed. The immunastaining index for APC protein in specimens with or without APC gene promoter methylation was not different. 
Table 3 Prevalence of APC mutations, APC and E-cadherin promoter methylation and expression of APC, E-cadherin, and $\beta$-catenin.

\begin{tabular}{|c|c|c|c|c|c|}
\hline \multicolumn{4}{|c|}{$\begin{array}{l}\text { Patient and fumor } \\
\text { characteristlos }\end{array}$} & \multicolumn{2}{|c|}{ APC aberrations } \\
\hline $\mathrm{Nr}$ & $\begin{array}{l}\text { stage; } \\
\text { grade }\end{array}$ & $R T$ & rec & $\begin{array}{l}\text { gene mutation } \\
\text { (rucleotide pos) }\end{array}$ & $\begin{array}{l}\text { protein change } \\
\text { (codon) }\end{array}$ \\
\hline 1 & $\mathrm{Ib} \|$ & + & + & wild type & - \\
\hline 2 & 16.11 & + & + & $\begin{array}{l}\text { A } 4411 G \\
4414 \text { del } 2 G \#\end{array}$ & $P 1467 X$ \\
\hline 3 & $\mathrm{IC}_{j}\|\| \|$ & + & + & wild type & - \\
\hline 4 & $\left|c_{1}\right| \| \mid$ & + & $\mp$ & $\begin{array}{l}\text { T } 4344 \text { A } \\
\text { C } 4496 \text { T / Polymorphism* }\end{array}$ & $\begin{array}{l}\text { P } 1442 \mathrm{P} \\
T 1493 \mathrm{MNJ}\end{array}$ \\
\hline 5 & $|c, \||$ & + & + & $\mathrm{T} 4344 \mathrm{~A}$ & P $1442 \mathbb{P}$ \\
\hline 6 & $\mid \mathrm{c}, \| \mathrm{I}$ & 4 & + & Polymorphism* & - \\
\hline 7 & $\mathrm{Ib}_{n}$ & + & + & Polymorphism* & - \\
\hline 8 & $\mid c, \|$ & - & + & wild type & - \\
\hline 9 & $\mathrm{Ib}_{1} \| \mathrm{II}$ & - & + & $\mathrm{G} 3967 \mathrm{C}$ & $E 1317 Q$ \\
\hline 10 & $\mid b_{n} \|$ & - & + & Polymorphism* & - \\
\hline 11 & $\left\|b_{1}\right\|$ & - & + & $\mathrm{G} 4265 \mathrm{~A}$ & G $1416 \mathrm{D}$ \\
\hline 12 & $\mathrm{Ib}_{\|} \|$ & - & + & wild type & - \\
\hline 13 & $\left|b_{n}\right|$ & - & + & C $4348 \mathrm{~T}$ & Q $1444 X$ \\
\hline 14 & $\mathrm{Ib}_{\mathrm{n}} \mathrm{H}$ & - & + & wild type & - \\
\hline 15 & $\mathrm{Ib}_{\mathrm{n}} \mathrm{II}$ & + & - & Polymorphism* & - \\
\hline 16 & $\mathrm{Ib}_{\|}$ & + & - & A 4360 G / Polymorphism * & $\mathrm{T} 1448 \mathrm{~A}$ \\
\hline 17 & $\mid \mathrm{C}, \mathrm{II|}$ & + & - & C 4303 T / Polymorphism* & Q $1429 X$ \\
\hline 18 & $|c|$, & + & - & wild type & - \\
\hline 19 & $\mid \mathrm{Ic},\|\|$ & + & - & Polymorphism* & - \\
\hline 20 & $\mid \mathrm{Ic}, \mathrm{II}$ & + & - & wild type & - \\
\hline 21 & $\mid \mathrm{c}, \|$ & + & - & Polymorphism* & - \\
\hline 22 & $\mid \mathrm{c}, \mathrm{II}$ & - & - & Polymorphism* & - \\
\hline 23 & $\mathrm{Ib}_{1} \mathrm{II}$ & - & - & A $4401 \mathrm{G}$ & $E 1461 E$ \\
\hline 24 & $\mid \mathrm{b}, \mathrm{I}$ & - & - & Polymorphism* & - \\
\hline 25 & $\mathrm{Ib}_{\mathrm{n}} \mathrm{II}$ & - & - & Polymorphism* & - \\
\hline 26 & $\left|b_{1}\right|$ & - & - & Polymorphism* & - \\
\hline 27 & $\mathrm{Ib}_{n} \|$ & $\approx$ & - & A 4431 T/Polymorphism* & A 1471 A \\
\hline 28 & $\operatorname{la}_{\|} \|$ & - & - & $\begin{array}{l}\text { C } 4049 \text { T } \\
\text { A } 4420 \text { G/ Polymorphism* }\end{array}$ & $\begin{array}{l}\mathrm{S} 1344 \mathrm{~L} \\
\mathrm{~K} 1468 \mathrm{E}\end{array}$ \\
\hline
\end{tabular}


Polymorphism G $4497 \mathrm{~A}$ is sillent, and would not lead to a change in the APC protein \# located directly downstream of an inserted stopcodon and therefore does not lead to an extra change of the protein. $\mathrm{RT}=$ radiotherapy $r e c=$ recumence, $\mathrm{X}=$ stopcodon $\mathrm{U}=$ ummethylated, $M=$ methylated

\begin{tabular}{|c|c|c|c|c|}
\hline \multicolumn{2}{|c|}{ APC aberrations } & \multicolumn{2}{|c|}{ E-cadherin } & \multirow{2}{*}{ 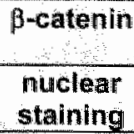 } \\
\hline methylation & $\begin{array}{l}\text { cytoplasmic } \\
\text { staining }\end{array}$ & methylation & $\begin{array}{c}\text { membranous } \\
\text { staining }\end{array}$ & \\
\hline$M$ & + & $\mathrm{U}$ & + & - \\
\hline U & + & $\mathrm{U}$ & - & - \\
\hline$M$ & + & $U$ & + & - \\
\hline$M$ & + & U & + & - \\
\hline U & + & - & + & - \\
\hline $\mathrm{U}$ & + & U & + & + \\
\hline$M$ & + & U. & - & + \\
\hline$M$ & + & $\mathrm{U}$ & - & - \\
\hline $\mathrm{M}$ & + & $\mathrm{U}$ & + & - \\
\hline $\mathrm{U}$ & + & U & + & + \\
\hline $\mathrm{u}$ & + & U & + & - \\
\hline$M$ & - & $U$ & + & + \\
\hline$M$ & - & U & - & - \\
\hline$U$ & + & U & + & - \\
\hline M & + & U & + & - \\
\hline$U$ & + & $U$ & + & + \\
\hline U & + & $U$ & + & - \\
\hline U & + & - & + & - \\
\hline $\mathrm{U}$ & + & $\mathrm{u}$ & + & - \\
\hline $\mathrm{U}$ & + & $u$ & + & + \\
\hline $\mathrm{M}$ & + & $u$ & + & - \\
\hline$M$ & + & U & + & + \\
\hline$U$ & + & $U$ & + & - \\
\hline $\mathrm{U}$ & + & $U$ & + & + \\
\hline$U$ & + & U & + & - \\
\hline $\mathrm{U}$ & + & $u$ & + & - \\
\hline $\mathrm{M}$ & + & $U$ & + & + \\
\hline U & + & $\mathrm{U}$ & + & $m$ \\
\hline
\end{tabular}




\section{E-cadherin methylation and immunostaining}

E-cadherin methylation was not found in the tested tumors $(0 / 26)$ (Table 3$)$. Representative samples and controls are demonstrated in Figure 2. Ecadherin protein was mainly located in the cell membrane (Fig. 3c, page 206), complete absence of E-cadherin staining was demonstrated in four patients with recurrence (grade I $(n=1)$, grade $\|(n=2)$, grade III $(n=1)$ (Fig. 3d, page 206, Table 3). Of these patients three had developed distant metastases and one a local recurrence. The absence of E-cadherin expression was significantly associated with the development of distant metastases $(p<0.05)$.

\section{$\beta$-catenin immunostaining}

Nuclear localization as well as membranous staining of $\beta$-catenin was observed in both patient groups (Fig. 3e-f, page 206, Table 3). Nuclear localization of $\beta$-catenin was not related to tumor differentiation, myometrial invasion, APC mutations or APC gene promoter methylation, and recurrent disease.

\section{Figure 1}

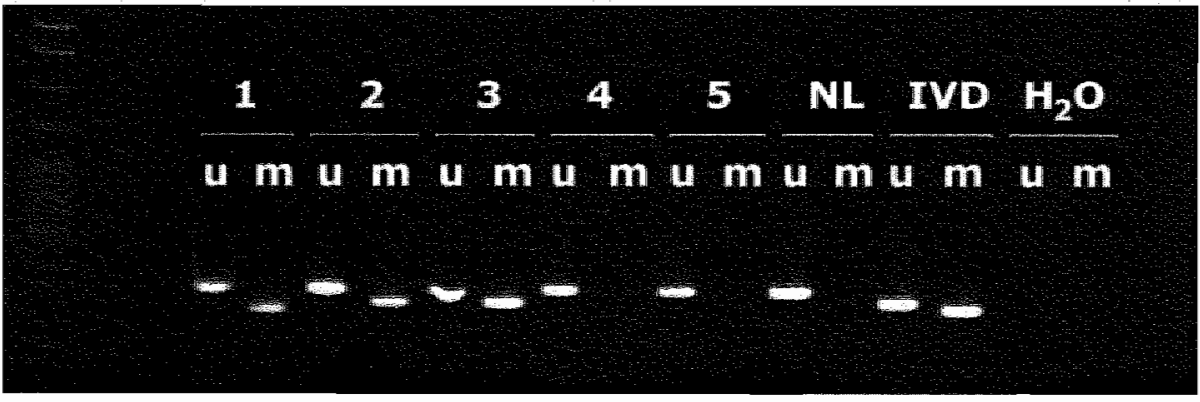

Representative examples of APC MSP reactions of five samples of endometrial carcinoma patients. A visible PCR product in the lanes marked $U$ indicates the presence of unmethyllated alleles. A PCR product in the M marked lanes indicates the presence of methylated alleles. Normal lymphocytes (NL) and in vitro methylated DNA (IVD) were used as negative and positive controls, respectively. The $\mathrm{H}_{2} \mathrm{O}$ control was included in the flanking PCR and in the MSP. 
Figure 2

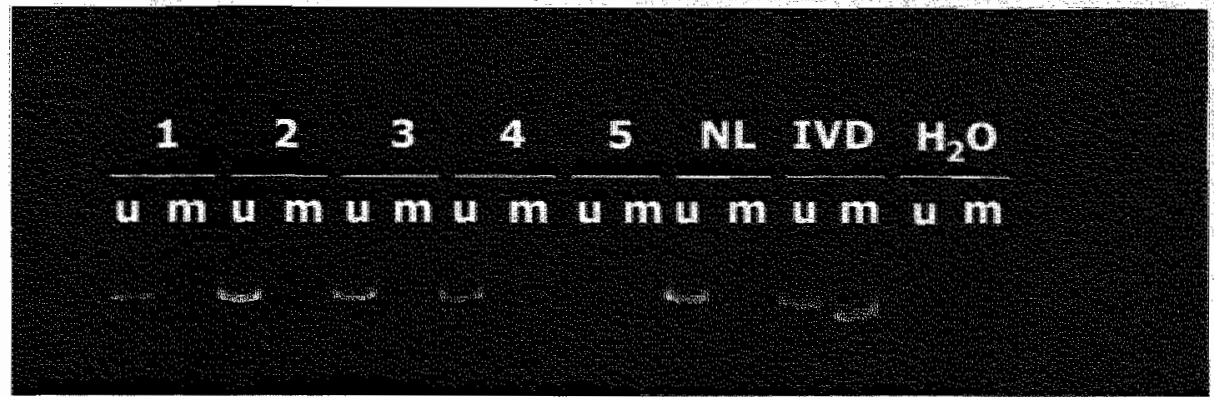

Representative examples of E-cadherin MSP reactions of five samples of endometrial carcinoma patients, of which case number 5 did not show a PCR product. A visible PCR product in the lanes marked $U$ indicates the presence of unmethylated alleles. A PCR product in the M marked lanes indicates the presence of methylated alleles. Normal lymphocytes (NL) and in viltro methylated DNA (IVD) were used as megative and positive controls, respectively. The $\mathrm{H}_{2} \mathrm{O}$ control was included in the flanking PCR and in the MSP. 


\section{Discussion}

Three components associated with the Wnt pathway were studied to determine their predictive role for recurrent endometrial carcinoma. Although mutations in the APC gene were present in $39 \%$ of patients with endometrial carcinoma, only three mutations would putatively lead to truncation of the APC protein. To date only two studies on mutation analysis of $A P C$ in endometrial carcinoma have been reported. Schlosshauer et al. [15] studied the APC protein in 32 cases with endometrial carcinoma using a protein truncation essay, and found no truncated APC. Obviously, no other genetic alterations than truncations were investigated. Recently, Moreno-Bueno et al. [2] presented data of $A P C$ mutation analysis of 95 endometrioid endometrial carcinomas and found no mutations in the mutation cluster region of the $A P C$ gene. In our study a low proportion of patients with mutations that potentially result in a truncating protein was found, and these mutations were not specific for the patients with recurrent disease.

Therefore, these results suggest that the occurrence of $A P C$ mutations is not necessary to develop recurrent endometrial carcinoma. This would be in line with a role of APC mutations predominantly early in the process of carcinogenesis in endometrial tissue. The high frequency of promoter methylation of $A P C$ is in concordance with data of Zysman et al.[20] and Moreno-Bueno et al.[2] and suggests that this mechanism of tumor suppressor inactivation may be important in tumor genesis of endometrial tissue. However, APC gene promoter methylation was not confined to the patients prone to recurrence, and not correlated with absence of APC immunostaining. This may be due to methylation of only one allele, which does not necessarily influence protein expression or function. Moreover, APC transcripts can be generated from promoter $1 B$ as well [41].

Alternatively, loss of heterozygosity $(\mathrm{LOH})$ may account for the absence of APC, however, in contrast to colorectal cancers, $L O H$ is found in only a minority of endometrioid endometrial carcinomas [2,42]. Zysman et al [20] reported that the percentage of $A P C$ promoter methylation was twice as high 
in tumors that demonstrated microsatellite instability (MSI) compared to tumors without MSI. This was also observed in the current study, although significance was not reached (data not shown).

APC staining was also present in two cases in which stopcodons were identified in the APC gene. This can be explained by the fact that the antibody only recognizes the $\mathrm{N}$-terminus, but not the $\mathrm{C}$-terminus of the APC protein. Immunohistochemical analysis was performed to correlate protein expression with the presence of $A P C$ promoter methylation. An antibody directed to the C-terminus of APC was available, but showed no immunoreactivity with paraffin embedded tissue.

E-cadherin is an epithelial-specific cell adhesion molecule that is responsible for maintaining epithelial integrity and polarity, and is a suppressor of both invasion and metastasis. In the present study reduced E-cadherin expression in endometrial carcinoma was significantly associated with the development of distant metastases, even in this small series of cases. This agrees with the finding of Sakuragi et al. who found that decreased Ecadherin expression is correlated with para-aortic node metastasis in endometrial carcinoma [24]. Decreased E-cadherin expression has also been associated with increasing tumor stage and tumor dedifferentiation [31]. In the current study only stage I carcinomas were included, but no correlation was found between decreased E-cadherin expression and tumor dedifferentiation. This is in accordance with the findings of Moreno-Bueno et al. [32], but contradicts the findings of Saito et al. [31] who did report a correlation between decreased $\mathrm{E}$-cadherin expression and E-cadherin promoter hypermethylation.

In the current study none of the patients demonstrated E-cadherin $\mathrm{CpG}$ promoter methylation. This is in contrast with other reports. Saito et al. [31] reported E-cadherin promoter methylation in $28 \%$ of stage I endometrial adenocarcinomas. Moreno-Bueno et al. [32] demonstrated E-cadherin promoter methylation in $21 \%$ of endometrial carcinomas, however the 
authors did not indicate to what extend E-cadherin promoter methylation was found in stage ! tumors.

To increase the sensitivity of the E-cadherin MSP, we designed a nested $\mathrm{PCR}_{\text {, }}$ based on the primer set of Moreno-Bueno et al. [32]. Despite the increased sensitivity, and repeated analyses, no E-cadherin promoter methylation was observed. There is no obvious explanation for the observed differences other than the fact that the patient populations used in our study and the studies of Moreno-Bueno et al. [32] and Saito et al. [31] are not comparable since we included only patients with stage I disease. Moreover, next to the use of different primer sets and conditions for the MSP, MorenoBueno et al. [32] and Saito et al. [31] did not give information with regard to the age and menopausal state of the patients, which is relevant with regard to DNA methylation [43].

Besides gene promoter methylation, reduced E-cadherin expression could be the result of $\mathrm{CDH}-1$ mutations or loss of heterozygosity $[22,44,45]$. Yet, in endometrial carcinoma the presence of $\mathrm{CDH}-1$ mutations has not been reported. There are conflicting reports about the influence of E-cadherin on the Wnt signaling pathway by binding with $\beta$-catenin, however in our study no correlation was found with nuclear accumulation of non-degraded free $\beta$ catenin and loss of E-cadherin [22,45-49].

Several studies have demonstrated nuclear localization of $\beta$-catenin and $\beta$ catenin gene mutations in a subset of endometrioid endometrial carcinomas $\llbracket 14,16,21,22,50]$. The incidence of nuclear localization of $\beta$-catenin in our study is similar to data of Nei et al.[14], who demonstrated $30 \%$ nuclear localization of $\beta$-catenin in endometrial cancer samples independent of tumor grade. Mutations in the $\beta$-catenin gene or differences in the immunohistochemical detected location of $\beta$-catenin could not predict outcome, or recurrence in the mentioned studies $[12,15,16,50]$. In accordance with these findings nuclear staining of $\beta$-catenin also did not predict recurrence in the present study. Nuclear localization of $\beta$-catenin corresponds with $90 \%$ of specimens with exon 3 gene mutations, but is also 
reported in $30 \%$ of the cases without mutations of the gene [16]. Mutations outside exon 3 as well as mutations in the APC gene could explain these cases with nuclear localization of $\beta$-catenin [50]. Since no mutational analysis of the $\beta$-catenin gene was performed, we have compared nuclear localization of $\beta$-catenin with the presence of APC gene mutations and promoter methylation, and no correlation was found.

In conclusion, mutations in the APC gene and abnormal expression patterns of APC and $\beta$-catenin protein, both involved in signal transduction of the Wnt pathway, are present in a minority of the endometrial carcinomas, but are not indicative for recurrent disease. The absence of E-cadherin immunostaining was associated with the development of distant metastases; however, it is likely that next to E-cadherin promoter methylation other mechanisms are required for the down-regulation of $\mathrm{E}$-cadherin expression.

\section{Acknowledgements}

The authors would like to thank Mr. Guido Roemen (Department of Pathology, UM) for expert advice with respect to mutation analyses.

\section{References}

1. Creasman, W., Odicino, F., Maisonneuve, P. and Benedet, d. (1998) FiGO aruuall report on the results of treatment in gynaecological cancer. Carcinoma of the corpus utteri. Journal of Epidemiology and Biostatistics, 3, 35-61.

2. Moreno-Bueno, G. Hardisson, D., Sanchez, C. Sarrio, D., Cassia, R., Garcia-Rostan, G., Prat, J., Guo, M., Herman, J.G. Matias-Guiu, X. Esteller, M. and Palacios, J. (2002) Abnormalities of the APC/betamcatenin pathway in endometrial cancer Oncogene, 21, 7981-90.

3. Akiyama, T. (2000) Wht/b-catenin signaling. Cytokine \& Growth Factor Reviews, 11. $273-282$.

4. Barker, N. and Clevers, H. (2000) Catenins, Wht signaling and cancer. BioEssays, 22, $961-965$.

5. Morin, J.P. (1999) B-catenin signaling and cancer. BioEssays, 21, 1021-1030. 
6. Christofori $\mathrm{G}$, and Semb, H. (1999) The role of the cell-adhesion molecule $\mathrm{E}$ Cadherin as a tumoursuppressor gene. Trends in Biochemical Science, 24, 73-76.

7. Guilford P. (1999) E-Cadherin downregulation in cancer: fuel on the fire? Molecular Medicine Today, 5, 172-177.

8. He TC, $S$. A, Rago $C$, Hermeking $H$, Zawel $L$, da Costa $L T$, Morin PJ, vogelstein $B_{n}$ Kinzler KW (1998) Identification of C-MYC as a target of the APC pathway, Science, 281, 1509-1512.

9. Sparks, A.B., Morin, J.P., Vogelstein, B. and Kinzler, K.W. (1998) Mutational analysis of teh APC/beta-catenim/Tcf pathway in colorectal cancer. Cancer Research, 58, 1130-1134.

10. Fearon, E.R. and Vogelstein, B. (1990) A genetic model for colorectal tumourgenesis. Cell, 61, 759-767.

11. Fodde, R. (2002) The APC gene in colorectal cancer. European Journal of Cancer, 38, 867-871.

12. Kitaeva, M.N., Grogan, L. "Wittiams, J.P., Dimond, E., Nakahara, K., Hausner, P., De Nobile, J.W., Soballe, P.W. and Kirsch, I.R. (1997) Mutations in beta-catenin are uncommon in colorectal cancer occurring in occasional replication error-positive tumors. Cancer Research, 57, 4478-4481.

13. Gamallo, C., Palacios, J., Moreno, G., Calvo de Mora, J., Suarez, A. and Armas, A. (1999) Beta-catenin expression pattern in stage I and II ovarian carcinomas. American Journal of Pathology, $155,527-536$.

14. Nei, H., Saito, T. Yamasaki, H., Mizumoto, H., Ito, E. and Kudo, R. (1999) Nuclear localization of beta-Catenin in normal and carcinogenic endometrium. Molecular Carcinogenesis, 25, 207-218.

15. Schlosshauer, P.W., Pirog, E.C., Levine, R.L. and Ellenson, L.H. (2000) Mutational analysis of the CTNNB1 and APC genes in uterine endometrioid carcinoma. Modern Pathology, 13, 1066-1071.

16. Kobayashi, K., Sagae, S., Nishioka, Y., Tokino, T. and Kudo, R.J.J.C.R.J.-. (1999) Mutations of the beta-catenin gene in endometrial carcinomas. Japanese Journal of Cancer Research, 90, 55-59.

17. Jubb, A.M., Bell, S.M. and Quirke, P. (2001) Methylation and colorectal cancer. Journal of Pathology 195, 111-134.

18. Virmani, A.K., Rathi, A., Sathyanarayana, U.G., Padar, A., Huang, C.X., Cunnigham, H.T., Farinas, A.J., Milchgrub, S., Euhus, D.M., Gilcrease, M. Herman, J., Minna, J.D. and Gazdar, A.F. (2001) Aberrant methylation of the adenomatous polyposis coli (APC) gene promoter $1 \mathrm{~A}$ in breast and lung carcinomas. Clinical Cancer Research, 7. 1998-2004.

19. Esteller, M., Corn, P.G., Baylin, S.B. and Herman, J.G. (2001) A gene hypermethylation profile of human cancer. Cancer Research, 61, 3225-3229. 
20. Zysman, M. Saka, A., Millar, A. Knight, d. Chapman, W. and Bapat, B. (2002) Methylation of adenomatous polyposis coll in endometrial cancer occurs more frequently in tumors with microsatellite instability phenotype. Cancer Research, 62, $3663-6$

21. Mirabelli-Primdahl, L., Gryfe, R., Kim, H., Millar, A., Luceri, C., Dale, D., Holowaty, E., Bapat, B., Gallinger, S. and Redston, M. (1999) Beta-catenin mutations are specific for colorectal carcinomas with microsatellite instability but occur in endometrial carcinomas irrespective of mutator pathway. Cancer Research, 59, 3346-3351.

22. Fujimoto, J., Ichigo, S., Hori, M. and Tamaya, T. (1998) Expressions of E-Cadherin and alpha- and beta-catenin mRNAs in uterine endometrial cancers. European Journal of Gynaecologic Oncology, 19, 78-81.

23. Tamura, S., Shiozaki, H., Miyata, M., Kadowaki, T., Inoue, M., Matsui, S., Iwazawa, T., Takayama, T., Takeichi, M. and Monden, M. (1996) Decreased E-cadherin expression is associated with haematogenous recurrence and poor prognosis in patients with squamous cell carcinoma of the oesophagus. British Journal of Surgery, 83, 1608-1614.

24. Sakuragi, N., Nishiya, M., Ikeda, K., Ohkouch, T., Furth, E.E., Hareyama, H., Satoh, C. and Fujimoto, S. (1994) Decreased E-cadherin expression in endometrial carcinoma is associated with tumor dedifferentiation and deep myometrial invasion Gynecologic Oncology, 53, 183-189.

25. Kallakury, B.V., Sheehan, C.E., Winn-Deen, E., Oliver, J., Fisher, H.A., Kaufman, R.P. and Ross, J.S. (2001) Decreased expression of catenins (alpha and beta), p120 CTN, and $\mathrm{E}$-cadherin cell adhesion proteins and $\mathrm{E}$-cadherin gene promoter methylation in prostatic adenocarcinomas. Cancer, 92, 2786-2795.

26. Kadowaki, T., Shiozaki, H., Inoue, M., Tamura, S., Oka, H., Doki, Y., lihara, K., Matsui, S., Iwazawa, T., Nagafuchi, A., Tsukita, S. and Mori, T. (1994) E-cadherin and a-catenin expression in human esophageal cancer. Cancer Research, 54, 291-296.

27. Jiang, W.G. (1996) E-Cadherin and its associated protein catenins, cancer invasion and metastasis. British Journal of Surgery, 83, 437-446.

28. Hu, X.C., Loo, W.T. and Chow, L.W. (2002) E-cadherin promoter methylation can regulate its expression in invasive ductal breast cancer tissue in Chinese women. Life Sciences, 71, 1397-1404.

29. Chang. H.W., Chow, V., Lam, K.Y., Wei, W.I. and Yuen, A. (2002) Loss of E-cadherin expression resulting from promoter hypermethylation in oral tongue carcinoma and its prognostic significance. Cancer, 94, 386-392.

30. Nojima, D., Nakajima, K., Li, L.C., Ribeiro-Filho, L., Ishii, N, and Dahiya, R. (2001) CpG methylation of promoter region inactivates E-cadherin gene in renal cell carcinoma. Molecular Carcinogenesis, 32, 19-27. 
31. Saito, T., Nishimura, M., Yamasaki, H. and Kudo, R. (2003) Hypermethylation in promoter region of E-cadherin gene is associated with tumor dedifferentiation and myometrial invasion in endometrial carcinoma. Cancer, 97, 1002-9.

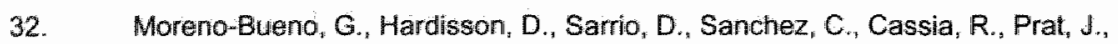
Herman, J.G., Esteller, M.n Matias Guil, X. and Palacios, J. (2003) Abnormalities of $E$ - and P-cadherin and catenin (beta-, gamma-catenin, and p120ctn) expression in endometrial cancer and endometrial atypical hyperplasila. Journal of Pathology. 199, 471-8:

33. Creasman, W.T. (1990) New gynecologic cancer staging. Obstetrics and Gynecology, 75. 287-288.

34. Hermsen, M., Ostma, C., Baak, J.P., Weiss, M., Rapallo, A., Sciutto, A., Roemen, G.M.J.M., Arends, J.-W., Williams, R., Giaretti, W., de Goeij, A. and Meijer, G. (2002) Colorectal adenoma to carcinoma progression follows multiple pathways of chromosomal instability. Gastroenterology, 123, 1109-1119.

35. Herman, J.G., Graff, J.R., Myohanen, S., Nelkin, B.D. and Baylin, S.B. (1996) Methylation-specific PCR. a novel PCR assay for methylation status of $C p G$ islands. Proceedings of the National Academy of Sciences of the United States of America, 93, 9821-9826.

36. Corn, P.G. Heath, E.I., Heitmiller, R., Fogt, F., Forastiere, A.A., Herman, J.G. and $\mathrm{Wu}$, T.T. (2001) Frequent hypermethylation of the $5^{\prime} \mathrm{CpG}$ island of E-cadherin in esophageal adenocarcinoma. Clinical Cancer Research, 7, 2765-9.

37. Esteller, M., Sparks, A., Toyota, M., Sanchez-Cespedes, M., Capella, G., Peinado, M.A., Gonzalez, S., Tarafa, G., Sidransky, D., Meltzer, S.J., Baylin, S.B. and Herman, J.G. (2000) Analysis of adenomatous polyposis coli promoter hypermethylation in human cancer. Cancer Research, 60, 4366-4371.

38. Kammerer, U., Kapp, M., Gassel, A.M., Richter, T., Tank, C., Dietl, J. and Ruck, P. (2001) A new rapid immunohistochemical staining technique using the EnVision antibody complex. Journal of Histochemistry and Cytochemistry, 49, 623-630.

39. Mangham, D.C. and Isaacson, P.G. (1999) A novel immunohistochemical detection system using mirror image complementary antibodies (MICA). Histopathology, 35, $129-133$.

40. Salvesen, H.B., MacDonald, N., Ryan, A., Iversen, O.E., Jacobs, I.J., Akslen, L.A. and Das, S. (2000) Methylation of hiMLH11 in a population-based series of endometrial carcinomas. Clinical Cancer Research, 6, 3607-3613.

41. Tsuchilya, T., Tamura, G., Sato, K., Endoh, Y., Sakata, K., Jin, Z., Motoyama, T., Usuba, O., Kimura, W., Nishizuka, S., Wilson, K.T., James, S.P., Yin, J., Fleisher, A.S., Zou, T., Silverberg, S.G., Kong, D. and Melitzer, S.J. (2000) Distinct methylation patterns of two APC gene promoters in normal and cancerous gastric epithelia. Oncogene, 19, 3642-6. 
42. Hao, X., Frayling, I.M. Willcocks, T.C., Han, W. Tomlinson, P. Plgnatell, M.N. Prettow, T.P. and Talbot, 1.C. (2002) Beta-catenin expressionand allelis loss at APC. in sporadic colorectal carcinogenesis. Virchows Archives, 440,3626

43. Lu, L., Wylie, R.C., Andrews, L.G. and Tolletsbol, T.O. (2003) Aging cancer and nutrition: the DNA methylation connection. Mechanisms of Ageing and Dewelopment, $124,989-98$.

44. Droufakou, S., Deshmane, $V_{n}$, Roylance, $\mathbb{R}_{\text {., Hanby }} \mathrm{A}_{4}$, Tomlinson, I. and Hart, I.R. (2001) Multiple ways of silencing E-cadherin gene expression in lobular carcinoma of the breast. International Journal of Cancer, 92, 404-8.

45. Humar, B., Toro, T., Graziano, F., Muller, H., Dobbie, Z, Kwang-Yang, H. Eng, C., Hampel, H., Gilbert, D., Winship, 1. Parry, S., Ward, R. Findlay, M, Christian, A., Tucker, M., Tucker. K., Merriman, T. and Guifford P. (2002) Novel germline CDH1 mutations in hereditary diffuse gastric cancer families. Human Mutation, 19, 518-25.

46. Orsulic, S., Huber, O., Aberle, H., Amold, S and Kemler, R. (1999) E-cadherin binding prevents beta-catenin nuclear localization and beta-catenin/LEF-1-mediated transactivation. Journal of Cell Science, 112, 1237-45.

47. van de Wetering, M., Barker, N., Harkes, M.C., var der Heyden, M. Dijk, N.4., Hollestelle, A., Klijn, J.G., Clevers, H. and Schutte, M. (2001) Mutant E-cadherin breast cancer cells do not display constitutive Wnt signaling. Cancer Research, 61, 278-84.

48. Yang, S.Z., Kohno, N., Yokoyama, A. Kondo, K., Hamada, H. and Hiwada, K. (2001) Decreased E-cadherin augments beta-catenin muclear localization: studies in breast cancer cell lines. International Journal of Oncology, 18, 541-8.

49. Gottardi, C.J., Wong, E. and Gumbiner, B.M. (2001) E-cardherin suppresses cellular transformation by inhibiting beta-catenin signaling in an adhesion-independent manner. Journal of Cell Biology, 153, 1049-60.

50. Fukuchĭ, T., Sakamoto, M. Tsuda, H., Maruyama, K. Nozawa, S. and Hirohashi, S. (1998) Beta-catenin mutation of the uterine endometrium. Cancer Research, 58 , $3526-3528$. 


\section{Chapter 4}

\section{Defective mismatch repair and the development of recurrent endometrial carcinoma}

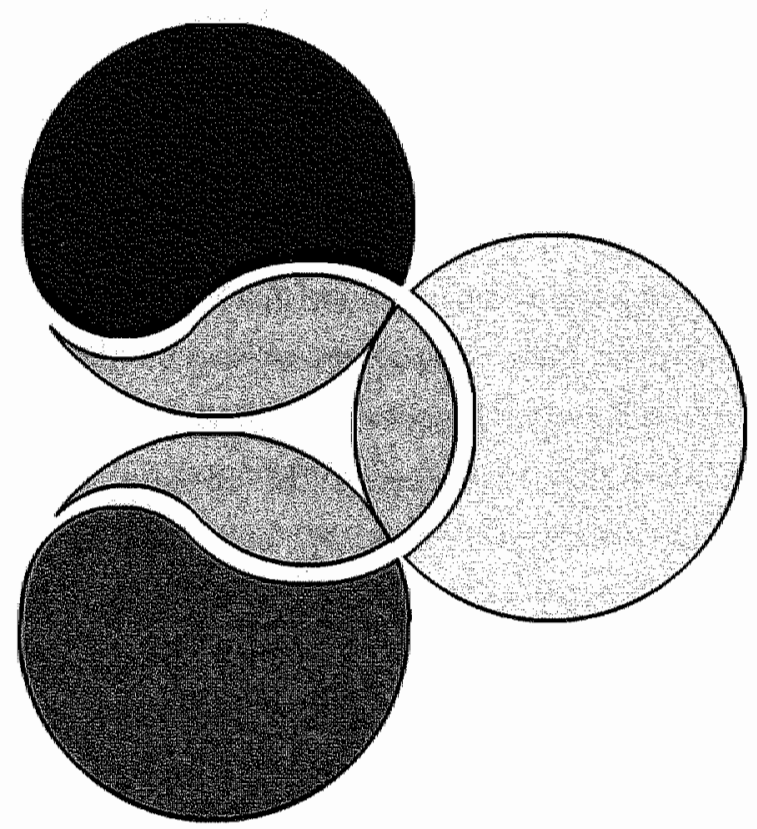

Johanna M.A. Pijnenborg, Geeske C. Dam - de Veen, Jelte de Haan, Manon van Engeland, Patrick G. Groothuis

Gynecol Oncol 2004 Aug;94(2):550-9 


\begin{abstract}
Objective: To investigate whether defective DNA mismatch repair (MMR) defines a subgroup at risk for recurrence in sporadic endometrial carcinoma patients.
\end{abstract}

Methods: Primary tumors from 44 patients with recurrent stage I endometrial carcinoma, were compared after matching, with tumors of 44 patients being free of recurrence for minimal three years. Paraffin-embedded primary tumors ( $n=88$ ) and recurrent tumors ( $n=32$ ), were subjected to immunohistochemical analysis for hMSH2 and hMLH1 expression. Subsequently, a staining index ( $S \mid=0-9$ ) was calculated based on staining intensity and quantity. DNA was extracted from paraffin-embedded tissues and promoter methylation of $h M L H 1$ was determined by nested Methylation Specific PCR (MSP). Microsatellite Instability (MSI) was assessed by BAT26/BAT-25.

Results: Low hMSH2 expression was observed in $2 \%$ of primary tumors of control patients without recurrence, $14 \%$ of primary tumors of patients with recurrence, and $0 \%$ of recurrent tumors. Low hMLH1 expression was observed in $32 \%, 19 \%$ and $22 \%$, respectively. $h M L H 1$ gene promoter methylation was detected in $50 \%, 47 \%$ and $32 \%$, and MSI was found in $16 \%, 14 \%$, and $30 \%$ respectively.

No significant differences were found between primary tumors of patients with and without recurrence with respect to $\mathrm{hMSH} 2 / \mathrm{hMLH} 1$ expression, hMLH1 promoter methylation and MSI. When primary and recurrent tumors were compared, there was and increased correlation of $h M L H 1$ methylation with low hMLH1 expression and MSI in recurrent tumors.

Conclusion: MSI, hMLH1 promoter methylation, and the expression of hMLH1 and hMSH2 are not predictive for the development of recurrent stage I endometrial carcinoma. In the progression of tumor, 'de novo' $h M L H 1$ methylation rarely occurs, instead there is further derailment of the MMR pathway in affected tumors. 


\section{Introduction}

In humans, defective MMR appears to be the most important pathway in the development of the hereditary nonpolyposis colorectal cancers (HNPCC), mainly as a result of germ line mutations in either $h M L H 1$ or $h M S H 2$. Inappropriate MMR leads to an accumulation of mutations, and hence loss of functional genes and progression of tumor growth [1-3]. Microsatellite instability is a hallmark of defective DNA mismatch repair. It is characterized by a change in the number of repetitive DNA sequences in either coding or non-coding regions of the DNA and results from the failure to correct slipped strand pairing during DNA replication [4,5]. Microsatellite instability is present in HNPCC related tumors, and in about $20 \%$ of sporadic colorectal carcinomas $[6,7]$. Endometrial carcinoma is the most common non-colorectal carcinoma occurring in women affected by HNPCC [8]. The frequency of MSI in sporadic endometrial carcinomas is reported to be present in $9 \%-43 \%$ [915].

In sporadic cases of both colorectal and endometrial cancer, the most important cause of defective MMR is not caused by germ line mutations, but by epigenetic inactivation of $h M L H 1$ [16-23]. The presence of $h M L H 1$ gene promoter methylation is frequently observed in premalignant and malignant endometrial tissue, and is strongly correlated with loss of hMLH1 protein expression $[16,17,24,25]$.

In biliary tract, hepatocellular and gastrointestinal cancer low hMLH1 protein expression defines a subgroup with a poor prognosis [14,26-28]. However in endometrial cancer MMR deficiency did not affect patient survival, and was in some studies even associated with a more favorable outcome as observed in colorectal cancer $[11,14,19,29]$.

Although the prognosis of endometrioid carcinomas is relatively good, some patients present with recurrent disease shortly after treatment, and their chances for surviving the disease decrease dramatically [30]. The aim of the present study was to investigate the prognostic capacity of defective MMR. for the development of recurrent disease. Therefore, a case-control study 
was performed in which patients with and whout recurrent stage endometrial carcinoma were included. Primary and recurrent tumors were compared regarding the presence of a defective MMR system. For this purpose we performed immunohistochemical analysis of hMSH2 and hMLH1 expression, evaluated hMLH1 gene promoter methylation status, and performed MSI analysis. 


\section{Material and Methods}

\section{Patients and tissue specimens}

Patients with recurrent endometrioid endometrial carcinoma were selected from the Dutch national pathology database (PALGA). Forty-four patients diagnosed with stage I disease according to the FIGO criteria [31], and who presented with recurrent disease within three years after the completion of therapy were included. All patients underwent a hysterectomy and bilateral salpingo-oophorectomy. Adjuvant radiotherapy was applied when myometrilal invasion was more than $50 \%$ and/or when the tumor was poorly differentiated. Patients presented with local recurrence at the vaginal vault $(n=35)$, pelvic wall $(n=1)$, distant metastases $(n=5)$ or a combination of local recurrence and distant metastases $(n=3)$. An independent pathologist revised primary and recurrent tumors, and the endometrioid type endometrial carcinoma was confirmed in all cases. Recurrent tumor tissue, if available, was used for analysis as well. Forty-four patients being free of recurrence for at least three years after diagnosis and treatment were sellected and served as controls. These control patients were matched for tumor stage, tumor differentiation, age at diagnosis, and therapy. The study was approved by the Medical Ethical Committee of the University Hospital of Maastricht (MEC $02-009.5)$

\section{DNA isolation}

DNA was isolated from five consecutive $20 \mu \mathrm{m}$ sections of paraffin embedded tissue specimens. The tumor area was identified by a pathologist on haematoxylin and eosin stained (HE) sections. Tumor cells were macroscopically dissected manually. Genomic DNA was extracted using a proteinase K (Qiagen, Hilden, Germany) digestion followed by DNA isolation using the Puregene DNA Isolation Kit (Gentra Systems, Minneapolis, Minnesota, USA). 
Methylation analysis of hMLHT

DNA methylation in the CDG island of the hMLH1 promoter was determined by methylation-specific PCR (MSP) as described elsewhere [32]. To enable MSP analysis on DNA retrieved from formalin-fixed, paraffin embedded tissue, nested MSP was performed as described by van Engeland et al. performed [33]. Primers for this nested MSP were especially developed, and were compared with primers, described by Herman ef al.[34] for determination of $h M L H 1$ methylation. Results of both sets of primers were $100 \%$ correlated 33]. All MSP's were performed with a control for unmethylated $h M L H 1$ alleles (DNA from normal lymphocytes), a control for methylated $h M L H 1$ alleles (in vitro methylated DNA of normal lymphocytes treated with Sss! methyltransferase (New England Biolabs)) and a negative control $\left(\mathrm{H}_{2} \mathrm{O}\right)$. A total of $6 \mu$ of each MSP reaction was loaded on a nondenaturing $6 \%$ polyacrylamide gel, stained with ethidium bromide and visualized under UV illumination. The presence of a PCR product in respectively the $U$ and $M$ lane indicates the presence of unmethylated or methylated alleles. Fifteen samples were analyzed in duplicate (reproducibility $93 \%$ ). One case was methylated in one and unmethylated in the second analysis, the result of the third analysis was used.

\section{Microsatellite instability analysis}

The samples were tested for microsatellite instability using BAT26 and BAT25 primer sets with a Cy5- labeled primer as described elsewhere [3537]. The PCR reaction mixture contained $10 \mathrm{mM}$ Tris- $\mathrm{HCl}, \mathrm{pH} 8,3,50 \mathrm{mM}$ $\mathrm{KCl}, 0.9 \mathrm{mM} \mathrm{MgCl}_{2}, 50 \mu \mathrm{M}$ each of four dNTP's, $0.2 \mu \mathrm{M}$ of each primer, and 1 unit of Platinum Taq (Invitrogen). In a total volume of $50 \mu \mathrm{l} 250 \mathrm{ng}$ DNA was added. For BAT26 PCR amplification, the samples underwent denaturation at $94^{\circ} \mathrm{C}$ for forty seconds, annealing at $55^{\circ} \mathrm{C}$ for one minute, and extension at $72^{\circ} \mathrm{C}$ for one minute for 35 cycles followed by a final extension at $72^{\circ} \mathrm{C}$ for ten minutes. For BAT25 PCR the annealing 
temperature was $55^{\circ} \mathrm{C}$ for 40 cycles. The amplified PCR product was loaded on a sequence gel with two base pair markers ( $100 \mathrm{bp}$ and $150 \mathrm{bp}$ ). Fragment length analysis was performed on the ALF Express DNA Analysis System, using Allele locator (version 1.03, Amersham Pharmacia Biotech). Microsatellite instability was defined when size differences were $>3$ basepairs [36-38]. Samples were analyzed twice by BAT26 primer (reproducibility $95 \%$ ) and in case there was no consensus ( $n=5$ ), a PCR with BAT25 was performed. When results after three PCRs were still inconsistent, cases were omitted from analysis.

\section{Immunohistochemistry}

Sections of $5 \mu \mathrm{m}$ were cut and mounted on starfrost adhesive slides (Klinipath, Duiven, The Netherlands). Sections were deparaffinized in xylol and rehydrated prior to blockage of endogenous peroxidase activity with incubation in $0,3 \%$ hydrogen peroxide/methanol solution for 20 minutes. Antigen retrieval was performed by heat treatment for 20 minutes in $10 \mathrm{mM}$ Tris-EDTA buffer ( $\mathrm{pH}$ 9.0). Sections were washed with PBS ( $\mathrm{pH} 7.2)$. Proliferative endometrial tissue served as a positive control for both hMSH2 and $\mathrm{hMLH} 1$ expression. First antibody incubation was performed at room temperature for one hour with a monoclonal antibody directed to hMSH2 (1:50: clone FE 11; Na 27; Oncogene Sciences), and overnight at $4{ }^{\circ} \mathrm{C}$ with a monoclonal antibody directed to hMLH1 (1:100: clone G168-15; 13271A; Pharmingen). Antibodies were diluted in PBS with $0.1 \%$ Tween and $0.1 \%$ Bovine Serum Albumin. Second antibody incubation was performed at room temperature for 30 minutes with Envision (Dako, ChemMate detection kit) Finally, visualization was obtained by the application of 3,3'diaminobenzidine and sections were counterstained by haematoxylin. 
Interpretation of immunostaining

Interpretation of immunostaining was performed blindly independently by two observers ( $P G, J P)$. One observer scored the sections once, and the other observer scored the sections twice, blinded for the tissue ID's. The correlation coefficient was calculated between two observations of one observer, and between two observations of two observers. Correlation coefficients were 0.89 and 0.89 for hMSH2, and 0.96 and 0.93 for hMLH1, respectively. The mean of the observations of two different observers was used for analysis. Percentage and intensity of staining were determined. The percentage of staining was classified by categories $0=0 \%, 1=0-10 \%, 2=$ $10-50 \%, 3=>50 \%$ of the positive tumor cells. The intensity was defined as 0 = absent, 1 = weak, 2 = moderate or $3=$ strong. $A$ staining index $(\mathrm{SI})$ was calculated by the product of the percentage and the intensity [19]. Low expression of hMSH2 and hMLH1 was defined as $\mathrm{SI} \leq 1.0$.

\section{Data analysis}

The SPSS software program (11.5) was used for statistical analysis. To compare both patient groups with and without recurrence median values were calculated for the age at diagnosis and time to follow-up. A T-test for paired analysis was performed to compare the continuous variables (age, follow-up), and a McNemar's test for paired analysis was performed for dichotomous variables (tumor differentiation, tumor stage, applied radiotherapy).

For few samples immunohistochemistry, and/or MSP and/or MSI analysis could not be done, due to either a lack or poor quality of the material. This is indicated as not determined (ND) and the samples are omitted from analysis. Mean values of the $\mathrm{hMSH} 2$ and $\mathrm{hMLH} 1$ staining indexes were calculated for tumors of control patients without recurrence, for tumors of patients with recurrence, and for recurrent tumors. An independent T-test was performed to compare differences in staining indexes. Odds Ratios were calculated for 
the presence of low hMSH2 / low hMLH1 expression, the presence of hMLH1 gene promoter methylation and the presence of MSI and the risk for recurrence. Owing to the fact that radiotherapy can prevent the development of recurrent disease and a few more patients in the control group received postoperative radiotherapy, correction was performed by calculation of a Mantel-Haenszel Odds Ratio. An independent T-test was performed for the comparison of the mean $\mathrm{hMLH} 1 \mathrm{SI}$ in $h M L H 1$ methylated and unmethylated samples, and in MSI positive and negative samples. 95\% confidence intervals $(95 \% \mathrm{Cl})$ were calculated and all statistical tests were two-sided. A p-value of 0.05 was considered significant. 


\section{Results}

\section{Patients}

All patients $(n=88)$ were postmenopausal at the time of diagnosis. No significant differences were found in clinico-pathological characteristics between patients with and without recurrence, except for the follow-up time, this was significantly longer in patients without recurrence (Table 1).

Table 1 Patient and tumor characteristics

\begin{tabular}{lccc}
\hline & $\begin{array}{c}\text { Patients with } \\
\text { recurrence }(\mathrm{n}=44)\end{array}$ & $\begin{array}{c}\text { Patients without } \\
\text { recurrence }(\mathrm{n}=44)\end{array}$ & P-value \\
\hline $\begin{array}{l}\text { Age at diagnosis } \\
\text { (median and range) }\end{array}$ & $70.5(51-83)$ years & $69.5(54-93)$ years & 0.422 \\
Figo stage & & & 1.000 \\
la & 2 & 3 & \\
Ib & 24 & 22 & \\
Ic & 18 & 19 & 0.388 \\
Tumor grade & 13 & 16 & \\
Gradle I & 21 & 21 & \\
Grade II & 10 & 7 & \\
Grade III & 14 & 19 & 0.125 \\
Post-operative radiotherapy & $12.5(2-32)$ months & - & \\
Time to recurrence & & & \\
(median and range) & $32(9-141)$ months & $45.5(34-120)$ months & 0.137 \\
Follow-up (median and range) & & & \\
\hline
\end{tabular}

\section{hMSH2 and hMLH1 expression}

Representative examples of hMSH2/hMLH1 expression with different staining index are shown in Fig.1 (page 207), and the results of our semi quantitative immunohistochemical analysis are summarized in Table 2 . The mean ( 1 SE) staining index for hMSH2 was $5.3 \pm 0.4$ in primary tumors of control patients without recurrence, $5.6 \pm 0.5$ in primary tumors of patients with recurrence, and $7.9 \pm 0.4$ in recurrent tumors (Fig. 2). Low hMSH2 expression (SI $\leq 1.0)$ was observed in $2 \%(1 / 44), 14 \%(6 / 44)$, and $4 \%(1 / 25)$ respectively. 


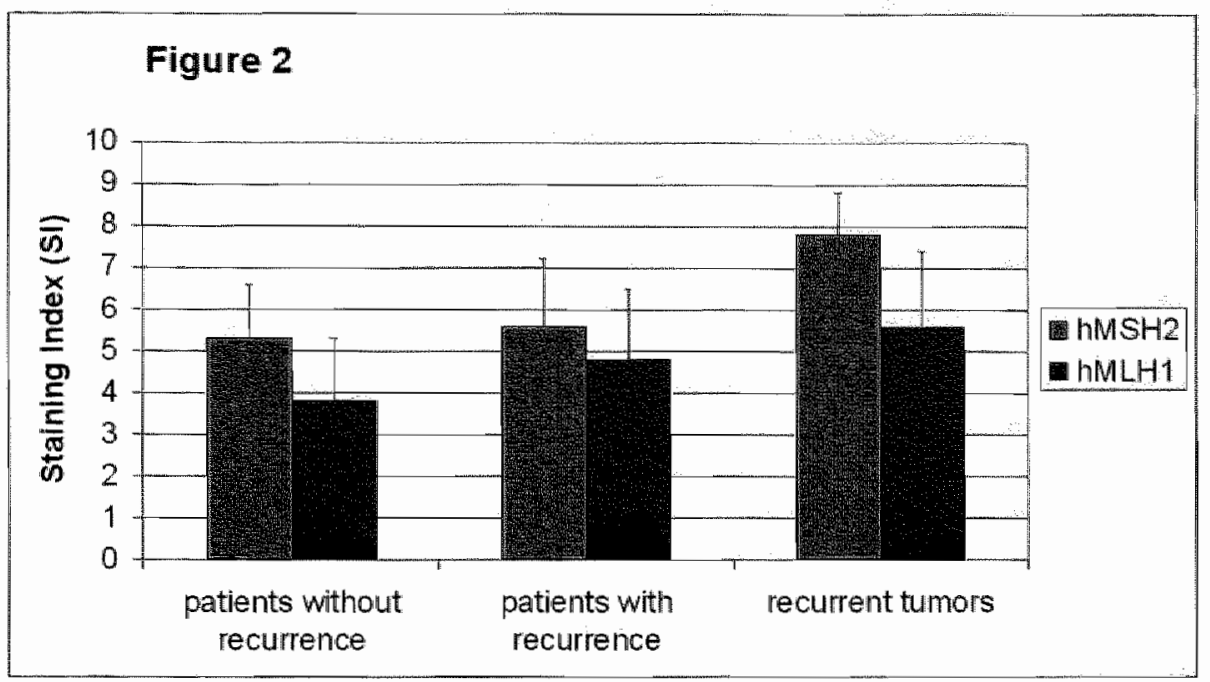

Mean Staining Indices ( \pm standard error) of both hMSH2 and hMLH1 expression in primary tumors of patients without recurrences, with recurrences and in recurrent tumars.

For hMLH1 the mean $( \pm S E)$ staining index was $3.8 \pm 0.5$ in primary tumors of control patients without recurrence, $4.8 \pm 0.5$ in primary tumors of patients with recurrence, and $5.6 \pm 0.6$ in recurrent tumors (Figure 2). Low hMLH1 expression ( $\mathrm{S} I \leq 1.0$ ) was observed in $32 \%(14 / 44), 19 \%$ (8/43), and $24 \%$ (9/37) respectively. Neither the differences in staining indexes of hMSH2/ hMLH1, nor the differences in low hMSH2/hMLH1 expression were significantly different in both patient groups (T-test, $p=0.64$ and $p=0.17$, Mantel-Haenszel OR 6.2; 95\% Cl: 0.7-51, and Mantel-Haenszel OR 0.47; $95 \% \mathrm{Cl}: 0.2-1.3$ respectively). When expression of $\mathrm{hMSH} 2 / \mathrm{hMLH} 1$ in primary tumors were compared with respect to vaginal and distant metastasis SI were $5.6( \pm 0.6)$ versus $5.3( \pm 0.6)$ in the tumors of patients with vaginal recurrence, and $5.6( \pm 1.2)$ versus $2.8( \pm 1.3)$ in those with distant metastasis. There was a difference in $\mathrm{hMLH} 1$ expression, but it did not reach statistical significance $(p=0.12)$.

Overall, expression of $\mathrm{hMLH} 1$ and $\mathrm{hMSH} 2$ was not correlated with the age at diagnosis, tumor grade, or tumor stage. 
hMLH1 promoter methylation

Representative examples of MSP reactions are shown in Figure 3, and the results are summarized in Table 2. $h M L H 1$ promoter methylation was observed $50 \%$ (21/42) of the primary tumors of patients without recurrence, and in $47 \%$ (20/43) of the primary tumors of patients with recurrence (Mantel-Haenszel OR 0.83;95\% Cl: $0.4-2.0$ ). In 32\% (7/22) of the recurrent tumors $h M L H 1$ promoter methylation was observed. The presence of $h M L H 1$ promoter methylation was correlated with a significantly lower SI of hMLH1 compared to tumors without methylation in both primary and recurrent tumors: 3.1 vs. 5.5 , and 1.8 vs. 7.9 respectively ( $T$-test, $p<0.05$ ). When primary and recurrent tumor of the same patients were compared regarding the hMLH1 promoter methylation status, no difference was observed in $64 \%$ (14/22). However, in $36 \%(8 / 20)$ the $h M L H 1$ promoter methylation status in primary and recurrent tumor tissue differed. Four cases were unmethylated in the primary tumor and methylated in the recurrent tumor, and four cases were methylated in the primary tumor, whereas the recurrent tumors were unmethylated. When $h M L H 1$ promoter methylation in primary tumors was compared with respect to vaginal and distant metastasis, $47 \%(16 / 34)$ was methylated in tumors of patients with vaginal recurrence compared to $44 \%$ (4/9) in those tumors with distant metastasis. The presence of $h M L H 1$ promoter methylation was not related to the age at diagnosis, tumor grade, or tumor stage.

\section{Microsatellite instability}

Results of the microsatellite instability analysis are demonstrated in Table 2. Microsatellite instability was observed in $16 \%(7 / 44)$ of the primary tumors of patients without recurrence compared to $14 \%(6 / 43)$ of the primary tumors of patients with recurrence (Mantel- Haenszel OR $0.9495 \% \mathrm{Cl}$ : 0.3-3.2). In the recurrent tumor tissue MSI was present in 29\% (6/21). When the presence of MSI in primary tumors was compared with respect to vaginal and distant 
metastasis, $14 \%(5 / 35)$ was MSI positive in tumors of patients with vaginal recurrence compared to $13 \%(1 / 8)$ in those tumors with distant metastasis. When primary and recurrent tumors were compared with respect to the presence of MSI, all primary tumors that were MSI positive were also MSI positive in the recurrent tumor tissue. In addition three recurrences demonstrated the presence of MSI. The hMLH1 staining index was significantly different for MSI positive and negative tumors both in primary and recurrent tumors: 1.5 vs. 4.7 , and 1.6 vs. 7.0 , respectively (T-Test, $\mathrm{p}<0.05$ ). For the staining index of hMSH2, this was not significantly different 4.6 vs 5.5 , and, 7.4 vs. 7.8 , respectively. In MSI positive tumors, hMLH1 promoter methylation was observed in $92 \%$ $(12 / 13)$ of the primary tumors and $100 \%(5 / 5)$ of the recurrent tumors. Tumors that demonstrated $h M L H 1$ promoter methylation were MSI positive in $29 \%(12 / 41)$ of primary tumors, and in $83 \%(5 / 6)$ of recurrent tumors. Tumors without $h M L H 1$ promoter methylation, showed MSI in respectively $2 \%(1 / 43)$, and $0 \%(0 / 11) . M S I$ was not related to the age at diagnosis, tumor grade, or tumor stage.

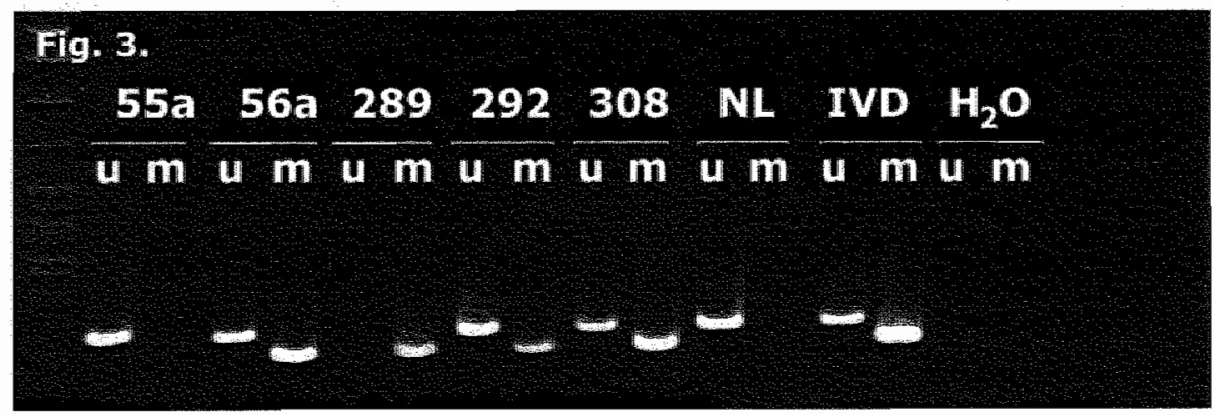

Representative examples of hMLH1 MSP reactions of five samples of endometrial carchoma patients. A visible PCR product in the lanes marked $U$ indicates the presence of unmethylated alleles. A PCR product in the M marked lanes indicates the presence of methylated alleles. Normal lymphocytes (NL) and in vitro methylated DNA (IVD) were used as negative and positive controls, respectively. The $\mathrm{H}_{2} \mathrm{O}$ control was included in the flanking PCR and in the MSP. 


\section{Discussion}

Aberrations in the DNA mismatch repair genes $h M L H 1$ and $h M S H 2$ have been implicated in the development of different tumor types [39]. This is the first case-control study on endometrial carcinoma in which the recurrent tumors were analyzed as well. In the current study of patients with stage I endometrioid type endometrial carcinoma, no significant differences were found in hMSH2 and hMLH1 protein expression, hMLH1 promoter methylation and MSI in primary tumors of patients with and without recurrence. These results indicate that defective MMR cannot discriminate patients with respect to prognostic outcome. This is supported by others who did not observe a difference in 5-year survival rate or in the recurrence free 5-year survival rate between patients with microsatellite stable or unstable tumors [19,40-42].

The frequency of low hMSH2 and low hMLH1 expression ( $\mathrm{SI} \leq 1.0)$ in endometrial carcinoma reported in this study is in accordance with the frequencies reported in literature $(1.1 \%-25.9 \%)[14,19,22,40]$. Comparing resuits from the different studies is complicated by the fact that different cutoff values for low expression are used. However, reanalyzing the data in the present study after increasing the cut-off value for low $S \mid$ from 0 till 3 , did not alter the significance when staining indexes of tumors of patients with and without recurrence were compared.

$h M L H 1$ promoter methylation was associated with a lower staining index of hMLH1 in primary tumors, but even more pronounced in recurrent tumors.

The frequency of $h M L H 1$ promoter methylation is in line with previous reports $[4,16,19,20,23,42,43]$, despite the use of a nested MSP approach.

Low hMLH1 expression in cases where the hMLH1 promoter was not methylated, may be due to mutations in the hMLH1 gene. However, somatic mutations have rarely been reported in $h M L H 1$ in sporadic endometrial carcinomas $[9,10,44,45]$. Recently it was shown that in the absence of promoter methylation, various domains in the promoter region have to act in concert in order to establish full expression of $h M L H 1$ [46]. Since various 
protein-binding sites have been identified in these domains, it is possible that in hMLH1 negative tumors one or several of these DNA binding-proteins are absent or non-functional.

In accordance with other studies in endometrial carcinoma, hMLH1 promoter methylation, microsatellite instability " and low hMLH1 expression are well correlated, and not related to tumor stage or tumor grade $[12,16,19]$. Only one patient with a MSI positive tumor did not demonstrate $h M L H 1$ methylation. MSI in this case could be the result of a mutation in hMSH6 [47]. In an unselected series of endometrial cancers, Goodfellow et al. found MSI positive, $h M L H 1$ unmethylated tumors in 35 of the 137 cases analyzed. From these tumors, $23 \%$ harbored mutations in $h M S H 6$ [47].

The presence of $h M L H 1$ promoter methylation is reported to be an early event $[11,16,48]$. Our finding strengthens this, since almost all MS| positive tumors demonstrated $h M L H 1$ promoter methylation, but not all tumors with $h M L H 1$ promoter methylation were MSI positive. Moreover, $h M L H 1$ promoter methylation has been found in atypical hyperplastic and normal endometrium, present adjacent to endometrial cancer, suggesting that hMLH1 methylation precedes MS\| [43,49].

Recently, Kanaya et al. [43] demonstrated that there are differences in the degree of $h M L H 1$ methylation in the promoter region. Decreased hMLH1 expression is mainly related to a high degree of methylation of CpG islands. The MSP could not discriminate between high or intermediate levels of hMLH1 methylation. Results of our study confirm these recently published data, since the differences in hMLH1 expression between tumors with and without $h M L H 1$ methylation was, although significant, relatively small. The findings in this study support the notion that in the progression of tumor, the degree of methylation increases, rather then 'de novo' promoter methylation. Even though there were no significant differences in $\mathrm{SI}, h M L H 1$ promoter methylation, or MSI, the correlation between decreased hMLH1 expression and the presence of MSI was dramatically higher in the recurrences compared to the primary tumors $(67 \%$ vs. $29 \%)$. The differences in degree of 
$h M L H 1$ methylation may also account for the fact that in four cases the primary tumors appeared to be methylated whereas the recurrent tumors were unmethylated. Alternatively, the recurrent tumor has developed from a small unmethylated subpopulation of cells in the primary tumor that was in the current study the presence of MSI was determined by using BAT26 alone, and only in doubtful cases the BAT25 marker was used. The BAT26 was shown to be highly sensitive. Loukola et al.[37] demonstrated in 73 patients with colorectal cancer, that $97 \%$ of MSI-H cases could be identified with the BAT26 marker alone. Extension of BAT 26 analysis to 542 other tumors, including endometrial carcinoma, demonstrated an efficiency of $99.5 \%$ for detection of MSI [38]. In this study BAT25 analysis was also used in cases of ambiguity. The advantage of BAT26 is that there is a negligible size variation either between both alleles of one individual or between individuals [36]. Therefore, normal DNA, which was not available in our study, is not necessary for comparison. Germ-line mutations interfering with BAT26 analysis have been described, but do occur in only $0.8 \%$ of Caucasians, like the patients in our study [50].

The frequency of MSI reported here is in accordance with other studies and the fact that MSI and decreased hMLH expression and $h M L H 1$ methylation are correlated, suggests that these data are reliable $[4,9,12,15,23,41,48,51]$. Some recurrent tumors were MSI positive whereas their corresponding primary tumor were microsatellite stable. This phenomenon was also described for lymph node metastases of stage Illc endometrial carcinoma, in which additional MSI positive lymph nodes were present compared to the primary tumors [52]. It supports the contention that it is the natural progression of tumor since MSI positivity is a matter of time when there is decreased hMLH1 expression and MMR function.

Although there tended to be less hMSH2/hMLH1 expression in the tumors of the control patients, this was not significant. However, hMSH2/hMLH1 expression was significantly increased in the recurrent tumors. The relevance of the accumulation of MMR proteins hMLH1 and $\mathrm{hMSH} 2$ in most 
of the recurrences remains unclear. A high activity of the MMR system could indicate a high frequency of mutations in the recurrent tumors, or in the case of hMSH2, high proliferative activity. In addition, overexpression of hMSH2 or $\mathrm{hMLH} 1$ is known to induce apoptosis [3]. In endometrial carcinoma an increase in the rate of proliferation and apoptosis appears to be associated with a lower differentiation grade, myometrial invasion and a poor prognosis [53-57].

Salvesen et al. [55] explained a better outcome in MMR defective endometrial tumors by the fact that $h M L H 1$ methylation and MSI in endometrial carcinoma represents an activated pathway that is different from the endometrial carcinomas that show disturbances in the p53 pathway, and that are characterized by aneuploidy and aggressive behavior. This is illustrated by the fact that endometrial tumors with low hMLH1 expression, did not have overexpression of $\mathrm{p} 53$, which is usually an indicator of dysfunctional p53 and a strong prognostic marker in endometrial carcinoma [55]. In this study, tumors with decreased hMLH1 expression (SI $\leq 1.0)_{\text {, also }}$ had a significantly lower expression of p53 compared to the tumors with a hMLH1 staining index of $>1.0$, but on the contrary, p53 expression was not different for tumors with or without MSI (results not shown). The possibility of the existence of different activated pathways could therefore not be confirmed by our study.

Although the absolute numbers are low, this is the first study in which data are presented of a series of 44 patients with recurrent stage I endometrial carcinoma. Due to the low incidence of recurrence in stage I disease, large series are difficult to collect [58]. Yet, analysis of primary and recurrent tumors is of additional value in the understanding of the role of MMR in the progression of the endometrial tumor. Results of our study underline that defective MMR plays a role in early carcinogenesis, and although further derailment of the MMR pathway during progression of cancer takes place in those tumors with $h M L H 1$ promoter methylation, the attribution to the development of recurrent disease is limited. The expression of 
hMSH2/hMLH1 could therefore not be used to select patients with respect to tumor aggressiveness and future recurrence.

In conclusion, the present case-control study shows that MSI, hMLH1 promoter methylation, and the expression of hMLH1 and hMSH2 are not predictive for the development of recurrence. Our results support the contention that MSU is a consequence of increased $h M L H 1$ promoter methylation, which results in dysfunctional MMR. Moreover, it is demonstrated that in the progression of tumor 'de novo' $h M L H 1$ methylation rarely occurs. An increased degree of methylation could explain the further derailment of the MMR pathway in affected recurrent tumors.

\section{Acknowledgement}

We would like to thank the PALGA, Dutch national pathology database, for the selection of patients with recurrent endometrial carcinoma, and the University Hospital of Maastricht for their financial support for this study. Finally, we would like to thank H.Te Riele, from the division of Molecular Biology of the Dutch National Cancer Institute for reading the manuscript critically and the helpful suggestions.

\section{References}

1. Laeb, K.R. and Loeb, L.A. (2000) Significance of multiple mutations in cancer, Carcinogenesis, 21, 379-385.

2. LI, G.M. (1999) The role of mismatch repair in DNA damage-induced apoptosis. Oncologic Research, 11, 393-400.

3. Zhang, H., Richards, B., Wilson, T., Lloyd, M., Cranston, A., Thornburn, A. Fishel, R. and Meuth, M. (1999) Apoptosis induced by overexpression of hMSH2 or hMLH1. Cancer Research, 59, 3021-3027.

4. Whelan, A.J., Babb, S., D.G., M., Rader, J", Herzog, T.J., Todd, C., Ivanovich, J.L. and Goodfellow. P.J. (2002) MSI in endometrial carcinoma: absence of hMLH1 promoter methylation is associated with increased familial risk for cancers. International doumal of Cancer, 99, 697-704. 
5. Parsons, R., Li, G.M., Longley, M.J., Fang, W.H., Papadopoulos, N., Jen, J., de la Chapelle, A., Kinzler, K.W., Vogelstein, B. and Modrich, P. (1993) Hypermutability and mismatch repair deficiency in RER+ tumor cells. Celf.75, 1227-1236.

6. Marra, G. and Boland, C.R. (1995) Hereditary nonpolyposis colorectal cancer: the syndrome, the genes and historical perspectives. Journal of the National Cancer Institute, 87, 1114-1125.

7. Thibodeau, S.N., Bren, G. and Schaid, D. (1993) Microsatellite instability in cancer of the proximal collon. Science, $260,816-819$;

8. Lynch, H.T., Smyrk, T.C., Watson, P., Lanspa ${ }^{\text {S.J. }}$, Lynch, J.F., Lynch, P.M., Cavalieri, R.J. and Boland C.R. (1993) Genetics, natural history, tumor spectrum, and pathology of hereditary nompolyposis colorectal cancer: an updated review. Gastroenterology, 104, 1535-1549.

9. Katabuchi, H., van Rees, B., Lambers, A.R., Ronnett, B.M., Blazes, M.S., Leach, F.S.. Cho, K.R. and Hedrick, L. (1995) Mutations in DNA mismatch repair genes are not responsible for microsatellite instability in most sporadic endometrial carcinomas. Cancer Research $55,5556-5560$.

10. Gurin, C.C., Federici, M.G., Kang, L. and Boyd, J. (1999) Causes and consequences of microsatellite instability in endometrial carcinoma. Cancer Research, 59, 462-466.

11. Caduff, R.F." Johnston C.M., Svoboda-Newman, S.M., Poy, E.L., Merajver, S.D. and Frank . T.S. (1996) Clinical and pathological significance of microsatellite instability in sporadic endometrial carcinoma. American Joumal of Pathology, 148, 1671-1678.

12. Catasus, L., Machin, P.., Matias-Gulu, X. and Prat, J. (1998) Microsatellite instability in endometrial carcinomas: clinicopathologic correaltions in a series of 42 cases. Human Pathology, 29, 1160-1164.

13. Parc, Y.R., Halling, K.C., Burgart, L.J., McDonnell, S.K., Schaid, D.J., Thibodeau, S.N. and Halling, A.C. (2000) Microsatellite instability and hMLH1/hMSH2 expression in young endometrial carcinoma patients:associations with family history and histopathology. International Journal of Cancer, 86, 60-66.

14. Peiro, G.. Diebold, J., Mayr, D., Baretton, G.B., Kimmig, R., Schmidt, M. and Lohrs, U. (2001) Prognostic relevance of hMLH1, hMSH2, and BAX protein expression in endometrial carcinoma. Modem Pathology, 14, 777-783.

15. Risinger, J.I., Berchuck, A., Kahler, M.F., Watson, P., Lynch, H.T. and Boyd, J. (1993) Genetic instability of microsatellites in endometrial carcinomas. Cancer Research, 53 , 5100-5103.

16. Esteller, M., Catasus, L., Matias-Guiu, X., Mutter, G.L., Prat, J., Bayllin, S.B. and Herman, J.G. (1999) hMLH1 Promoter hypermethylation is an early event in human endometrial tumorigenesis. American Joumal of Pathology, 155, 1767-1772.

17. Leung, S.Y., Yuen, S.T., Chung, L.P., Chu, K.M., Chan, A.S.Y. and Ho, J.C.I. (1999) hMLH1 Promoter methylation and lack of hMLH1 expression in sporadic gastric 
carcinomas with high-frequency microsatellite instability. Cancer Research, 59, 159 164.

18. Bevilacqua, R.A.U. and Simpson, A.J.G. (2000) Methylation of the hMLH1 promoter but no hMLH1 mutations in sporadic gastric carcinomas with high-level microsatellite instability. Intemational Journal of Cancer, 87, 200-203.

19. Salvesen, H.B., MacDonald, N. Ryan, A., Iversen, O.E., Jacobs, I.J., Akslen, LA. and Das, $S$. (2000) Methyllation of hMLH1 in a population-based series of endometrial carcinomas. Clinical Cancer Research, 6, 3607-3613.

20. Ellenson, L.H. (1999) hMLH1 promoter hypermethylation in microsatellite instabilitypositive endometrial carcinoma. American Joumal of Pathology, 155, 1399-1402.

21. Jacob, S. and Praz, F. (2002) DNA mismatch repair defects: role in colorectal carcinogenesis. Biochimie, 84, $27-47$.

22. Chiaravalli, A.M., Furlan, D., Facco, C., Tibiletti, M.G., Dionigi, A., Casati, B., Albarello, L., Riva, C. and Capella, C. (2001) Immunohistochemical pattern of hMSH2/hMLH1 in familial and sporadic colorectal, gastric, endometrial and ovarian carcinomas with instability in microsatellite sequences. Virchows Archives, 438, 3948.

23. Simpkins, S.B., Bocker, T. Swisher, E.M., Mutch, D.G., Gersell, D.J., Kovatich, A.J., Palazzo, J.P., Fishel, R. and Goodfellow, P.J. (1999) MLH1 promoter methylation and gene silencing is the primary cause of microsatellite instability in sporadic endometrial cancers. Human Molecular Genetics, 8, 661-6.

24. Kang, G.H., Shim, Y.H. and Ro, J.Y. (1999) Correlation of methylation of the hMLH1 promoter with lack of expression of hMLH1 in sporadic gastric carcinomas with replication error. Laboratory investigation, 79, 903-909.

25. Kane, M.F., Loda, M. Gaida, G.M., Lipman, J., Mishra, R., Goldman, H., Jessup, J.M. and Kolodner, R. (1997) Methylation of the hMLH1 promoter correlates with lack of the expression of hMLH1 in sporadic colon tumors and mismatch repair-defective human tumor cell lines. Cancer Research, 57, 808-811.

26. Edmonston, T.B., Cuesta, K.H., Burkholder, S., Barusevicius, A., Rose, D., Kovatich, A.J., Boman, B., Fry, R., Fishel, R. and Palazzo, J.P. (2000) Colorectal carcinomas with high microsatelite instability: defining a distinct immunologic and molecular entity with respect to prognostic markers. Human Pathology, 31, 1506-14.

27. Kohya, N., Miyazaki, K., Matsukura, S., Yakushiji, H., Kitajima, Y., Kitahara, K., Fukuhara, M. Nakabeppu, $Y_{\text {n }}$ and Sekiguchi, M. (2002) Deficient expression of $O(6)$ methylguanine-DNA methyltransferase combined with mismatch-repair proteins $\mathrm{hMLH} 1$ and $\mathrm{hMSH} 2$ is related to poor prognosis in human biliary tract carcinoma. Annals of Surgical Oncology. 9, 374-9.

28. Matsukura, S., Miyazaki, K., Yakushifi, H., Ogawa, A., Chen, Y. and Sekiguchi, M. (2003) Combined loss of expression of O6-methylguanine-DNA methyltransferase 
and hMLH1 accelerates progression of hepatocellular carcinoma. Joumal of Surgical Oncology, B2, 194-200.

29. Maxwell, G.L., Risinger, J.I., Alvarez, A.A., Barrett, J.C. and Berchuck, A. (2001) Favorable survival associated with microsatellite instability in endometrioid endometrial cancer. Obstetrics and Gynecology, 97, 417-22.

30. Creasman $W^{\circ}$ W., Odicino, F., Maisonneuve, $P$. and Benedet, J. (1998) FIGO aninual report on the results of treatment in gynaecological cancer. Carcinoma of the corpus uteri. Joumal of Epidemiology and Biostatistics, 3, 35-61.

31. Creasman, W.T. (1990) New gynecologic cancer staging. Obstetrics and Gynecology. 75, 287-288.

32. Herman, J.G., Graff, J.R. Myohanen, S., Nelkin, B.D. and Bayiin, S.B. (1996) Methylation-specific PCR. a novel PCR assay for methylation status of CPG islands. Proceedings of the Netional Academy of Sciences of the United States of America, 93, 9821-9826.

33. van Engeland, M., Weijenberg, M.P., Roemen, G.M., Brink, M., de Bruine, A.P., Goldbohm, R.A., van Den Brandt, P.A., Baylin, S.B., De Goeil, A.F. and Herman, J.G. (2003) Effects of dietary folate and alcohol intake on promoter methylation in sporadic. colorectal cancer: the Netherlands cohort study on diet and cancer. Cancer Research. 63, 3133-7.

34. Herman, J.G., Umar, A., Polyak, K. Graff, J.R., Ahuja, N., Issa, J.P. Markowitz, S., Willson, J.K., Hamilton, S.R., Kinzler, K.W. Kane, M.F., Kolodner, R.D., Vogelstein, B., Kunkel, T.A. and Baylin, S.B. (1998) Incidence and functional consequences of hMLH1 promoter hypermethylation in colorectal carcinoma. Procedings of the National Academy of Science, 95,6870-5.

35. Cravo, M., Lage, P., Albuquerque, C., Chaves, P., Claro, I. "Gomes, T., Gaspar, C., Fidalgo, P., Soares, J and Nobre-Leitao, C. (1999) BAT-26 identifies sporadic colorectal cancers with mutator phenotype: a correlative study with clinicopathological features and mutations in mismatch repair genes. Joumal of Pathology. $188,252-257$.

36. Hoang, J.-M., Cottu, P.H., Thuille, B., Salmon, R.J., Thomas, G. and Hamelin, R. (1997) BAT-26, an indicator of the replication error phenotype in colorectal cancers and cell lines. Cancer Research, 57, 300-303.

37. Loukolla, A., Eklin, K., Laiho, P.., Salovaara, R., Kristo, P., Jarvinen, H., Mecklin, J.-P., Launonen, $V$. and Aaltonen, L.A. (2001) Microsateilite marker analysis in screening for hereditary nonpolyposis colorectal cancer (HNPCC). Cancer Research, 61, 45454549.

38. Zhou, X.-P., Hoang, ل.-M., Li, Y.-J., Seruca, R., Carneiro, F., Sobrinho-Simoes, M., Lothe, R.A.y Gleeson, C.M., Russell, S.E.H., Muzeau, F., Flejou, J.-F., Hoang-Xuan, K., Lidereau, R., Thomas, G. and Hamelin, R. (1998) Determination of the replication 
arror phenotype in human tumors without the requirement for matching normal DNA by analysis of mononucleotide repeat microsatellites. Genes, Chromosomes \& Cancer, 21, 101-107.

39. Kinzler, KK.W. and Vogelstein, B. (1996) Lessons from hereditary colorectal cancer. Cell, $87,159-170$.

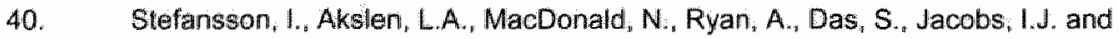
Salvesen; H.B. (2002) Loss of hMSH2 and hMSH6 expression is frequent in sporadic endometrial carcinomas with microsatellite instability: a population-based study. Clinical Cancer Research, $8,138-143$.

41. Basill, J.B., Goodfellow, P.J., Rader, J.S., Mutch, D.G. and Herzog, T.J. (2000) Clinical significance of microsatellite instability in endometrial carcinoma. Cancer, 89, 175864.

42. Hirasawa, A., Aoki, D., Inoue, J., Imoto, I., Susumu, N., Sugano, K., Nozawa, S. and Inazawa, J. (2003) Unfavorable prognostic factors associated with high frequency of microsatellite instability and comparative genomic hybridization analysis in endometrial cancer. Cinical Cancer Research, 9, 5675-82.

43. Kanaya, T., Kyo, S., Maida, Y. Yatabe, N., Tanaka, M., Nakamura, M. and Inoue, M. (2003) Frequent hypermethylation of MLH1 promoter in normal endometrium of patients with endometrial cancers. Oncogene, 22, 2352-2360.

44. Baldinu, P., Cossu, A, Manca, A., Satta, M.P., Pisano, M., Casula, M., Dessole, S., Pintus, A., Tanda, F. and Palmieri, G. (2002) Microsatelite instability and mutation analysis of candidate genes in unselected sardinian patients with endometrial carcinoma. Cancer, 94, 3157-68.

45. Thibodeau, S.N., French, A.J., Roche, P.C., Gunningham, J.M., Tester, D.J., Lindor, N.M., Moslein "G., Baker, S.M., Liskay, R.M., Burgart, L.J., Honchel, R. and Halling, $\mathrm{KCC}$. (1996) Altered expression of $\mathrm{hMSH} 2$ and $\mathrm{hMLH} 1$ in tumors with microsatellite instability and genetic alterations in mismatch repair genes. Cancer Research, 56 , $4836-4840$.

46. Arita, M., Zhong, X, Min, Z." Hemmi, H. and Shimatake, H. (2003) Multiple sites required for expression in $5^{\prime}$-fllanking region of the hMLH1 gene. Gene, 306, 57-65.

47. Goodfellow, P.J., Buttin, B.M., Herzog, T.J., Rader, J.S., Giblb, R.K., Swisher, E., Look, K., Walls, K.C., Fan, M.-Y. and Mutch, D.G. (2003) Prevalence of defective DNA mismatch repair and MSHG mutation in an unselected series of endometrial cancers. Procedings of the National Academy of Science, 100, 5908-5913.

48. Faquin, W.C. Fitzgerald, J.T., Lin, M.-C., Boyinton, K.A., Muto, M.G. and Mutter, G.L. (2000) Sporadic microsatellite instability is specific to neoplastic and preneoplastic endometrial tissues. American Joumal of Clinical Pathology, 113, 576-582.

49. Horowilz, N., Pinto, K., Mutch, D.G., Herzog, T.J., Rader, J.S., Gibb, R., BockerEdmonston, T. and Goodfellow, P.J. (2002) Microsatellite instability, MLH\| promoter 
methylation, and loss of mismatch repair in endometrial cancer and concomitant atypical hyperplasia. Gynecologic Oncology, 86, 62-68.

50. Samowitz, W.S., Slattery, M.L., Potter, J.D. and Leppert, M.F. (1999) BAT-26 and BAT-40 instability in colorectal adenomas and carcinomas and germline polymorphisms. American Joumal of Pathology. 154, 1637-41.

51. Lax, S.F., Kendall, B., Tashiro, H., Slebos, R.J.C. and Ellenson, L.H. (2000) The frequency of $\mathrm{p} 53, \mathrm{~K}$-ras mutations, and microsatellite instability differs in uterine endometroid and serous carcinoma. Cancer, 88, 814-824.

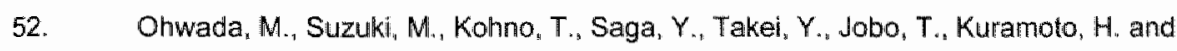
Sato, 1. (2002) Involvement of microsatellite instability in lymph node metastasis of endometrial carcinoma. Cancer Genetics and Cytogenetics, 132, 152-5.

53. Rupa, J.D., de Bruine "A.P., Gerbers, A.J., Leers, M.P., Nap, M. Kessels, A.G., Schutte, B. and Arends, J.W. (2003) Simultaneous detection of apoptosis and proliferation in colorectal carcinoma by multiparameter flow cytometry allows separation of high and low-turnover tumors with distincl clinical outcome. Cancer, 97 , $2404-11$.

54. Cherchi, P.L., Marras, V., Capobianco, G., Ambrosini, G., Piga, M.D., Fadda, G.M., Rosas, N. and Dessole, S. (2001) Prognostic vaiue of $p 53$, c-erb-B2 and MIB-1 in endometrial carcinoma. European Journal of Gynaecololgic Oncology, 22, 451-3.

55. Salvesen, H.B., Iversen, O.E. and Aksien, L.A. (1999) Prognostic significance of angiogenesis and ki-67, p53, and p21 expression: a population based endometrial carcinoma study. Journal of Clinical Oncology, 17 (5), 1382-1390.

56. Morsi, H.M., Leers, M.P., Radespiei-Troger, M., Bjorklund, V., Kabarity, H.E., Nap, M. and Jager, W. (2000) Apoptosis, bci-2 expression and proliferation in benign and malignant endometrial epithelium: An approach using multiparameter flow cytometry. Gynecologic Oncology, 77, 11-7.

57. Heatley, M.K. (4997) A high apoptotic index occurs in subtypes of endometrial adenocarcinoma associated with a poor prognosis. Pathology, 29, 272-5.

58. Creutzberg, C.L., wan Putten, W.L.J., Koper, P.C.M., Lybeert, M.L.M., Jobsen, J.J., Wárlám-Rodenhuis, C.C." De Winter, K.A.J., Lutgens, L.C.H.W., van den Bergh, A.C.M., van de Steen-Banasik, W."Beerman, H. and van Lent, M. (2000) Surgery and postoperative radiotherapy versus surgery alone for patients with slage-1 endometrial carcinoma: multicenter randomised trial. 355, 1404-1411. 


\section{Chapter 5}

\section{Aberrations in the progesterone receptor gene and the risk of recurrent endometrial carcinoma}

Johanna M.A. Pijnenborg, Andrea Romano, Geeske C. Dam-de Veen, Gerard A.J. Dunselman, Dagmar-Christine Fischer, Patrick G. Groothuis, Dirk G. Kieback

J Pathol 2005 Apr;205(5):597-605

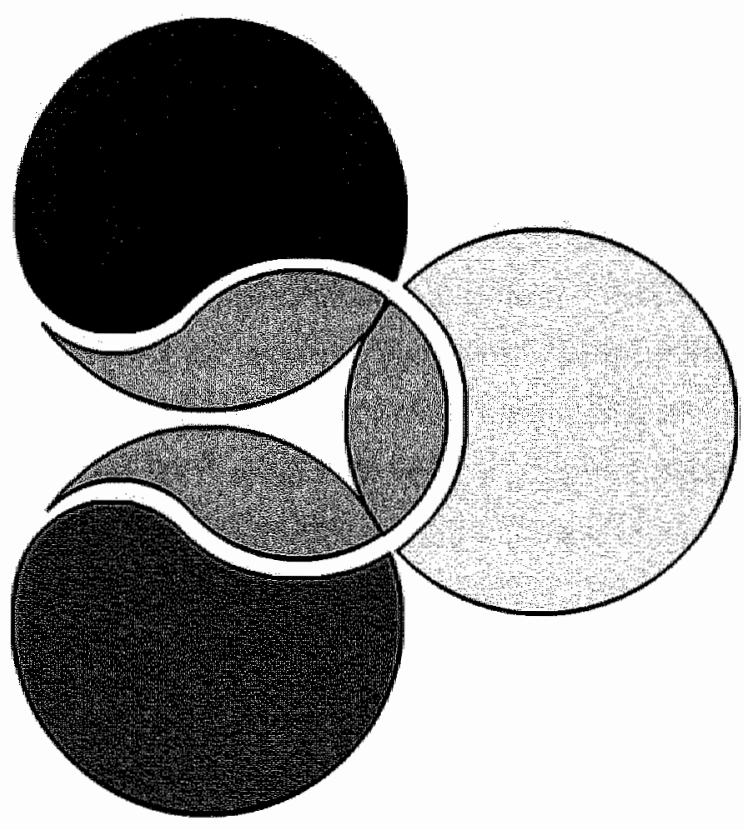




\section{Abstract}

A case-control study was performed in order to determine whether the expression of the progesterone receptor (PR) and/or aberrations of the PR gene contribute to the devellopment of recurrent endometrial carcinoma. Primary tumors from 44 patients with recurrence of stage I endometrial carcinoma (patients) within three years after initial treatment were compared to tumors of 44 matched patients being free of recurrence for minimally three years (controls). Paraffin-embedded primary tumors $(n=88)$ and recurrent tumors ( $n=32$ ) were subjected to immunohistochemical analysis of PR expression. A staining index $(S \mid=0-9)$ based on staining intensity and number of stained cells was calculated. DNA extracted from paraffinembedded tissues was subjected to PCR-restriction fragment length polymorphism analysis (PCR-RFLP) for determination of the PROGINS DNA sequence alterations and the $+331 \mathrm{G} / \mathrm{A}$-promoter polymorphism.

Low PR expression $(S \mid<1.0)$ was observed in $7 \%$ of primary tumors derived from controls, in $25 \%$ of primary tumors from patients with recurrence, and in $38 \%$ of recurrent tumors. The expression of PR was significantly lower in primary tumors of patients with recurrence $(S I=4.0 \pm 0.5)$ compared to the tumors in the control group $(S \|=5.6 \pm 0.5)$ (T-Test for paired analysis, $p<0.05$ ). The PROGINS and $+331 \mathrm{G} / \mathrm{A}$-promoter polymorphism were not related to age at diagnosis, tumor grade or myometrial invasion. The $+331 \mathrm{G} / \mathrm{A}-$ promoter polymorphism was present in $14 \%$ of primary tumors from patients without recurrence, compared to $17 \%$ of patients with recurrence. The PROGINS polymorphism was observed in $16 \%$ of primary tumors of patients without, and in $34 \%$ of pattents with recurrence (OR 2.6; $95 \% \mathrm{Cl}: 0.9-7.6$ ). Most interestingly, patients carrying the PROGINS variant and being diagnosed with a PR expressing tumor were at significantly enhanced risk of relapse (OR 4.7; 95\% Cl:1.3-17.1). In conclusion, low PR expression tended to be associated with recurrent disease, and PR expression in tumors of patients carrying the PROGINS allele was predictive for the risk of recurrence. 


\section{Introduction}

Endometrial carcinoma is the most common malignancy of the female genital tract and the incidence is increasing in industrialized countries. The majority of the tumors is of the endometrioid type (type 1) [1]. Current treatment consists of total abdominal hysterectomy with bilateral salpingooophorectomy. Pelvic lymphadenectomy is not routinely performed in the Netherlands. Despite adequate therapy $4-10 \%$ of patients still presents with local recurrences [2-4]. Currently, mainly clinicopathological characteristics like tumor grade and myometrial invasion are used in the selection for appropriate therapy. Apparently, these tumor characteristics are not sufficient in the prediction of recurrence, and therefore new markers are needed.

The risk of developing type I endometrial carcinoma is associated with risk factors that suggest a relationship with the life-time exposure to estrogens, i.e. early menarche, late menopause, and nulliparity [5]. The natural antagonist of estrogen-induced prolliferative response in the endometrium, is progesterone. Therefore, an adequate progesterone response in the endometrium is essential to control normal cell proliferation. The principle variable governing a response to progesterone therapy was shown to be the availability of functional PR [6]. This is illustrated by the fact that the reported clinical response to progesterone therapy was six times higher for $P R$ positive tumors compared with PR negative tumors, and that progesterone treatment has successfully been utilized in patients who developed recurrent endometrial cancers as a result of estrogen-dependent proliferation [7-9]. Also, PR positivity in endometrial carcinoma was shown to be an independent prognostic factor for disease-free survival [10-13]. The actions of progesterone are mediated by two functionally distinct isoforms: PR-A and PR-B, which are expressed from a single gene as a result of the transcription from two alternative promoters [14]. The spatiotemporal expression of PR-A and PR-B in the human endometrium, is regulated by both estrogen and progesterone, and undergoes dynamic 
changes during the menstrual cycle and early pregnancy [15]. The functiona! significance of the PR isoforms with regard to the regulation of proliferation is not fully understood. Selective activation of PR-B in PR-A knockout mice induces epithelial cell proliferation in the endometrium, indicating that PR-A is required to control the potential adverse effects of PR-B [16]. Moreover, analysis of the function of PR-A in PR-B knockout mice has learned that expression of PR-A is both necessary and sufficient to mediate the antiproliferative responses to progesterone and to inthibit estrogen-induced hyperplasia. Therefore, the PR-A isoform is responsible for antagonising estrogen-induced proliferation in these models.

Endometrial cancers are frequently associated with aberrant ratio's of PR-A and PR-B $[17,18]$, most probably as a result from genetic, epigenetic or posttranslational changes. These changes may also affect the function of the PR isoforms, which is illustrated by the fact that, in contrast to the responses in the knockout mice, the PR-B rather than PR-A mediated the antiproliferative effects of progestins in endometrial cancer cell lines [19].

Recently, De Vivo and colleagues described a functionally relevant $+331 \mathrm{G} / \mathrm{A}$ polymorphism of the PR promoter [18]. The G-to-A exchange gives rise to an additional TATA-box, resulting in an increased production of PR-B. Although this polymorphism was seen to be associated with an increased risk for endometrial carcinoma in the general population, it has not been analyzed with respect to the risk of recurrence.

Another complex of nucleic acid sequence aberrations of the PR, known as PROGINS (NCBI Data Bank accession numbers AF016381 and Z49816) has recently been identified. It consists of a haplotype carrying a $306 \mathrm{bp}$ PV/HS-1 Alu insertion in intron-G, a silent point mutation in exon $5(\mathrm{H} 770 \mathrm{H})$ and a single amino acid change in exon 4 (V660L) [20,21]. PROGINS has been identified as a risk modifier for benign and malignant gynecological diseases, thereby indicating that the function of PR is affected [22-24]. Whereas PROGINS is likely to be associated with altered activity of either 
PR isoform, the +331G/A polymorphism might affect the ratio of PR-A to PR$B$.

A case-control study in stage I endometrioid endometrial carcinoma patients was performed in order to investigate whether detection of PROGINS and the $+331 \mathrm{G} / \mathrm{A}$ polymorphism in addition to immunohistochemical analysis of PR expression can improve the prediction of the risk for recurrence. 


\section{Methods}

\section{Patients and tissue specimens}

Patients with recurrent endometrioid endometrial carcinoma were selected from the Dutch National Pathology Database (PALGA). Each group consisted of forty-four patients diagnosed with stage I disease (FIGO [25]). Patients with recurrent disease within three years were compared with patients being free of recurrence for at least three years. Both groups were matched for tumor stage, tumor differentiation, age at diagnosis, and radiotherapy. Since no blood or other normal tissues were collected at the time of surgery, the analyses were performed on archival material.

The study was approved by the Medical Ethical Committee of the University Hospital of Maastricht (MEC 02-009.5). In both groups first-line therapy consisted of a hysterectomy and bilateral salpingo-oophorectomy. Radiotherapy was applied, when myometrial invasion was more than $50 \%$, and/or when the tumor was poorly differentiated. Patients presented with local recurrence at the vaginal vault $(n=35)$, pelvic wall $(n=1)$, distant metastases $(n=5)$ or a combination of local recurrence and distant metastases $(n=3)$. The histopathology of all primary $(n=88)$ and available recurrent tumors $(n=32)$ was revised by an independent pathologist.

\section{DNA isolation}

Areas predominantly containing tumor cells were identified by a pathologist on Haematoxylin/Eosin- stained sections, and manually dissected from five consecutive sections $(20 \mu \mathrm{m})$ of the paraffin-embedded tissue specimens. Genomic DNA was extracted using proteinase K (Qiagen, Hilden, Germany) digestion in combination with the Puregene DNA Isolation Kit (Gentra systems, Minneapolis, Minnesota, USA) as recommended by the manufacturer. 


\section{Validation of PR antibodies}

CHO-K1 (Chinese Hamster Ovary, ATCC) cells expressing either PR-A or PR-B subsequent to transient transfection with appropriate plasmids were used to verify, that PgR636 is able to detect both PR isoforms in paraffinembedded tumor cells. The cells were scraped, pelleted and resuspended in $2 \%$ agar. Upon solidifying, the agar blocks were fixed in formalin and embedded in paraffin.

Likewise, the specificity of clone B30 (1:25, PR-B specific, Santa Cruz) and clone PGR312 (1:200, PR-A, Nova Castra was investigated [26].

\section{Immunohistochemical analysis}

Sections $(5 \mu \mathrm{m})$ of the paraffin-embedded tissues and cells were prepared on Starfrost adhesive slides (Klinipath, Duiven, The Netherlands), deparaffinated in xylene and rehydrated prior to blocking endogenous peroxidase by incubation with $3 \%$ hydrogen peroxide/methanol ( 20 minutes), and antigen retrieval (10 mM Tris-EDTA, pH 9.0; microwave treatment: 750 $W, 20$ minutes). The tissue sections were left to cool down to room temperature and were washed with phosphate buffer saline (PBS) (pH 7.2) prior to incubation. Antibody binding was visualized with the avidin-biotin complex immunoperoxidase technique (ChemMate detection kit; DAKO, Copenhagen, Denmark), and 3,3'-diaminobenzidine as substrate. Haematoxylin was used for counterstaining.

\section{Evaluation of immunostaining in tumor tissues}

Percentage of stained tumor cells (0\%, 0-10\%, $10-50 \%,>50 \%)$, and intensity of staining (absent, weak, moderate or strong) were determined $(0,1,2$, or 3 for each variable) for the entire tumor area within the section, and a staining index ( $\mathrm{S} \|$, ranging 0-9) was calculated by multiplying categorized parameters [27]. Determination of immunostaining was performed in a blinded fashion and independently by two observers (PG, JP). One observer scored the 
sections once, and the other observer scored the sections twice, blinded for the tissue ID's. The correlation coefficients calculated for two observations made by the same observer, and for two observations made by two observers were 0.95 and 0.86 , respectively. The mean of three observations was used for analysis. Low PR expression was defined as a $\mathrm{SI}<1.0$.

PROGINS and $+331 \mathrm{G} / \mathrm{A}$ detection.

Restriction fragment length polymorphism analysis (RFLP) was performed for detection of the two PR polymorphisms. Since only archival tissue was available, a nested-PCR was designed to generate the PCR products. To determine the presence or absence of PROGINS, samples were analyzed for the V660L mutation in exon 4 (primers listed in Table 1). The $138 \mathrm{bp}$ fragment contained $2 \mathrm{Brs}$ restriction sites (corresponding to fragments of 95 bp, 23 bp and $20 \mathrm{bp}$ ) in the wild type allele and one in the PROGINS allele, resulting in two fragments of $115 \mathrm{bp}$ and $23 \mathrm{bp}$. After electrophoresis $(2 \%$ agarose gel), the degradation products were visualized by ethidium bromide staining (Figure1).

Figure 1

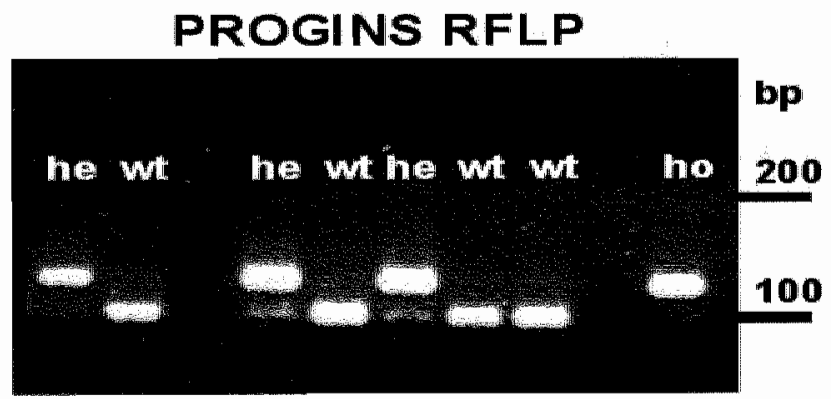

Restriction fragment length polymorphism analysis of the mutation in exon 4 of the PROGINS complex of aberrations. Examples of wild-type (wt), heterozygous (he), and homozygous (ho) endometrial carcinomas. Fragments of less than $30 \mathrm{bp}$ are not resolved.

A clear differentiation between the $115 \mathrm{bp}$ and $95 \mathrm{bp}$ bands was possible and could sufficiently discriminate between both alleles. 
For detection of the $+331 \mathrm{G} / \mathrm{A}$-promoter polymorphism, a similar procedure was carried out (primers listed in Table 1). The 206 bp amplicon generated with the nested PCR contained one NlalV restriction site (generating two fragments of $149 \mathrm{bp}$ and $57 \mathrm{bp}$ ) if derived from a wild-type allele (+331G), and no NalV restriction site if derived from the $+33 \Downarrow \mathrm{A}$ allele (Figure 2)

\section{Figure 2}

\section{G/A polymorphism-N/alV}

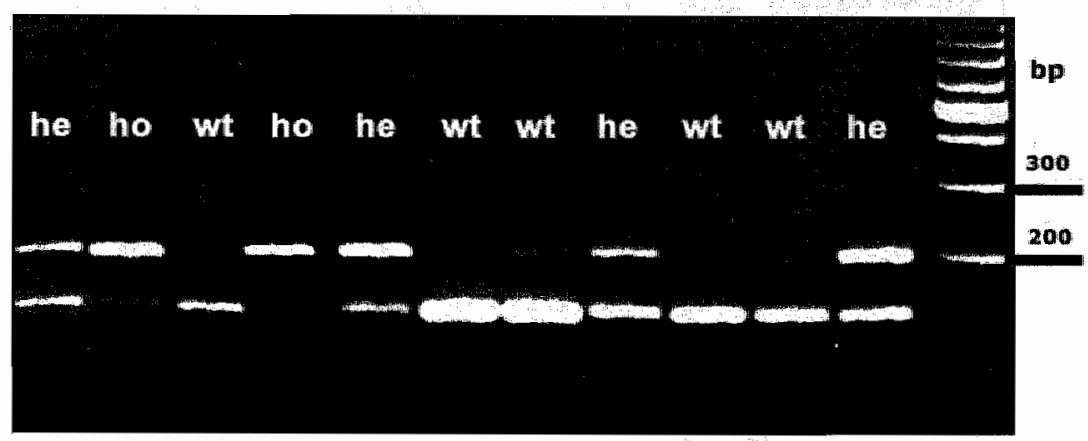

Restriction fragment length polymorphism analysis of +331 G/A-promoter polymorphism. Examples of wild-type (wt), heterozygous (he), and homozygous (ho) endometrial carcinomas Fragments of less than $30 \mathrm{bp}$ ane not resolved.

All PCRs were performed in a volume of $20 \mu l$ containing $50 \mathrm{ng}$ genomic DNA, $50 \mathrm{nM}$ of each primer, $0.1 \mathrm{mM}$ of each dNTP, 1 unit of Taq DNA polymerase (Qiagen, Hilden, Germany) and $1 x$ buffer with $2.5 \mathrm{mM} \mathrm{MgCl} 2$. The restriction endonucleases BrsI (isoschizomer BrsSI, Promega) and NlalV (isoschizomer BspLI, Fermentas) were used according to the manufacturer's recommendations. The presence of the PROGINS and $+331 \mathrm{G} / \mathrm{A}$ polymorphism was also assessed in the recurrent tumors, and the presence of PR aberrations was in 100\% agreement with the primary tumors $(n=21)$. 


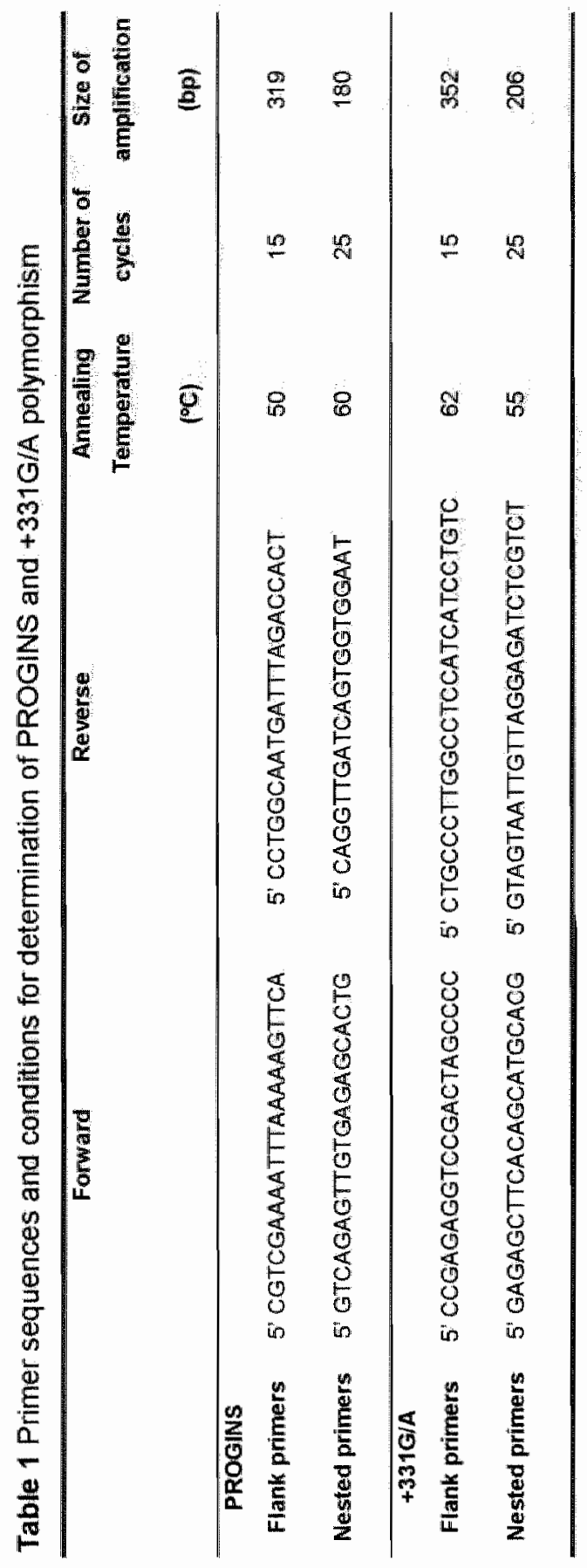




\section{Statistics}

The SPSS software (version 11.5) was used for statistical analysis, and median values for age and follow-up were calculated. To test whether patients with and without recurrence were comparable with respect to baseline characteristics, a T-test for paired analysis (continuous variables), and a McNemar test (dichotomous variables) were performed. For few samples derived from patients with recurrent disease immunohistochemistry $(n=5)$ and/or RFLP analysis (PROGINS $(n=3)$ and +331 G/A polymorphism $(n=2))$ was not possible, due to either a lack or poor quality of the material. This was indicated as not determined (ND) and these samples were omitted from analysis. The difference in PR expression between primary tumors of patients with and without recurrence was determined by a paired T-test. Odds Ratios (OR) were calculated for low PR expression and PROGINS and the risk of recurrence. A correction by Mantel-Haenszel was performed for radiotherapy and tumor grade. A paired T-test was performed to compare PR expression in primary and recurrent tumor. All statistical tests were twosided, and a p-value of 0.05 was considered significant. 


\section{Results}

Patients

All patients $(n=88)$ were postmenopausal at the time of diagnosis. Clinicopathological parameters of patients in both groups were well comparable, whereas the follow-up time is longer in patients without recurrence (Table 2). From those patients with recurrent disease, 32 recurrent tumors were available for immunohistochemical analysis, and 21 for DNA extraction.

Table 2 Patient and tumor characteristics

\begin{tabular}{|c|c|c|c|}
\hline & $\begin{array}{l}\text { Control patients without } \\
\text { recurrence }(n=44)\end{array}$ & $\begin{array}{l}\text { Patients with } \\
\text { recurrence }(n=44)\end{array}$ & P-value \\
\hline $\begin{array}{l}\text { Age at diagnosis } \\
\text { (median and range) }\end{array}$ & $69.5(54-93)$ years & $70.5(51-83)$ years & $0.268^{\pi}$ \\
\hline Figo stage & & & $1000^{22}$ \\
\hline la & 3 & 2 & \\
\hline $\mathrm{lb}$ & 22 & 24 & \\
\hline 10 & 19 & 18 & \\
\hline Tumor grade & & & $0.219^{.2}$ \\
\hline Grade 1 & 16 & 13 & \\
\hline Grade II & 21 & 21 & \\
\hline Grade III! & 7 & 10 & \\
\hline Post-operative radiotherapy & 19 & 14 & $0.125^{\circ 2}$ \\
\hline $\begin{array}{l}\text { Tilme to recurrence } \\
\text { (median and range) }\end{array}$ & 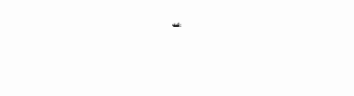 & $12.5(2-32)$ months & \\
\hline $\begin{array}{l}\text { Follow-up } \\
\text { (median and range) }\end{array}$ & $45.5(34-120)$ months & $32(9-141)$ months & 0.018 \\
\hline
\end{tabular}

"T-test for paired analysis, "McNemar test 


\section{Validation of PR antibody}

$\mathrm{CHO}-\mathrm{K} 1$ cells expressing either PR-A or PR-B were used to confirm ${ }^{\prime}$ that clone PgG636 (Dako, Copenhagen, Denmark) detected both PR-isoforms in paraffin-embedded cells with similar sensitivity. The PR-B specific antibody stained the CHO-PR-B cells, but not the CHO-PR-A cells. PR-B staining was also visible in the endometrium (Figure 3). The PgR636 antibody from Dako and the PGR312 antibody from Nova Castra stained both the CHO-PRA and the $\mathrm{CHO}-\mathrm{PRB}$ cells, and demonstrated a strong staining in endometrial tissue (Fig.3, page 208).

\section{PR expression}

Representative examples of tumors with different PR expression intensities are shown in Figure 4A-D (page 209). Results are listed in Table 3. Mean $( \pm S E)$ PR expression was significantly lower in grade III tumors ( $S \mid=2.5 \pm 0.5$ ) compared to grade I and II (SI=5.3 $\pm 0.6, S I=5.4 \pm 0.5)(T$-test, $p<0.05)$. The mean PR staining index was $5.6 \pm 0.5$ in tumors of controls, $4.0 \pm 0.5$ in tumors of patients with recurrence, and $3.6 \pm 0.6$ in recurrent tumors. The difference in PR staining index from patients with and without recurrence was statistically significant (T-test for paired analysis, $p<0.05$ ). Low PR expression $(S \mid<1.0)$ was observed in $7 \%(3 / 42)$ of tumors of controls, in $25 \%$ (9/39) of tumors with recurrence, and in $38 \%(12 / 32)$ of recurrent tumors (Table 4). After correction for postoperative radiotherapy and tumor grade, the OR for the development of recurrence in patients bearing tumors with low PR expression $(\mathrm{S} \|<1.0)$ was 3.5 (95\% $\mathrm{Cl} 0.9-13.1)$. Analysis of primary and recurrent tumors taken from the same patient revealed no individual differences in PR expression (T-test for paired analysis, $p=0.62$ ). 


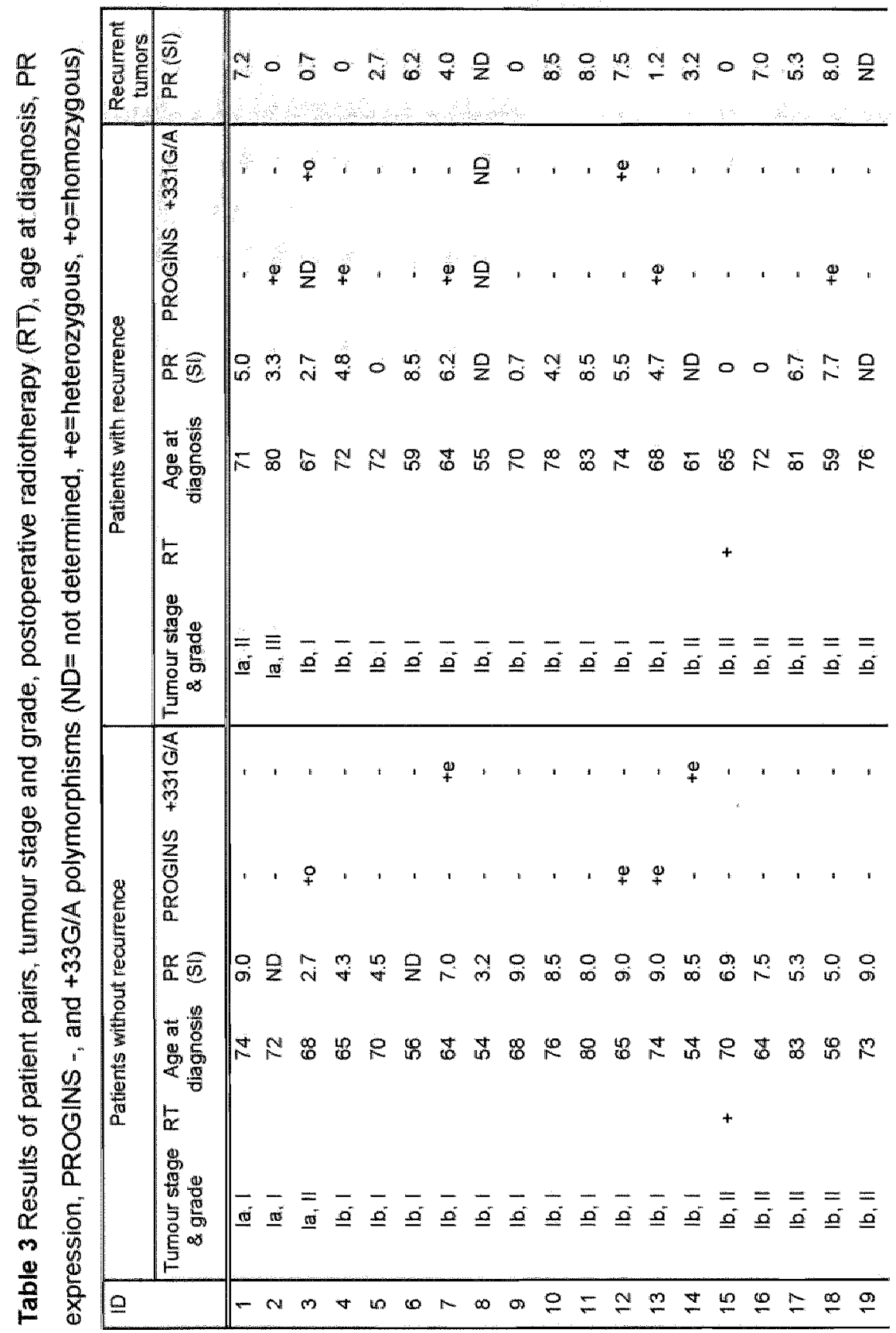




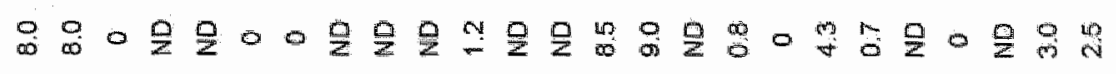

, '

, ,

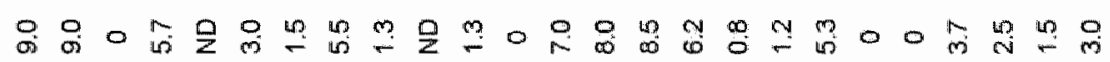

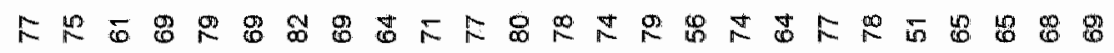

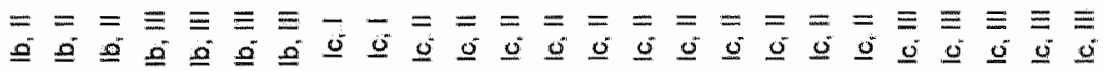

$$
\text { , , , 古, " }
$$

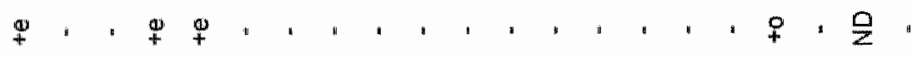

응

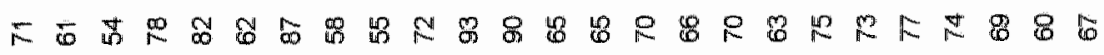

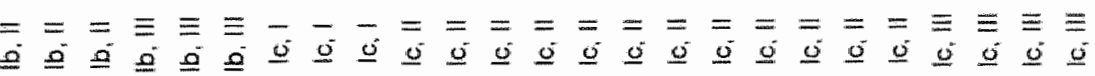

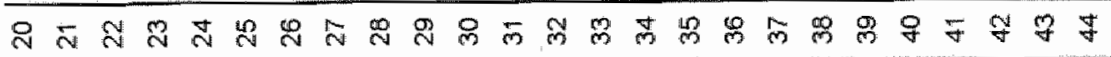




\section{PROGINS polymorphism}

Overall, the PROGINS complex of genomic alterations was present in $23 \%$ (6/26) of grade I, $23 \%(9 / 40)$ of grade II, and in 38\% (6/16) of grade $I I I$ tumors. In the control group, seven women carried the PROGINS allele: two homozygous, and five heterozygous. By contrast, 14 patients in the recurrence group carried the PROGINS allele: one homozygous and 13 heterozygous. Data of all patients are listed in Table 3 and results are summarized in Table 4. After correction for radiotherapy and tumor grade, PROGINS was seen to be positively associated with the risk of recurrence (OR $2.6 ; 95 \% \mathrm{Cl} 0.9-7.6$ ). When this analysis was restricted to patients with PR-expressing tumors ( $S I \geq 1.0$ ), the influence of PROGINS on the risk of recurrence was even more pronounced and statistically significant (OR 4.7; $95 \%$ Cl 1.3-17.1; $p<0.05$; Table 5). The combination of low PR expression and the presence of PROGINS, corrected for radiotherapy and tumor grade, did not increase the $O R$ for the risk of recurrence compared to the PROGINS alone (OR $3.5 ; 95 \% \mathrm{Cl} 1.4-9.0$ ), but did narrow the confidence interval (Table 5).

Table 4 Summary of results of PR expression and PROGINS-, and +331G/A polymorphisms.

\begin{tabular}{|c|c|c|c|}
\hline & \multicolumn{2}{|c|}{ Primary tumors } & \multirow[t]{2}{*}{ Recurrent tumors } \\
\hline & $\begin{array}{c}\text { Patients withoult } \\
\text { recurrence }\end{array}$ & $\begin{array}{l}\text { Patients with } \\
\text { recurrence }\end{array}$ & \\
\hline \multicolumn{4}{|l|}{ PR expression } \\
\hline - mean S| ( $\pm S E)$ & $5.6 .( \pm 0.5)$ & $4.0( \pm 0.5)$ & $3.6( \pm 0.6)$ \\
\hline$-10 w \mathrm{PR}(S \mid<1.0)$ & $7 \%(3 / 42)$ & $25 \%(9 / 39)$ & $38 \%(12 / 32)$ \\
\hline PROGINS & $16 \%(7 / 43)$ & $34 \%(14 / 41)$ & - \\
\hline$+331 \mathrm{G} / \mathrm{A}$ & $14 \%(6 / 43)$ & $17 \%(7 / 42)$ & - \\
\hline
\end{tabular}


Table 5 Summary of calculated Odss ratio's and the risk of recurrence

\begin{tabular}{lcc}
\hline Low PR expression $(\mathrm{S} \mid<1.0)$ & Odds Ratio * & $95 \% \mathrm{Cl}$ \\
PROGINS & 3.5 & $0.9-13.1$ \\
PROGINS in PR expressing tumors $\left.(S)^{3} 4.0\right)$ & 2.6 & $0.9-7.6$ \\
& 4.7 & $1.3-17.1$ \\
PROGINS and Low PR expression & & \\
\end{tabular}

\footnotetext{
"Mantel-Haenszel Odds Ratio's are calculated after correction for applied radiotherapy and tumor grade
}

$+331 \mathrm{G} / \mathrm{A}$ polymorphism

Among all patients with endometrial carcinoma, the +331 G/A polymorphism was observed in $25 \%$ (7/28) of grade $1,5 \%$ (2/40) of grade II, and in $24 \%$ (4/17) of grade III tumors.

In the control group, there were six carriers of the $+331 \mathrm{G} / \mathrm{A}$ polymorphism: two homozygous, and four heterozygous. Among the patients with recurrence, seven women carried the $+331 \mathrm{G} / \mathrm{A}$ allele (Tables 3 and 4 ).

\section{$P R$ expression and PR aberrations}

Neither PROGINS nor the $+331 \mathrm{G} / \mathrm{A}$ polymorphism were related to the age at diagnosis, age at onset of menopause, tumor grade, or tumor stage. The presence of the PROGINS polymorphism did not affect the PR staining index (5.1 \pm 0.6 in PROGINS carriers vs. $4.8 \pm 0.4$ in non-PROGINS carriers). Although not statistically significant, we found lower PR expression in tumors with the $+331 \mathrm{G} / \mathrm{A}$ polymorphism $(\mathrm{SI}=3.6 \pm 0.8$ ) compared to tumors carrying the wild type allele $(S \mid=5.1 \pm 0.4)$. Three patients carried both PR gene aberrations and two of them presented with recurrent disease. 


\section{Discussion}

A case-control study was performed to evaluate the association between PR polymorphisms and the risk for recurrence of stage I endometrial carcinoma. Moreover, these genetic aberrations were analyzed with respect to the additional prognostic value compared to immunohistochemical determination of PR expression only. We were able to show that the PROGINS complex of genetic aberrations can be used as predictor for the risk of recurrence. This prognostic value was independent of tumor grade, myometrial invasion or age at diagnosis, and significant in PR expressing tumors $(S \mid \geq 1.0)$. Low PR expression $(S \mid<1.0)$ in the primary tumor tended to be associated with the development of recurrent disease, was found predominantly in the recurrence group, and even more frequently in the recurrent tumors. The predictive value of $P R$ expression with respect to disease-free survival has been demonstrated by others, and was seen to be superior to the prognostic value of estrogen receptor expression $[10,11,28,29]$. Loss of PR expression during the progression of tumor could be explained by the progressive dedifferentiation of the tumor and/or selection of more aggressive PR negative clones.

The $+331 \mathrm{G} / \mathrm{A}$ promoter polymorphism results in an additional TATA-box in the promoter, and subsequently in an increased expression of PR-B [18]. However, in our study the $+331 \mathrm{G} / \mathrm{A}$ promoter polymorphism was associated with a lower SI for PR. While most of the commercially available pan-PR specific antibodies recognize both PR isoforms on western blots, they failed to do so in paraffin embedded tissue $[26,30]$. We were able to confirm that clone PR 636 (Dako, Copenhagen, Danmark) is suitable for immunohistochemical detection of both PR-isoforms (Figure 4). In addition, analysis of PR-B expression was performed in a subset of patients and no difference was observed between patients with and without the $+331 \mathrm{G} / \mathrm{A}$ polymorphism and between patients with and without recurrence (data not shown). Thus, it is likely, that the effect of the $+331 \mathrm{G} / \mathrm{A}$ polymorphism on expression of PR-B is overruled by another process that results in silencing 
of the PR-B gene, such as promoter methylation. This point of view is supported by the observation, that in endometrial carcinoma cell lines and in endometrial cancer tissues, PR-B was more frequently (70\%) inactivated by promoter methylation when compared to normal endometrial tissue $[31,32]$. De Vivo and co-workers showed, that women carrying the $+331 \mathrm{~A}$ allele are more susceptible to the development of endometrial carcinoma and breast cancer $[18,33]$. Yet, evidence was obtained, that down regulation of PR-B was associated with poorly differentiated endometrial carcinoma. This implicates, that the $+331 \mathrm{G} / \mathrm{A}$ polymorphism together with an increased expression of PR-B should be associated with better differentiated tumors, and a longer disease-free survival $[31,34]$. However, as we did not see an increased expression of PR-B in tumors bearing the $+331 \mathrm{G} / \mathrm{A}$ polymorphism, we cannot support these statements.

So far PROGINS, present in $2-22 \%$ of the population [24], has not been studied in relation to recurrent endometrial carcinoma. Among all patients with endometrial carcinoma and those with recurrent disease, $25 \%$ and $34 \%$ were carriers of the PROGINS allele, respectively. Noteworthy, $43 \%$ of those patients bearing a $P R$-expressing tumor $(S I \geq 1.0)$ and suffering from recurrent disease carried the PROGINS allele. The exact functional impact of the PROGINS aberration is not clear. Comparative functional characterization of wild type PR and PROGINS in-vitro revealed, that the mutated PR was more stable and expressed an increased hormone-induced transcriptional activity, virtually independent from the zygosity status [21]. The V660L mutation in the hinge region is likely to affect the bending of the chromatin, which also will affect receptor induced transcriptional activity [35]. Whether this affects the inhibitory effect of the progesterone on estrogeninduced proliferation remains to be elucidated. Thus far inconclusive results with respect to the association of PROGINS with breast- or ovarian cancer were obtained. PROGINS has to be envisaged preferentially as a risk modifier rather than being a determinator of either disease. Recently, a systematic review of the literature revealed that homozygous carriers of the 
PROGINS allele are protected against breast cancer, although this observation is of borderline statistical significance [36]. By contrast, the effect of PROGINS on the risk of ovarian cancer could not be established conclusively [37].

This is the first study comparing primary and recurrent stage I endometrial carcinoma in order to evaluate the role of progesterone and it's receptors in the progression of the endometrial tumor.

In conclusion, low PR expression and PROGINS were tended to be associated with the development of recurrent endometrial carcinoma. In the presence of PR expression, PROGINS was significantly predictive for the risk of recurrence.

\section{References}

1. Longacre, T.A., Kempson, R.L. and Hendrickson, M.R. (1995) Obstetricall and Gynaiecological Pathology. Churchill Livingstone "Edinburgh.

2. Creutzberg, C.L., van Putten, W.L.J., Koper, P.C.M., Lybeert, M.L.M., Jabsen, J.J., Wárlám-Rodenhuis, C.C. De Winter, K.A.J., Lutgens, L.C.H.W., van den Bergh, A.C.M. van de Steen-Banasik, W., Beerman, H. and van Lent, M. (2000) Surgery and postoperative radiotherapy wersus surgery alone for patients with stage-1 endometrial carcinoma: multicenter randomised trial. 355, 1404-1411.

3. Brady, L.W., Perez, C.A. and Bedwinek, J.M. (1986) Failure patterns in gynecologic cancer. International Journal of Radiation Oncology, Biology, Physics, 12, 549-57.

4. Grigsby, P.W., Perez, C.A., Kuten, A. Simpson, J.R., Garcia, D.M. Camel, H.M., Kao, M.S. and Galakatos, A.E. (1992) Clinical stage I endometrial cancer: prognostic factors for local control and distant metastasis and implications of the new FIGO surglcal staging system. International Joumal of Radiation Oncology and biological physiology, 22, 905-41.

5. Kaaks, R., Lukanova, A. and Kurzer, M.S. (2002) Obesity endogenous hormones, and endometrial cancer risk: a synthetic review. Cancer, Epidemiology „Biomarkers \& Prewention, 11, 1531-1543.

6. Ehrtich, C.E., Young. P.C. "Stehman, F.B., Sutton, G.P. and Alford, W.M. (1988) Steraid receptors and clinical outcome in patients with adenocarcinoma of the endometrium. American Journal of Obstetrics and Gynecology, 158, 796-807. 
7. Podratz, K.C., O'Brien "P.C., Malkasian " G.D.J., Decker, D.G., Jefferies, J.A. and Edmonson, J.H. (1985) Effects of progestational agents in treatment of endometrial carcinoma. Obstetrics and Gymecology, 106-10.

8. Thigpen, T., Blessing, J. and DiSaia, P. (1986) Oral medroxyprogesterone acetate in advanced or recurrent endometrial carcinoma. In Baulieu, E.E., lacobelli, S. and McGuire, W.L. (eds.) Eindocrinology and malignancy. Parthenon, New York, pp. 446454.

9. Fleming, G.F. (1999) Systemic therapy for advanced of recurrent endometrial carcinoma. Current Oncology Reports, 1, 47-53.

10. Steiner, E., Eicher, O., Sagemuller, J., Schmidt, M. "Pilch, H., Tanner, B., Hengstler, J.G., Hofmann, M. and Knapstein, P.G. (2003) Multivariate independent prognostic factors in endometrial carcinoma: a clinicopathologic stuidy in 181 patients: 10 years experience at the Department of Obstetrics and Gynecology of the Mainz University. International Journal of Gynecologic Cancer, 13, 197-203.

11. Gehrig, P.A. and Van Le, L. (2000) The prognostic value and clinical utility of estrogen and progesterone receptors in endometrial carcinoma. Prim Care Update Ob/Gyn 7 , 55-59.

12. Hiraî, M., Hirono, M., Oosaki, T. Hayashi, Y., Yoshihara, T, and Matsuzaki, O. (1999) Prognostic factors relating to survival in uterine endometrioid carcinoma. International Journal of Gynaecology and Obstetrics, 66, 155-62.

13. Salvesen, H.B. and Akslen, L.A. (2002) Molecular pathogenesis and prognostic factors in endometrial carcinoma. Acta Pathologica, Microbiologica, et Immunologica Scandinavica, 110, 673-689.

14. Punyadeera, C., Verbost, P. and Groothuis, P. (2003) Oestrogen and progestin responses in human endometrium. Journal of Steroid Biochemistry and Molecular Biology, 84, 393-410.

15. Mote, P.A., Balleine, R.L., McGowan, E.M. and Clarke, C.L. (2000) Heterogeneity of progesterone receptors $\mathrm{A}$ and $\mathrm{B}$ expression in human endometrial glands and stroma. Human Reproduction, 15, 48-56.

16. Mulac-Jericevic, B., Mullinax, R.A., DeMayo, F.J., Lydon, J.P. and Conneely, O.M. (2000) Subgroup of reproductive functions af progesterone mediated by progesterone receptor-B isoform. Science, 289, 1751-4.

17. Arnett-Mansfield, R.L., deFazio, A., Wain, G.V., Jaworski, R.C., Byth, K., Mote, P.A. and Clarke, C.L. (2001) Relative expression of progesterone receptors $A$ and $B$ in endometrioid cancers of the endometrium. Cancer Research, 61, 4576-82.

18. De Vivo, I., Huggins, G.S., Hankinson, S.E., Lescault, P.J., Baezen, M., Colditz, G.A. and Hunter, D.J. (2002) A functional polymorphism in the promoter of the progesterone receptor gene associated with endometrial cancer risk. Proceedings National Academy Science, 99, 12263-12268. 
19. Smid-Koopman, E., Blok, L.J., Kuhne, L.C., Burger, C.W., Helmerhorst, T.J., Brinkmann, A.O. and Huikeshoven, F.J. (2003) Distinct functional differences of human progesterone receptors $A$ and $B$ on gene expression and growth regulation in two endometrial carcinoma cell lines. Journall of the Society for Gynecologic Investiglation, $10,49-57$.

20. McKenna, N.J., Kleback, D.G., Carney, D.N. Fanning, M. McLinden, J. and Headon, D.R. (1995) A germine Taql restriction fragment length polymorphism in the progesterone receptor gene in ovarian carcinoma. British Journal of Cancer, 71, 4515.

21. Agoulinik, 1.U., Tong $X_{\text {. }}$-W., Fischer, D.C., Korner, W., Atkinson, N.E., Edwards, D.P., Headon, D.R., Weigel, N.L. and Kieback, D.G. (2004) A germline variation in the progesterone receptor gene increases transcriptional activity and may modify ovarian cancer risk. Journal of Clinical Endocrinology \& Metabolism, in press.

22. Wang-Gohrke, S., Chang-Claude, J., Becher, H., Kieback, D.G. and Runnebaum, I.B. (2000) Progesterone receptor gene polymorphism is associated with decreased risk for breast cancer by age 50. Cancer Research, 60, 2348-50.

23. Wieser, F., Schneeberger, C., Tong, D., Tempfer, C., Huber, J.C. and Wenzl, R. (2002) PROGINS receptor gene polymorphism is associated with endometriosis. Fertility and Sterility. 77, 309-12.

24. Donaldson, C.J., Crapanzano, J.P., Watson, J.C., Levine, E.A. and Batzer, M.A. (2002) PROGINS Alu insertion and human genomic diversity. Mutation Research, $501,137-14 \%$.

25. Creasman, W.T. (1990) New gynecologic cancer staging. Obstetrics and Gynecology, 75, 287-288

26. Mote, P.A., Johnston, J.F., Manninen, T., Tuohimaa, P. and Clarke, C.L. (2001) Detection of progesterone receptor forms $A$ and $B$ by immunohistochemical analysis. Journal of Clinical Pathology, 54, 624-630.

27. Salvesen, H.B., MacDonald, N., Ryan, A. Iversen, O.E., Jacobs, 1.J., Akslen, L.A. and Das, S. (2000) Methylation of hMLH1 in a population-based series of endometrial carcinomas. Clinical Cancer Research, 6, 3607-3613.

28. Creasman, W.T. (1993) Prognostic significance of hormone receptors in endometrial cancer. Cancer, 71, 1467-70.

29. Gehrig, P.A. Van Le, L., Olatidoye, B. and Geradts, J. (1999) Estrogen receptor status, determined by immunohistochemistry, as a predictor of the recurrence of stage I endometrial carcinoma. Cancer, 86, 2083-2089.

30. Bain, D.L., Franden, M.A., McManaman, J.L., Takimoto, G.S. and Horwitz, K.B. (2001) The N-terminal region of human progesterone B-receptors: biophysical and biochemical comparison to Amreceptors. Joumall of Biological Chemistry, 276, 2382531. 
31. Kumar, N.S., Richer, J., Owen, G. Litman, E., Horwitz, K.B. and Leslie, K. K. (1998) Selective down-regulation of progesterone receptor isoform B in poonly differentiated human endometrial cancer cells: implications for unopposed estrogen action. Cancer Research, 58, 1860-5.

32. Sasaki, M., Dharia, A., Oh, B.R., Tanaka, Y., Fujimoto, S.-1, ano Dahiya, R. (2001) Progesterone receptor $B$ gene inactiviation and $C p G$ hypermethylation in human uterine endometrial cancer. Cancer Research, 61, 97-102.

33. De Vivo, I., Hankinson, S.E., Colditz, G.A. and Hunter, D.J. (2003) A functional polymorphism in the progesterone receptor gene is associated with an increase in breast cancer risk. Cancer Research, 63, 5236-8.

34. Sasaki, M., Kaneuchi, M., Fujimoto, S., Tanaka, Y. and Dahiya, R. (2003) Hypermethylation can selectively silence multiple promoters of steroid receptors in cancers. Molecular Cell Endocrinology, 202, 201-7.

35. Metivier, R., Penot, G., Hubner, M.R., Reid, G., Brand, H., Kos, M. and Gannon, F. (2003) Estrogen receptor-alpha directs ordered, cyclical, and combinatorial recruitment of cofactors on a natural target promoter. Cell, 12, 751-63.

36. Dunning, A.M., Healey, C.S., Pharoah, P.D., Teare, M.D., Ponder, B.A. and Easton, D.F. (1999) A systematic review of genetic polymorphisms and breast cancer risk. Cancer Epidemialogy, Biomarkers \& Prevention, 10, 843-54.

37. Modugno, F. (2004) Ovarian cancer and polymorphisms in the androgen and progesterone receptor genes: a HuGE review. American Journal of Epidemiology, 15 , 319-35. 


\section{Chapter 6}

\section{RASSF1A methylation and $K$-ras and $B$-raf mutations and recurrent endometrial cancer}

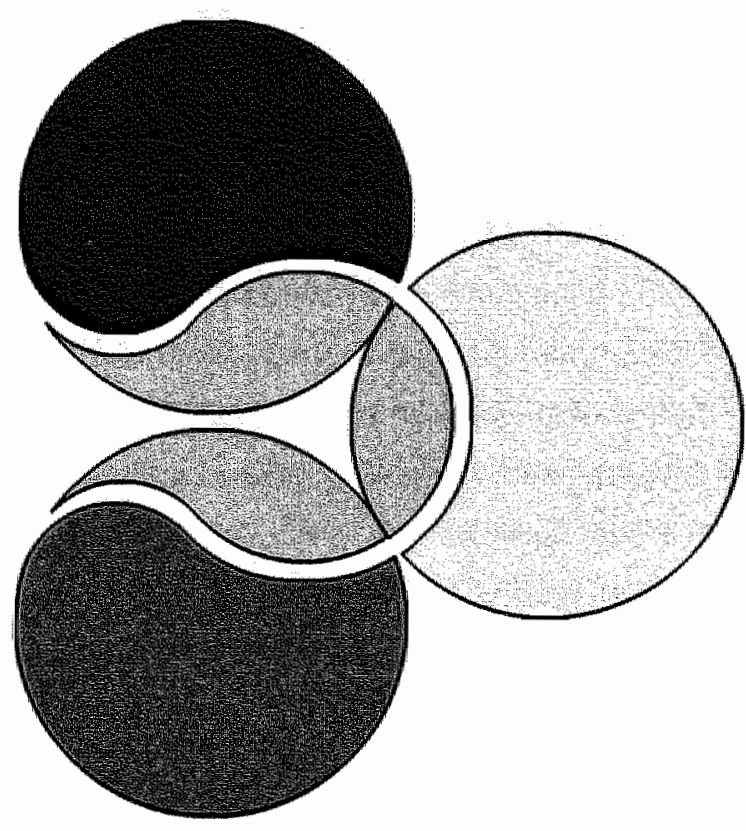

Johanna M.A. Pijnenborg, Geeske C. Dam-de Veen, Natasja Kisters, Jelte de Haan, Manon van Engeland, James G. Herman, Patrick.G. Groothuis

(submitted) 


\section{Abstract}

In order to evaluate the role of Ras signaling in recurrent endometrial carcinoma, a case-control study was performed on patients with $(n=44)$ and without $(n=44)$ recurrent stage I endometrial carcinoma.

In primary tumors $K$-ras mutation analysis was performed by direct sequencing, $B$-raf mutation (V600E) detection by restriction fragment length polymorphism, and RASSF1A methylation by methylation specific PCR. Overall, K-ras mutations were present in $18 \%$ of the patients, and were not related to the development of recurrent disease. None of the tumors harbored a V600E B-raf mutation. RASSF1A methylation was demonstrated in $85 \%$ of endometrial carcinomas, independent of recurrence. The presence of K-ras mutations and RASSF1A promoter methylation were not related, either directly or inversely.

Analysis in samples of cyclic -, hyperplastic -, atrophic endometrial tissue, and premenopausal endometrial carcinomas demonstrated $K$-ras mutations in $40 \%$ of premenopausal endometrial carcinomas, and no $B$-raf mutations. RASSF1A promoter methylation was also observed in $70 \%$ premenopausal carcinomas. Cyclic - , hyperplastic -, and atrophic endometrium showed RASSF $1 A$ methylation in respectively; $21 \%, 50 \%$ and $38 \%$.

Concluding, a high prevalence of RASSF1A methylation in endometrial carcinoma was observed, independent of the development of recurrent disease. On the contrary, K-ras and B-raf mutations were observed in a low frequency but also independent of recurrence. The high frequency of RASSF1A methylation in premenopausal carcinomas and increased frequency in endometrial hyperplasia suggests that this may be an early event in endometrial carcinogenesis. 


\section{Introduction}

Endometrial carcinoma is one of the most common malignancies of the female tract [1]. At least two different types of endometrial carcinoma with distinctive molecular characteristics and tumor behavior can be distinguished; the endometrioid and the serous type endometrial carcinoma [2-5]. The serous type is the most aggressive variant and accounts for less than $10 \%$ of the endometrial tumors [3]. The endometrioid type occurs most frequently and accounts for $57-80 \%$ of all cases $[6,7]$. This tumor type is characterized by mutations in the $K$-ras and PTEN gene, microsatellite instability and the expression of steroid receptors $[4,5]$. Although the prognosis of the endometrioid type is relatively good, some patients present with recurrent disease shortly after treatment $[8,9]$. Metastases are the major cause of death of carcinoma patients. The increase in cellular mobility of the carcinoma cells is usually the result of a phenotypic conversion, which is referred to as epithelial to mesenchymal transition (EMT). The hallmark of EMT are the loss of cell-cell adhesion and cytoskeletal rearrangements, by which epithelial cells acquire migratory behavior and escape from the wellorganized tissue structures [10]. Activation of the Ras signaling cascade is required for the accomplishment of these processes. Ras is known to participate in various signaling pathways one of which is the Raf/MAPK pathway. Overexpression of Ras and Raf results in increased cell mobility and dispersion [11]. Therefore, mutations in the Ras and Raf genes that result in proteins that are continuously in an activated stage, may lead to a migratory phenotype of subsets of carcinoma cells.

The K-ras gene is the locus for the $\mathrm{c}-\mathrm{k}$-ras protoncogene, lying on chromosome $12 \mathrm{p} 12$, and is about $45,000 \mathrm{bp}$ in length. It encodes for a 2.0 $\mathrm{kb}$ transcript that is highly conserved across species, and is translated into the p21-ras protein. These proteins are located in the plasma membrane and transduce growth and differentiation signals from activated receptors to protein kinases within the cell [12] . The K-ras proteins are in a weak GTPbound, active state, thereby altering transduction into the cell. The majority of 
mutations have been found at K-ras codons 12 and 13, and to a lesser extent, at codon 61 [13]. These mutations are somatic rather than in the germ-line, and consist of single base-pair substitutions which lead to the change of one amino acid in the protein. These mutations result in a K-ras protein that remains in the GTP-bound, activated state. Mutations in codon 12 and 13 of $K$-ras are found in $10-30 \%$ of the endometrial carcinomas [1417], and have been associated with a more aggressive behavior [15] " a finding which has not been confirmed by others [18, 19].

Mutations in B-raf, which encodes for a serine/threonine kinase, have been reported in several human cancers. Most of these mutations occur within the kinase domain, resulting in elevated kinase activity and transforming capacity in NIH3T3 cells [20]. A single base substitution (T-A change at nucleotide 1796) resulting in an amino acid substitution (V600E) accounts for $80-90 \%$ of these mutations [20]. B-raf, but not K-ras, mutations occur more frequently in mismatch repair deficient colon tumors and are correlated with hMLH1 hypermethylation [21,22]. So far the presence of $B$-raf mutations has not been reported in endometrial carcinoma.

Recently a new ras effector, RASSF1A, was characterized by Dammann et al. [23]. The gene is located at chromosome 3p21.3, a region which frequently shows allelic loss in many ciancers [24]. RASSF1 encodes for more than seven isoforms including; RASSF1A, RASSF1B, and RASSF1C, derived from alternative mRNA splicing and promoter usage [25]. RASSF1A is thought to be responsible for the Ras-dependent growth inhibition through its pro-apoptotic function [26], since elimination of Ras inhibits apoptosis induced by transilent transfection of RASSF1 into 293-T cells. In addition, Shivakumar and co-workers [27] showed that RASSF1A can induce cell cycle arrest by inhibiting accumulation of cyclin D1, thus preventing G1/Sphase cell cycle progression. Loss of RASSF1A expression by methylation may shift the balance towards a growth promoting effect without the necessity of activating Ras mutations. Methylation of the RASSF1A gene 
promoter has been observed in many human tumors, and is an important mechanism for inactivation of the RASSF1A.

In the present study, we investigated whether activation of the ras signaling pathway is associated with recurring endometrial carcinoma. To this end, we performed a case-control study and evaluated whether activating mutations in K-ras, B-raf, and promoter hypermethylation of RASSF1A are related to recurrent disease. 


\section{Materials and Methods}

Patients and tissue specimens

Patients with recurrent endometrial carcinoma were selected from the Dutch National Pathology Register (PALGA). Forty-four patients treated for stage I disease, classified according the FIGO criteria [28], with recurrent disease within three years of diagnosis were included. Patients were treated by hysterectomy and bilateral salpingo-oophorectomy. Postoperative radiotherapy was applied when tumor invasiveness was $>50 \%$ of the myometrial wall and/or when the tumor was poorly differentiated. Forty-four control patients were selected and matched for tumor stage, tumor differentiation, age at diagnosis, and therapy. Patients with recurrent endometrial carcinoma presented with local recurrence at the vagina vault $(n=35)$, pelvic wall $(n=1)$, distant metastases $(n=5)$ or both local recurrence and distant metastases $(n=3)$. A pathologist revised the histopathology and the endometrioid type adenocarcinoma was confirmed in all cases. All patients ( $n=88$ ) were postmenopausal, and no significant differences were found in clinico-pathological characteristics and treatment between patients with and without recurrence. In the patient group with recurrence, the recurrence was diagnosed after a median of 12.5 months after primary treatment (range 2-32 months).

Cyclic endometrial tissue was obtained from healthy women who underwent laparoscopic surgery for benign indications, not related to endometrium pathology (median: 34 , range: $30-49$ years). Postmenopausal atrophic endometrial tissue was collected from 13 women who underwent a hysterectomy for genital prolapse (median: 63 , range: $47-83$ years). Hyperplastic endometrial tissue of eight patients was obtained from the pathology archive (median: 57 , range: 46-73). Tumor tissue of ten patients with premenopausal stage I endometrial carcinoma, was subjected to analysis as well (median 47, range: $43-52$ years). The Medical Ethical Committee of the University Hospital of Maastricht approved the study. 


\section{DNA isolation}

DNA was extracted from three endometrial carcinoma cell lines ( $E C C$ 1, AN3CA, RL95.2).

After identification of the tumor area by a pathologist, tumor tissue was manually dissected from five consecutive $20 \mu \mathrm{m}$ sections of the paraffin embedded tissue. Genomic DNA was extracted using a proteinase $\mathrm{K}$ (Qiagen) digestion followed by DNA isolation using the Puregene DNA Isolation Kit (Gentra Systems).

\section{Mutation analysis of K-ras}

A K-ras codon 12 and 13 PCR product of $179 \mathrm{bp}$ was amplified and used as a template for the amplification of a $114 \mathrm{bp}$ fragment. Genomic DNA (250 $\mathrm{ng}$ ) was added to $50 \mathrm{mmol} / / \mathrm{KCl}, 10 \mathrm{mmol} / / \mathrm{Tris}-\mathrm{HCl}(\mathrm{pH} 8.3), 2.0 \mathrm{mmol} \mathrm{MgCl}_{2}$, $250 \mu \mathrm{mol} / \mathrm{l} \mathrm{dNTP}$ (Pharmacia, Uppsala, Sweden), $200 \mathrm{nmol} / / \mathrm{l}$ of the flank primers: 5'- AGGCCTGCTGAAAATGACTGAATA-3' (sense), and 5'CTGTATCAAAGAATGGTCCTGCAC-3' (antisense), and 1 U Platinum-Taq (Invitrogen, Breda, The Netherlands) (annealing temperature $50^{\circ} \mathrm{C}$ ). Water was added to a final volume of $50 \mu \mathrm{l}$. The subsequent PCR was performed in a final volume of $50 \mu \mathrm{l}$, containing $5 \mu$ of a 1:100 dilution of the flank product, $50 \mathrm{mmol} / \mathrm{I} \mathrm{KCl}, 10 \mathrm{mmol} / / \mathrm{Tris}-\mathrm{HCl}(\mathrm{pH} 8.3), 1.5$ to $2.5 \mathrm{mmol} \mathrm{MgCl}_{2}, 250$ $\mu \mathrm{mol} / / \mathrm{I}$ dNTP, $200 \mathrm{nmol} / /$ nested primers: 5'AAAATGACTGAATATAAACTTGTGG-3 (sense), and 5'CTCTATTGTTGGATCATATTCGTC-3' (antisense), and 1 U Platinum-Taq (annealing temperature $58^{\circ} \mathrm{C}$ ). Amplification was performed using one standard and one biotinylated primer. DNA isolated from the colorectal cancer cell line ( $\mathrm{CaCo} 2)$ was used as positive control. In the negative controls, no DNA was added. The size and amount of the PCR products were checked by electrophoresis on $2 \%$ agarose gels. The sequencing reactions of the biotinylated products were performed using the autoload solid phase sequencing kit (Amersham Pharmacia, Uppsala, Sweden) with 
an extended Cy5-labeled primer. The biotinylated PCR products were captured on a sequencing comb coated with streptavidin, and the nonbiotinylated strand was removed by alkaline denaturation. The remaining strand served as a template for dideoxy sequencing reactions using a Cy5 labeled primer (5-Cy5-CTCTATTGTTGGATCATATTCGTCCAC-3') and T7 polymerase. The PCR products were separated on the ALF express DNA Analysis System and analyzed by ALFwin software (Amersham Pharmacia Biotech).

\section{B-raf mutation detection.}

The presence of a mutation in B-raf (V600E) was determined by semi-nested restriction fragment length polymorphism analysis (RFLP) based on the protocol as described by Davies et al. [20] resulting in a 255 bp product. Primer sequences 5'-TCATAATGCTTGCTCTGATAGGA (flank forward, nested forward), 5'-ATGACTTTCTAGTAACTCAGCAGC (flank reverse), GGCCAAAAATTTAATCAGTGGA (nested reverse). The PCR mix ( $50 \mu \mathrm{l}$ final volume) contained $150 \mathrm{ng}$ of genomic DNA, $0.5 \mu \mathrm{l}(10 \mathrm{pmol})$ of each primer, $0.5 \mu \mathrm{l} 25 \mathrm{mM}$ dNTP's, $0.2 \mu \mathrm{l}(1 \mathrm{U})$ of Platinum Taq DNA polymerase (Invitrogen, Breda, The Netherlands) and $1.5 \mathrm{mM} \mathrm{MgCl}_{2}$. The mix for the nested PCR ( $50 \mu \mathrm{l}$ final volume) consisted of $5 \mu \mathrm{l}$ of 1:100 diluted flank PCR product, $0.5 \mu \mathrm{l}(10 \mathrm{pmol})$ of each primer, $0.5 \mu \mathrm{l}(25 \mathrm{mM}) \mathrm{dNTPs}, 0.2 \mu \mathrm{l}(1 \mathrm{U})$ of Platinum Taq DNA polymerase (Invitrogen, Breda, The Netherlands) and $1.5 \mathrm{mM} \mathrm{MgCl}_{2}$.

The wild type allele contains a TspR I (New England Biolabs, Beverly MA, USA) restriction site. Thus, upon TspR I digestion, PCR products derived from a wild type allele generate 2 fragments ( 124 and 109 bp both with a 9 base single stranded overhang) and PCR products derived from the B-raf (V600E) mutated allele generate a single fragment of $224 \mathrm{bp}$. Digestion was performed with $15 \mu \mathrm{l} P C R$ product for three hours at $65^{\circ} \mathrm{C}$ according to the manufacturers instructions. Subsequently, $5 \mu$ l sample buffer $(98 \%$ 
formamid $v / v, 0.025 \%$ w/v bromophenol blue, $0.025 \%$ w/v xylene cyanol FF) was added to the digestion mixture, which was heated to $95^{\circ} \mathrm{C}$ for three minutes and placed on ice directly afterwards. The digested PCR products were separated on a nondenaturing $6 \%$ polyacrylamide gel, and visualized by UV illumination after staining with ethidium bromide. Colorectal cancer cell lines $\mathrm{CaCo} 2$ and $\mathrm{HT} 29$ were used as negative and positive controls respectively.

Methylation analysis of RASSF1A \& cell culture

DNA methylation in the CpG island of RASSF1A was determined as described previously [29].

Demethylation of ECC1 and RL95.2 endometrial carcinoma cells with 200 nM 5-aza-2'deoxycytidine (DAC), resulted in the demethylation of the RASSF1A promoter and concordantly in the reexpression of RASSF1 mRNA. Endometrial carcinoma cell lines (ECC1 and RL 95.2) were cultured for 3 days in the presence of 200 nM 5-aza-2'deoxycytidine. RNA was isolated and RT-PCR was performed with the RSF-4 and RSF-3 primers as described by Lee M-G et al. [30]. The colorectal cancer cell line SW 480 was used as a positive control for RASSF1A, GAPDH was used as internal control. Subsequently, DNA isolated from both untreated (control) and treated endometrial carcinoma cell lines were subjected to bisulphite treatment and MSP for the detection of RASSF1A gene promoter methylation.

\section{Data analysis}

The SPSS software program (11.5) was used for statistical analysis. Median values were calculated for the patient's age and follow-up time. To test whether the differences in both patient groups were significant, T-test for paired analysis was performed for continuous variables (age, follow-up). Mc Nemar's test for paired analysis was performed for dichotomous variables 
(K-ras and B-raf mutations, RASSF1A methylation, tumor differentiation, and tumor invasion). T-test was performed for the comparison of the patient's age at diagnosis for RASSF1A methylated and unmethylated cases, and $K$ ras mutated and non-mutated cases. Odds Ratios were calculated for the presence of K-ras mutations in patients with compared to patients without recurrence, and in premenopausal compared to postmenopausal endometrial carcinomas. To determine the statistical significance, $95 \%$ confidence intervals $(\mathrm{Cl})$ were calculated. All tests of statistical significance were two-sided, and a p-value of 0.05 was considered significant. 


\section{Results}

\section{K-ras mutations}

K-ras mutations were detected in 15 out of $85(18 \%)$ endometrial carcinomas (Table 1). In three cases K-ras mutation analysis could repeatedly not be performed, most probably due to poor DNA quality. K-ras mutations were detected in five patients with recurrence and in ten control patients. This frequency difference was not statistically significant (Odds Ratio: 0.42 ; $95 \% \mathrm{Cl} ; 0.13-1.36$ ). In premenopausal endometrial carcinomas, K-ras mutations were defected in four out of ten patients $(40 \%)$. Although the presence of K-ras mutations in premenopausal endometrial carcinomas was much higher compared to postmenopausal endometrial carcinomas: $40 \% \mathrm{vs}$. $18 \%$, the difference was not statistically significant. (OR: $3.1 ; 95 \% \mathrm{Cl} ; 0.8$ 12.4). In endometrial carcinoma cell lines, cyclic, hyperplastic and atrophic endometrial tissue no K-ras mutations were observed.

Table 1. Prevalence of K-ras and B-raf mutations and RASSF1A gene promoter methylation in benign and malignant endometrial samples

\begin{tabular}{|c|c|c|c|c|}
\hline & \multirow{2}{*}{$\begin{array}{c}\text { K-ras } \\
\text { mutations } \\
+(\%)\end{array}$} & \multirow{2}{*}{$\begin{array}{c}\begin{array}{c}\text { B-raf } \\
\text { mutations }\end{array} \\
+(\%)\end{array}$} & \multicolumn{2}{|c|}{ RASSFIA methylation } \\
\hline & & & $U(\%)$ & $M(\%)$ \\
\hline $\begin{array}{l}\text { Postmenopausal endometrial } \\
\text { carcinomas }\end{array}$ & $15 / 85(18 \%)$ & $0 / 85(0 \%)$ & $13 / 85(15 \%)$ & $73 / 85(86 \%)$ \\
\hline with recurrent disease & $5 / 43(12 \%)$ & $0 / 42(0 \%)$ & $9 / 43(21 \%)$ & $34.43(79 \%)$ \\
\hline without recurrence & $10 / 42(24 \%)$ & $0 / 43(0 \%)$ & $4 / 42(10 \%)$ & $38 / 42(90 \%)$ \\
\hline $\begin{array}{l}\text { Premenopausal endometrial } \\
\text { carcinomas }\end{array}$ & $4 / 10(40 \%)$ & $0 / 10(0 \%)$ & $3 / 10(30 \%)$ & $7 / 10(70 \%)$ \\
\hline \multicolumn{5}{|l|}{ Endometrial tissue } \\
\hline Cyclic endometrium & $0 / 14(0 \%)$ & $0 / 14(0 \%)$ & $11 / 14(79 \%)$ & $3 / 14(21 \%)$ \\
\hline Atrophic endometrium & $0 / 13(0 \%)$ & $0 / 13(0 \%)$ & $8 / 13(62 \%)$ & $5 / 13(38 \%)$ \\
\hline Hyperplastic endometrium & $0 / 8(0 \%)$ & $0 / 8(0 \%)$ & $4 / 8(50 \%)$ & $4 / 8(50 \%)$ \\
\hline
\end{tabular}




\section{B-raf mutations}

Neither the 86 postmenopausal endometrial cancer patients nor cyclic-, hyperplastic-, and atrophic endometrial tissue, endometrial carcinoma cell lines, and premenopausal endometrial carcinomas, demonstrated a base substitution at nucleotide position 1796 in B-raf. In three cases RFLP analysis was repeatedly not successful, i.e. two patients with recurrence and one sample of atrophic endometrial tissue, most likely due to poor DNA quality. Representative examples of the restriction fragment length polymorphism (RFLP) are shown in Figure 1.

\section{Figure 1}

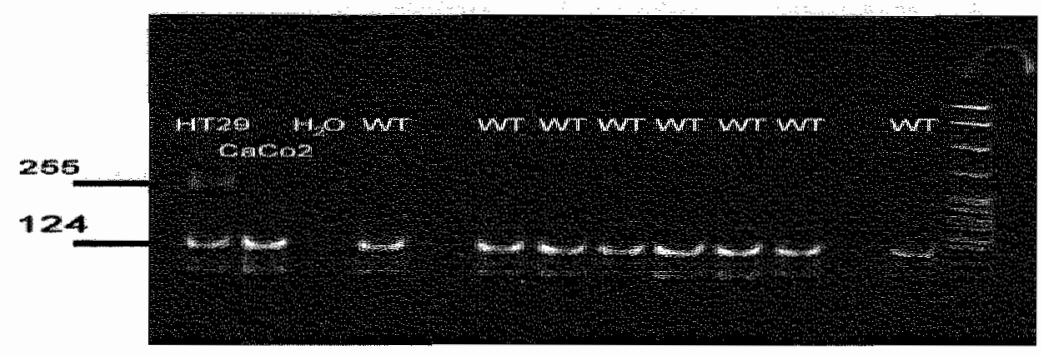

Representative results of the restriction fragment length polymorphism for the detection of B-raf (V600E) mutations of eight samples. Colorectal cancer cell lines CaCo2 and HT29 were used as negalive and positive controls respectively.

\section{Methylation of RASSFTA promoter}

Overall, RASSF1A gene promoter methylation was present in $85 \%$ (72 of 85 ) of the endometrial carcinomas (Table 1). In three cases, MSP analysis was repeatedly not successful, probably due to poor DNA quality. Representative results are shown in Figure 2. Patients with recurrence demonstrated RASSF1A gene promoter methylation in $79 \%$, compared to $90 \%$ in patients without recurrence, which was not significantly different (Table l). Premenopausal endometrial carcinomas showed an equally high percentage of RASSF1A methylation $70 \%$ (7/10). There was no difference between the age at diagnosis of patients with RASSF1A gene promoter methylation (69.7 
years) compared to those without RASSF1A gene promoter methylation (70.6 years). Since methylation of RASSF1A was so common in endometrial cancers, we examined this in non-malignant endometrial tissue. RASSF1A gene promoter methylation was present in $21 \%(3 / 14)$ of cyclic endometrial tissue and in $38 \%(5 / 13)$ of postmenopausal atrophic endometrial tissue. Hyperplastic endometrial tissue demonstrated RASSF1A promoter methylation in $50 \%(4 / 8)$ of the samples (Table I). All three endometrial carcinoma cell lines were fully methylated for RASSF1A. The presence of RASSF1A gene promoter methylation was not (inversely) correlated with the presence of $K$-ras mutations.

\section{Figure 2}

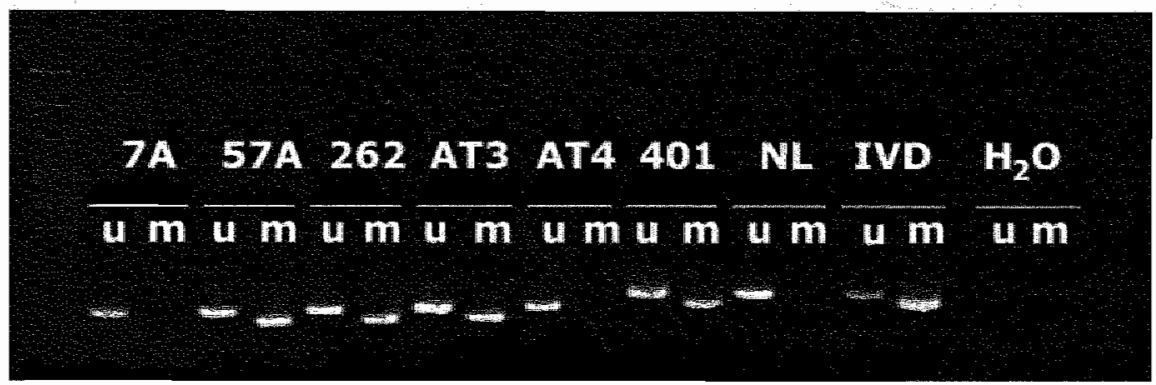

Representative examples of RASSFIA MSP reactions of six endometrial carcinoma patients. The presence of a visible PCR product in those lanes marked $U$ indicates the presence of unmethylated alleles. The presence of PCR product in the M marked lanes indicates the presence of methylated alleles Normal lymphocytes (NL) and in vitro methylaled DNNA (IVD) were used as negative and positive controls. 


\section{Figure 3}

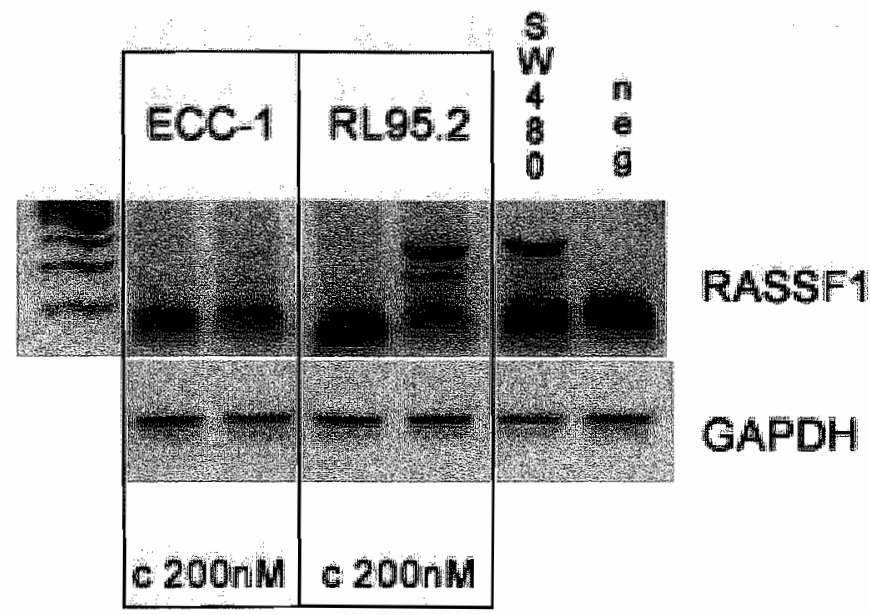

A) Expression of RASSFTA in untreated endometrial carcinoma cell tines (control) and reexpression of RASSF1A by treatment with 5-Aza-CdR in two endometrial carcinoma cell lines (ECC1, RL95.2). The cell ines were treated for 3 days with 200nM of 5-Aza-CdR (DAC). RASSF1A was analysed by RT-PCR. Expression of GAPD was cietermined as a control for RNA integrity.

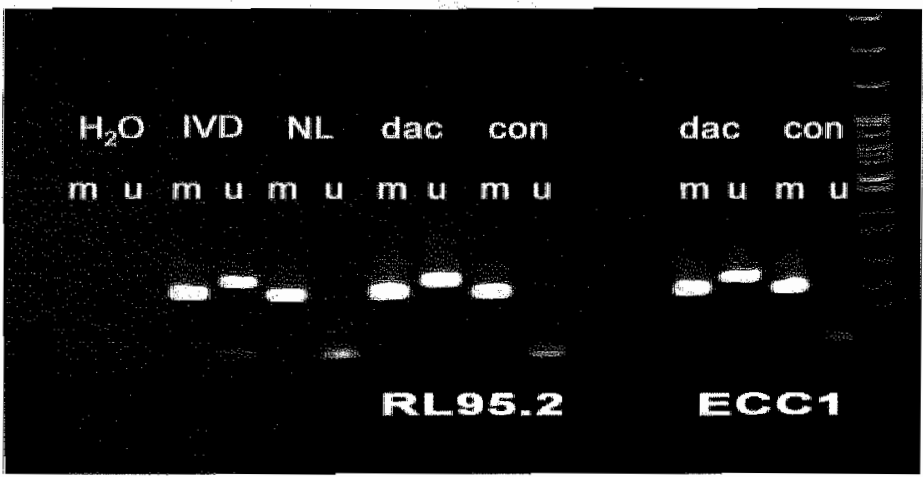

B) MSP reactions of the untreated (control) endometrial carcinoma cell lines (ECC1, RL95.2) and of the cell lines treated with $200 \mathrm{nM} 5$-Aza-CdR (DAC). The presence of a visible PCR product in those lanes marked $U$ indicates the presence of unmethylated alleles. The presence of PCR product in the M marked lanes indicates the presence of methylated alleles. Normal lymphocytes (NL.) and in vitro methylated DNA (IVD) were used as negative and positive controis. The $\mathrm{H}_{2} \mathrm{O}$ conitrol was included in both the flanking PCR and in the MSP. 


\section{Discussion}

The Ras signaling pathway is an essential mediator in the signaling that occurs in cells undergoing epithelial-mesenchymal transition, which ultimately results in loss of cell-cell contacts, cytoskeletal remodeling and increased mobility, which are typical characteristics of metastasizing cells. In a case control study of patients who developed recurrent disease, we evaluated whether the presence of activating mutations of K-ras and $B-r a f$, or methylation of the RASSF1 promoter are associated with aggressive tumor behavior.

RASSF1A promoter methylation was demonstrated in $85 \%$ of the primary tumor tissue of patients with endometrial carcinoma, independent of future recurrent disease. Recently a short report was published of RASSF1A methylation in endometrial carcinoma, but analysis was performed in only 15 cases and the frequency of RASSF1A methylation was not mentioned [31]. It is unlikely that the high frequency of RASSF1A methylation is due to the nested PCR procedure, since the same detection was performed on paraffin embedded tissue of colorectal cancers in which a frequency of $20 \%$ RASSF1A methylation was found, which is in accordance with other reports [29,32]. RASSF1A methylated endometrial carcinoma cell lines were treated with the demethylating agent 5-aza-2'deoxycytidine (DAC) resulting in a cell population unmethylated for RASSF1A. That methylation of the investigated promoter region has functional relevance, was demonstrated by the fact that after demethylation, re-expression of RASSF1A did occur.

Gene promoter methylation is reported to be associated with aging. To exclude age as a confounder, a number of premenopausal endometrial carcinomas were tested as well. RASSF1A gene promoter methylation was also present in the majority of tested premenopausal endometrial carcinomas and the frequencies were similar, given this small number of premenopausal tumors examined. This could indicate that RASSF1A methylation is a phenomenon correlated with carcinogenesis, rather than with age [33], and it may be an early change in tumor development. This is 
strengthened by the fact that RASSF1A gene promoter methylation was found in $50 \%$ of cases with endometrial hyperplasia, which is considered a precancerous state. The fact that a low frequency of RASSF1A methylation was also found in atrophic and normal cyclic endometrium, indicates that RASSF1A methylation alone does not result in tumor development, but may increase susceptibility for malignant transformation. To confirm the present findings, analysis should be extended to a larger group of normal cyclic and atrophic endometrial tissues.

Loss of RASSF1A expression could shift the balance towards a growthpromoting effect as a result of the loss of the pro-apoptotic and cell cyclesuppressive actions, without the necessity of Ras-activating mutations $[27,34]$. Cells that have accumulated mutations may therefore not be adequately disposed of. In this regard it is interesting to note that RASSF1 is a binding partner for the E1A-regulated transcription factor $p 120(E 4 F)$, which also binds to p14ARF, Rb and p53 [35]. In the presence of this transcription factor, RASSF1 induces $\mathrm{G}_{1}$ cell cycle arrest and S-phase inhibition, which makes it a putative tumor suppressor. Therefore, loss of RASSF1 function may enhance the risk of developing cancer. K-ras mutations were detected in $18 \%$ of postmenopausal endometrial carcinomas, which corresponds with the frequency reported by others $[18,36,37]$, and were not correlated with tumor relapse. In various tumors the presence of $K$-ras mutations and RASSF1A methylation were found to be mutual exclusive $[29,38]$. This suggests that both epigenetic and genetic alterations of the ras pathway are involved in the formation or progression of different tumors. Our data do not support this mutual exclusivity in endometrial carcinoma.

Similarly, it has been described that mutations in B-raf and RASSF1A promoter methylation are mutually exclusive [39]. The fact that no B-raf mutations were detected in our patient groups is therefore probably due to the high prevalence of RASSF1A promoter methylation. In a recent study, Mutch et al. found one only $B$-raf mutation in 146 mismatch deficient 
endometrial tumors [40], which shows that $B$-raf mutations are not a frequent event in endometrial carcinomas. In this study only the most frequently mutated nucleotide position of B-raf [20] was evaluated. It is therefore possible that mutations outside exon 15 exist.

The presence of MSI in our series was observed in 15\% (13/87) of all patients [41] and was not related to RASSF1A methylation or K-ras mutations.

We describe for the first time a high prevalence of RASSF1A promoter methylation in endometrial carcinoma. The low frequency of K-ras mutations and the absence of B-raf mutations, suggest that RASSF1A methylation may play an independent role in the development of endometrial carcinoma. The high frequency of RASSF1A methylation in premenopausal carcinomas and increased frequency in hyperplasias suggests that this may be an early event in endometrial carcinogenesis. Whether RASSF1A methylation alone is sufficient for the predisposition of the endometrial epithelial cells to become malignant, remains to be elucidated.

\section{Acknowledgement}

We would like to thank Guido Roemen for his technical support for the B-raf mutation analysis, and Raymond Hessing for his help with cell culturing with 5-aza-2'deoxycytidine, and RT-PCR.

\section{References}

1. Rose, P.G. (1996) Endlometrial carcinoma. New England Journal of Medicine. 335 , 640-649.

2. Baker, V.V. (1996) The molecular biology of endometrial adenocarcinoma. Clinical Obstetrics and Gynecology, 39, 707-715.

3. Burton, d.L. and Wells, M. (1998) Recent advances in the histopathology and molecular pathology of carcinoma of the endometrium. Histopathology, 33, 297-303. 
4. Kounelis, S., Kapranos; N, Kouni, E., Coppola, D., Papadaki, H. and Jones, M.W. (2000) Immunohistochemical profile of endometrial adenocarcinoma: a study of 61 cases and review of the literature. Modern Pathology, 13 (4), 379-388.

5. Sherman, M.E. (2000) Theories of endometrial carcinogenesis: A multidisciplinary approach. Modern Pathology, 13, 295-308.

6. Longacre, T.A. Kempson, R.L. and Hendrickson, M.R. (1995) Obstetrical and Gynaecological Pathology. Churchill Livingstone, Edinburgh.

7. Hoffman ${ }_{n}$ K., Nekhlyudar, L. and Deligdisch, L. (1995) Endometrial carcinoma in elderly women. Gynecologic Oncology, 58, 198-201.

8. Creasman, W., Odicino, F., Maisonneuve, P. and Benedet, J. (1998) FIGO annual report on the results of treatment in gynaecological cancer. Carcinoma of the corpus uteri. Joumal of Epidemiology and Biostatistics, 3, 35-61.

9. Ng, T.Y., Perrin, L.C., Nicklin, J.L., Cheuk, R. and Crandon, A.J. (2000) Local recurrence in high-risk node-negative stage I endometrial carcinoma treated with postoperative vagina vault brachytherapy. Gynecologic Oncology, 79, 490-494.

10. Gotzmann, J., Mikula, M., Eger, A., Schulte-Hermann, R., Foisner, R., Beug, H. and Mikulits, W. (2004) Molecular aspects of epithelial cell plasticity: implications for local tumor invasion and metastasis. Mutation Research, 566, 9-20.

11. Edme, N., Downward, ل., Thiery, J.P. and Boyer, B. (2002) Ras induces NBT-Il epithelial cell scattering through the coordinate activities of Rac and MAPK pathways. Joumal of Cell Science, 115, 2591 601.

12. Barbacid, M. (1987) ras genes. Annual Review of Biochemistry, 56, 779-827.

13. Bos, J.L. "Fearon, E.R., Hamilton, S.R., Verlaan-de Vries, M., van Boom, J.H., van der Eb, A.J. and Vogelstein, B. (1987) Prevalence of ras gene mutations in human colorectal cancers. Nature, 327, 293-7.

14. Semczuk, A., Berbec, H., Kostuch, M., Cybulski, M., Wojcierowskì, J. and Baranowski, W. (1998) K-ras gene point mutations in human endometrial carcinomas: correlation with clinicopathological features and patients' outcome. Joumal of Cancer Research and Clinical Oncology, 124 (12), 695-700.

15. Ito, K., Watanabe, K., Nasim, S., Sasano, H. Sato, S., Yajima, A., Silverberg, S.G. and Garrett, $C_{2} T_{2}$ (1996) K-ras point mutation in endometrial carcinoma: effect on outcome is dependent on age of patient. Gynecologic Oncology, 63, 238-246.

16. Lax, S.F., Kendall, B., Tashiro, H., Slebos, R.J.C. and Ellenson, L.H. (2000) The frequency of $p 53$, K-ras mutations, and microsatellite instability differs in uterine endometroid and serous carcinoma. Cancer, 88, 814-824.

17. Mizuuchi, H., Nasrim, S., Kudo, R., Silverberg, S.G., Greenhouse, S. and Garret, C.T. (1992) Clinical implications of K-ras mutations in malignant epithelial tumors of the endometrium. Cancer Research, 52, 23777-2781. 
18. Esteller, M., Garcia, A. Martinex-Palones; J.M., Xercavins, J. and Reventos, J. (1997) The clinicopathological significance of $K$-ras point mutation and gene amplification $h$ endometrial cancer. European Journal of Cancer, 33 (10), 1572-1577.

19. Jones, M.W., Kounelis "S., Hsu, C., Papadaki, H., bakker, A., Swalsky. P.A. and Finkelstein, S.D. (1997) Prognostic value of $p 53$ and K-ras-2 topographic genotyping in endometrial carcinoma. International Jounal of Gynecological Pathology, 16. 354360.

20. Davies, H., Bignell, G.R., Cox, C., Stephens, P., Edkins, S., Clegg, S., Teague, J., Woffendin, H., Garnett, M.J., Bottomley, W., Davis, N., Dicks, E., Ewing. R., Floyd, Y., Gray, K., Hall, S., Hawes, R. Hughes, J., Kosmidou, V., Menzies, A., Mould, C., Parker. A., Stevens, C. Watt, S., Hooper, S., Wilson, R., Jayatilake, H., Gusterson, B.A., Cooper, C., Shipley, J., Hargrave, D., Pritchard-Jones, K., Mailland, N., Chenevix-Trench, G., Riggins, G.J., Bigner, D.D., Palmieri, G., Cossu, A., Flanagan, A., Nicholson, A., Ho, J.W., Leung, S.Y., Yuen, S.T., Weber, B.L., Seigler, H.F., Darrow, T.L., Patersan, H., Marais, R., Marshall, C.J., Wooster, R., Stratton, M.R. and Futreal, P.A. (2002) Mutations of the BRAF gene in human cancer. Nature, 417, 94954.

21. Rajagopalan, $H_{\text {, }}$ Bardelii, A., Lengauer, C., Kinzler, K.W., Vogelstein, B. and Velculescu, V.E. (2002) Tumorigenesis: RAF/RAS oncogenes and mismatch-repair status. Nature, 418, 934.

22. Domingo, E., Espin, E., Armengol, M., Oliveira, C., Pinto, M., Duval, A., Brennetot, C., Seruca, R. Hamelin, R., Yamamoto, H. and Schwartz, S.J. (2004) Activated BRAF targets proximal colon tumors with mismatch repair deficiency and MLH1 inactivation. Genes Chromosomes Cancer, 39, 138-42.

23. Dammann, R., Li, C., Yoon, J.-H., Chin, P.L., Bates, S. and Pfeiffer, G.P. (2000) Epigenetic inactivation of a RAS association family protein from the lung tumor suppressor locus 3p21.3. Nature Genetics, 25, 315-319.

24. Kok, K., Naylor, S.L. and Buys, C.H. (1997) Deletions of the short arm of chromosome 3 in solid tumors and the search for suppressor genes. Advances in Cancer Research, 71, 27-92.

25. Byum, D.-S., Lee, M.-G. Chae, K.-S., Ruy, B..G. and Chi, S.-G. (2001) Frequent epigentic inactivation of RASSF1A by aberrant promoter hypermethylation in human gastric adenocarcinoma. Cancer Research, 61, 7034-7038.

26. Vos, M.D. Ellis, C.A., Bell, A., Birrer, M.J, and Clark, G.J. (2000) Ras uses the novel lumor suppressor RASSF1 as an affector to mediate apoptosis. Journal of Biological Chemistry, 275, 35669-35672.

27. Shivakumar, L., Minna, J., Sakamaki, T., Pestell, R. and White, M.A. (2002) The RASSF1A tumor suppressor blocks cell cycle progression and inhibits cyclin D1 accumulation. Molecular Cell Biology, 22, 4309-18. 
28. Creasman. W.T. (1990) New gynecologic cancer staging. Obstetrics and Gynecology. $75,287-288$.

29. van Engeland, M., Roemen, G.M.J.M., Brink, M., Pachen, M.M.M., Weijenberg. M.P., de Bruine, A.P., Arends, J.-W., van den Brandt, P.A., Goej, A.F.P.M. and Herman, J.G. (2002) K-ras mutations and RASSF1A promoter methylation in colorectal cancer. Oncogene, 21, 3792-3795.

30. Lee, M.-G., Kim, H.-Y., Byun, D.-S., Lee, S.-J, Lee, C.-H., Kim il, J., Chang, S.-G. and Chi, S.-G. (2001) Frequent epigenetic inactivation of RASSF1A in human bladder carcinoma: Cancer Research, 61, 6688-6692.

31. Fiegl, $H_{\text {, }}$ Gattringer, C., Widschwendter, A., Schneitter, A., Ramoni, A., Sarlay, D., Gaugg, I, Goebel, G, Muller, H.M., Mueller-Holzner, E., Marth, C. and Widschwendter. M. (2004) Methylated DNA collected by tampons--a new tool to detect endometrial cancer. Cancer Epidemiology Biomarkers \& Prevention, 13, 882-8.

32. Wagner, K.J., Cooper, W.N., Grundy, R.G., Caldwell, G., Jones, C., Wadey, R.B., Morton, D., Schofield, P.N., Reik, W., Latif, F. and Maher, E.R. (2002) Frequent RASSF1A tumour suppressor gene promoter methylation in Wilms' tumour and colorectal cancer. Oncogene, 21, 7277-82.

33. Ahuja, N., Li, Q., Mohan, A.L., Baylin, S.B. and Issa, J.-P. (1998) Aging and DNA methylation in colorectal mucosa and cancer. Cancer Research, 58, 5489-5494.

34. Dammann, R., Yang, G. and Pfeiffer, G.P. (2001) Hypermethylation of the CpG island of ras association domain family 1 A(RASSF1A), a putative tumor suppressor gene from the $3 p 21.3$ locus, occurs in a large percentage of human breast cancers. Cancer Research, 61، 3105-3109.

35. Fenton, S.L., Dallol, A., Agathanggelou, A., Hesson, L., Ahmed-Choudhury, J., Baksh, S., Sardet, C., Dammann, R., Minna, J.D., Downward, J., Maher, E.R. and Latif, IF. (2004) Identification of the E1A-regulated transcription factor $\mathrm{p} 120 \mathrm{E} 4 \mathrm{~F}$ as an interacting partner of the RASSF1A candidate tumor suppressor gene. Cancer Research 64 , 102-7.

36. Enomoto, T., Fujita, M., Inove, M., Nomura, T. and Schroyer, K.R. (1995) Alteration of the p53 tumor suppressor gene and activation of $\mathrm{C}-\mathrm{K}$-ras-2 protooncogene in endometrial carcinoma from Colorado. American Joumal of Clinical Pathology, 103, 224-230.

37. Mutter, G.L., Wada, H. Faquin, W.C. and Enomoto, T. (1999) K-ras mutations appear in the premalignant phase of both micosatellite stable and unstable endometrial carcinogenesis. Molecular Pathology, 52, 257-262.

38. Dammann, R., Schagdarsurengin, U., Liu, L., Otto, N., Gimm, O., Dralle, H., Boehm, B.O., Pfeifer, G.P. and Hoang-Vu, C. (2003) Frequent RASSF1A promoter hypermethylation and $\mathrm{K}$-ras mutations in pancreatic carcinoma. Oncogene, 22, 380612. 
39. Xing, M., Cohen "Y. Mambo, E., Tallini, G. Udelsman, R. Ladenson, P.W. and Sidransky, D. (2004) Early occurrence of RASSF 1 A hypermethylation and its mutual exclusion with BRAF mutation in thyroid tumorigenesis. Cancer Research, 64, 1664-8.

40. Mutch, D.G. Powell, M.A. Mallon, M.A. and Goodfellow, P.J. (2004) RAS/RAF mutation and defective DNA mismatch repair in endometrial cancers. American Joumal of Obstetrics and Gynecology, 190, 935-42.

41. Pijnenborg, J.M. Dam-de Veen, G.C., de Haan, J., van Engeland, M. and Groothulis. P.G. (2004) Defective mismatch repair and the development of recurrent endometrial carcinoma. Gynecologic Oncology, 94, 550-9. 


\title{
Chapter 7
}

\section{TP53 overexpression in recurrent endometrial}

\author{
carcinoma
}

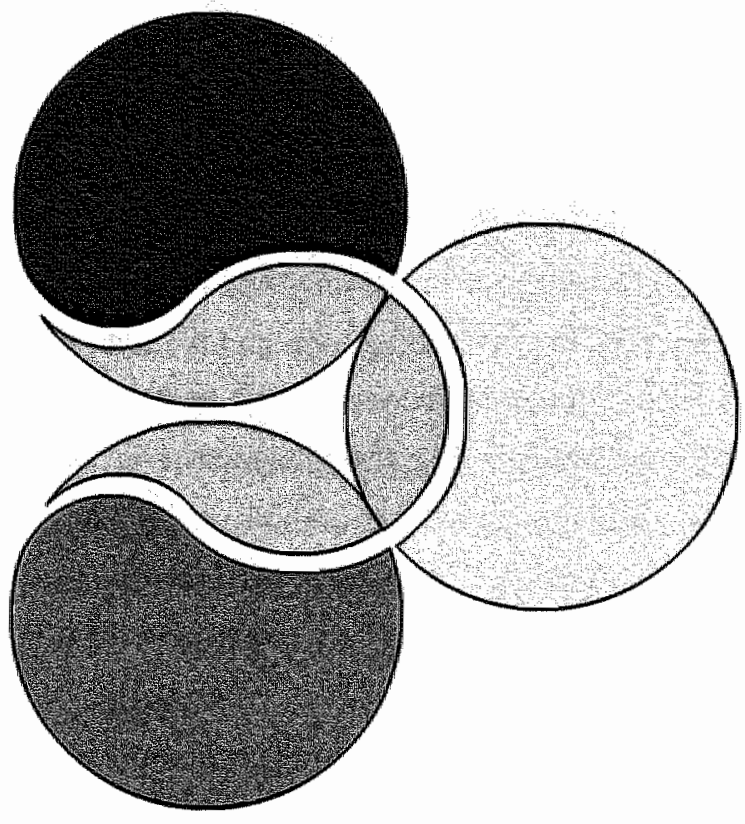

Johanna M.A. Pijnenborg, Leonie van de Broek, Geeske C. Dam - de Veen, Guido M.J.M. Roemen, Jelte de Haan, Manon van Engeland, Jan-Willem Voncken, Patrick G. Groothuis

(Gynecol Oncol accepted for publication sept 2005) 


\section{Abstract}

Objective: To study alterations within the p53 pathway in relation to the development of recurrent stage I endometrioid endometrial carcinoma. Methods: Paraffin-embedded tumor tissue of both primary and recurrent tumors from 44 patients with and 44 without recurrence was used for immunohistochemical analysis of TP53, hMdm2, P21 Waf/cip1 , and M30. DNA was extracted and mutation analysis of $p 53$ (exon $5-8,11)$ was performed by direct sequencing.

Results: TP53 overexpression was significantly associated with recurrent disease: Odds Ratio 3.8 (95\% Cl: 1.5-9.8). Overexpression of TP53 was associated with lower staining indices (SI:0-9) of both hMdm2 and P21 in tumors of patients with recurrence, compared to controls: $2.0 \pm 0.4$ vs. $4.0 \pm 0.8$ and $1.9 \pm 0.8$ vs. $3.6 \pm 0.8$, respectively. Eight $p 53$ missense mutations were identified in six patients with recurrence, and two controls. One nonsense mutation was found in a patient with recurrence and one deletion in a control patient. Only a minority of TP53 overexpression cases could be explained by the presence of these $p 53$ mutations.

Conclusion: TP53 overexpression was significantly predictive for recurrent endometrial carcinoma, and mostly not correlated with p53 mutations. Concomitant low hMdm2 and P21 Waf1/Cip1 expression in tumors with overexpressed TP53 suggest a dysfunctional TP53-P21 Waftcipt pathway. 


\section{Introduction}

One of the most frequently mutated cell cycle check-points in human cancer involves TP53 and P21Waf1/Cip1. The p53 gene encodes a $53 \mathrm{kD}$ nuclear phosphoprotein, which in response to cellular stress is stabilized by posttranslational modification and induces proliferative arrest or apoptosis. Functionally active TP53 will then induce transcription of P21Waf1/Cip 1 and hMdm2 [1]. Upregulation of hMdm2 negatively feeds back onto TP53, in that hMdm2-mediated Ubiquitylation of TP53 on C-terminal Lys residues (exon 11) signal its proteosomal degradation. Through this mechanism hMdm2 inhibits the TP53-dependent transcription of P21Waf1/Cip 1 [2,3]. P21 Waf1/Cip1 is an important transcriptional target of wild type TP53. P21Waf1/Cip1 mediates cell cycle arrest by blocking cyclin/CDK-dependent phosphorylation of $\mathrm{pRB}$ (retinoblastoma protein). $\mathrm{pRB}$ represses $\mathrm{E} 2 \mathrm{~F}$ dependent gene-activation necessary for G1/S transition. The pRB/E2F constitutes another major target of mutational inactivation in many human cancers $[4,5]$

Mutations in P53 often introduce stop codons which result in a truncated, non-functional protein. The Truncations often involve the C-terminus; as a consequence hMdm2 can not bind TP53 and non-functional TP53 accumulates in the cell. Alternatively, missense mutations affect amino acids involved in post-translational modification of TP53 which in turn may also affect the stability of the protein [6].

TP53 overexpression in endometrial cancer is associated with high grade tumors, lymph node metastasis and myometrial invasion [7-12]. In endometrial carcinoma TP53 overexpression is related to high-risk clinicopathological features $[13,14]$ and is in addition an independent prognostic factor $[9,10,15]$. In serous papillary carcinomas, TP53 overexpression is frequently present and associated with truncating $p 53$ mutations [16]. In the endometrioid type carcinoma TP53 overexpression is also frequently observed, however, p53 mutations are rare and if present, not related to TP53 overexpression $[7,17]$. 
The relation between TP53 overexpression and/or mutation in endometrial neoplasia and its possible relation to recurrent disease are not known. The objectives of the present study were to examine whether TP53 overexpression in stage I endometrioild endometrial carcinomas is predictive for recurrence, whether TP53 overexpression in these tumors is associated with p53 mutations: Ultimately, this is expected to contribute to improved understanding of the molecular basis of pathogenic TP53-check point functioning. A case-control study was designed of patients who developed recurrent endometrial carcinoma within three years. We quantified TP53 expression by immunohistochemical methods, and performed $p 53$ mutation analysis of exons 5-8 and 11. Functionally active TP53 is a known transcriptional activator of $\mathrm{P} 21^{\mathrm{Cip} / \mathrm{Waf} 1}$ and $\mathrm{hMdm} 2$ [1]. To this end, concomitant immunohistochemical analysis of these commonly used markers was used to determine TP53 functionality. In addition, since induction of apoptosis is one of the important functions of TP53, we examined M30 expression, an early marker for apoptosis-related caspase activation, as a measure for the ability of tumor cells to respond to apoptotic signals [18]. 


\section{Material and Methods}

Patients and tissue specimens

Patients with recurrent endometrioid endometrial carcinoma were selected from the Dutch national pathology database (PALGA). Forty-four patients diagnosed with stage I disease, according to the FIGO criteria [19], and who presented with recurrent disease within three years were included. Patients underwent initially hysterectomy and bilateral salpingo-oophorectomy. Radiotherapy was applied when myometrial invasion appeared to be $>50 \%$, and/or when the tumor was poorly differentiated. Patients presented with local recurrence at the vaginal vault $(n=35)$, pelvic wall $(n=1)$, distant metastases $(n=5)$ or local recurrence and distant metastases $(n=3)$. Histopathology of primary and recurrent tumors was independently reassessed by pathologists and an endometrioid type adenocarcinoma was confirmed in all cases. Where available, recurrent tumor tissue was used for analysis as well. Control patients being free of recurrence for at least three years after diagnosis and treatment, were selected and matched for tumor stage, tumor differentiation, age at diagnosis and therapy. The study was approved by the Medical Ethical Committee of the University Hospital of Maastricht (MEC 02-009.5).

\section{DNA isolation}

DNA was isolated from five consecutive $20 \mu \mathrm{m}$ sections of paraffin embedded tissue specimens. The tumor area was identified by a pathologist on haematoxylin and eosin stained (HE) sections. Tumor tissue was manually dissected. Genomic DNA was extracted using a proteinase K (Qiagen, Hilden, Germany) digestion followed by DNA isolation using the Puregene DNA Isolation Kit (Gentra Systems, Minneapolis, Minnesota, USA). 
Immunohistochemistry

Sections ( $5 \mu \mathrm{m}$ ) of paraffin-embedded tissues were prepared on starfrost adhesive slides (Klinipath, Duiven, The Netherlands). For TP53 immunostaining a commercial staining kit was used (CSA, Dako, Copenhagen, Denmark) with a monoclonal antibody directed to TP53 (Do-7, Dako, Copenhagen, Denmark (1:2000)). For P21, hMdm2 and M30 staining, sections were dewaxed and rehydrated prior to blocking endogenous peroxidase activity with $0.3 \%$ hydrogen peroxide/methanol (20 minutes), and antigen retrieval (10 $\mathrm{mM}$ Tris-EDTA buffer, $\mathrm{pH}$ 9.0; microwave treatment: $750 \mathrm{~W}, 20$ minutes). Antibody incubation was performed at room temperature for one hour with monoclonal antibodies directed to hMdm2 (1:50: Ab-1, clone IF2; EMD Biosciences, Breda, San Diego, USA), P21 War1/cip1 (1:200: P21 WAF1 Ab-3, clone DCS-60.2; Neomarkers, Duiven, The Netherlands), and M30 (1:200, kindly provided by B.Schutte, Department of Cell Biology, University of Maastricht, The Netherlands). Antibody binding was visualized with the avidin-biotin complex immunoperoxidase technique (ChemMate detection kit; DAKO, Copenhagen, Denmark), and 3,3'-diaminobenzidine as substrate. Sections were counterstained with Haematoxylin. Negative control slides were incubated with mouse IgG antibody of the same isotype and concentration.

\section{Interpretation of immunostaining}

Percentage of stained tumor cells (0\%, 0-10\%, 10-50\%, >50\%), and intensity of staining (absent, weak, moderate or strong) were determined $(0,1,2$, or 3 for each variable) for the entire tumor area within the section, and a staining index ( $\mathrm{SI}$, ranging 0-9) was calculated by multiplying categorized parameters [20]. Interpretation of immunostaining was performed in a blinded fashion and independently by two observers ( $P G, J P)$. One observer scored the sections ance, and the other observer scored the sections twice, blinded for the tissue ID's. The correlation coefficients calculated for the two 
observations made by the same observer, and for two observations made by two observers were respectively: 0.95 and 0.85 for TP53,0.97 and 0.91 for $\mathrm{P} 21^{\text {Waf1/ip } 1}$, and 0.91 and 0.78 for $\mathrm{hMdm} 2$ expression. The mean of three observations was used for analysis. Overexpression of TP53 was defined as a $S \mid>5.0$. The apoptotic index was defined as the number of M30 positive cells in ten randomly selected high power fields ( $x 400)$.

\section{Mutation analysis of p53exons 5-8 and 11}

For sequence analysis amplicons were generated by semi-nested PCR's. First, a multiplex PCR was performed using flanking PCR primers, generating products of $268,240,261,231$ and $194 \mathrm{bp}$ (respectively covering exons $5,6,7,8$ and 11). This mix was used to generate the individual amplicons for sequence analysis (257, 164, 230, 212 and $145 \mathrm{bp}$ ). For the p53 multiplex PCR flanking, genomic DNA (250 $\mathrm{ng}$ ) was added to $50 \mathrm{mM}$ $\mathrm{KCl}, 10 \mathrm{mM}$ Tris- $\mathrm{HCl}(\mathrm{pH} 8.3$ ), $0.2 \mathrm{mM} \mathrm{MgCl} 2,250 \mu \mathrm{M}$ dNTP (Pharmacia, Uppsala, Sweden), $400 \mathrm{nM}$ flank primers of exon 5,6,7 and 8 (Table 1), and $1 \mathrm{U}$ Platinum Taq (Invitrogen, Breda, The Netherlands) to a final volume of $50 \mu \mathrm{l}$. Multiplex PCR conditions were: predenaturation $94^{\circ} \mathrm{C}(3 \mathrm{~min}) ; 35$ cycles of denaturation $94^{\circ} \mathrm{C}, 40$ seconds annealing $56^{\circ} \mathrm{C}, 1 \mathrm{~min}$; elongation $72^{\circ} \mathrm{C}, 1 \mathrm{~min}$; followed by post-elongation $72^{\circ} \mathrm{C}, 10 \mathrm{~min}$. The subsequent nested PCR was performed in a final volume of $50 \mu \mathrm{l}$, containing $5 \mu \mathrm{l}$ of a 1:100 dilution of the flank product, $50 \mathrm{mM} \mathrm{KCl}, 10 \mathrm{mM}$ Tris- $\mathrm{HCl}(\mathrm{pH} 8.3)$, 0.15 to $0.20 \mathrm{mM} \mathrm{MgCl}_{2}, 250 \mu \mathrm{M}$ dNTP, $400 \mathrm{mM}$ nested primers from one of the four exons (Table 1), and $1 \cup$ Platinum Taq. PCR conditions are the same as the multiplex PCR except for the annealing temperature $\left(59^{\circ} \mathrm{C}\right.$ for exon 6 and $60^{\circ} \mathrm{C}$ for exon $5,7,8$ and 11) and number of cycles (30 cycles). Amplification of the $p 53$ fragments was performed using one unlabeled and one biotinylated primer. In each PCR, DNA isolated from the endometrial cancer cell line AN3CA served as positive control. In negative controls, no 
DNA was added. The length and concentration of the PCR products were checked by electrophoresis on $2 \%$ agarose gels.

The sequencing reactions of the biotinylated products were performed using the Autoload Solid Phase Sequencing Kit (Amersham Pharmacia, Uppsala, Sweden) with an extended Cy5-labeled primer. The biotinylated PCR products were captured on a sequencing comb coated with streptavidin, and the non-biotinylated strand was removed by alkaline denaturation. The remaining strand served as a template for dideoxy sequencing reactions using a Cy5 labeled primer (Table 1) and T7 polymerase and was analysed on the ALF express DNA Analysis System using ALFwin software (Amersham Pharmacia Biotech).

Table 1 Primer sequences $p 53$

\begin{tabular}{|c|c|c|c|c|}
\hline exon & Sequence primer $\left(5^{\prime}-3^{\prime \prime}\right)$ & unlabeled & $5^{*}$ biatinyllated & $\begin{array}{l}5^{\prime} \text { Cy5 } \\
\text { labeled }\end{array}$ \\
\hline \multirow[t]{3}{*}{5} & TGC CCT GAC TTT CAA CTG TG (CC) & S inside & & S cy5 \\
\hline & CTG TTC ACT TGT GCC CTG AC & Si outside & & \\
\hline & AGC CCT GTC GTC TCT CCA G & AS outside & AS inside biotin & \\
\hline \multirow[t]{3}{*}{6} & GGC CTC TGA TTC CTC ACT G (ATT) & S oul / inside & & S cy 5 \\
\hline & GAC CCC AGT TGC AAA CCAG & AS inside & AS inside biotin & \\
\hline & ATA AGC AGC AGG AGA AAG CC & AS outside & & \\
\hline \multirow[t]{3}{*}{7} & CAT CTT GGG CCT GTG TTA TC & S outside & $S$ inside biotin & \\
\hline & GGA AGA AAT CGG TAA GAG GTG (GAC) & AS inside & & AS cy5 \\
\hline & GAT GTG ATG AGA GGT GGA TGG & AS outside & & \\
\hline \multirow[t]{3}{*}{8} & GAT TTC CTT ACT GCC TCT TGC & S outside & S inside biotin & \\
\hline & TCC TCC ACC GCT TCT TGT C (CTG) & AS inside & & AS cy5 \\
\hline & CAT AAC TGC ACC CTT GGT CTC & AS outside & & \\
\hline \multirow[t]{3}{*}{11} & GTG GGG AAC AAG AAG TGG AG & AS outside & AS inside biotin & \\
\hline & CCC TTC AAA GCA TTG GTC AG & S oulside & & \\
\hline & TGT GAT GTC ATC TCT CCT CC (CTG) & Sinside & & S cy 5 \\
\hline
\end{tabular}


Data analysis

The SPSS software (version 11.5) was used for statistical analysis, and median values for age at time of diagnosis, and follow-up period were calculated. To test whether patients with and without recurrence were comparable with respect to age at diagnosis, tumor stage, tumor grade, and radiotherapy, a T-test for paired analysis (continuous variables), and a McNemar test (dichotomous variables) were performed. Odds Ratios were callculated for TP53 overexpression (S\| 5.0) and the risk of recurrence. A correction by Mantel-Haenszel was performed to correct for radiotherapy and tumor grade. A paired T-test was performed to compare expression of TP53, hMdm2, P21 and M30 in primary and recurrent tumor. A Pearson's correlation coefficient was determined to investigate correlations between different immunohistochemical expression. All statistical tests were twosided, and a p-value of 0.05 was considered significant. 


\section{Results}

\section{Patients}

All patients $(n=88)$ were postmenopausal at the time of diagnosis. Clinicopathological parameters of patients in both groups were well comparable, whereas the follow-up time is markedly longer in patients without recurrence (Table 2).

Table 2 Patient and tumor characteristics

$\begin{array}{ccc}\text { Control patients without } & \text { Patients with } & \text { P-value } \\ \text { recurrence }(n=44) & \text { recurrence }(n=44) & \end{array}$

Age at diagnosils (median and range)

Figo stage

la

118

IC

Tumor grade

Grade I

Grade III

Grade III

Post-operative radiotherapy

Time to recurrence

(median and range)

Follow-up

(median and range)

T-test for paired anallysis, "2McNemar test

Immunohistochemistry

Immunohistochemical results of all patients are summarized in Table 3. The immunohistochemical analysis could not be used in some cases, either due to the lack of material, the quality of the material or difficulties in interpretation. These samples are indicated in Table 3 as not determined (ND). This was true for TP53 expression ( $n=2), h M d m 2$ expression $(n=3)$, P21 expression ( $n=11)$, and M30 expression ( $n=21)$. TP53 expression in the primary tumors of patients with recurrence was significantly higher compared 
to the control group: $5.3 \pm 0.5$ and $3.3 \pm 0.4$ respectively (paired T-test, $p<0.05$ ) (Figure 1).

\section{Figure 1}

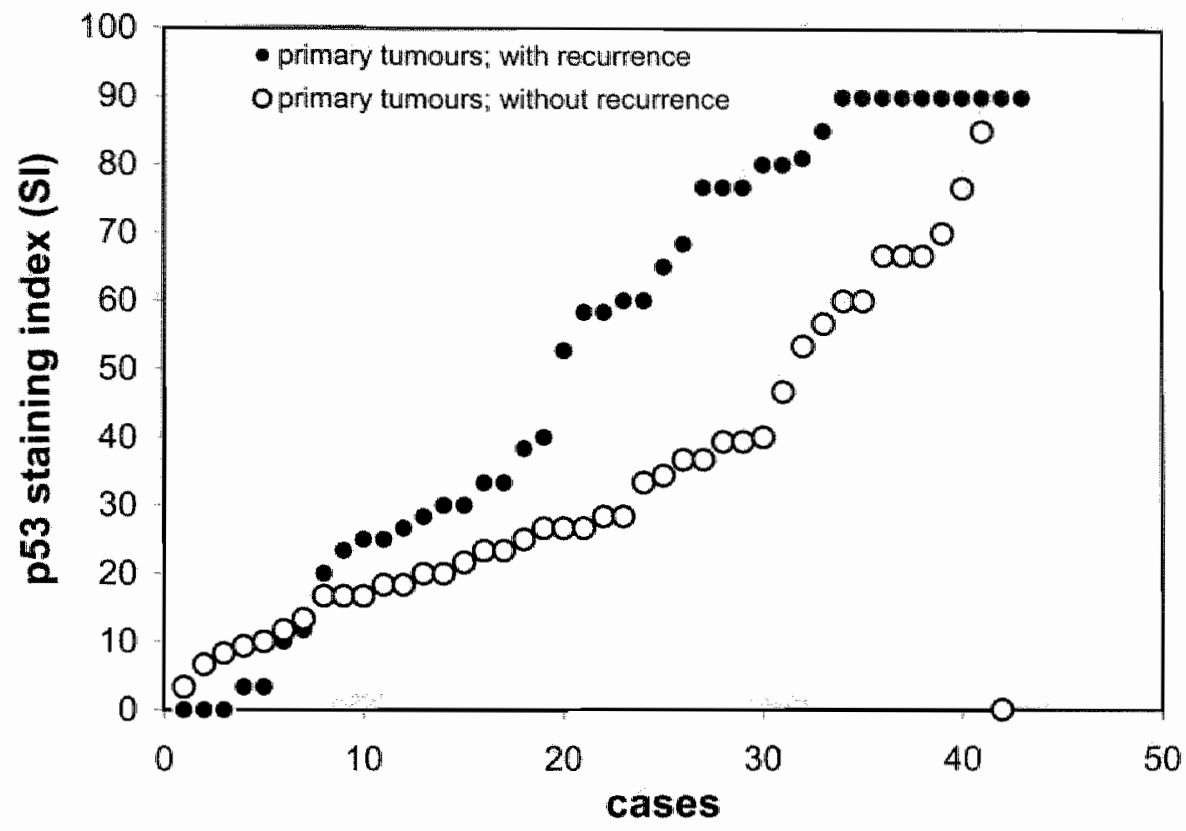

TP53 expression in primary tumors of patients with recurrence is significantly higher than in primary tumors of patients without recurrence. Primary tumors of patients with recurrent malignancies (closed circles) were randomly paired to primary tumors of patients without tumor recurrence (open circles). Elevation of TP53 was statistically significant (see text) in the recurrence group aver the control group (no recurrence). The graph displays the resultant separate staining indices of all cases analysed.

All pairs as used for paired analysis and Mc Nemar are shown in Table 3 Analysis of available recurrent tumors, indicated that TP53 expression was increased in recurrent tumors compared to primary tumors: $6.8 \pm 0.4$ and 5.0 \pm 0.5 respectively (paired $T$-test, $p<0.05$ ).

Expression of $\mathrm{hMdm} 2$ in primary tumors of patients with recurrence was significantly lower compared to controls: $1.9 \pm 0.3$ and $3.1 \pm 0.3$, respectively 
(paired T-test, $p<0.05$ ). However, in recurrent tumors hMdm2 expression was significantly higher compared to primary tumors: $1.9 \pm 0.3$ and $3.2 \pm 0.4$ respectively (paired $T$-test, $p<0.05$ ). A similar profile was observed for $\mathrm{P} 21^{\text {Wart/Cip1 }} . \mathrm{P} 21^{\text {Wart/Cipt }}$ expression in primary tumors of patients with recurrence was lower compared to controls. However, the difference did not reach statistical significance ( $1.8 \pm 0.4$ vs. $2.4 \pm 0.4$, respectively; paired $T$ test, $p=0,16$ ). Expression of $P 21^{\text {Warf/Cip } 1}$ in recurrent tumors was increased compared to primary tumors ( $2.9 \pm 0.4$ vs. $1.8 \pm 0.4$, respectively; paired $T$ test, $p<0.05$ ). Figure 2 demonstrates the mean staining indices of TP53, hMdm2 and P21 War1/Cip1 expression in primary tumors of both patients with and without recurrence and in malignant recurrences.

\section{Figure 2}

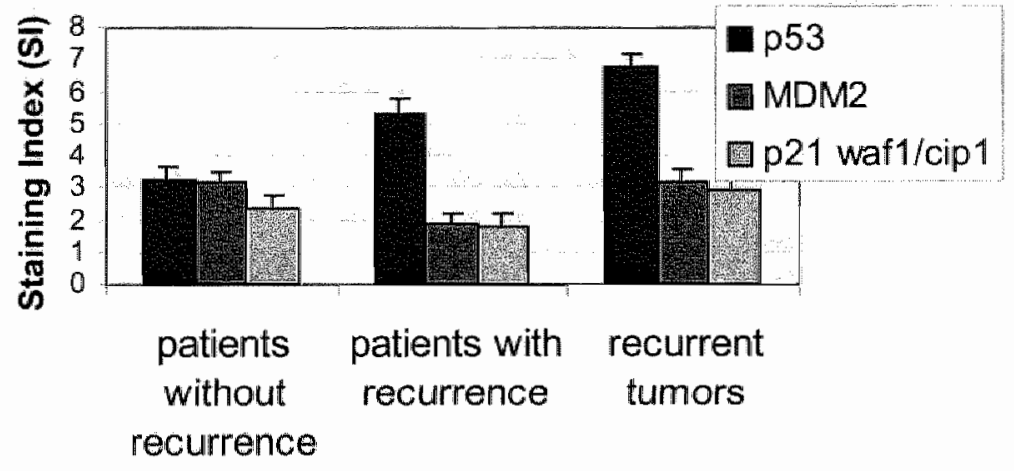

Mean staining indices (SI) of TP53, hMdm2 and P2 $1{ }^{\text {Wat icip1 }}$ expression in respectively primary tumors of controls „primary tumors of patients with recurrence and recurrent tumors.

Expression of $\mathrm{M} 30$, only performed in primary tumors, demonstrated an apoptotic index of $32.5( \pm 14.6)$ in primary tumors of patients with recurrence and $12.4( \pm 2.7)$ in controls (paired T-test, $p=0.19)$. TP53 expression was not correlated with M30 expression.

Overexpression of TP53 (S|>5.0) was significantly associated with the risk of recurrence: OR $3.8,95 \% \mathrm{Cl}$; 1.5-9.8 (Mantel Haenszel OR, corrected for 
radiotherapy and tumor grade). A classification of data towards the presence or absence of TP53 overexpression is demonstrated in table 4. It is shown that in primary tumors of patients with recurrence and TP53 overexpression, expression of both hMdm2 and P21 Waf1/Cipt is lower compared to tumors of controls with TP53 overexpression (Fig. 3a, page 210). In those tumors without TP53 overexpression this difference could not be observed (Fig. 3b, page 210). Moreover, an inverse correlation was observed in primary tumors with TP53 overexpression, between TP53 expression and hMdm2, and P21 Waf1/Cip1 (Pearson's correlation coefficient, -0.511 and -0.539 respectively, $p<0.05)$.

Table 4 Immunohistochemical data catagorized towards TP53 overexpression and recurrence

\begin{tabular}{|c|c|c|}
\hline & \multicolumn{2}{|c|}{ Primary tumors } \\
\hline & Control patients & Patients with recurrence \\
\hline $\begin{array}{l}\text { TP53 overexpression } \\
(S 1>5.0)\end{array}$ & $23 \%(10 / 43)$ & $56 \%(24 / 43)$ \\
\hline P53 mutations & $20 \%(2 / 10)$ & $13 \%(3 / 24)$ \\
\hline hMdm2 mean SI ( \pm SE) & $4.0( \pm 0.8)^{*}$ & $2.0( \pm 0.4)^{\pi}$ \\
\hline P21 mean SI ( \pm SE) & $3.6( \pm 0.8)$ & $1.9( \pm 0.5)$ \\
\hline M30 mean $( \pm S E)$ & $20.2( \pm 7.7)$ & $27.0( \pm 8.6)$ \\
\hline $\begin{array}{l}\text { Normal TP53 expression } \\
(\mathrm{S} \mid \leq 5.0)\end{array}$ & $77 \% \%(33 / 43)$ & $44 \%(19 / 43)$ \\
\hline P53 mutations & $0 \%$ & $11 \%(2 / 19)$ \\
\hline hMdm2 mean SI ( \pm SE) & $2.7( \pm 0.3)$ & $1.9( \pm 0.4)$ \\
\hline $\mathrm{P} 2 \|$ mean $\mathrm{SI}$ ( $\pm \mathrm{SE}$ ) & $2.0( \pm 0.3)$ & $1.9( \pm 0.5)$ \\
\hline M30 mean $( \pm S E)$ & $20.2( \pm 7.7)$ & $27.0( \pm 8.6)$ \\
\hline
\end{tabular}

${ }^{*}$ T-test, $p<0.05$ 


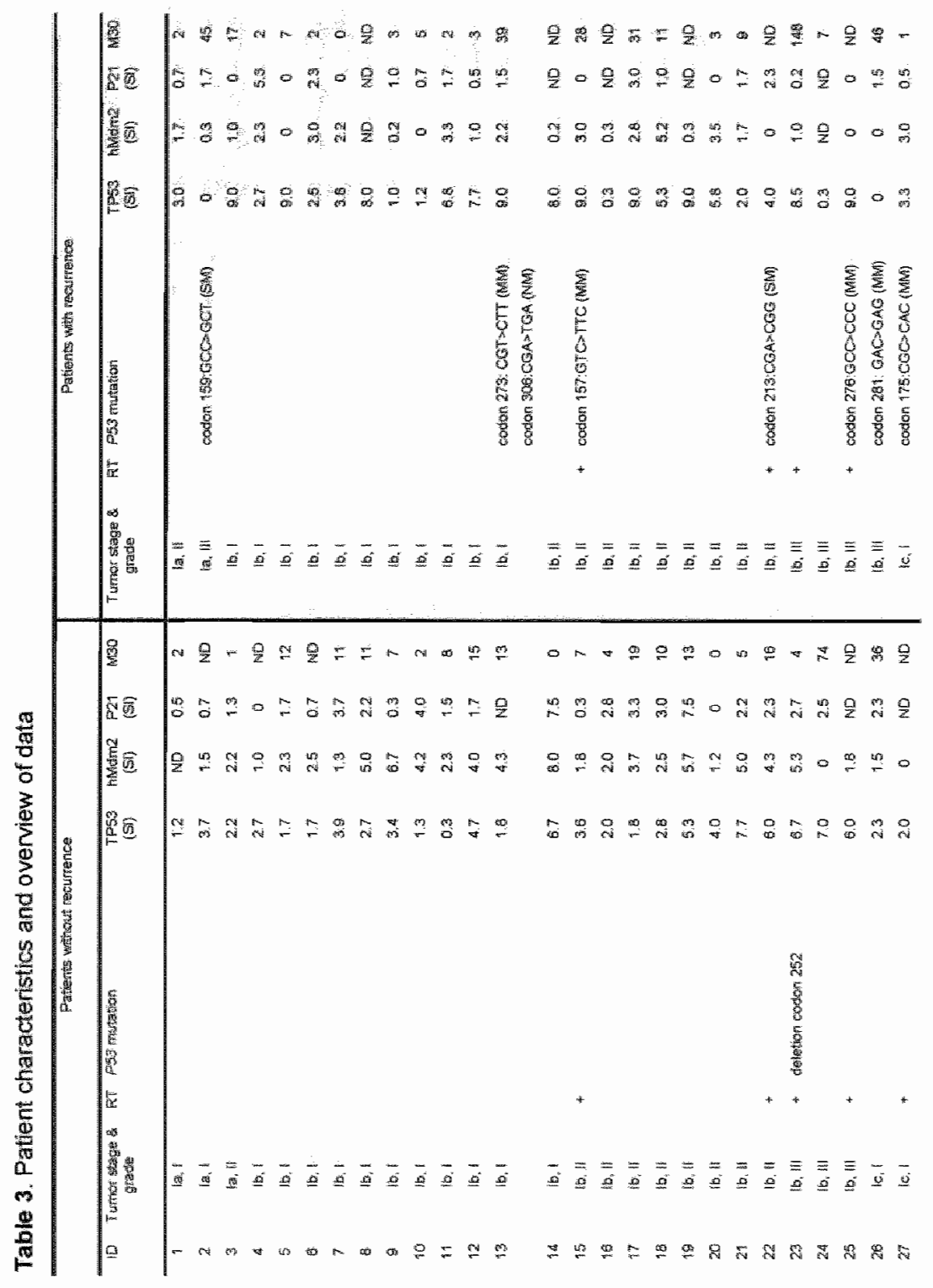




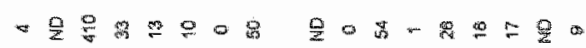

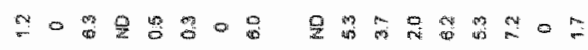
○ 0 倠

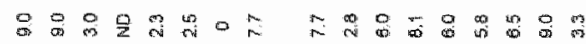

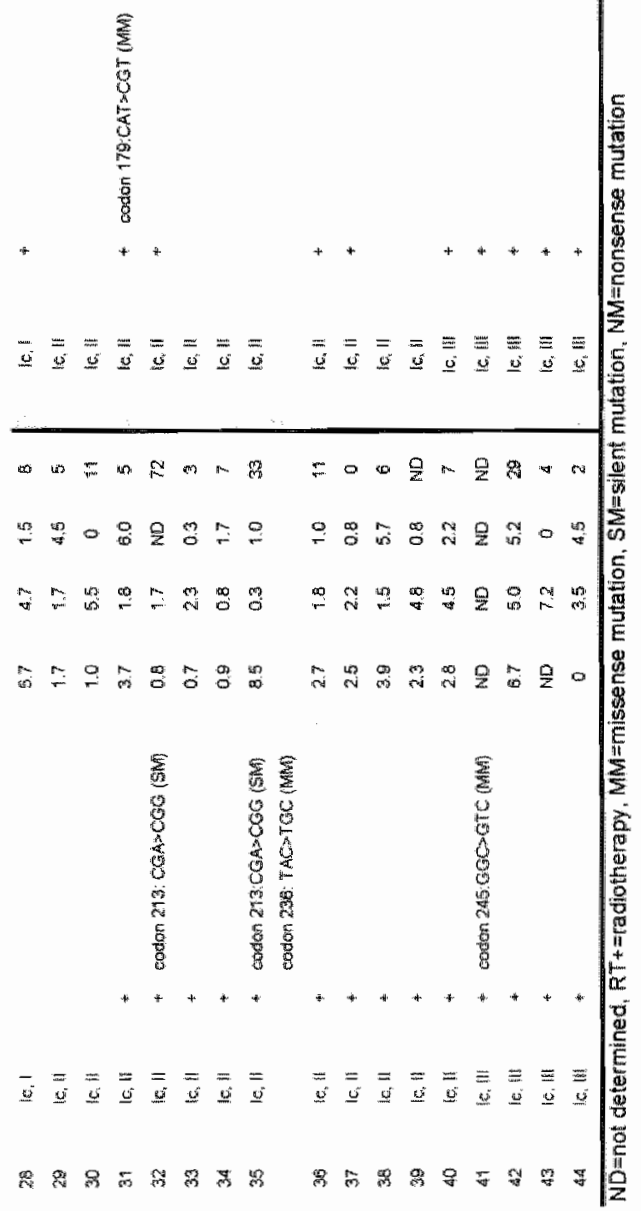




\section{P53 mutations}

A total of 14 mutations were detected in 12 patients. Four (29\%) silent mutations, and eight $(57 \%)$ missense mutations and one nonsense $(7 \%)$ mutation, and one deletion $(7 \%)$. Six of these missense mutations were found in primary tumors $(n=6)$ of patients with recurrences, whereas two were observed in primary tumors of controls $(n=3)$. All identified mutations are listed in table 5. The TP53 staining index was significantly higher in tumors with p53 missense or nonsense mutations compared to those without mutations ( $6.5 \pm 1.3$ vs. $4.1 \pm 0.3$ ). However, expression of hMdm2, $\mathrm{P} 21^{\text {Waf1/Cip1 }}$ and $\mathrm{M} 30$ did not differ between tumors with or without $\mathrm{p} 53$ mutations.

Table 5 Description of $p 53$ gene mutations.

\begin{tabular}{|c|c|c|c|c|c|c|}
\hline & patient & recurrence & exon & codon & $\begin{array}{c}\text { gene } \\
\text { mutation }\end{array}$ & $\begin{array}{l}\text { protein } \\
\text { change }\end{array}$ \\
\hline \multirow[t]{8}{*}{ missense mutations } & 1 & + & 5 & 157 & GTC $>$ TTC & Val > Phe \\
\hline & 2 & + & 5 & 179 & $\mathrm{CAT}>\mathrm{CGT}$ & His $>$ Arg \\
\hline & 3 & + & 5 & 175 & $\mathrm{CGC}>\mathrm{CAC}$ & Arg $>$ His \\
\hline & 4 & + & 8 & 276 & $\mathrm{GCC}>\mathrm{CCC}$ & Ala $>$ Pro \\
\hline & 5 & + & 8 & 273 & $\mathrm{CGT}>\mathrm{CTT}$ & Arg $>$ Leu \\
\hline & 6 & + & 8 & 218 & $\mathrm{GAC}>\mathrm{GAG}$ & Aps $>$ Glu \\
\hline & 7 & " & 7 & 245 & $\mathrm{GGC}>\mathrm{GTC}$ & Gly $>$ Vall \\
\hline & 8 & - & 7 & 236 & $\mathrm{TAC}>\mathrm{TGC}$ & Tyr $>$ Cys \\
\hline nonsense mutations & 5 & + & 8 & 306 & $C G A>T G A$ & Arg $>$ stop \\
\hline deletion & 9 & $=$ & 7 & 252 & CTC dell & \\
\hline \multirow[t]{4}{*}{ silent mutation } & 10 & + & 5 & 159 & $\mathrm{GCC}>\mathrm{GCT}$ & $\mathrm{Ala}=\mathrm{Ala}$ \\
\hline & 11 & - & 6 & 213 & $\mathrm{CGA}>\mathrm{CGG}$ & $\operatorname{Arg}=\operatorname{Arg}$ \\
\hline & 8 & - & 6 & 213 & $\mathrm{CGA}>\mathrm{CGG}$ & $\operatorname{Arg}=\operatorname{Arg}$ \\
\hline & 12 & - & 6 & 213 & $\mathrm{CGA}>\mathrm{CGG}$ & $\operatorname{Arg}=\operatorname{Arg}$ \\
\hline
\end{tabular}




\section{Discussion}

To our knowledge, this is the first study which addresses the role of TP53 in recurrent tumors in a case-control setting. Information on protein expression levels in recurrent tumors may be of additional value for the identification of prognostic markers for tumor progression, and may provide more insight in the molecular pathogenesis of recurrent disease.

It is well established that overexpression of TP53 correlates with high cell turn-over and tumor aggressiveness, and it is widely considered as a prognostic marker for recurrent disease [21]. Our analysis of endometrioid type adenocarcinomas herein showed that overexpression of TP53 in the primary tumor was predictive for the development of recurrent disease (OR $3.8,95 \% \mathrm{Cl} ; 1.5-9.8)$. This agrees with the recent findings of Lundgren et al.[22], who also showed in a large series of stage I endometrial carcinomas of the endometrioid type, that TP53 overexpression correlated significantly with tumor relapse. The fact that increasing expression of TP53 was observed in the recurrent tumors, supports the fact that TP53 is involved in tumor progression. Yet, there are indications that the overexpressed TP53 is not functional. Functionally active TP53 is expected to induce transcription of P21 ${ }^{\text {Waf1/Cip1 }}$ and hMdm2 [1]. In control tumors, TP53 overexpression (SI>5.0) correlated with higher expression of $\mathrm{P} 21^{\text {Waf1/Cip } 1}$ and hMdm2. In contrast, in primary tumors of patients with recurrence, TP53 overexpression did not result in higher expression levels of $\mathrm{P} 21^{\text {Waf1/Cip1 }}$ and $\mathrm{hMdm} 2$.

Other groups have shown a correlation between hMdm2 and TP53 expression in endometrioid type endometrial carcinomas [23-25], in agreement with our findings in the no-recurrence group.

Comparing our data and published data is complicated by the use of different cut-off values for the assessment of TP53 overexpression. In literature criteria such as $>70 \%[26]$, and a score of $8-12$ in the range of $0-12$ [25], have been used as indicators for TP53 overexpression. Reanalysing the data with a lower cut-off value for TP53 overexpression $(<3.0)$, did not affect the results or the significance of our data. 
In endometrial carcinoma, expression of $\mathrm{P} 21^{\text {Waft/cipt }}$ is usually not associated with TP53 immunoreactivity, in contrast to other tumors $[1,27,28]$. The inverse correlation between TP53 overexpression and hMdm2 and P21 ${ }^{\text {Wafticip1 }}$ expression in endometrioid endometrial cancer, suggests that hMdm2-TP53- P21 $1^{\text {Waf1/Cip1 }}$ pathway is deregulated [3]. However, this postulation must be regarded with some caution as it has been reported that P21 Waryicip1 $c a n$ be activated in a TP53-independent fashion in endometrial carcinoma $[27,29,30]$.

High expression of non-mutated TP53 is expected to induce apoptosis, and therefore in parallel to increased TP53 expression, high M30 expression was expected. The monoclonal antibody against $M 30$, recognizes a neo-epitope in cytokeratin 18 (CK18), created by early caspase cleavage during apoptosis [31]. We did, however, not observe a positive correlation of TP53 expression and M30 expression in either subgroup. Burton et al. [27] described a close correlation of TP53 expression and the apoptotic index in tumors with $<40 \%$ of TP53 expression, whereas in those tumors with high TP53 expression no relation was observed. loffe et al.[21] observed a correlation between the presence of TP53 expression and the apoptotic index, however, this was observed in only 18 cases without the calculation of a staining index. The fact that no correlation was found in the current study again seems to point to compromised TP53 functioning, or, perhaps more likely, since the SI for M30 was substantially lower in primary tumors of the two study groups, to interruption of apoptotic signalling downstream of TP53. The origin of TP53 overexpression and its biological significance for tumorigeneses remain enigmatic. Overexpression of TP53 has been attributed to mutations in the $p 53$ gene, mostly in exons 5 through 8 , or to post-translational modifications impairing degradation or increasing stabilization of TP53 protein [32-34]. In this study, only 5 of 34 tumors with TP53 overexpression harboured $p 53$ mutations. This low prevalence of $p 53$ mutations in endometrioid endometrial carcinoma is in line with the findings of Lax et al. [7] and Stewart et al. [17]. Moreover, these findings indicate that 
TP53 overexpression in our study is not caused by mutations in exons $5,6,7$ or 8 . Among tumors that harbour $p 53$ mutations, overexpression is observed in $71 \%$ of cases. Similarly, Lax et al. observed TP53 overexpression in $85 \%$ of the endometrial carcinomas with $p 53$ gene mutations. Overexpression of TP53 in the other tumors may therefore result from mutations (coding or noncoding) elsewhere in the p53 gene [35], or from excessive production, impaired degradation of the TP53 protein.

Under normal physiological conditions, hMdm2 predominantly maintains low TP53 levels in the cell. It acts as a specific ubiquitin E3 ligase for TP53: covalent ligation of ubiquitin chains to lysine residues at the C-terminal end of TP53, targets it for proteolytic degradation [36]. These lysine residues $(370,372,373,381,382$, and 386), are all located in exon 11 [36]. However, mutation analysis of p53 exon 11 did not reveal any mutations in this study. Therefore, if stability is the underlieing cause, failure to degrade TP53 may be due to an alternative mechanism. Acetylation of lysines residue at the $\mathrm{C}$ terminal end of TP53, was also shown to lead to a longer half-live of endogenous TP53 [37], as it prevents the ubiquitylation of these lysine residues by $\mathrm{hMdm} 2$. It is conceivable that changes in expression of proteins that regulate TP53 acetylation (CBP/P300, HDAC1, KAP1, p14 ${ }^{\text {ARF }}$ ) are involved in TP53 stabilization $[38,39]$. Interestingly, it was recently shown that PTEN inactivation, which is a frequent event in endometrial carcinoma, results in an increase in the half-life of TP53 and P21 War1/Cip1 and induces growth arrest $[40,41]$. Moreover, new data indicate that certain non-coding hMdm2 mutations, may impinge on TP53 transactivation activity, by overexpression of hMdm2, without affecting its' stability [42].

Finally , overexpression of TP53 in cells occurs also in response to a variety of cellular stresses. In response to hypoxia, nutrient deprivation, hyperproliferative signals or by DNA damage signals arising from compromised genome stability, TP53 is induced to arrest cell proliferation [43-45]. In addition, oncogenic proteins, including Ras, Myc, E2F and Seladin-1 were also shown to induce accumulation of wild-type TP53 [46]. 
Decreased apoptotic signalling in recurrent tumors may provide indirect evidence for ongoing mutation and progressive malignant disease. Aneuploidy is frequently associated with inactive TP53, aggressive tumor behaviour and poor treatment outcome. There is increasing evidence that inactive TP53 may not only cause aneuploidy, but also facilitate genomic instability [47-49]. Although we currently have no unequivocal explanation for the concurrently increased expression of hMdm2 and $\mathrm{P} 21^{\text {Waf1/ip1 }}$ in recurrent tumors, this observation may ultimately provide clues with regard to subpopulations of cells that have the potential to relapse.

Clearly, the regulatory mechanisms in control of TP53 function, are complex and interlock at multiple levels. Exactly which molecular mechanisms contribute to accumulation of TP53 in endometrial carcinoma of the endometrioid type, remains yet to be elucidated.

In summary, TP53 overexpression in primary tumors show a clear association with the development of recurrent stage 1 endometrial carcinoma, independent of tumor grade and myometrial invasion. Concurrent expression of $\mathrm{P} 21^{\text {War1/Cip1 }}$ and hMdm2 suggest dysfunctional TP53-signalling in primary tumors of patients with recurrence. TP53 overexpression coincided in only a minority of the cases with gene mutations. Alternative pathways for TP53 inactivation need to be studied to explore the molecular mechanism underlying TP53 signalling in endometrial carcinoma. 


\section{References}

1. Veloso, M., Wrba, F., Kaserer, K., Heinze, G., Magalhaes, A. Herbst F. and Teleky, B. (2000) P53 gene status and expression of p53, mdm2, and p21Waf//Cip/ proteins in colorectal cancer. Virchows Archives, 437, 241-247.

2. Wunderlich, M. and Berberich, S.J. (2002) Mdm2 inhibition of p53 induces E2F1 Iransactivation vie p21. Oncogene, 21, 4414-4421.

3. Juven-Gershon, T. and Oren, M. (1999) Mdm2: The ups and downs. Molecular Medicine, 5, 71-83.

4. Dyson, N. (1994) pRB, p107 and the regulation of the E2F transcription factor. Journal of Cell Science. Supplement., 18, 81-7.

5. Waldman, T., Kinzler, K.W. and Vogelstein, B. (1995) p21 is necessary for the p53mediated $\mathrm{G} 1$ in human cancer celis. Cancer Research, 55, 5187-5190.

6. Reich, N.C., Oren, M. and Levine, A.J. (1983) Two distinct mechanisms regulate the levels of a cellular tumor antigen, p53. Molecular Cell Biology, 3, 2143-50.

7. Lax, S.F., Kendall, B., Tashiro, H., Slebos, R.J.C. and Ellenson, L.H. (2000) The frequency of $p 53, K$-ras mutations, and microsatelite instability differs in uterine endometroid and serous carcinoma. Cancer, 88, 814-824.

8. Kounelis, S., Kapranos, N., Kouri, E., Coppola, D., Papadaki $H$. and Jones, M.W. (2000) Immunohistochemical profile of endometrial adenocarcinoma: a study of 61 cases and review of the literature. Modem Pathology 13 (4), 379-388.

9. Bur, M.E., Pertman, C., Edelmann, L., Fey, B.S.E. and Rose, P.G. (1992) P53 expression in neoplasms of the uterine corpus. American Jounal of Clinical Pathology, 98, 81-87.

10. Ozsaran, A.A., Turker, S., Dikmen, Y., Erhan, Y., Itil, I, Terek, C. and Ozdemir, N. (1999) P53 staining as a prognostic indicator in endometrial carcinoma. European Joumal of Gynaecologic Oncology, 20, 156-159.

11. Taskin, M. Lallas, T.A., Barber, H.R.K. and Shewchuk, M.M. (1997) Bcl-2 and p53 in endometrial adenocarcinoma. Modem Pathology, 10, 728-734.

12. Inoue, M. Okayama A., Fujita, M. Enomoto, T., Sakata, M., Tanizawa, $O$. and Ueshima, H. (1994) Climicopathological characteristics of p53 overexpression in endometrial cancers., 58, 14-19.

13. Giatromanolaki, A., Sivridis, E., Koukourakis, M.l., Harris, A.L. and Gatter, K.C. (1998) $\mathrm{Bcl}-2$ and $\mathrm{p} 53$ expression in stage lendometrial carcinoma. Anticancer Research, 18. 3689.3694 .

14. Reinartz, J.d., George, E., Lindgren, B.R. and Niehans, G.A. (1994) Expression of p53, transforming growth factor alpha, epidermal growth factor receptor, and c-erbB-2 
in endometrial carcinoma and correlation with survival and known predictors of survival. Human Pathology, 25, 1075-1083.

15. Powell, B., Soong, R., Grieu, F., Knowles, S., Hammond, I. and lacopetta, B. (1999) P53 protein overexpression is a prognostic indicator of poor survival in stage I endometrial carcinoma. International Joumal of Oncology, 14, 175-179.

16. Tashiro, H. Isacsion, C., Levine, R., Kuman, R.J., Cho, K.R. and Hedrick, L. (1997) p53 gene mutations are common in uterine serous carcinoma and occur early in their pathogenesis. American Journal of Surgical Pathology, 150, 177-185.

17. Stewart, R.L., Roydls, J.A., Burton, J.L., Heatley, M.K. and Wells, M. (1998) Direct sequencing of the 53 gene shows absence of mutations in endometroid endometrial adenocarcinomas expressing p53 protein. Histopathology, 33, 440-445.

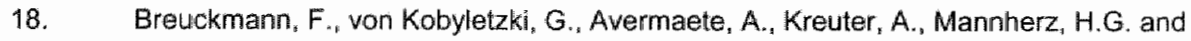
Altmeyer, P. (2002) Apoptosis of human dermal endothelial cells as a potential side effect following therapeutic administration of UVA1 irradiation: preliminary results. Archives of Dermatological Research, 294, 303-9.

19. Creasman, W.T. (1990) New gynecologic cancer staging. Obstetrics and Gynecology, 75, 287-288.

20. Salvesen H.B., MacDonald, N., Ryan, A., Iversen, O.E., Jacobs, I.J., Akslen, L.A. and Das,$S .(2000)$ Methylation of hMLH1 in a population-based series of endometrial carcinomas. Clinical Cancer Research, 6, 3607-3613.

21. loffe, O.B. Papadimitriou, J.C. and Drachenberg, C.B. (1998) Correlation of proliferation indices, apoptosis, and related oncogene expression (bcl-2 and c-erbB2) and p53 in proliferative, hyperplastic, and malignant endometrium. Human Pathology, 29, 1150-1159.

22. Lundgren, C. Auer, G., Frankendal, B. Nilsson, B. and Nordstrom, B. (2004) Prognostic factors in surgical stage I endometrial carcinoma. Acta Oncologica, 43, 4956.

23. Skomedal, H., Kristensen, G.B., Nesiand, J.M., Borresen-Dale, A.L., Trope, C. and Holm, R. (1999) TP53 alterations in relation to the cell cycle-associated proteins p21, cyclin D1, CDK4, RB, MDM2, and EGFR in cancers of the uterine corpus. Journal of Pathology, 187, 556-62.

24. Ambros, R.A., Sheehan, C.E., Kallakury, B.V.S., Ross, J.S., Malfetano, J., Paunovich, E. and Figge. J. (1996) MDM2 and p53 protein expression in the histologic subtypes of endometrial carcinoma. Modern Pathology, 9, 1165-1169.

25. Soslow, R.A., Shen, P.U.-F., Chung, M.H. and Isacson, C. (1998) Distinctive p53 and mdm2 immunohistochemical expression profiles suggest different pathogenetic pathways in poorly differentiated endometrial carcinoma. International Journal of Gynaecological Pathology, 17, 129m134. 
26. Coronado, P.J., Vidart, J.A., Lopez-asenjo, J.A., Fasero, M., Furio-bacete, V., Magrina, J. and Escudero, M. (2004) P53 overexpression predicts endometrial carcinoma recurrence better than HER-2/neu overexpression. European Joumal of Obstetrics, Gynecology and Reproductive biology, 98, 103-8.

27. Burton, J.L., Stewart, R.L., Heatley, M.K., Royds, J.A. and Wells, M. (1999) p53 expression, p21 expression and the apoptotic index in endiometroid endometrial carcinoma. Histopathology, 35, 221-229.

28. Ito, K., Watanabe, K., Nasim, S., Sasano, H., Sato, S., Yajima, A., Silverberg, S. G. and Garett, C.T. (1994) Prognostic significance of $p 53$ overexpression in endometrial cancer. Cancer: $54,4667-4670$.

29. Cox L.S. (1997) Multiple pathways control cell cycle growth and transformation: overlapping and independent activities of $p 53$ and $p 21$ cip/WAF/Sdi1. Joumal of Patholagy, 183, 134-140.

30. Ito, K., Sasano, H., Matsunaga, G., Sato, S., Yajima, A., Nasim, S. and Garret, C.T. (1997) Correlation between p21 expression and clinicopathological findings, p53 gene and protein alterations, and survival in patients with endometrial carcinoma. Journal of Pathology, 183, 318-324.

31. Leers, M.P., Kolgen, W., Bjorklund, V., Bergman, T., Tribbick, G., Persson, B., Bjorklund, P., Ramaekers, F.C.S., Bjorklund, B., Nap, M., Jornvall, $H_{\text {. }}$ and Schutte $B$. (1999) Immunocytochemical detection and mapping of a cytokeratin 18 neo-epitope exposed during early apoptosis. Journal of Pathology, 187, 567-572.

32. Wunderlich, M. and Berberich, S.J. (2002) Midm2 inhibition of p53 induces E2F1 transactivation via p21. Oncogene, 21, 4414-21.

33. Nkamura, S., Gamyo, Y., Roth, J.A. and Mukhopadhyay, T. (2002) C-terminus of p53 required for $\mathrm{G}(2)$ arrest. Oncogene, 21, 2102-7.

34. Vogelsteim, B., Lane, D.P. and Levine, A.J. (2000) Surfing the p53 network. Nature, 408, 307-310.

35. Olivier, M., Eeles, R., Hollstein, M., Khan, M.A., Harris, C.C. and Hainaut, P. (2002) The IARC TP53 database: new online mutation analysis and recommendations to users. Human Mutation, 19, 607-14.

36. Rodriguez, M.S., Desterro, J.M., Lain, S., Lane, D.P. and Hay, R.T. (2000) Multiple Cterminal lysine residues target $p 53$ for ubiquitin-proteasome-mediated degradation.

Molecular Cell Biology, 20, 8458-67.

37. Ito, A., Lai, C.H., Zhao, X. Saito. S., Hamilton, M.H. Appella, E. and Yao, T.P. (2001) p300/CBP-mediated p53 acetylation is commonly induced by p53-activating agents and inhibited by MDM2. EMBO Journal, 20, $1331-40$.

38. Wang, C., Ivanov, A., Chen, L., Fredericks, W.J., Seto, E., Rauscher, F.J. and Chen, J. (2005) MDM2 interaction with nuclear corepressor KAP1 contributes to p53 inactivation. The EMBO Journal, Aug 18, [Epub ahead of print]. 
39. Gu, W. Luo. Ji, Brooks, C.L., Nikolaev, A.Y. and Li, M. (2004) Dynamics of the p53 acerylation pathway, Novartis Found Symposium, 259, 197-205.

40. Chen, $Z_{*}$ Trotman, L.C., Shaffer, D. Lin, H.K., Dotan, Z.A., Niki, M., Koutcher, J.A., Scher, H.I., Ludwig, T., Gerald, W., Cordon-Cardo, C. and Pandolfi, P.P. (2005) Crucial role of p53-dependent cellular senescence in suppression of Pten-deficient tumorigenesis. Nature, 436, 725-30.

41. Salvesen, H.B., Stefansson, 1., Kretzschmair, E.I, Gruber, P., MacDonald, N.D., Ryan,

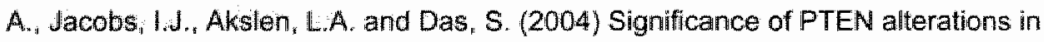
endometrial carcinoma: a population-based study of mutations, promoter methylation and PTEN protein expression. International Joumal of Oncalogy, 25, 1615-23.

42. Arva, N.C., Gopen, T.R., Talbott, K.E., Campbell, L.E., Chicas, A., White, D.E., Bond, G.L. Levine A.J. and Bargonetti, J. (2005) A chromatin-associated and transcriptionally inactive p53-Mdm2 complex occurs in mdm2 SNP309 homozygous cells. Journal of Biological Chemistry, 280, 26776-87.

43. Appella, E and Anderson, C.W. (2001) Post-transiational modifications and activation of p53 by genotoxic stresses. European Journal of Biochmistry, 268, 2764-72.

44. Attardi, L.D. (2005) The role of p53-mediated apoptosis as a crucial anti-tumor response to genomic instability: lessans from mouse models. Mutation Research, 569, $145-57$.

45. Lowe, S.W., Cepero, E. and Evan, G. (2004) Intrinsic tumor suppression. Nature, 432. $307-15$.

46. Wu, C., Miloslavskaya, I., Demontis, S., Maestro, R. and Galaktionov, K. (2004) Regulation of cellular response to oncogenic and oxidative stress by Seladin-1. Nature, 432, 640-5.

47. Duensing, A. and Duensing, S. (2005) Guilt by association? p53 and the development of aneuploidy in cancer. Biochemical and Biophysical Research Cormmunications. 331. 331(3):694-700.

48. Coates, P.J., Lorimore, S.A. and Wright, E.G. (2005) Cell and tissue responses to genotoxic stress. Joumal of Pathology, 205, 221-35.

49. Woo, R.A. and Poon, R.Y. (2004) Activated oncogenes promote and cooperate with chromosomal instability for neoplastic transformation. Genes \& Development, 18. 1317-30. 


\section{Chapter 8}

Microvessel density and carbonic anhydrase IX expression in recurrent endometrial carcinoma

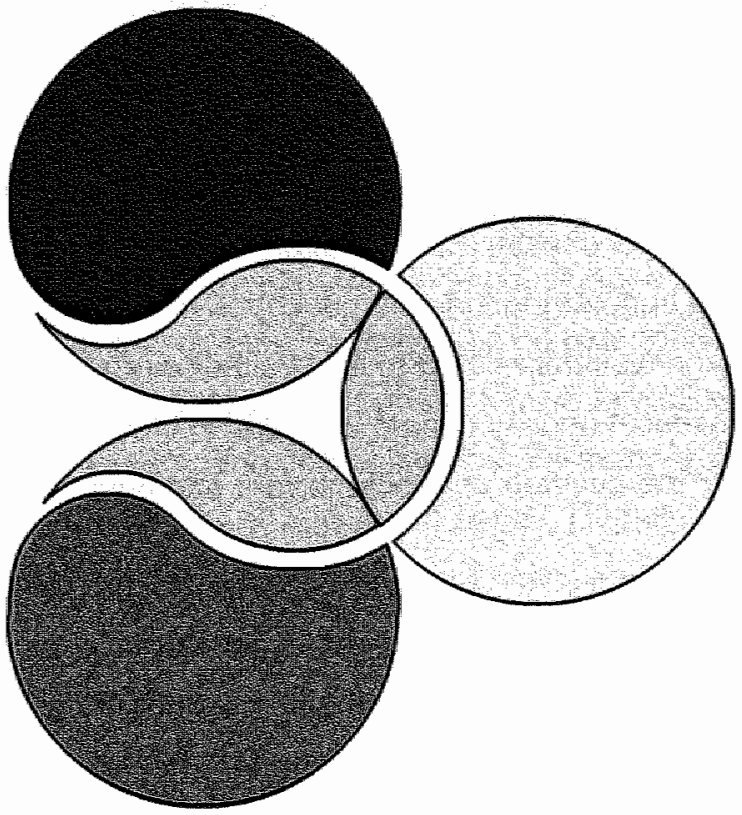

Johanna M.A. Pijnenborg, Mirel Wijnakker, Koen Baeten, Patrick G. Groothuis

(submitted) 


\section{Abstract}

Background: Tumor hypoxia can trigger the induction of angiogenesis. In endometrial carcinoma high microvessel density has been associated with the development of recurrent disease. The presence of hypoxia could also be related to tumor aggressiveness, but has not been studied so far in endometrial carcinoma.

Methods: A case-control study was performed on primary tumors of 25 patients with stage I endometrial carcinoma who developed a recurrence, and compared with 25 primary tumors of patients without recurrence. Immunohistochemical analysis was performed on paraffin embedded tumor tissue. Microvessel density (MVD) was determined by quantitative evaluation of CD31/FVIII expression. Tumor hypoxia was estimated by evaluating the expression of the hypoxia-regulated gene carbonic anhydrase IX (CA-IX). Results: High microvessel density $(>2 \%)$ was a significant and independent predictor for recurrent endometrial carcinoma. CA-IX expression did not predict recurrence, and was not related to MVD either directly or inverselly. Conclusions: Microvessel density can be used as an independent prognostic marker for the development of recurrent endometrial carcinoma. 


\section{Introduction}

Angiogenesis is the formation of new blood vessels by proliferation of new capillaries from preexisting vessels and capillary endothelial cells.

Angiogenesis appears to play an important role in the malignant progression of several gynecologic tumors [1]. In the endometrial tissue a significant increase in the microvessel count was observed from simple to complex hyperplasia [2]. In endometrial carcinoma microvessel density (MVD) was found to be related to myometrial invasion and tumor grade, and overall high MVD has been associated with poor survival, independent of tumor stage [35]. Induction of angiogenesis is a fundamental event in the process of tumor growth and metastatic dissemination. Several mechanisms have been elucidated which lead to increased angiogenesis in human tumors including the presence of hypoxia. Tumor hypoxia arises due to the rapid growth of the tumor and is a consequential imbalance in oxygen consumption and supply. Hypoxia can also arise due to irregular and poorly developed tumor vasculature. Tumor hypoxia has been shown to be an independent prognostic indicator of treatment outcome and is known to cause direct resistance to both radiotherapy and chemotherapy. Furthermore, hypoxia leads to the up regulation of several classes of genes, including several that stimulate angiogenesis, through stabilization and activation of the hypoxiainducible factor-1 (HIF-1) transcription factor [6]. The tumor-associated transmembrane-linked carbonic anhydrase IX (CA-IX) also contains a hypoxia-response-element (HRE) within its promoter and is a known transcriptional target of HIF-1. CA-IX catalyzes the reversible conversion of carbon dioxide to carbonic acid, and hence regulates micro environmental $\mathrm{pH}$. CA-IX expression is present in normal human upper gastro-intestinal mucosa and gastro-intestinal associated structures, but has also been identified in solid tumors $[7,8]$. Since $\mathrm{CA}-\mathrm{IX}$ is known to be a direct target of HIF-1 and is activated at the same oxygen tension at which HIF-1 $\alpha$ and its other downstream target genes are induced, it has also been proposed to act as a surrogate marker of hypoxia and thus be used to estimate the 
hypoxic subpopulation of the tumor [9]. So far, the presence of CA-IX has not been reported in endometrial carcinoma.

Endometrial carcinoma has a good prognosis [10], yet still some patients present with recurrent disease shortly after completion of therapy. Currently, the application of radiotherapy is dependent on tumor stage and grade. Molecular markers could be helpful to select risk criteria for the development of recurrent disease and eventually be used for the application of adjuvant radiotherapy or even for the prediction of tumor sensitivity to radiotherapy. The objectives of the present study were to confirm the predictive capacity of MVD for the development of recurrent endometrial carcinoma using a quantitative analysis, and to determine whether expression of CA-IX was of additional value for this prognosticator. The study was conducted in a casecontrol set of patients with and without recurrent stage I endometrial carcinoma. 


\section{Methods}

Patients and tissue specimens

Patients with recurrent endometrioid endometrial carcinoma were selected from the Dutch national pathology database (PALGA). Twenty-five patients diagnosed with stage I disease, according to the FIGO criteria [11], and who presented with recurrent disease within three years were included. Control patients being free of recurrence for at least three years after diagnosis and treatment, were selected and matched for tumor stage, tumor differentiation, age at diagnosis, and therapy. Patients underwent initially hysterectomy and bilateral salpingo-oophorectomy. Radiotherapy was applied when myometrial invasion appeared to be $>50 \%$, and/or when the tumor was poorly differentiated. Patients presented with local recurrence at the vaginal vault $(n=21)$, distant metastases $(n=3)$ or local recurrence and distant metastases $(n=1)$. An independent pathologist revised histopathology of primary and recurrent tumor, and the diagnosis was confirmed in all cases. The study was approved by the Medical Ethical Committee of the University Hospital of Maastricht (MEC 02-009.5).

\section{Immunohistochemical analysis}

Immunohistochemical staining was performed on formalin-fixed, paraffinembedded specimens. Haematoxylin and eosin (HE) stained sections were used to select the tumor area, and sections of $5 \mu \mathrm{m}$ were prepared on Starfrost adhesive slides (Klinipath, Duiven, The Netherlands). Sections were deparaffinized in xylol and rehydrated prior to blockage of endogenous peroxidase activity by incubation in $3 \%$ hydrogen peroxide/methanol solution for 20 minutes. Antigen retrieval was performed by heat treatment for 20 minutes in $10 \mathrm{mM}$ Tris-EDTA buffer $(\mathrm{pH} 9.0)$. Sections were left to cool down to room temperature and rinsed in phosphate buffer saline (PBS) ( $\mathrm{pH} 7.2)$. Incubation with polyclonal and monoclonal antibodies directed to respectively CD31/FVIII (1:100/1:1800; Dako, Copenhagen, Denmark) was 
performed for two hours at room temperature diluted in PBS with $0.1 \%$ Tween and $0.1 \%$ bovine serum albumin (BSA). For the CA-IX antibody. antigen retrieval was not required, however prior to antibody incubation sections were blocked with $5 \%$ BSA for 30 minutes at room temperature. Subsequently incubation was performed with a monoclonal antibody directed to CA-IX (1:50; M75, kindly given by Dr. Silvia Pastorekova, Centre of Molecular Medicine, Institute of Virology, Slovak Academy of Sciences, Bratislava, Slovak Republic), diluted PBS with $0.1 \%$ Tween and $0.1 \%$ BSA, for 45 minutes at room temperature. Antibody binding was visualized with the avidin-biotin complex immunoperoxidase technique (ChemMate detection kit; DAKO, Copenhagen, Denmark), and 3,3'-diaminobenzidine. Sections were counterstained with haematoxylin.

Normal endometrial tissue served as positive and negative control (Mouse IgG 1:100) for CD31/FVIII staining, and cervix carcinoma served as positive and negative control (Mouse IgG 1:50) for CA-IX expression.

\section{Evaluation of immunostaining}

Microvessel density (MVD) and CA-IX staining were calculated as the percentage positive expression of CD31/FVIII and CA-IX, respectively of the whole tumor area. The Leica Qwin digital imaging system with software from Leica (Bensheim, Germany) was used for analysis. Briefly, tumor area is determined, subsequently threshold for positive staining is set, followed by excluding non-specific stained areas, and finally resulting in the percentage of positive staining. The correlation coefficients calculated for the two observations made by the same observer, and for two observations made by two observers were respectively: 0.95 and 0.92 , determined on nine tested slides with the Leica Qwin digital imaging system. 


\section{Statistical Analysis}

The SPSS software (version 11.5) was used for statistical analysis, and median values for age at time of diagnosis, and follow-up period were calculated. To test whether patients with and without recurrence were comparable with respect to age at diagnosis, tumor stage, tumor grade, and radiotherapy, a T-test for paired analysis (continuous variables), and a McNemar test (dichotomous variables) was performed. High and low levels of MVD were determined by dividing the groups into less or more than the mean value $(2.0 \%)$. Odds Ratios were calculated for high $M V D(>2 \%)$ and the risk of recurrence. A correction by Mantel-Haenszel was performed to correct for applied radiotherapy and tumor grade. High and low levels of CAIX were equally determined by dividing the groups into less or more than the mean CA-IX expression (10\%). A paired T-test was performed to compare expression of $C D 3 \| / F V I I I$ and $C A-1 X$ in primary and recurrent tumor. $A$ Spearman's correlation coefficient was determined to investigate the correlation between CD31/FVIII and CA-IX expression. All statistical tests were two-sided, and a $p$-value of 0.05 was considered significant. 


\section{Results}

\section{Patients}

All patients $(n=50)$ were postmenopausal at the time of diagnosis. Clinicopathological parameters of patients in both groups were well comparable. Table 1 Patient and tumor characteristics

\section{Control patients without Patients with P-value recurrence $(n=25) \quad$ recurrence $(n=25)$}

Age at diagnosis

(median and range)

Figo stage

\section{$67(54-93)$ years}

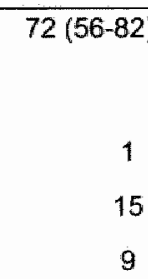

Tumor grade

$0.687^{2}$

$\begin{array}{lccc}\text { Grade I } & 10 & 9 & \\ \text { Grade II } & 11 & 10 & \\ \text { Grade III } & 4 & 6 & \\ \text { radiotherapy } & 10 & 6 & 0.125^{2}\end{array}$

Post-operative radiotherapy

$13(2-31)$ months

Time to recurrence

(median and range)

Follow-up

42 (34-120) months

33 (9-141) months

$0.346^{\circ 1}$

T-test for paired analysis, "McNemar tesit

\section{Microvessel density}

Representative examples of high and low CD31/FVIII expression are demonstrated in Figure 1(page 211), and results of the quantitative analysis are summarized in Table 2. Overall, microvessel density (MVD) was not correlated with tumor grade or tumor stage. MVD in primary tumors of patients with a recurrence was significantly higher compared to MVD in primary tumors of controls, $2.7 \%( \pm 0.4)$ vs. $1.6 \%( \pm 0.2)$ respectively (paired T-test, $p<0.05$ ). After correction for tumor grade and applied radiotherapy, high MVD ( $>2 \%$ ) was significantly associated with the development of recurrent disease (Mantel-Haenszel Odds Ratio 12.0; 95\% Cl: 2.8-52.0). 
Within those patients treated postoperatively with radiotherapy, MVD was not predictive for recurrence.

\section{CA-IX expression}

Representative examples of membranous CA-IX expression are shown in Figure 2 (page 211), and results of the quantitative analysis are summarized in Table 2. Overall, CA-IX expression was not correlated with tumor grade however, there was a trend towards increased expression with increased myometrial invasion. Figo stage la: $5.4 \%( \pm 5.3)$, Figo lb: $9.5( \pm 2.3)$, Figo lc: $13.1( \pm 3.8)$. The mean $( \pm$ SE) percentage of positive CA-IX expression was $9.1 \%( \pm 2.4)$ in primary tumors of patients with recurrence, and $12.5 \%( \pm 3.3)$ in primary tumors of controls (paired T-test, $p=0.26$ ). High CA-IX expression $(>10 \%$ ) was not associated with recurrent disease. Expression of CA-IX was not related to the presence of MVD, either directly or inversely (Spearman's correlation coefficient, $-0,132)$. Within those patients treated postoperatively with radiotherapy, CA-IX was not predictive for recurrence. 
Table 2 patient pairs and immunohistochemical results of MVD and CA-IX expression

\begin{tabular}{|c|c|c|c|c|c|c|c|c|}
\hline \multicolumn{5}{|c|}{ Patients without recurrence } & \multicolumn{4}{|c|}{ Patients with recurrence } \\
\hline & Tumor stage & & & & umor stage & & & \\
\hline 10 & \& grade & RT & MVD $(\%)$ & $C A-1 \times(\%)$ & $\&$ grade & RT & MVD $(\%)$ & $\mathrm{CA}-1 \times(\%)$ \\
\hline 1 & Ie, lill & + & 3.7 & & Ic, III & + & 6.8 & 5.9 \\
\hline 2 & $\left\|c_{i}\right\|$ & * & 1.6 & 2.9 & 10,11 & + & 4.3 & 3.7 \\
\hline 3 & $\mid \mathrm{b}, \mathrm{I}$ & - & 0.8 & 52.4 & $\| b$, & - & 3.2 & 39.1 \\
\hline 4 & $|b| \mid$, & - & 3.8 & 5.5 & $\mid \mathrm{b}, \mathrm{ll}$ & $=$ & 3.7 & 25.4 \\
\hline 5 & Ib, II & + & 1.1 & 1.6 & $\mid \mathrm{b}, \| \mathrm{II}$ & + & 0.6 & 3.6 \\
\hline 6 & $\mathrm{Ib}, \mathrm{I}$ & - & 0.3 & 8.5 & $|b|$, & - & 3.1 & 1,0 \\
\hline 7 & $\mathrm{Ib}, \mathrm{I}$ & - & 1.2 & 4.4 & $\left|b_{1}\right|$ & - & 1.6 & 1.7 \\
\hline 8 & la, II & - & 1.9 & 0.0 & $\mid b_{n} \|$ & - & 2.9 & 15.0 \\
\hline 9 & $\mathrm{Ib}, \|$ & - & 1.3 & 2.6 & Ib, II & - & 0.7 & 15.0 \\
\hline 10 & $1 \mathrm{~b}, 11$ & - & 1.6 & 18.0 & $\mid \mathrm{lb}, \mathrm{II}$ & - & 2.2 & 3.2 \\
\hline 11 & $\mathrm{Ib}, \mathrm{I}$ & - & 0.7 & 4.8 & Ia, III & - & 4.4 & 10,7 \\
\hline 12 & $\left|c_{1}\right| \mid$ & + & 1.7 & 6.3 & $\mid \mathrm{Ic}, \mathrm{I}$ & - & 1.4 & 26.2 \\
\hline 13 & $\|\mathrm{C}\|$, & - & 0.8 & 36.5 & $\mathrm{lb}, \mathrm{II}$ & - & 4.3 & 0.0 \\
\hline 14 & $|b|$, & - & 1.5 & 1.7 & $\mid b_{y} I$ & - & 2.8 & 9.9 \\
\hline 15 & $\|\mathrm{~b},\| \mathrm{ll}$ & + & 0.2 & 28.4 & IC, II & - & 1.2 & 38.6 \\
\hline 16 & $|c|$, & - & 0.8 & 4.2 & $\| c, 1$ & - & 0.8 & 3.8 \\
\hline 17 & $\left\|c_{n}\right\|$ & + & 2.2 & 7.6 & 16,111 & - & 1.4 & 2.3 \\
\hline 18 & $\|\mathrm{c}\|$, & + & 2.5 & 0.2 & $\|c\|$, & + & 1.1 & 3.4 \\
\hline 19 & $\left\|\mathrm{C}_{*}\right\|$ & + & 2.8 & 42.5 & $\mid \mathrm{lc}, \mathrm{I}$ & - & 1.0 & 1.6 \\
\hline 20 & $\mid \mathrm{IC},\|\| \|$ & + & 0.7 & 45.6 & IC, III & + & 0.9 & 3.2 \\
\hline 21 & $1 \mathrm{~b}, \mathrm{I}$ & - & 1.5 & 4.1 & $\|\mathrm{~b}\|$, & - & 2.1 & 0.3 \\
\hline 22 & $I \mathrm{C}_{1} \| \mathrm{II}$ & * & 1.3 & 1.0 & Ic, III & $*$ & 0.7 & 3.5 \\
\hline 23 & $|b|$, & - & & 13.5 & $\mathrm{Ib}$ & - & & 0.4 \\
\hline 24 & $1 \mathrm{~b}, 1$ & - & 1.5 & 1.1 & $\| b, 1$ & - & 7.4 & 6.4 \\
\hline 25 & Ib. I & - & 2.4 & 5.8 & $1 \mathrm{~b}, \|$ & - & 5.1 & 0.0 \\
\hline
\end{tabular}




\section{Discussion}

In the current case-control study MVD was determined in primary tumors of patients with and without recurrence, and expressed as a percentage of the total tumor area. In accordance to several other studies, high MVD was predictive for the development of recurrent endometrial carcinoma [3$5,12,13]$. Microvessel density was determined by a quantitative evaluation of the whole tumor area. Most of the reports on microvessel density use the 'hot spot' method [3,12]. The rationale of counting microvessels in vascular 'hot spots', is that these areas originated from tumor cells with the highest angiogenic potential. Yet, this method is limited by subjective selection of those 'hot spots'[14]. The alternative Chalkley count is a relative area estimate rather than a true vessel count, but it is also based on selection of vascular 'hot spots'. Determination is performed by measuring the number of grid points that hit stained microvessels. In a series of breast tumors, the Chalkley count appeared a rapid method of quantifying tumor angiogenesis, well correlated with computer image analysis [15]. Although the quantitative analysis is less subjective, still manually non-specific staining and non-tumor areas should be erased before analyzing. The threshold for positive staining was set once for all tumor sections.

So far, the expression of CA-IX has not been reported in endometrial carcinoma. In the current study no difference was found between CA-IX expression in patients with, compared to patients without recurrence. Moreover, no correlation could be observed between the expression of CAIX and MVD. In several tumor cell lines, CA-IX was strongly induced by hypoxia and related to the HIF response [6]. CA-IX expression has been related to prognosis and survival of head and neck cancer, renal carcinoma, and sarcomas [16-18]. High expression of either CA-IX or MVD resulted in the highest risk of recurrent head and neck cancer [19]. Since we have not tested other markers for hypoxia, it is unclear whether CA-IX expression indeed reflects the hypoxic areas of the tumor. Probably, other hypoxic related enzymes are relevant in endometrial carcinoma. 
Recently, it was demonstrated that $\mathrm{p} 53$ and $\mathrm{CA}-\mathrm{IX}$ are closely related, explained by the induction of apoptosis through p53 in a hypoxic area [20]. In our small series of patients, expression of 553 was not correlated with CA-IX and MVD (data not shown):

Both the expression of CA-IX and MVD have been related to radio resistance of tumors [8].Yet we were unable to confirm these data in the current study, which could be explained by the fact that a limited number of tumors were tested.

In conclusion, Microvessel density determined by quantitative analysis, can be used as an independent prognostic marker for recurrent endometrial carcinoma, the presence of concomitantly high $\mathrm{CA}-\mathrm{IX}$ is not relevant for the prediction for recurrence.

\section{References}

1. Abulafia, O., Triest, W.E. and Sherer, D.M. (1999) Angiogenesis in malignancies of the female genital tract. Gynecologic Oncology, 72, 220-31.

2. Abulafia, O. and Sherer, D.M. (1999) Angiogenesis of the endometrium. Gynecolagic Oncology, 94, 148-53.

3. Salvesen, H.B., Iversen, O.E. and Akslen, L.A. (1999) Prognostic significance of angiogenesis and ki-67, p53, and p21 expression: a population based endometrial carcinoma study. Joumal of Clinical Oncology, 17 (5), 1382-1390.

4. Ozalp, S., Yalcin, O.T., Acikalin, M., Tanir, H.M., Oner, U. and Akkoyunlu, A. (2003) Microvessel density (MVD) as a prognosticator in endometrial carcinoma. European Journal of Gynaecololgic Oncology, 24, 305-8.

5. Giatromanolaki, A., Sivridis, E., Koukourakis, M.I., Georgoulias "V., Gatter, K.C. and Harris, A.L. (1999) Intratumoral angiogenesis: a new prognostic indicator for stage I endometrial adenocarcinomas? Oncologic Research, 11، 205-12.

6. Wykoff, C.C., Beasley, N.J., Watson, P.H. "Turner, K.J., Pastorek, J., Sibtain, A., Wilson, G.D., Turley, H., Talks, K.L., Maxwell, P.H., Pugh, C.W., Ratcliffe, P.J. and Harris, A.L. (2000) Hypoxia-inducible expression of tumor-associated carbonic anhydrases. Cancer Research, 60, 7075-83.

7. Pastorekova, S. Parkkila, S., Parkkila, A.K, Opavsky, R., Zelnik, V., Saarnio, J. and Pastorek, J. (1997) Carbonic anhydrase IX, MN/CA IX: analysis of stomach complementary DNA sequence and expression in human and rat alimentary tracts. Gastroenterology, 112, 398-408. 
8. Loncaster, J.A. Harris, A.L., Davidson, S.E., Logue, J.P., Hunter, R.D., Wyicoff, C.C, Pastorek, J., Ratcliffe, P.J., Stratford, I.J: and West, C.M. (2001) Carbonic anhydrase (CA IX) expression, a potential new intrinsic marker of hypoxia: correlations with tumor oxygen measurements and prognosis in locally advanced carcinoma of the cervix. Cancer Research, 61, 6394-9.

9. Jiang, B.H., Semenza, G.L., Bauer, C. and Marti, H.H. (1996) Hypoxia-inducible factor 1 levels vary exponentially over a physiologically relevant range of $\mathrm{O} 2$ tension.

American loumal of Physiology, 271, C1172-80.

10. Rose, P.G. (1996) Endometrial carcinoma. New England Joumal of Medicine. 335 , 640-649.

11. Creasman, W.T. (1990) New gynecologic cancer staging. Obstetrics and Gynecology, 75, 287-288.

12. Ozuysal, S., Bilgin, T., Ozan, H., Kara, H.F., Ozturk, H. and Ercan, I. (2003)

Angiogenesis in endometrial carcinoma: correlation with survival and clinicopathologic risk factors. Gynecologic and Obstetric Investigation, 55, 173-7.

13. Kaku, T., Kamura, T., Kinukawa, N., Kobayashi, H., Sakai, K., Tsuruchi, N, Saito, T., Kawauchi, S., Tsuneyoshi, M. and Nakano, H. (1997) Angiogenesis in endometrial carcinoma. Cancer, 80, 741-7.

14. Vermeulen, P.B., Gasparini, G., Fox, S.B., Colpaert, C. Marson, L.P., Gion, M. Belien. J.A., de Waal, R.M., Van Marck, E., Magnani, E., Weidner, N., Harris, A.L. and Dirix, L.Y. (2002) Second international consensus on the methodology and criteria of evaluation of angiogenesis quantification in solid human tumours. European Journal of Cancer, 38, 1564-79.

15. Fox, S.B., Leek, R.D., Weekes, M.P., Whitehouse, R.M., Gatter, K.C. and Harris, A.L. (1995) Quantitation and prognostic value of breast cancer angiogenesis: comparison of microvessel density, Chalkley count, and computer image analysis. Journal of Pathology. 177, 275-83.

16. Bui, M.H., Visapaa, H., Seligson, D., Kïm, H., Han, K.R., Huang, Y., Horvath, S., Stanbridge, E.J., Palotie, A., Figlin, R.A. and Belldegrun, A.S. (2004) Prognostic value of carbonic anhydrase IX and KI67 as predictors of survival for renal cilear cell carcinoma. Joumal of Urology, 171, 2461-6.

17. Maseide, K., Kandel, R.A., Bell, R.S., Catton, C.N., O'Sullivan, B., Wunder, J.S., Pintilie, M., Hedley, D. and Hill, R.P. (2004) Carbonic anthydrase $I X$ as a marker for poor prognosis in soft tissue sarcoma. Clinical Cancer Research, 10, 4464-71.

18. Beasley, N.J., Wykoff, C.C., Watson, P.H., Leek, R., Turley, H., Gatter, K., Pastorek, J. Cox, G.J., Ratcliffe, P, and Harris, A.L. (2004) Carbonic anlhydrase IX, an endogenous hypoxia marker, expression in head and neck squamous cell carcinoma and its relationship to hypoxia, necrosis, and microvessel density. Cancer Research.

61. $5262-5267$. 
19. Koukourakis, M.1., Giatromanolaki, A., Sivridis, E., Simopoulos, K., Pastorek, J.. Wykoff, C.C., Gatter, K.C. and Harris, A.L. (2001) Hypoxia-regulated carbonic anhydrase-9 (CA.9) relates to poor vascularization and resistance of squamous cell head and neck cancer to chemoradiotherapy. Clinicial Cancer Research, 7, 3399-403.

20. Kaluzova, M. Kaluz, S., Lerman, M.I. and Stanbridge, E.J. (2004) DNA damage is a prerequisite for p53-mediated proteasomal degradation of HIF-1 alpha in hypoxic cells and downregulation of the hypoxia marker carbonic anhydrase IX. Molecular Cell Biology, 24, 5757-66. 
Chapter 9

\section{General Discussion}

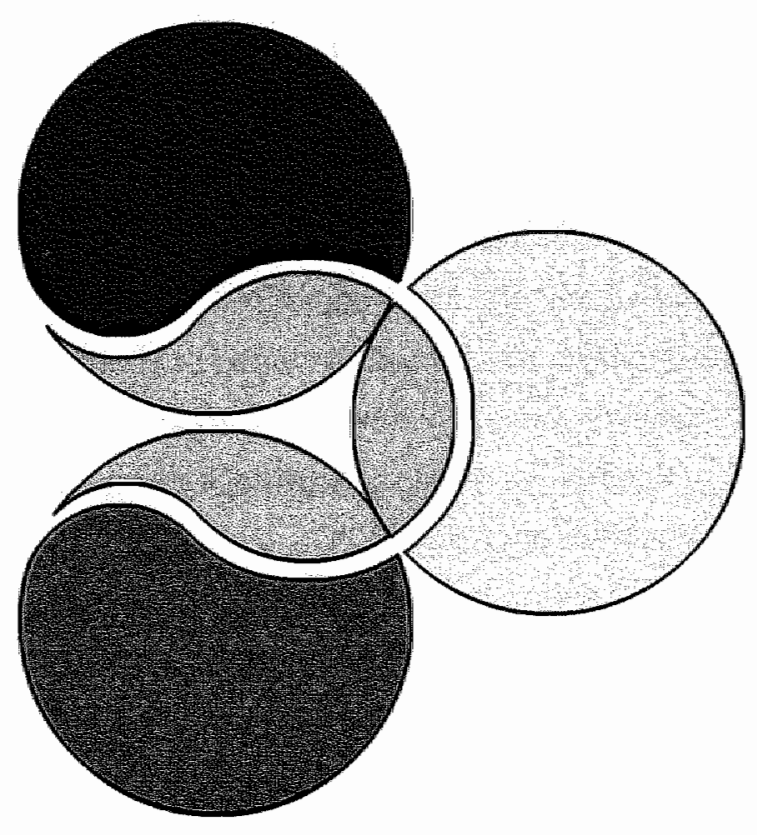


In this thesis different molecular pathways were studied with regard to their potential involvement in and their predictive value of recurrence in stage I endometrioid type endometrial carcinoma. The relevance and clinical implications of the findings of these studies as well as the future perspectives are discussed in this chapter.

\section{Can we predict a relapse?}

In this thesis PROGINS in combination with Progesterone Receptor (PR) expression, TP53 overexpression and microvessel density (MVD) were shown to be significant predictors for the development of recurrent endometrial carcinoma. The predictive capacity of these markers was independent of tumor grade and adjuvant radiotherapy. The fact that the presence of PROGINS in PR positive tumors attributes to the prediction of recurrence in endometrial carcinoma is a new finding. It illustrates that PR expression alone does not imply that the receptor is functional, i.e. that it regulates the hormonal inhibition of estrogen-induced proliferation of the endometrium. This could very well explain why some studies report PR to be a prognostic marker for the development of recurrence or poor prognosis [15], whille other studies do not confirm this $[6,7]$.

It is not surprising that TP53 overexpression predicts recurrence. Several studies report on TP53 overexpression in endometrial cancer in relation to the development of recurrent disease or poor prognosis [8-13]. Due to differences in the scoring systems comparing the results of these studies is hampered. Alkushi and coworkers recently demonstrated in 200 patients with endometrial carcinoma that a cut-off value of $50 \%$ correlates best with a poor prognosis and outcome [14]. The bimodal distribution of TP53 expression observed in the study by Alkushi and coworkers and the scoring system used are comparable with our results and scoring classification. Compared to earlier studies, the present study on TP53 differs with regard to three important aspects: (1) the design, which is a case control study, (2) the 
inclusion of the analysis of recurrent tumors (3) and the mutation analysis of exon 11 of $p 53$.

By performing a case control study the power of the statistical analysis is increased, and information can be gathered with regard to pathophysiological processes that may lead to the development of recurrences. Exon 11 contains lysine residues that are required for the ubiquitination and subsequent degradation of TP53. Mutation analysis of exon 11 in endometrial carcinoma has not been reported in literature so far. Expression patterns of both $m d m 2$ and $\mathrm{p} 21$ suggested that overexpressed TP53 in the primary tumors of patients with recurrence was not functional. Mutation analysis revealed no mutations in $p 53$. Mutations could reside outside the tested regions, or post-translational modifications of the TP53 protein could impair its function. However, these modifications were not evaluated in the present study. In the future functional analysis of the TP53 protein in endometrial carcinoma should be studied to resolve the problem of protein functionality.

The presence of a high MVD was an independent prognostic factor in endometrial carcinoma. This was also reported by several other studies [1518]. In contrast to these studies, however, the MVD in the current study was not assessed by the "hotspot" method [19], but advanced image analysis software allowed us to assess the percentage of CD31/FVIII positive staining in the entire tumor area Still, the MVD was an independent predictor of relapse. 


\section{Can recurrent tumors attribute to the selection of predictive molecular markers?}

As the progression of a tumor is often the result of an accumulation of molecular alterations that eventually lead to derailment of cell growth, small and apparently insignificant differences in primary tumors may become more obvious in the recurrences. Therefore expression profiles of the evaluated proteins as well as most of the molecular aberrations tested in the current thesis were evaluated in the recurrent tumors as well.

Not many studies are available in which metastases are compared with the original tumors. One study has evaluated microsatellite instability (MSI) in primary tumors and lymph node metastasis in endometrial carcinoma. Significantly more MSI was found in the recurrences as compared to MSI in the primary tumors [20]. It was therefore suggested that MSI is also involved in lymph node metastasis and in the development and/or progression of endometrial carcinoma [21].

In our study for example, recurrent tumors TP53 expression was significantly increased as compared with its expression in primary tumors. Similar observations were described by Kamura and coworkers in primary and recurrent ovarian carcinoma [22]. This suggests that overexpression of TP53 is associated with the progression of the disease and development of recurrences.

Comparing primary and recurrent tumors also indicated that $h M L H 1$ gene promoter methylation is an early step in the deregulation of the mismatch repair system (MMR). This is supported by data of Esteller and coworkers who did observe $h M L H 1$ methylation in atypical endometrial hyperplasia, considered to be a precancerous state [23]. The tendency of an increased expression of both hMLH1 and hMSH2 in recurrent tumors, suggests a relation to the development of recurrences. However, there were also recurrent tumors without any $\mathrm{hMLH} 1$ or hMLH2 expression, underlining the different mechanisms responsible for recurrences. 


\section{Can combinations of the predictive markers increase the predictive power for recurrences?}

To determine if a combination of the separate prognostic tests increased the predictive power for tumor recurrence a multivariate analysis was performed. When the presence of TP53 overexpression was combined with the presence of PROGINS, a low PR expression or a high microvessel density, the predictive value for the risk of recurrence did not increase. To investigate whether the significant predictive markers reflected the same activated pathways, correlation between these markers was performed. There appeared to be no direct or inverse correlation between TP53 expression, PR expression, PROGINS or MVD. This again suggests that distinct molecular pathways are responsible for the development of recurrent disease.

\section{Can molecular markers predict radiation sensitivity?}

It has been demonstrated in transgenic mice that p 53 mutations are associated with increased resistance to radiotherapy [24]. The DNA damage induced by ionizing radiation initiates signals that can either activate checkpoints that permit time for repair, or for irreversible growth arrest resulting in apoptosis [25]. TP53 is the key mediator of this ATM-dependent DNA damage response followed after exposure to ionizing radiation [26]. Loss of TP53 and ATM alter the G1 and G2 cell cycle checkpoints, and hence influences DNA repair, cell death and genetic instability. The TP53 induced response to radiation, i.e. reversible or irreversible growth arrest is not only dependent on the tissue type, but also on cell turnover. Moreover, it Imight not be the p53 pathway itself that determines the chaice between an apoptotic or a non-apoptotic response, but rather the availability of the apoptotic machinery that could be used by the p53-generated signal [27]. The majority of endometrial cancers are sensitive to radiotherapy [28]. Our data support the fact that alterations in TP53 influence the response to 
radiotherapy. In primary tumors with TP53 overexpression, postoperative radiotherapy was less successful compared to tumors without TP53 overexpression (OR $5.8,95 \% \mathrm{Cl} 1.2-28$ ) however, after correction for tumor grade, statistical significance was not reached (OR 4.4: 95\% Cl 0.8-24). Still, in the subgroup of patients receiving postoperative radiotherapy, TP53 expression was significantly increased in those patients who developed a recurrent tumor compared to those who did not receive radiotherapy ( 6.4 \pm 0.7 vs. $3.4 \pm 0.6$, T-test, $p<0.05$ ). Furthermore, within the group of patients treated for their recurrences by radiotherapy, there tended to be increased TP53 expression in those patients who developed a second recurrence. However, due to the small number of cases $(n=10)$, no firm conclusions can be drawn.

\section{Limitations of the thesis}

The treatment of the patients studied in the current thesis consisted of an abdominal hysterectomy with bilateral adnectomy without pelvic lymphadenectomy in accordance with the Dutch oncological guidelines. The incidence of pelvic lymph node involvement in stage I endometrial carcinoma appears to be associated with both tumor stage and tumor grade [29]. Since patients with a recurrence were matched according to tumor stage and tumor grade, understaged patients will be present equally in both patient groups. Moreover, most of the recurrences were local, which is in accordance with the site of recurrences in stage I disease. Patients, who received postoperative radiotherapy, were treated by external pelvic radiation only. Therefore, advantages or disadvantages of supplemental vaginal brachytherapy to external beam radiation could not be studied, or related to molecular alterations and their predictive capacity for success of treatment. We focused on the majority of the endometrial cancer patients, those with stage I disease and an endometrioid type endometrial carcinoma. 
Therefore, results could not be extrapolated to tumors of higher stages, or with different histological characteristics.

Finally, standardized scoring systems for the interpretation of immunohistochemical data should be developed in order to be able to compare results worldiwide. Alternatively, quantitative analysis by flow cytometry could be performed.

\section{Conclusions}

The results of this thesis indicate that activation of different molecular pathways can lead to a recurrent endometrial carcinoma. Alterations in TP53, the progesterone receptor in combination with PROGINS and microvessel density appear to be important factors that contribute to the development of recurrent disease. These findings are of importance to select those patients that are prone to develop recurrent disease. It is tempting to suggest that the decision to start adjuvant radiotherapy could be based on these criteria as well.

\section{Future perspectives}

To confirm the value of the predictive markers tested in this thesis, these markers should be studied prospectively. Since patients with high TP53 expression in their tumors appeared to be less sensitive to radiation, chemotherapy could be considered as an alternative treatment modality for the prevention of recurrent disease. Currently, the PORTEC III study is prepared in which patients with high-risk stage I/II endometrial carcinoma i.e. grade 3 and/or deep myometrial invasion, are randomized between postoperative radiotherapy and combined radiotherapy and chemotherapy. Prospective collection of tumor tissue in a tissue bank will be of value to extend analysis with respect to predictors of treatment outcome. Considering the overexpressed TP53, further evaluation should be performed to unravel the mechanism of TP53 inactivation. Proteomics studies protein function 
within biological systems. The protein microarrays are suitable to collect information about post-translational modifications and hence the activity state of the signaling network [30,31]. Mapping tumor cell protein networks in vivo will be necessary to understand carcinogenesis, and lead to patientspecific treatment. Markers could be used for a preoperative selection of patients with endometrial carcinoma and a high risk of positive lymph nodes. Recently, Mariani et al. demonstrated that indeed unfavorable levels of TP53 in pretreatment curettage specimens, could predict lymph node status, and thus pelvic lymphadenectomy could be more selectively performed [32]. Preclinical studies on gene therapy have shown that adenovirus-mediated expression of TP53 in ovarian cancer cell lines causes growth inhibition and apoptosis in vitro and in vivo [33]. Equally in a papillary serous endometrial carcinoma cell line it was demonstrated that adenovirus-mediated expression of p53 resulted in growth inhibition and apoptotic cell death [34]. Also angiogenesis has been used to target tumor therapy [35]. In endometrial carcinoma the presence of angiostatin, a potent inh ibitor of neovascularization and tumor growth, was shown to be associated with a longer disease free survival [36]. Yet, angiostatic agents in the prevention of recurrent endometrial carcinoma have not been reported so far.

It will take time to adapt from the clinicopathological criteria to new molecular criteria. Yet, it is expected that in the future tumor behavior will be more important in the decision making of the individual proper treatment. Therefore it is important for clinicians to understand the molecular background of the tumor in order to select the proper treatment for each patient. 


\section{References}

1. Steiner, E., Eicher, O., Sagemulter, J., Schmidt, M., Pilch, H., Tanner, B., Hengstler, J.G., Hofmann, M. and Knapstein, P.G. (2003) Multivariate independent prognostic. factors in endometrial carcinoma: a clinicopathologic study in 181 patients: 10 years experience at the Department of Obstetrics and Gynecology of the Mainz University. Intermational Journal of Gynecologic Cancer, 13, 197-203.

2. Gehrig, P.A. and Van Le. L. (2000) The prognostic value and clinical utility of estrogen and progesterone receptors in endometrial carcinoma. Prim Care Update Ob/Gyn, 7. $55-59$

3. Hirai, M., Hirono, M., Oosaki, T., Hayashi, Y., Yoshihara, T. and Matsuzaki, O. (1999) Prognostic factors relating to survival in uterine endometrioid carcinoma. International Journal of Gynaecology and Obstetrics, 66, 155-62.

4. Salvesen, H.B. and Akslen, L.A. (2002) Molecular pathogenesis and prognostic factors in endometrial carcinoma. Acta Pathologica ${ }_{1}$ Microbiologica, et Immunologica Scandinavica, 110, 673-689.

5. Creasman, W.T. (1993) Prognostic significance of hormone receptors in endometrial cancer. Cancer, $71,1467-70$.

6. Gehrig, P.A., Van Le, L., Olatidoye, B. and Geradts, J. (1999) Estrogen receptor status, determined by immunohistochemistry, as a predictor of the recurrence of stage I endometrial carcinoma. Cancer, 86, 2083-2089.

7. Fanning, J., Brown, S., Phibbs, G., Kramer, T. and Zaher, A. (2002) Immunohistochemical evaluation is not prognostic for recurrence in fully staged highrisk endometrial cancer. International Journal of Gynecologic Cancer, 12, 286-9.

8. Cononado, P.J. Vidart, J.A., Lopez-asenjo, J.A., Fasero, M., Furio-bacete, V., Magrina, J. and Escudero, M. (2001) P53 overexpression predicts endornetrial carcinoma recurrence better than HER-2/neu overexpression. European Journal of Obstetrics, Gynecology and Reproductive biology. 98, 103-8.

9. Ito, K. Watanabe, K., Nasim, S., Sasano, H., Sato, S., Yajima, A., Silverberg, S.G. and Garett, C.T. (1994) Prognostic significance of p53 overexpression in endometrial cancer. Cancer, 54, 4667-4670.

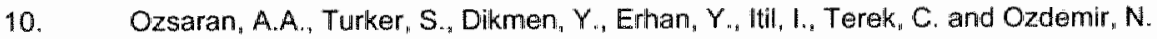
(1999) P53 staining as a prognostic indicator in endometrial carcinoma. European Journal of Gynaecologic Oncology, 20, 156-159.

11. Powell, B., Soong, R., Grieu, F., Knowles, S., Hammond, I. and lacopetta, B. (1999) P53 protein overexpression is a prognostic indicator of poor survival in stage I endometrial carcinoma. International Journal of Oncology, 14, 175-179. 
12. Satwesen, H.8. wersen, O.E. and Aksien, L. (1999) Prognostic significance of angiogenesis and $k-67,053$, and $p 21$ expression: a population based endometrial carcinoma siudy. Joumal of Clinical Oncology, $17(5), 1382-1390$.

13. Lundgren, C. Auer, G., Frankendal, B., Nilsson, B. and Nordstrom, B. (2004) Prognostic factors in surgical stage I endometrial cancinoma. Acta Oncologica, 43, 4956.

14. Alkushi, A. Lim, P., Coldman, A., Huntsman, D., Miller, D, and Gilks, C.B. (2004) Interpretation of p53 immunoreactivity in endometral carcinoma: establishing a clinically rellevant cut-off level. Inteirnational Journal of Gynaecological Pathology. 23 . $129-37$

15. Ozuysal, S., Bilgin, T. Ozan, H. Kara, H.F., Ozturk, H, and Ercan, I. (2003) Anglogenesis in endometrial carcinoma: correlation with survival and clinicopathologic risk factors. Gynecologic and Obstetric Inwestigation $, 55,173-7$.

16. Salwesen, H.B., Iversen, O.E. and Akslen, L.A. (1998) Independent prognostic importance of microvessel density in endometrial carcinoma. British Journal of Cancer, $77,1140-1144$.

17. Giatromanolaki, A., Sivridis, E., Koukourakis, M.I., Georgoulias, V., Gatter, K.C. and Harris, A.L. (1999) Intratumoral angiogenesis: a new prognostic indicaltor for stage I endometrial adenocarcinomas? Oncologic Research, 11, 205-12.

18. Ozalp, S. Yalcin, O.T." Acikalin, M., Tanir, H.M., Oner, U. and Akkoyunlu, A. (2003) Microvessel density (MVD) as a prognosticator in endometrial caarcinoma. European Journal of Gynaecololgic Oncology, 24, 305-8.

19. Agathanggelou, A. Honorio, S., Macartney, D.P., Martinez, A., Dallol, A., Rader "J., Fullwood, P. Chauhan, A., Walker, R., Shaw, J.A., Hosoe, S., Lerman, M.I., Minna, J.D., Maher, E.R. and Latif, F. (2001) Methylation associated inactivation of RASSF1A. from region $3 p 21.3$ in lung, breast and ovarian tumors. Oncogene, 20, 1509-1518.

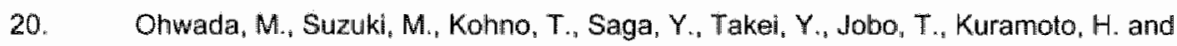
Satto, 1. (2002) involvement of microsatelihte instability in lymph node metastasis of endometrial carcinoma. Cancer Genetics and Cytogenetics, 132, 152-5.

21. Abulafia, O. and Sherer, D.M. (1999) Angiogenesis of the endometrium. Gynecologic Oncology, 94, 148-53.

22. Kamura, T., Sakai, K., Kaku. T., Kobayashi, H., Mitsumoto, M., Tsuneyoshi, M. and Nakano, H. (1999) Comparison of $p 53$ and CD44 variant 6 expression between paired primary and recurrent ovarian cancer: an immunohistochemical analysis. Oncology Reports, 6, 97-101.

23. Esteller, M., Catasus, L., Matias-Guiu, X., Mutter, G.L., Prat, J. Baylin, S.B. and Herman, J.G. (1999) hML.H1 Promoter hypermethylation is an early event in human endometrial tumorigenesis. American Journal of Pathology, 155, 1767-1772. 
24. Lee, J.M. and Bernstein, A. (1993) p53 mutations increase resistance to tonizing radiation. Procedings of the National Academy of Science, 90, 5742-6.

25. Pawlik TM, K.K. (2004) Role of cell cycle in mediating sensitivity to radiotherapy. International Journal of Radiation Oncology and biological physiology, 59, 9.28-42.

26. Cuddihy, A.R. and Bristow, R.G. (2004) The p53 protein family and radiation sensitivity: Yes or no? Cancer Metastasis Reviews, 23, 237-57.

27. Gudkov, A.V. and Komarova, E.A. (2003) The role of $\mathrm{p} 53$ in determining sensitivity to radiotherapy. Nature Reviews Cancer, 3,117-129.

28. Rantanen, V., Grenman, S., Kulmala, J., Salmi, T. and Grenman, R. (1992) Radiation sensitivity of endometrial carcinoma in vitro. Gynecologic Oncology, 44, $217-22$.

29. Creasman, W.T., Morrow, C.P., Bundy, B.N., Homesley, H.D., Graham, J.E. and Heller, P.B. (1987) Surgical pathologic spread patterns of endometrial cancer. A Gynecologic Oncology Group Study. Cancer, 60, 2035-41.

30. Petricoin, E.F.r., Bichsel, V.E., Calvert, V.S., Espina, V., Winters, M., Young, L., Belluco, C., Trock, B.J., Lippman, M., Fishman, D.A., Sgroi, D.C., Munson, P.J., Esserman, L.J. and Liotta, L.A. (2005) Mapping molecular networks using proteomics: a vision for patient-tailored combination therapy. Journal of Clinical Oncology, 23 , 3614-21.

31. Mohr, S., Leikauf, G.D., Keith, G. and Rihn, B.H. (2002) Microarrays as cancer keys: an array of possibilities. Journal of Clinical Oncology, 20, 3165-75.

32. Mariani, A., Sebo, T.J., Katzmann, J.A., Roche, P.C., Keeney, G.L., Lesnick, T.G. and Podratz, K.C. (2005) Endometrial cancer: can nodal status be predicted with curettage? gynecologic Oncology, 96, 594-600.

33. Santoso, J.T., Tang, D.C., Lane, S.B., Hung, J. Reed, D.J., Muller, C.Y., Carbone, D.P., Lucci, J.A.r., Miller, D.S. and Mathis, J.M. (1995) Adenovirus-based p53 gene therapy in ovarian cancer. Gynecologic Oncology, 59; 171-8.

34. Ramondetta, L., Mills, G.B., Burke, T.W. and Wolf, J.K. (2000) Adenovirus-mediated expression of p53 or $\mathrm{p} 21$ in a papillary serous endometrial carcinoma cell line (SPEC2) results in both growth inhibition and apoptotic cell death: potential application of gene therapy to endometrial cancer. Clinical Cancer Research, 6, 278-84.

35. Rosen "L.S. (2005) VEGF-targeted therapy: therapeutic potential and recent advances. Oncologist, 10, 382-91.

36. Yabushita, H., Noguchi, M., Kinoshita, S., Kishida, T., Sawaguchi, K. and Noguchi, M. (2002) Angiostatin expression in endometrial cancer. Oncologic Reports, 9, 1193-6. 


\section{Summary}

Endometrial carcinoma is the most frequent malignancy of the female genital tract. Mainly postmenopausal women are affected, and most of the patients are diagnosed at an early stage. This is due to the fact that endometrial cancer leads to complaints of postmenopausal blood loss in the majority of the cases. Current treatment consists of hysterectomy with bilateral oophorectomy and dependent on tumor stage, tumor grade and patient age, postoperative radiotherapy is applied. With this treatment strategy endometrial carcinoma generally has a good prognosis; $>80 \%$-year disease free survival. However, some patients present with recurrent disease shortly after completed therapy. Insight in the molecular alterations observed in endometrial carcinoma, could be helpful for the identification of aggressive tumors and for the selection of additional treatment modalities. In the current thesis various molecular pathways were studied in patients with FIGO stage I endometrioid endometrial carcinoma and related to the development of recurrent disease.

An outline of the clinical background and current treatment strategy as well as the conventional clinico-pathological risk factors for recurrence, are described in chapter 1. After a short introduction into the cell cycle and its checkpoints, the molecular pathways studied in this thesis, are described in more detail. Finally, the aims of the thesis are presented with an outline of the individual chapters.

In chapter 2, the study design is described with the selection procedure for both patients and their matched controls. Paraffin embedded tumor tissue of both primary and available recurrent tumor was used for immunohistochemical analysis, and DNA was isolated from the paraffin sections for mutation analysis. Three specialized techniques employed in this thesis are described in detail: direct sequencing, restriction fragment length polymorphism (RFLP), and methylation specific PCR (MSP). 
Three components of the Wnt pathway were studied in relation to the development of recurrent endometrial carcinoma (chapter 3).

Immunohistochemical expression of APC, $\beta$-catenin and E-cadherin could not be used to predict recurrence. However, absence of E-cadherin expression was significantly associated with the devellopment of distant metastasis. Yet, the absence of $\mathrm{E}$-cadherin expression in primary tumors could not be explained by the presence of $E$-cadherin gene promoter methylation. Innovative findings in this study were the identification of APC gene mutations in up to $43 \%$ of primary endometrial cancers. However, oly a minority of these mutations would putatively lead to a truncating, and hence a dysfunctional APC protein. Determination of APC promoter methylation was not useful for either the prediction of recurrence, or the expression patterns of the tested proteins.

In chapter 4 , we evaluated whether a defective mismatch repair system was correlated with recurr endometrial carcinoma. Although some previous reports observed a more favorable outcome in patients with tumors demonstrating a defective MMR system, we could not confirm these findings in our study. Immunohistochemical expression of hMLH1 and hMSH2 were determined in both primary and recurrent tumors. Although there tended to be higher expression levelsof both $\mathrm{hMLH} 1$ and $\mathrm{hMSH} 2$ in recurrent tumors compared to primary tumors, the discriminative effect was not strong enough to select those primary tumors prone to recurrence. Besides, a few recurrent tumors appeared to be completely negative for hMLH1 or hMSH2, which supports the fact that this marker is not an appropriate tool for the selection of aggressive tumors. The comparative analysis of primary and recurrent tumors was illustrative for the understanding of the subsequently events in derailment of the MMR system. The initial step towards a defective MMR appears to be $h M L H 1$ gene promoter methylation. During progression of tumor the level of $h M L H 1$ methylation seems to increase followed by decreased hMLH1 expression, and an increased incidence of MSI. 
During progression of tumor the level of methylation seems to increase followed by decreased expression of $\mathrm{hMLH} 1$ and finally demonstrating the presence MSI. In chapter 5 the expression levels of the progesterone receptor by immunohistochemi and determined the presence of those two polymorphisms in the PR gene: PROGINS, and +331 G/A polymorphism. W demonstrated that low PR expression tended to be associated with recurrent disease, in the presence of PR, PROGINS alterations were significantly associated with the development of recurrent disease.

In chapter 6, we investigated whether activating genetic or epigenetic mutations in the Ras signaling cascade are predictive for the development of recurrences. Te presence of $K$-ras and $B$-raf mutations was determined in both patient groups, together with the detection of RASSF1A promoter methylation. No differences were found between patients with and without recurrence. The high percentage of RASSF1A methylation ( $85 \%$ ) was striking. So far RASSF1A methylation was not and $B$-raf mutations only once reported in endometrial carcinoma. Also in premenopausal endometrial cancers, an equally high percentage of RASSF1A methylation was established. Therefore, methylation of the RASSF1A promoter could not only be explained by advanced age but appears to be an early event in the pathogenesis of endometrial carcinoma.

Alterations associated with p53 function were studied with respect to the development of recurrent endometrial carcinoma (chapter 7 ). Immunohistochemical analysis of $\mathrm{p} 53, \mathrm{mdm} 2$, and p21 was performed, as well as $p 53$ mutation analysis of exons $5-8$ and 11 by direct sequencing. Overexpression of $p 53$ was significantly associated with the development of recurrent disease, independent of tumor grade or applied radiotherapy. However, verexpression of p53 could only in a minority of the cases be explained by mutations, suggesting that $p 53$ overexpression is the result of 
aberrations in the $p 53$ degradation mechanism. As the levels of $p 53$ protein do not correlate with the expression levels of p53-inducible proteins $\mathrm{mdm} 2$ and $p 21$, it is likely that the overexpressed p53 in patients with recurrence is dysfunctional. The exact mechanism of p53 dysfunction in endometrial carcinoma could not be clarified.

In chapter 8, we evaluated whether microvessel density (MVD) and hypoxia are predictive for recurrent endometrial carcinoma. Immunohistochemical double staining was performed for WWF(FVIII) and CD31, both markers for endothelial cells, and for carbonic anhydrase IX (CA-IX), a marker for hypoxia. The staining was evaluated using image analysis software. High microvessel density was an independent predictor for relapse. MVD was not related to CA-IX expression, either directly or inversely.

In chapter 9 , the aims of the thesis are discussed in the light of the results from the different studies. Interactive analysis of the different studied pathways is performed and the results are compared to the literature. Limitations of the thesis are mentioned, and the future perspectives regarding the implementation of the current findings into clinical practice are discussed. 


\section{Samenvatting}

Het endometriumcarcinoom is de meest frequent voorkomende maligniteit van de vrouwelijk tractus genitalis. Het betreft voornamelijk postmenopauzale vrouwen, die meestal in een vroeg stadium worden gediagnosticeerd. Dit kan worden verklaard door het feit dat het endometriumcarcinoom in de meerderheid van de gevallen tot klachten van postmenopauzaal bloedverlies leidt. De huidige behandeling bestaat uit een uterusextirpatie met meenemen van beide adnexa. Afhankelijk van tumorstadium, tumorgraad en de leeftijd wordt postoperatieve radiotherapie gegeven. Met deze behandelingsstrategie heeft het endometriumcarcinoom een goede prognose. Echter, in sommige patiënten ontwikkelt zich kort na adequate therapie een recidief. Inzicht in de moleculaire veranderingen in het endometriumcarcinoom, zou kunnen bijdragen aan de identificatie van agressieve tumoren en de selectie voor aanvullende behandelingsmodaliteiten. In dit proefschrift zijn moleculaire veranderingen in verschillende cellulaire mechanismen bestudeerd in als FIGO stadium I geclassificeerde endometrioìd endometriumcarcinoom en gerelateerd aan de ontwikkeling van een recidief.

Een overzicht van de klinische achtergrond en de huidige behandelingsstrategie wordt gegeven in hoofdstuk 1 waarbij de conventionele klinisch-pathologische risicofactoren worden genoemd. $\mathrm{Na}$ een korte introductie in de celcyclus en de bijbehorende controlemechanismen, worden de verschillende cellulaire mechanismen die bestudeerd zijn in dit proefschrift, in detail beschreven. De onderzoeksvragen en een overzicht van de hoofdstukken van dit proefschrift worden vermeld.

In hoofdstuk 2, wordt de onderzoeksopzet beschreven met de selectie procedure van patiënten en hun 'matched' controles. Paraffine ingebed weefsel van zowel primaire als beschikbare recidief tumoren werd gebruikt voor immunohistochemische analyses, bovendien werd DNA geïsoleerd 
voor o:a. mutatieanalyse. Drie gespecialiseerde technieken die gebruikt zijn in dit proefschrift zijn in detail beschreven: 'direct sequencing", "restriction fragment length polymorphism' (RFLP) en de methylering specifieke PCR (MSP).

Drie componenten van de Wht signaaltransductiecascade werden bestudeerd in relatie tot de ontwikkeling van een recidief endometriumcarcinoom (hoofdstuk 3). De immunohistochemische expressie van $A P C, \beta$-catenin en $E$-cadherine kon niet worden gebruikt voor het voorspellen van het optreden van een recidief. De aanwezigheid van $A P C$ mutaties in $43 \%$ van de primaire endometriumcarcinomen is een nieuwe bevinding in deze studie. Slechts een minderheid van deze APC mutaties zou potentieel tot truncering en een disfunctioneel APC eiwit leiden. De aanwezigheid van $A P C$ promoter methylering was niet bruikbaar voor de voorspelling van een recidief noch voor de expressie van de geteste eiwitten. Echter, de afwezigheid van E-cadherine expressie in primaire tumoren was significant geassocieerd met het optreden van metastasen op afstand. Deze afwezigheid van expressie bleek niet het gevolg te zijn van $E$ cadherine promoter methylering.

In hoofd'stuk 4, hebben we de relatie van een defect 'mismatch repair' (MMR) mechanisme bestudeerd met prognose en het optreden van een recidief endometriumcarcinoom. Hoewel enkele studies een gunstiger beloop lieten zien van patiënten met een defect 'mismatch repair', konden wij deze bevinding niet bevestigen. Immunohistochemische expressie van $\mathrm{hMLH} 1$ en hMSH2 werd bepaald in zowel primaire als recidieftumoren. $\mathrm{Er}$ was een tendens zichtbaar van toenemende expressie van zowel hMLH1 als hMSH2 in recidieftumoren vergeleken met primaire tumoren. Echter, binnen de groep van primaire tumoren bleek de expressie van hMLH1 en hMSH2 niet bruikbaar voor de selectie van agressieve tumoren. Daarbij bleken ook een aantal recidief tumoren compleet negatief voor hMLH1 of hMSH2. Dit 
ondersteunt het feit dat deze marker niet bruikbaar lijkt woor de selectie van agressieve tumoren. De vergelijking van primaire en recidieftumoren was illustratief voor het inzicht in de opeenvolgende stappen van een toenemend defect MMR systeem. De eerste stap naar een disfunctioneel MMR systeem lijkt het optreden van $h M L H 1$ promoter methylering. Tijdens tumorprogressie neemt de mate van methylering toe, gevolgd door afname van hMLH1 expressie en toename van microsatelliet instabiliteit.

In hoofdstuk 5 werd de immunohistochemische expressie van de progesteronreceptor (PR) bestudeerd en de aanwezigheid van deze twee polymorphismen: PROG NS en het $+331 \mathrm{G} / \mathrm{A}$ polymorphisme. We lieten in deze studie zien dat lage PR expressie met het optreden van een recidief was geassocieerd. In aanwezigheid van normale of hoge PR expressie, bleek een additionele PROGINS verandering in het PR gen significant geassocieerd met de ontwikkeling van een recidief.

In hoofdstuk 6, onderzochten we of activerende genetische of epigenetische veranderingen in de Ras signaal transductie voorspellend waren voor de ontwikkeling van een recidief. De aanwezigheid van $K$-ras en $B$-raf mutaties werd bepaald in de beide patiënten groepen, samen met de detectie van RASSF1A promoter methylering. Er werd geen verschil gevonden tussen patiënten met en zonder recidief. Opvallend was het hoge percentage patiënten met RASSF1A methylering ( $85 \%)$. Tot op heden is RASSF1A methylering niet, en zijn $B$-raf mutaties nog slechts éénmaal gerapporteerd in endometriumcarcinoom. Ook in premenopauzale vrouwen werd een vergelijkbaar hoog percentage RASSF1A methylering vastgesteld. Daarom lijkt RASSF1A methylering niet alleen verklaard te kunnen worden door de hogere leeftijd, maar lijkt het ook een vroeg fenomeen in de pathogenese van het endometriumcarcinoom te zijn.

Veranderingen geassocieerd met de TP53 functie werden bestudeerd in relatie tot de ontwikkeling van een recidief endometriumcarcinoom 
(hoofdstuk 7). De expressie van p53, mdm2, en p21 werd bestudeerd met immunohistochemie. Bovendien werd door middel van 'direct sequencing' mutatieanalyse verricht van de exonen 5-8 en 11 van $p 53$. Overexpressie van p53 was geassocieerd met de ontwikkeling van een recidief, onafhankelijk van tumor graad of toegepaste postoperatieve radiotherapie. Slechts in een klein aantal gevallen van p53 overexpressie, werden mutaties gevonden in het $p 53$ gen. Dit suggereert dat p53 overexpressie vooral het resultaat is van veranderingen in het afbraakmechanisme. Doordat hoge p53 expressie niet gecorreleerd was met p53-geïnduceerde eiwitten zoals mdm2 en p21, is het aannemelijk dat het tot overexpressie gekomen p53 niet functioneel is. Het exacte mechanisme van p53 disfunctie in endometriumcarcinoom kon niet worden opgehelderd.

In hoofdstuk 8 werd de microvaatdichtheid en hypoxie bestudeerd in relatie tot het ontstaan van een recidief endometriumcarcinoom. Dit werd gedaan door een immunohistochemische dubbelkleuring uit te voeren op WWF (FVIII) en CD31, beide markers voor endotheelcellen en op carbonanhydrase IX (CA-IX), een marker voor o.a. chronische hypoxie. De kleuring werd beoordeeld met behulp van een image analysis systeem. Een hoge microvaatdichtheid was een onafhankelijke voorspeller voor het optreden van een recidief. De microvaatdichtheid was niet gerelateerd aan CA-IX expressie, direct of omgekeerd.

In hoofdstuk 9 worden de onderzoeksvragen bediscussieerd in het licht van de resultaten van de verschillende studies. Een interactieve analyse van alle bestudeerde cellulaire mechanismen is verricht en de resultaten zijn vergeleken met de literatuur. Beperkingen van het proefschrift worden besproken en de toekomstperspectieven voor wat betreft de implementatie van de huidige bevindingen in de klinische praktijk wordt beschreven. 


\section{Curriculum Vitae}

Hanny Pijnenborg is geboren op 30 oktober 1969, in Haaren. Zij behaalde haar eindexamen WWO in 1988 aan het Maurick-college te Vught. Aansluitend studeerde zij geneeskunde aan de Rijksuniversiteit Limburg, (thans Universiteit Maastricht). In april 1996 behaalde zij haar artsexamen en begon in mei 1996 als AGNIO gynaecologie in het St. Joseph ziekenhuis te Veldhoven. Op 1 februari 1997 startte zij de opleiding tot gynaecoloog in het St. Joseph ziekenhuis te Veldhoven onder leiding van Dr. H.A.M. Brölmann. In januari 1999 vervolgde zij haar opleiding in het Academisch Ziekenhuis Maastricht onder leiding van Prof. Dr. J. de Haan en Prof. Dr. J.L.H. Evers. Tijdens haar academische periode heeft zij middels een verrichte 'pilot'-studie subsidie toegekend gekregen bij het profileringsfonds van het Academisch Ziekenhuis Maastricht. Hierdoor werd het mogelijk om een jaar, vrijgesteld van klinische taken, wetenschappelijk onderzoek te verrichten. Het onderzoek vond plaats op de afdeling pathologie in nauwe samenwerking met de afdeling gynaecologie. Het project was ondergebracht bij het onderzoeksinstituut Groei \& Ontwikkeling (GROW). Van juli 2003 tot maart 2004 volgde zij haar laatste deel van de opleiding in het Màxima Medisch Centrum, Veldhoven onder leiding van Prof. Dr. S.G. Oei, en werd 1 april 2004 ingeschreven als gynaecoloog in het Specialisten Register. Vanaf mei 2004 tot heden is zij werkzaam als gynaecoloog in het Tweesteden ziekenhuis te Tilburg. 


\section{Dankwoord}

Bij het tot stand komen van een proefschrift zijn vele mensen gedurende vele jaren betrokken. Zonder iedereen bij naam te willen noemen wil ik hen die in welke vorm dan ook een bijdrage hebben geleverd aan dit proefschrift danken voor de hulp. In het bijzonder wil ik een aantal mensen noemen

Prof. Dr. J. de Haan, Uw persoonlijke begeleiding tijdens mijn promotie onderzoek heb ik zeer gewaardeerd. Regelmatig werd ik door Uw secretaresse gebeld om weer eens langs te komen om de stand van zaken te bespreken, een kopje koffie een gezellig praatje en dan ter zake. UW belangstelling voor ook andere zaken dan alleen het onderzoek heeft ervoor gezorgd dat ik altijd weer een beetje thuiskom in Maastricht. Dank voor Uw vertrouwen in de "goede afloop" tijdens mijn promotie onderzoek.

Dr. P.G. Groothuis, beste Patrick, mijn proefschrift is natuurlijk een grote verdienste van jouw inspanningen om een clinicus als ik, de moleculaire celbiologie bij te brengen. Tijdens de eerste besprekingen bij de endometriumgroep duizelde het me van de terminologie: PCR, Western blots, immunohistochemie, 2D electroforese. Inmiddels kan ik aardig meepraten met de echte wetenschappers. Ik waardeer je manier van werken en je openheid voor nieuwe dingen. Je wist mijn soms iets te enthousiaste gedrevenheid altijd weer in goede en rustige banen te leiden. Ik hoop ook na dit proefschrift nog regelmatig eens van gedachten te wisselen over nieuwe experimentele uitdagingen.

Dr. G.A.J. Dunselman, beste Dr. D. de basis van mijn onderzoek begon met de "meest gevreesde ziekte" Ook het endometriumcarcinoom wordt steeds meer gevreesd en bovendien is er toch enig overlap met endometriose. $U$ heeft me over de streep kunnen trekken om eens wat langer op het lab rond te lopen. $k \mathrm{k}$ wil $\mathrm{U}$ hartelijk dlanken voor de kritische opmerkingen tijdens mijn 
onderzoek en de gezelligheid op het lab. Ook een mannelijke gynaecooloog moet wel eens zijn ei kwijt.

PALGA en mw Casparie in het bijzonder, ben ik veel dank verschuldigd. Dankzij jullie medewerking heb ik in een vrij vlot tempo de patiënten weten op te sporen. Via versleuteling kreeg ik ook de klinisch relevante informatie van de behandeiend gynaecoloog. Dat was goud waard

Alle mensen werkzaam op de afdeling pathologie van het AZM. Ik heb me zeer welkom gevoeld op de pathologie waar een enorme prettige werksfeer heerst. Ik vind het een prestatie om met zoveel studenten, stagiaires en wisselingen van AlO's toch zo'n stabiele goede sfeer te behouden. Dank voor jullie gastvrijheid.

Alle mensen van de endometriumgroep. I $k$ heb veel van jullie geleerd en vooral ook dat het lab veel gezelliger is dan menig clinicus denkt. Natasja, jij hebt de basis gelegd voor mijn vaardigheden op het lab. Coupes snijden, kleuringen, een PCR ook zonder Taq. Je hebt me de precisie van de labvaardigheden bijgebracht. Ik heb veel waardering voor je enorme wetenschappelijke drang om "re-search" te verrichten. Ook jouw dag zal eens komen. Christa, je rust en bescheidenheid heb ik zeer gewaardeerd, zonder jouw hulp was het me nooit gelukt om dit onderzoek tot een goed eind te brengen. Guido, ik heb je leren kennen als colonexpert, maar weet inmiddels dat jouw kennis op het lab veel verder gaat dan dat. Slim en een beetje eigenwijs, ze moeten maar zuinig op je zijn. Helen, Rick, Raymond en Chamindie en niet te vergeten zij die mij voorgingen Caroline Koks, Jacques Maas, Ayse Demir, Annemiek Nap. Nu is mijn boekje dan ook eindelijk af. Leonie, José en Mirel, als student hebben jullie een belangrijke bijdrage voor mijn proefschrift geleverd, mijn dank daarvoor. Hopelijk zijn jullie er zelf ook nog wat wijzer van geworden. 
Lieve Manon, ik bewonder je enorme drijfveer om steeds dieper in the pathways te duiken. Ik vond het erg prettig om met je samen te werken. Je hebt mijn onderzoek aanzienlijk meer body gegeven. Beste Ton, door je sabbatical heb ik maar weinig met je samen gewerkt, maar de precisie waarmee jij artikelen leest en bekritiseert is bewonderenswaardig. Dank voor je hulp.

Gynaecologen van het St.Joseph ziekenhuis te Veldhoven. De onderzoekscultuur in het Veldhovense is erg bijzonder voor een perifere opleidingskliniek. Jullie hebben mij de spirit meegegeven om wat meer te schrijven dan een case-report. Verrijking voelt altijd prettig. Hans Brölmann, ook al zit je weer wat jaren in de VU, voor mij heb je een cruciale rol gespeeld in mijn carrière dank voor je vertrouwen.

Assistenten gynaecologie van de Maastrichtse cluster, vele van jullie zijn inmiddels gynaecoloog, dank voor het aanhoren van mijn gemopper en geklaag

Collega's in het Tweesteden, tijdens het afronden van het boekje ben ik bij jullie als gynaecoloog begonnen. De overgang van assistent naar gynaecoloog kost veel energie, maar verliep zeker ook door jullie prettige werksfeer prima. Nu het boekje dan eindelijk af is, is er weer tijd voor al die andere dingen die ik nog zo graag zou willen doen. $\mathrm{k}$ ben blij dat jullie me hebben weten te overtuigen om in het Tweesteden te komen werken.

Lieve Ella en Mariëlle, zonder enige aarzeling wist ik dat jullie mijn paranimfen moesten worden. Mariëlle, onze vriendschap sinds de $1^{e}$ onderwijsgroep in Maastricht is een stevig fundament. Na alle kleine onderzoekjes nu dan eindelijk het echte werk. Fijn dat je me ook nu wilt bijstaan. Ella, via Maastricht en Veldhoven en ruim 180.000 kilometer snelweg hebben we ons doel bereikt. Beide gynaecoloog en een 
vriendschap rijker, inmiddels zitten we wat wederom wat kilometers van elkaar, maar je blijft mijn maatje fijn dat je nu aan mijn zìjde staat.

Pap en mam, zelfstandigheid en verantwoordelijkheid zijn met de paplepel ingegeven, dank voor jullie steun en vertouwen.

Lieve Willian, zus en psycholoog zo blijf ik altijd in balans. Dank voor je creatieve bijdrage om mijn boekje wat kleur te geven.

Lieve Rob, al meer dan 15 jaar steun je mijn plannen en ideeën en trap je zo nodig op de rem. Dit proefschrift was er nooit gekomen zonder jouw rust en stabiliteit. "Para mi corazon basta tu pecho.......lo que estaba dormido sobre tu alma llegaré de mi boca hasta el cielo" Merel en Tjerk, ik geniet met volle teugen van juilie vanaf het moment dat jullie groeiden in mijn buik. Het lijkt alsmaar intenser te worden, ik hoop dat we nog lang met ons gezinnetje in goede gezondheid samen mogen zijn! 


\section{Chapter 2}

Figure 2

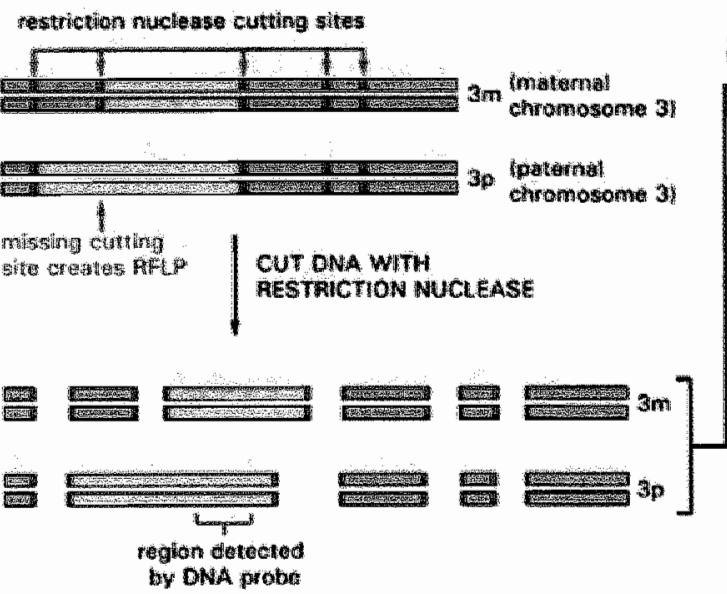

GEL ELCTAOPHOAESTS

AND SOUTHERM ELOTTHA WITH LAEELE POOBE DNA

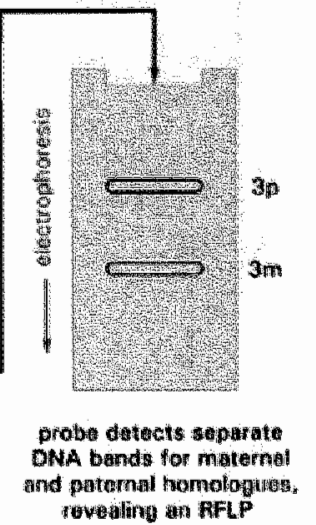

Illustration of restriction fragment length polymorphism (RFLP) technique. 


\section{Chapter 3}

\section{Figure 3}
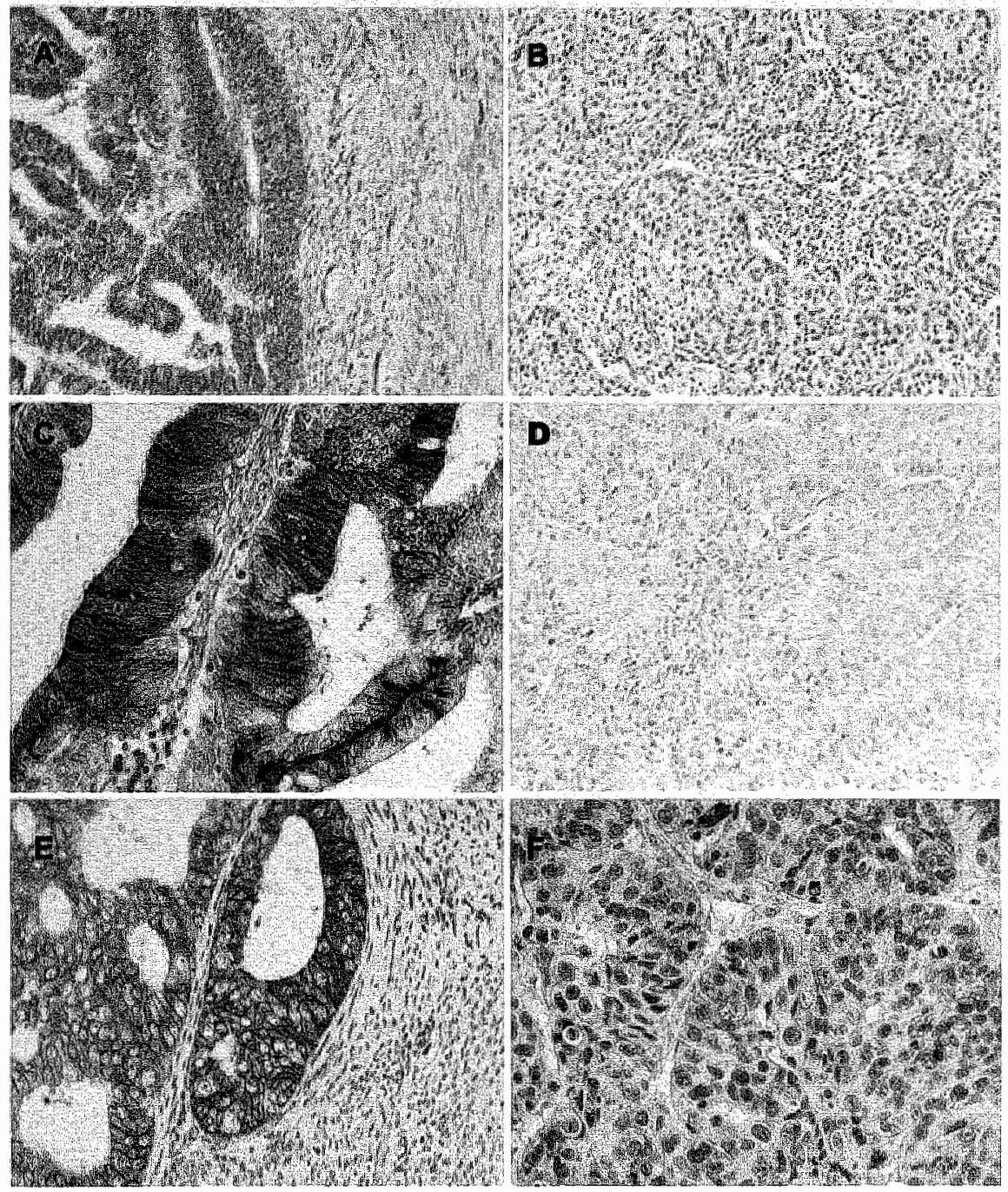

Representative examples of the immunohistochemical staining. (A) cytoplasmic staining of $A P C,(B)$ negative control, (C) E-cadherin membranous staining, (D) E-cadherin negative tumor, (E) membranous staining of $\beta$-catenin, and $(F)$ nuclear staining of $\beta$-catenin. $(A, B: 200 x ; C-F$ : 400x). 


\section{Chapter 4}

Figure 1

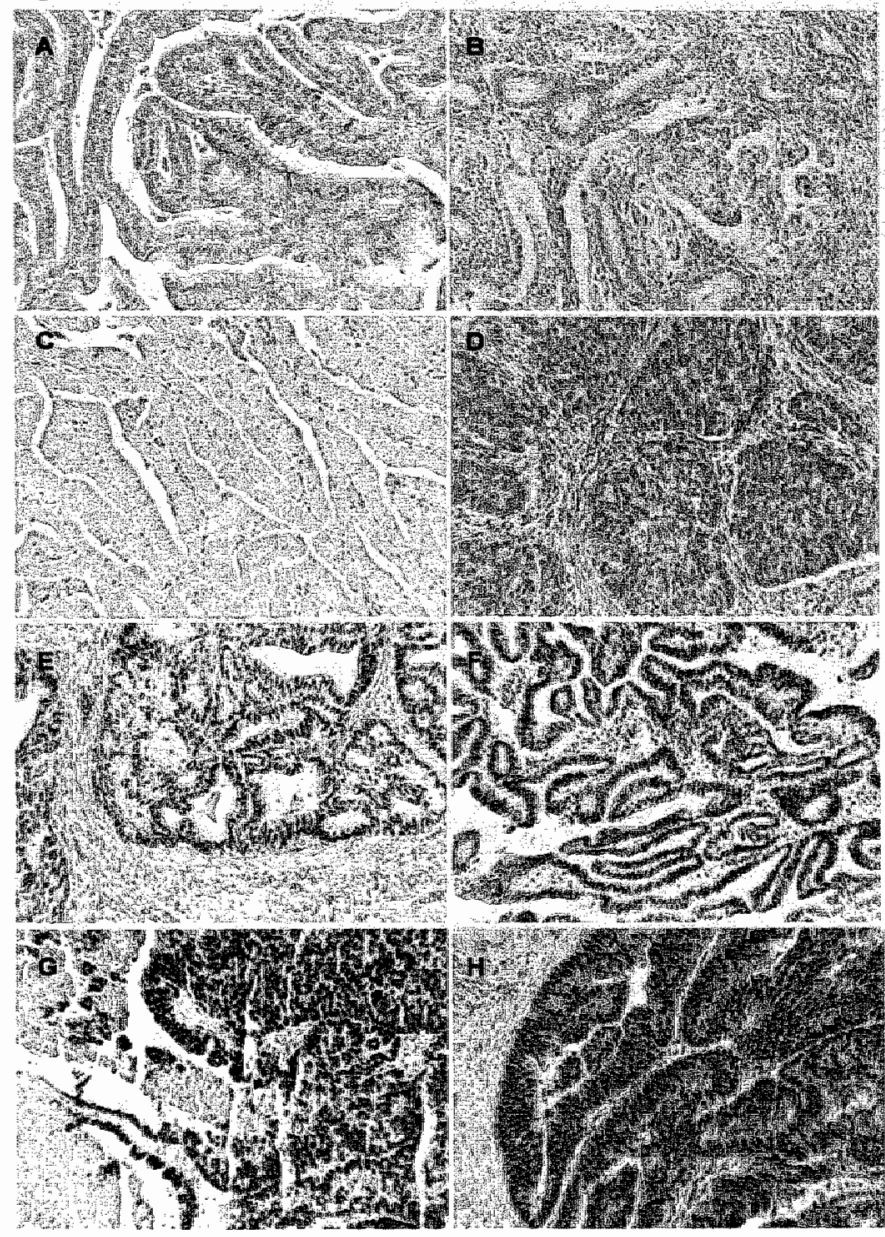

Representative examples of negative controls (A, B) and hMSH2/hMLH1 expression (C-H).

\begin{tabular}{lllll}
\hline & Protein & Staining percentage & Staining intensity & Staining Index \\
\hline C & $\mathrm{hMSH2}$ & $<10 \%$ & Moderate & 2.0 \\
$\mathrm{D}$ & $\mathrm{hMLH} 1$ & $<10 \%$ & Weak & 1.0 \\
$\mathrm{E}$ & $\mathrm{hMSH} 2$ & $>50 \%$ & Mloderate - strong & 7.5 \\
$\mathrm{~F}$ & $\mathrm{hMLH} 1$ & $>50 \%$ & Moderate - strong & 7.5 \\
$\mathrm{G}$ & $\mathrm{hMSH} 2$ & $>50 \%$ & Strong & 9.0 \\
$\mathrm{H}$ & $\mathrm{hMLH} 1$ & $>50 \%$ & Strong & 9.0 \\
\hline
\end{tabular}




\section{Chapter 5}

\section{Figure 3}

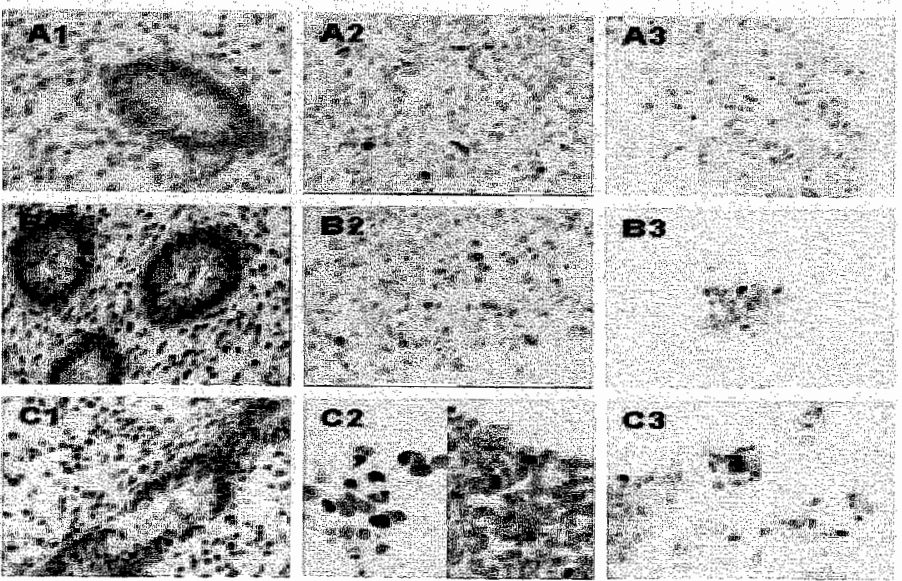

Representative examples of the staining obtained with the PR-B specific antibody B30 (A), PR antibody PR636 (B) and PR antibody PGR312 (C) on endometrial tissue (1), CHO-K1 cells expressing PR-B (2) and CHO-K1 cells expressing PR-A (3). 


\section{Chapter 5}

Figure 4
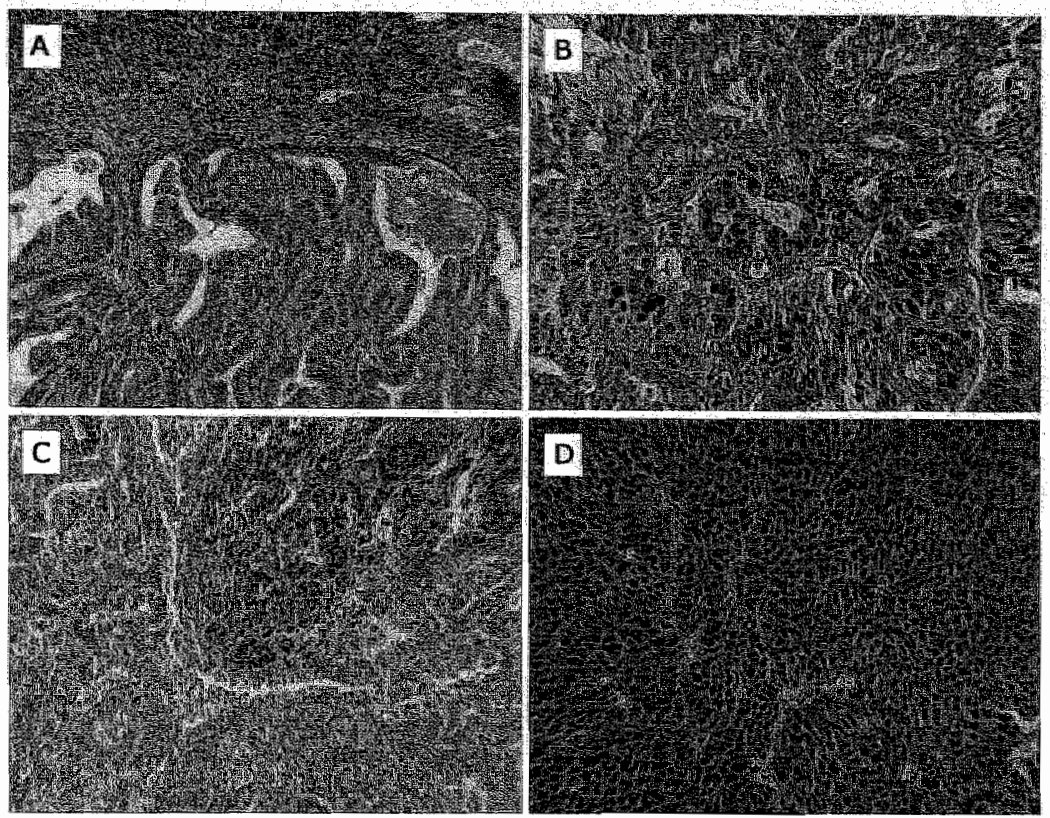

Representative examples of tumors without (A), with low (B), moderate (C) and strong (D) expression of $P R(A+B)$. 


\section{Chapter 7}

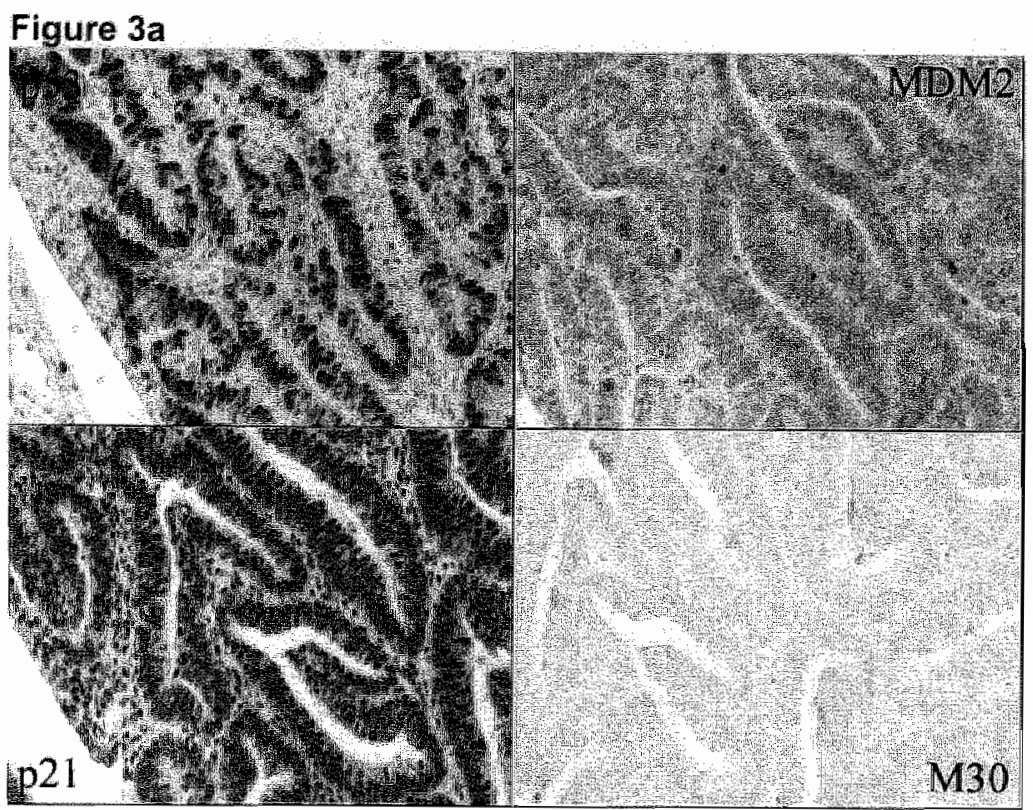

\section{Figure 3b}

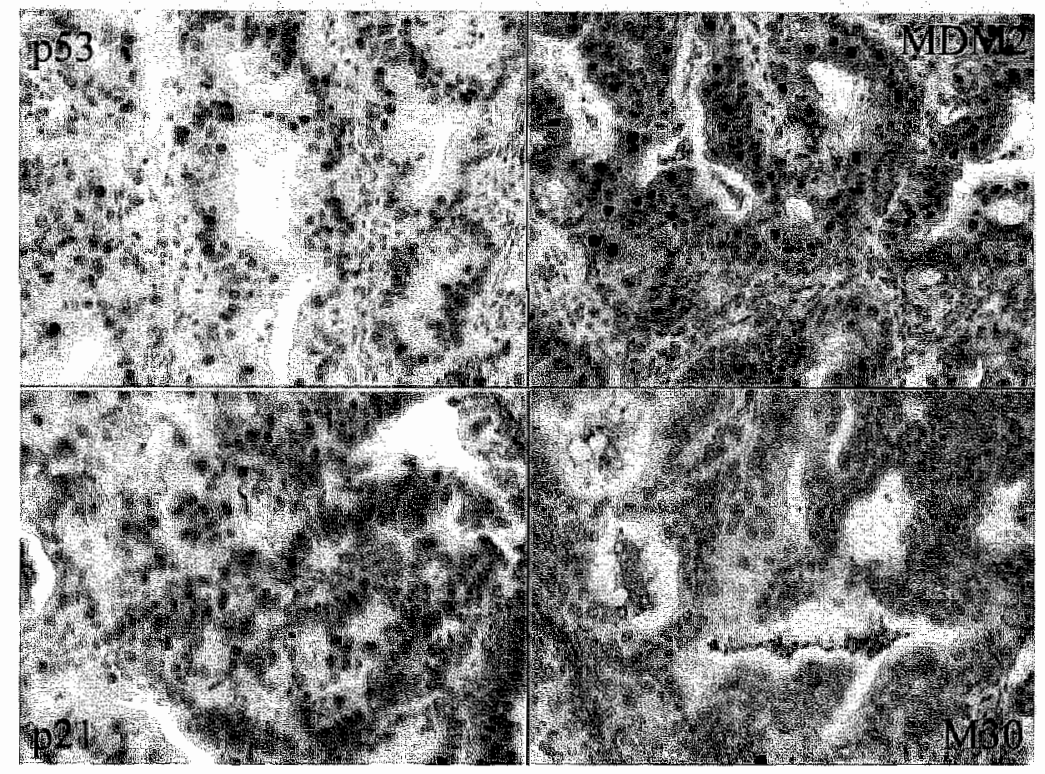

Example of a primary tumor of a patient with $(A)$ and without $(B)$ recurrence with TP53 averexpression and subsequently the expression of hMdm2, P2 $1^{\text {wafticipt }}$ and Mi30 in the same tumor area. 


\section{Chapter 8}

Figure 1 High and low MVD.

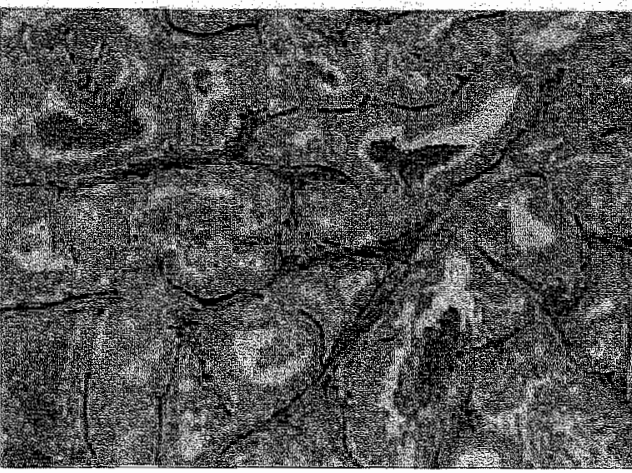

High

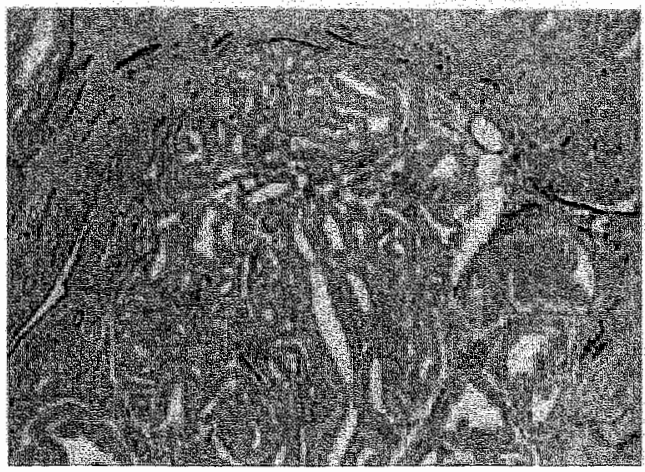

Low

\begin{tabular}{cccc}
\hline Slide ID & Staining area & Tissue area & Staining area\% \\
\hline 53 a (high) & 24488.77 & 491315.20 & 4.98 \\
27 (low) & 256.81 & 31027.03 & 0.83 \\
\hline
\end{tabular}

Figure 2 Low and high expression of CA-IX

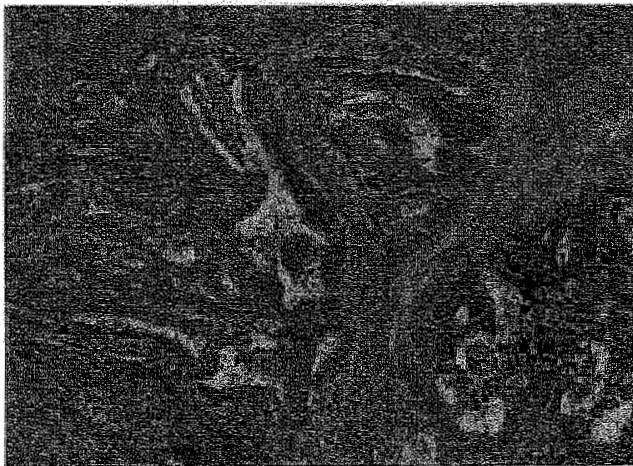

Low

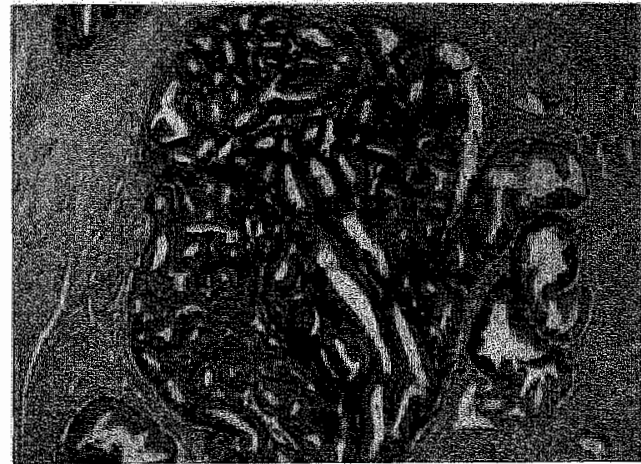

High

\begin{tabular}{lccc}
\hline Slide ID & Staining area & Tissue area & Staining area $\%$ \\
\hline 53 (low) & 9521.722 & 770000.0 & 1.24 \\
27(high) & 524200.00 & 749657.4 & 69.92 \\
\hline
\end{tabular}

